REDUCING POTENTIAL DISASTER IMPACTS

IN IRRIGATED RICE FIELDS IN WEST JAVA 
Graduation committee:

Chairman/Secretary:

Prof.dr.ir. A. Veldkamp University of Twente / ITC

Supervisors:

prof. dr. V.G. Jetten

University of Twente / ITC

prof.dr. J. Sartohadi

Universitas Gadjah Mada

Co-supervisor:

Dr. J. Ettema

University of Twente / ITC

Members:

Prof.dr. N. Kerle

Prof.dr. A.D. Nelson

Prof.dr.-ing.habil. J. Birkmann

(ITC

Prof.dr. F. Ludwig

Dr.ir. L.G.J. Boerboom

University of Twente / ITC

University of Stuttgart

Wageningen University

University of Twente / ITC

ITC dissertation number 322

ITC, P.O. Box 6, 75000 AA Enschede, The Netherlands

ISBN 978-90-365-4554-9

DOI 9789036545549

Cover designed by Benno Masselink

Printed by ITC Printing Department

Copyright (C) 2018 by Riswan S. Sianturi

TUC FACULTY OF gEO-INFORMATION SCIENCE AND EARTH OBSERVATION 


\title{
REDUCING POTENTIAL DISASTER IMPACTS IN IRRIGATED RICE FIELDS IN WEST JAVA
}

\author{
DISSERTATION
}

to obtain

the degree of doctor at the University of Twente on the authority of the rector magnificus, prof.dr. T.T.M. Palstra on account of the decision of the graduation committee, to be publicly defended on Wednesday 30 May 2018 at 14.45 hrs

by

Riswan Septriayadi Sianturi

born on 19 September 1988

in Pangkalpinang, Indonesia 
This thesis is approved by

Prof.dr. V.G. Jetten (supervisor)

Prof.dr. J. Sartohadi (supervisor)

Dr. J. Ettema (co-supervisor) 


\section{Acknowledgements}

First of all, I would like to express my most profound gratitude: Praise be unto God! He is worthy of all praise. Now to HIM who is able to do immeasurably more than all we ask or imagine, according to HIS power that is at work within us (Ephesians 3:20).

Deepest appreciation is owed to many individuals who have helped me over the past four years. I would like to take this opportunity to thank them.

I would like to express my sincere gratitude to my promoter, Prof.dr. V.G. Jetten (Victor), for his advice, encouragement, and commitment during the period of my Ph.D. Words are not enough to convey my gratitude for your constructive comments. They are invaluable in shaping this thesis in its present form. I would like to thank my Co-promoter, Prof.dr. Junun Sartohadi, for his generous support and continuous motivation. Your thoughtful remarks and comments are indispensable. My heartfelt appreciation goes to my supervisor, Dr. Janneke Ettema (Janneke) for her valuable and inspiring scientific discussions. Your constructive criticism and continuous encouragement have been extremely practical.

To Beasiswa Pendidikan Indonesia Lembaga Pengelola Dana Pendidikan (BPI LPDP). This doctoral journey will not be possible without their financial support. I am deeply indebted.

Sincere thanks go to farmers, extension officers, and water managers in my study area. Thank you for your continuous and generous support during the data collection processes. Thank you for your patience with my nagging questions and lack of understanding during the whole interview sessions.

I would like to thank ESA secretariat for their prompt responses in handling administration issues. Christie and Lise-Lotte, thank you for helping me with the endless letters of progress reports and financial matter claims. I would also like to thank the whole staff members of ESA department for their friendships. Nanette, Bart, Dhruba, Dinand, Mark, Cees, Harald, Christ, Norman, Wim, Frank, Robert, Caroline, Olga, and Freek, thank you! Special thanks go to my Ph.D. colleagues Dr. Thea Turkington, Haydar, Saad Khan, Matthew Dimal, Effie, Bastian, Evelien, Oscar, Vasily, Islam Fadel, Chenxiao Tang, Tunde, Irena, Asti, and Jarot. Thank you for pleasant and insightful conversations during lunch and morning and afternoon coffee breaks.

Special thanks to Dr. C.A.J.M. (Kees) de Bie, for teaching the course in hypertemporal remote sensing. The knowledge of the tools has become an essential starting point for this study. Thank you also for Willem Nieuwenhuis for 
allowing the use of time-series analysis extension tools. My appreciation goes to all ITC lectures, staff members, librarian, ICT service, student affair, and travel agency. Thank you for your helping hands. I also like to thank all friends from other departments in ITC Faculty Oliver Macapinlac, Sonia Asilo, J.R. Bergado, Mitra, Elnaz, Xi, Festus, Meng-Meng, Fangyuan, and Xiaojian "Chris" Wang. I apologize for not able to mention all by names.

My sincere thanks go to Ibu Dewi Nurhamad for her incredible support and continuous encouragement. Backenlhagenlaan, Hengelo has been my second home in while pursuing this Ph.D. journey. I will always remember the taste of foods and all hilarious and entertaining conversations. Thank you for familiarizing me to the beauty of nature and handicrafts from many countries. Thank you for the cooking and gardening lessons. More importantly, thank you for introducing the amazing The Netherlands to me.

My sincerest thanks go to all International Christian Fellowship (ICF) Enschede members, for Paul and Mieke, Brother Jan, Kwame Aviane. My fellow choir members, Bai, Femi, Adrian, Joshua, Beverly, Celeste, Harry Mantong, Dominik, Margareth, Linda Ong, Dominik, Paulina, Loulou, and Edson. I apologize for not able to mention all by names.

I also want to thank all staff of ITC International Hotel, especially for Saskia Groenendijk, Patrick Harlief, and Ruben J. Versteeg. Special thanks also to all crew members both in ITC International Hotel and Faculty of ITC building who is always trying their best to keep the rooms clean and tidy.

Thank you for all members of BandIDS: Citra, Abrar, Karisa, Bayu, Rheza, Faisal, Louise Vania, Kevin, Iwan, Fai, and Aldi. I am extraordinarily having fun!

I extend my gratitude to all my Indonesian acquaintances during the periods of my study in The Netherlands. Mba Dewi, mba Novi R., Rizka, Pak Budi, Pak Hunggul, mas Aji, Armen, Deva, Bani, Bang Roy, kak Monica, and Novi S, thank you for your friendships. Again, I apologize for not able to mention all by names.

Finally, I am grateful to my mother and late father, brother and sister, for their endless encouragement and love. I know we are and will always grow up together as a family. Thank you for letting me have so much of 'my own time' for the last four years.

To you all, I dedicate this thesis. 


\section{Table of Contents}

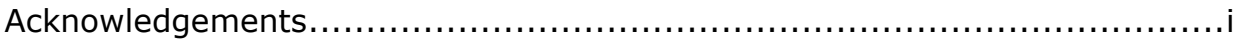

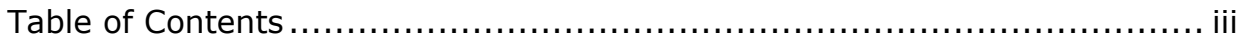

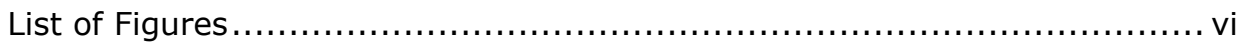

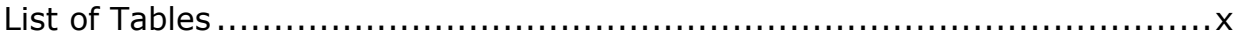

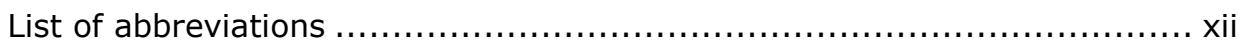

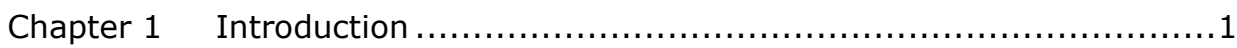

1.1. Risk of natural hazards in irrigated rice fields: the need for studies...1

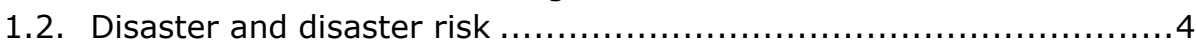

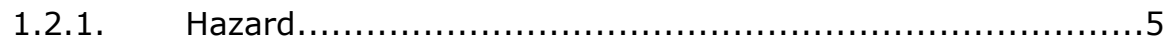

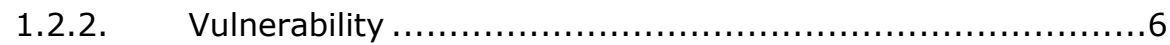

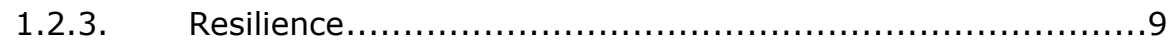

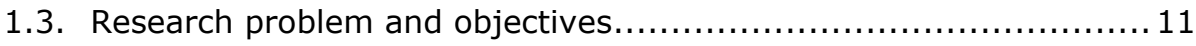

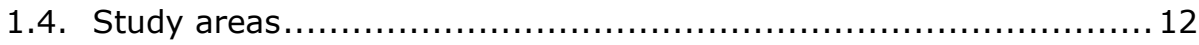

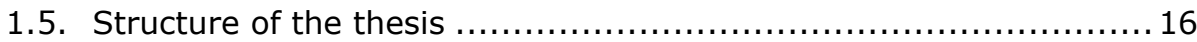

Chapter 2 Mapping cropping patterns in irrigated rice fields in West Java:

Towards mapping vulnerability to flooding using time-series MODIS

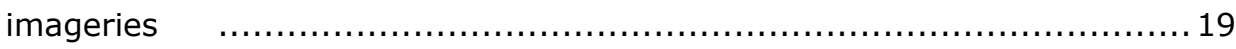

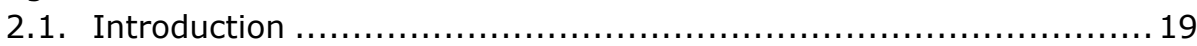

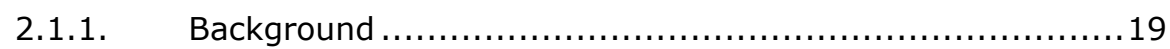

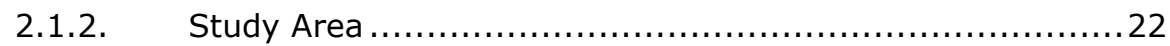

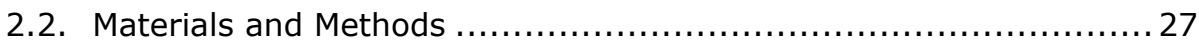

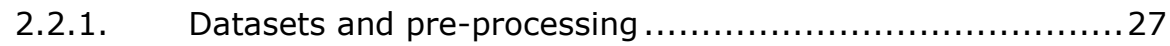

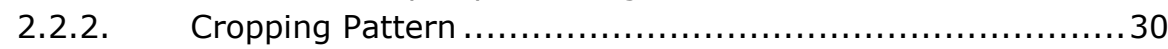

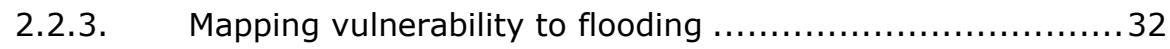

2.2.4. Accuracy Assessment..................................... 34

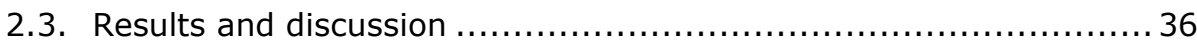

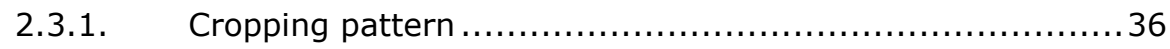

2.3.2. Vulnerability to flooding ..................................... 41

2.3.3. Accuracy Assessment......................................... 44

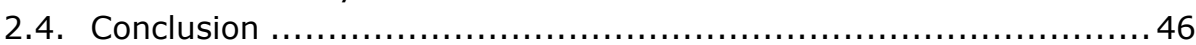

Chapter 3 Distinguishing between Flooding and Agronomic Inundation in

Irrigated Rice Fields: A case study from West Java .......................49

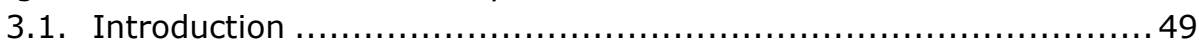

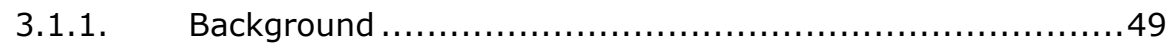

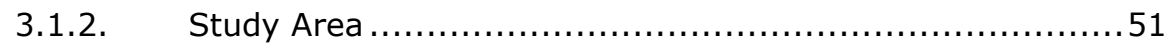

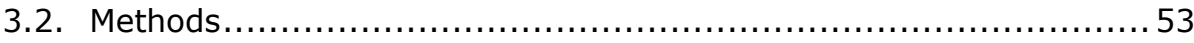

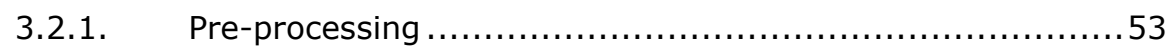

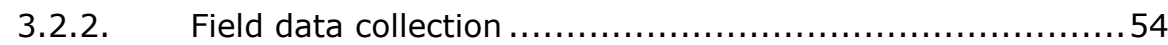

3.2.3. Distinguishing between flooding and agronomic inundation. 56

3.2.4. Accuracy assessment .................................60

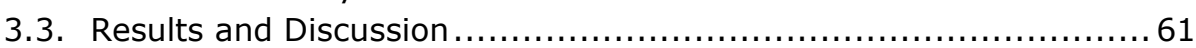

3.3.1. EVI $\leq 0.1$ for distinguishing between RFAI $\ldots \ldots \ldots \ldots \ldots \ldots \ldots 1$ 
3.3.2. $\mathrm{EVI}_{40}$ for distinguishing between RFAI....................63

3.3.3. Comparisons of surface water areas ......................65 65

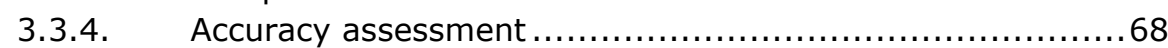

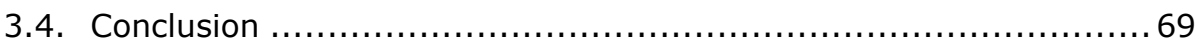

Chapter 4 Towards understanding vulnerability: Investigating disruptions

in cropping schedules in irrigated rice fields in West Java ................... 71

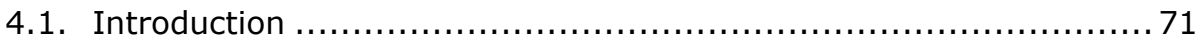

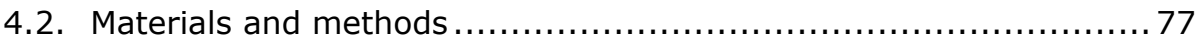

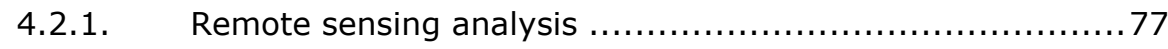

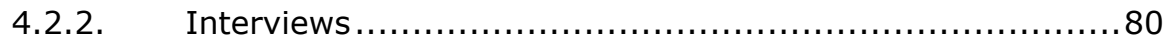

4.2.3. Qualitative content analysis and Bow-Tie analysis ........... 81

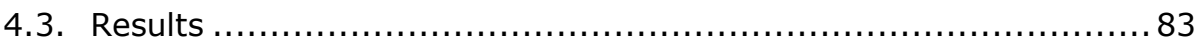

4.3.1. Deviation from official cropping calendar.................... 83

4.3.2. Reasons for disruptions in cropping schedules ................ 86

4.3.3. Bow Tie analysis............................................... 98

4.3.4. Reducing vulnerability to natural hazards ................. 102

4.4. Discussion and conclusion ....................................... 104 Chapter 5 Factors influencing Resilience of Farmers to Natural Hazards in

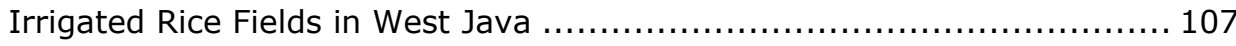

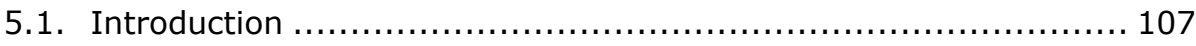

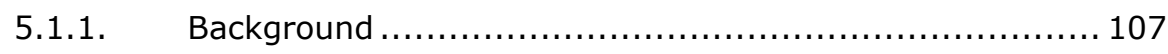

5.1.2. Study Area ............................................. 109

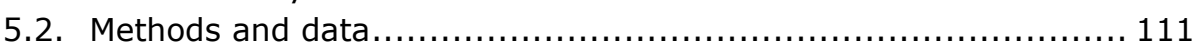

5.2.1. Conceptual framework .................................... 111

5.2.2. Data collection and analyses ........................... 112

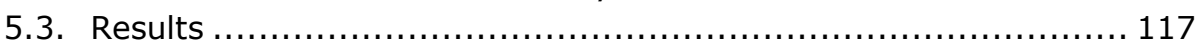

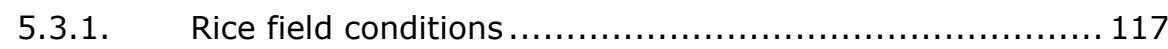

5.3.2. Households' characteristics ............................ 118

5.3.3. Resilience scores of households ............................ 119

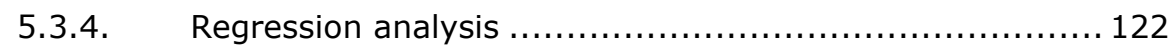

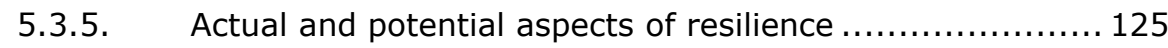

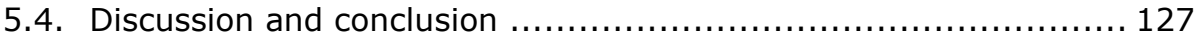

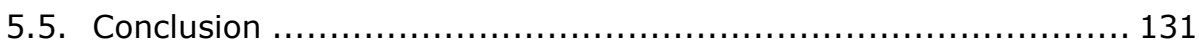

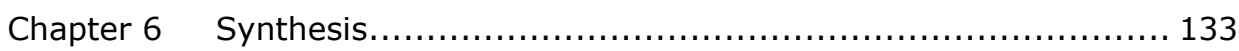

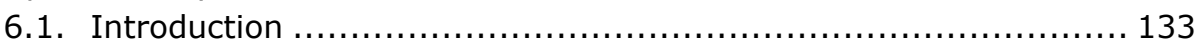

6.2. Towards mapping vulnerability to flooding using time-series MODIS imageries: Mapping cropping patterns in irrigated rice fields in West Java............................................... 133

6.3. Distinguishing between flooding and agronomic inundation in

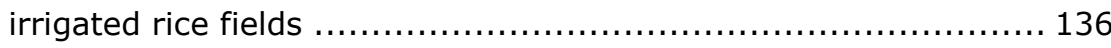

6.4. Towards understanding vulnerability: Investigating disruptions in cropping schedules in irrigated rice fields in West Java............. 139

6.5. How can the impacts of natural hazards in irrigated rice fields be reduced? 


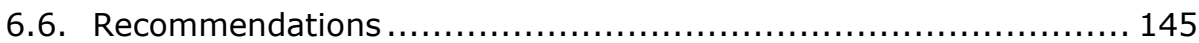

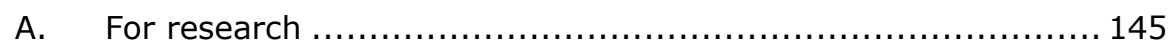

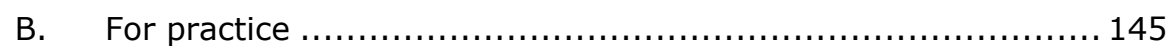

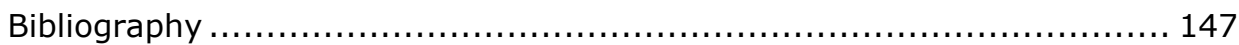

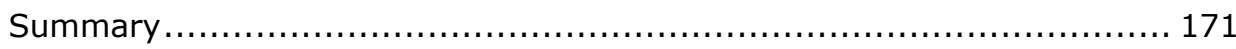

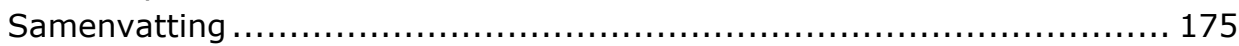

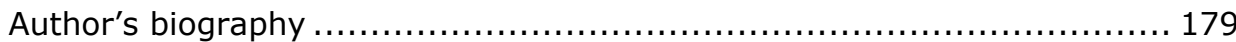




\section{List of Figures}

Figure 1.1 Framework of physical vulnerability (modified from Westen et al. 2011)

Figure 1.2 Pressure and Release (PAR) model..............................

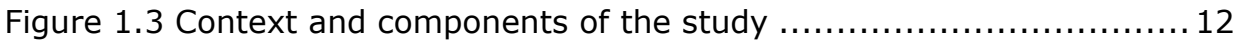

Figure 1.4 Study areas: Bekasi, Karawang, Subang, and Indramayu districts. Water for irrigation in vast rice field areas is distributed from Ir. Djuanda reservoir and managed by Perusahaan Umum Jasa Tirta II. Other irrigated rice fields are served by local water sources (e.g., reservoirs,

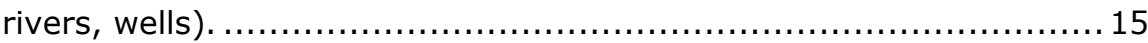

Figure 2.1. Framework for estimating vulnerability to flooding in irrigated rice fields (slightly modified from Van Westen and Woldai (2012)). Vulnerability curves are derived from the relative damages of rice growing stages at varying hazard intensities. 22

Figure 2.2. Study areas: Irrigated rice fields located in Bekasi, Karawang, Subang, and Indramayu districts. Water for irrigating rice fields are distributed from Ir. Djuanda reservoir and is managed by Perusahaan Umum Jasa Tirta II. Other irrigated rice fields are served by local water sources (e.g., reservoirs, rivers, deep wells) $\ldots \ldots \ldots \ldots \ldots \ldots \ldots \ldots \ldots \ldots 25$

Figure 2.3. Flowchart for determining the vulnerability to flooding from timeseries 8-day 500-m spatial resolution MODIS (MOD09A1) imageries. Cropping pattern is one of the inputs for mapping the vulnerability to flooding in irrigated rice fields.

Figure 2.4. Smoothed time-series Enhanced Vegetation Index (EVI) using the Adaptive Savitzky-Golay filter. Illustration of rice growth phases (e.g., vegetative, generative, ripening), planting seasons (e.g., wet and dry planting seasons), and phenology metrics (e.g., start of season, heading stage, end of season) is provided.

Figure 2.5. Divergence statistics (minimum and average separability scores) generated using an ISODATA unsupervised classification. Eighty-eight clusters were selected as the optimal number of clusters to represent land uses in the northern districts of West Java (Bekasi, Karawang, Subang, and Indramayu). 30

Figure 2.6. Vulnerability curves derived from the Reynolds number. Clustering, harvesting, shooting, and transplanting classes belong to the low, moderate, high, and very high vulnerability levels, respectively. Figure 2.6 corresponds to Figure 9. Source: Ganji et al. (2012)............... 34

Figure 2.7. Reference rice field maps. Areas of irrigated rice fields are derived from (Top) Agricultural Statistics and (Bottom) ALOS PALSAR. Source: (Top) Ministry of Agriculture and (Bottom) Ministry of Public Works of Republic of Indonesia. ............................................ 36

Figure 2.8. Spatial distribution of irrigated rice fields in the northern districts of West Java, represented by thirty-five rice clusters. Grouped using the 
hierarchical cluster analysis, rice clusters show elongated shape representing a gradient of wet season planting dates. Figure 2.8 corresponds to Table 2.3 38

Figure 2.9 Cropping patterns in irrigated rice fields in West Java. A rice cluster is used to represent the rice cluster groups (Letter $\mathrm{A}-\mathrm{K}$ ) generated from the hierarchical cluster analysis. Figure 2.9 corresponds to Figure 2.3.43

Figure 2.10. Vulnerability to flooding in irrigated rice fields varies in space and time. Fallow, clustering, harvesting, shooting, and transplanting stages belong to the no, low, moderate, high, and very high vulnerability levels.

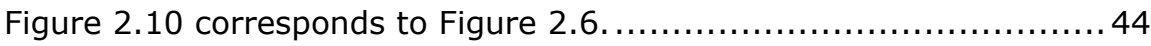

Figure 2.11. Comparison between the estimated and observed areas of irrigated rice fields derived from MOD09A1 and ALOS PALSAR and MOD09A1 and Agricultural Statistics. .............................. 45

Figure 2.12 One-to-one comparison between estimated and observed DOYs of phenology metrics. ................................................... 46

Figure 3.1 (A) Study areas: Irrigated rice fields (purple) in Bekasi, Karawang, Subang, and Indramayu districts (black line). Green dots and black dots represent visited rice fields with agronomic inundation and flooding, respectively. Yellow dots (I-IV) and a red dot (V) represent examples of rice fields with agronomic inundation and flooding, respectively. Yellow dots and the red dot correspond to Figure 3.2. (B) Blue rectangle represents swampland rice fields affected by the dyke failure on January 18, 2014. Yellow star marks the location of the dyke failure (inset). Conditions in the black rectangle in Figure 3.1B are explained in Table 3.1 53

Figure 3.2. EVI profiles (average of $5 \times 5$ pixels) in rice fields with flooding and rice fields with agronomic inundation in 2013/2014 and LTA (2000-2015). Each dot represents an 8-day MOD09A1. Lines with solid- and non-filled markers represent rice fields with flooding and rice fields with agronomic inundation, respectively. Symbols I-IV correspond to the yellow dots and the $\mathrm{V}$ red dot in Figure 3.1A. AI stands for Agronomic Inundation. LTA stands for Long-term Average.

Figure 3.3 Time series of surface water maps generated using EVI $\leq 0.1$ in irrigated rice fields in West Java. (Top) wet planting season: DOY 337 (2013) - 49 (2014). (Bottom) dry planting seasons DOY 137- 217 (2014). Value at the left corner of each figure is the area of surface water in $\mathrm{km}^{2}$. Rice field areas presented in Figure 3.1 is used as a mask. 63

Figure 3.4 Rice fields with $(A)$ surface water detected using EVI $\leq 0.1$ (blue) and (B) with flooding detected using $\mathrm{EVI}_{40}$ (black). Black rectangle represents rice fields affected by a dyke failure on January 18, 2014. Dotted green circle is misclassified flooded rice fields. (C) Total area rice fields with flooding detected using $\mathrm{EVI}_{40}$ in 2013/2014 and 2014/2015. Figure 3.4 corresponds to Figure 3.1B 
Figure 3.5 Time series of total rice fields with surface water areas $\left(\mathrm{km}^{2}\right)$ derived from EVI $\leq 0.1$ and with flooding using $\mathrm{EVI}_{40}$ in 2013/2014, 2014/2015, and long-term average (2000-2015). Black arrow points to misclassified flood pixels (False Positive) detected using $\mathrm{EVI}_{40}$ during dry planting seasons 2014 and 2015. 66

Figure 3.6 Maps of flood duration generated using $\mathrm{EVI}_{40}$ during wet planting seasons (DOY 1-89) in 2013/2014 and 2014/2015 .......................68

Figure 4.1 Pressure and Release (PAR) model................................. 73

Figure 4.2. Study area is irrigated rice fields served by Perusahaan umum Jasa Tirta (PJT) II. Water managers supervise irrigation water distribution at sub-division offices (Letters A-H). Cropping schedules for each rice field class (I-V) correspond to Table 1.1. Blue points $(n=85)$ are respondents and correspond to Table 4.2. Orange points correspond to Table 4.4 and Figure 4.7. (Source: Perusahaan Umum Jasa Tirta II and Sianturi et al. (2018)). 76

Figure 4.3. Example of a smoothed time-series Enhanced Vegetation Index (EVI) profiles. 79

Figure 4.4 Bow-Tie analysis diagram. Elements include hazards, causes, preventive barriers, top events, recovery barriers, consequences, escalation factors, and escalation factor barriers....

Figure 4.5. Deviation (days) of long-term average (2000-2015) planting dates from the official cropping calendar in irrigated rice fields served by Ir. Djuanda reservoir during (top) wet and (bottom) dry planting seasons ....................................................................... 85

Figure 4.6. Deviations (days) of long-term average planting dates (2000-2015) from the official cropping calendar in irrigated rice fields served by Ir. Djuanda reservoir in four rice-producing districts of West Java. 86

Figure 4.7 Examples of reasons for disruptions in cropping schedules derived from the time-series Enhanced Vegetation Index (EVI) dataset (average $5 \times 5$ pixels). (A) Delay in planting dates until the middle of December (e.g. 2012/13) to avoid harvesting difficulties during wet seasons; (B) Alternating double- (e.g. 2006/07) and triple- (e.g., 2009/10) rice cropping cycle; (C) Farmers resort to delaying wet season planting dates due to flooding events; (D) Shift in cropping schedules due to a change in government control on farming practices since the wet planting season in 2003. Start of Season is when the EVI value is 0.1 during a growing phase. Reasons and locations were obtained through in-depth interviews. Figure 4.7 corresponds to Figure 4.2 and Table 4.4 ....

Figure 4.8 Bow-Tie analysis of reasons for disruptions in cropping schedules in irrigated rice fields served by Ir. Djuanda reservoir in West Java. Reasons comprise economic motives, weather variabilities, geographic locations, coping strategies, farmers' interactions, and agricultural infrastructures. 101 
Figure 5.1. Study Area. Irrigated rice fields in villages in Subang district suffering from a water-deficit event during the dry planting season 2015.

Figure 5.2 Component framework. Each component in the framework is used to construct a questionnaire for investigating factors influencing the resilience of farmers to natural hazards in irrigated rice fields....

112

Figure 5.3. Conditions of rice fields illustrated using the Vegetation Condition Index (VCI) during the (Top) dry and wet planting seasons in the DOY 281 (2015) and DOY 073 (2016), respectively; (Middle) dry planting season 2015; (Bottom) wet planting season 2016. High VCI percentage reflects good vegetation conditions. Low VCI percentage reflects either fallow conditions or water-deficit events.

119

Figure 5.4. H istogram (top left), normal P-P plots (top right), scatterplot of standardized residual and standardized predicted values (bottom left), and scatterplot of independent variables and a dependent variable in the multiple linear regression (bottom right). 124

Figure 5.5. One-to-one relationship between independent variables and resilience scores 125

Figure 5.6. Examples of interrelationships among farming households in the study area. Rice fields are connected through socio-economic, institutional, and environmental processes........................ 130

Figure 6.1. Flowchart for determining the vulnerability to flooding from timeseries 8-day 500-m spatial resolution MODIS (MOD09A1) imageries. 134

Figure 6.2. Vulnerability to potential flooding in irrigated rice fields varies in space and time. Fallow, clustering, harvesting, shooting, and transplanting stages belong to the no, low, moderate, high, and very high vulnerability levels.

136

Figure 6.3 Rice fields with (A) surface water detected using EVI $\leq 0.1$ (blue) and (B) with flooding detected using $\mathrm{EVI}_{40}$ (black). Black rectangle represents rice fields affected by a dyke failure on January 18, 2014. Dotted green circle is misclassified flooded rice fields. (C) Total area rice fields with flooding detected using EVI $_{40}$ in 2013/2014 and 2014/2015. 138

Figure 6.4. Deviation (days) of long-term average (2000-2015) planting dates from the official cropping calendar in irrigated rice fields served by Ir. Djuanda reservoir during (top) wet and (bottom) dry planting

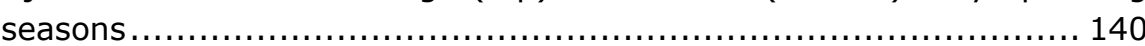

Figure 6.5 Bow-Tie analysis of reasons for disruptions in cropping schedules in irrigated rice fields served by Ir. Djuanda reservoir in West Java. Reasons comprise economic motives, weather variabilities, geographic locations, coping strategies, farmers' interactions, and agricultural infrastructures................................................. 142 
Figure 6.6. Examples of interrelationships among farming households in the study area. Rice fields are connected through socio-economic, institutional, and environmental processes....................... 143

\section{List of Tables}

Table 1.1. Official cropping calendar for irrigated rice fields under Ir. Djuanda (Jatiluhur) reservoir command area. T: tillage (30 days); P: planting (15 days); G: growth (30 days); F: flowering (45 and 30 days in wet and dry planting seasons, respectively); M: maturation (30 days); "blank space": fallow period (farmer can use rice fields for planting cash crops); D: irrigation channel drying. In practice, farmers adjust planting dates according to perceived environmental and socio-economic factors...... 16

Table 2.1. Official cropping calendar for irrigated rice fields under Ir. Djuanda (Jatiluhur) reservoir command area. T: tillage (30 days); P: planting (15 days); G: growth (30 days); F: flowering (45 and 30 days in wet and dry planting seasons, respectively); M: maturation (30 days); "blank space": fallow period (farmer can use rice fields for planting cash crops); D: irrigation channel drying. In practice, farmers adjust planting dates according to perceived environmental and socio-economic factors...... 26

Table 2.2. Equation for Reynolds number $(x)$ - loss ( $y$ ) function for rice paddies at various growth stages

Table 2.3 Generalized phenology metrics (Mean \pm Stdv, in DOY \pm days) for rice clusters in irrigated rice fields in the northern region of West Java. Table

2.3 corresponds to Figure 2.8 . 39

Table 2.4 Duration (Mean \pm Stdv, in days) between phenology metrics. Variation is the average of all clusters (rounded).

Table 3.1. Conditions of rice fields with flooding and rice fields with agronomic inundation in Bobos and Pangarengan villages (Legonkulon sub-district) in the wet planting season 2014 (wet year) and 2015 (dry year). Table Table 3.1 corresponds to Black dot (V) in Figure $3.1 \mathrm{~A} . \ldots \ldots \ldots \ldots \ldots . \ldots 56$

Table 3.2. Duration (Mean \pm Stdev, in days) of surface water (agronomic inundation and flooding) in irrigated rice fields per year derived from EVI from $2000 / 2001$ to $2014 / 2015$ ( $n=$ number of pixels). Duration is the difference between transplanting date $\left(\mathrm{SOS}^{a}\right)$ and the date when agronomic inundation or flooding first detected. ...................... 58

Table 3.3. Evaluation matrix to assess estimated flooded rice pixels derived using $\mathrm{EVI}_{40}$ 61

Table 3.4. Results of accuracy assessment (\%) for rice fields with flooding detected using $\mathrm{EVI}_{40}$ during the wet planting season 2013/2014. The wet planting season $2013 / 2014$ is compared to long-term average (2000-

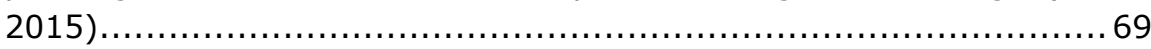

Table 4.1. Official cropping calendar for irrigated rice fields served by Ir. Djuanda (Jatiluhur) reservoir. Farmers may adjust planting dates 
according to perceived environmental and socioeconomic factors. Letter $P$ (Planting) is the reference Day of Year (DOY) for the Start of Season (SOS). Rice field classes in Table 4.1 corresponds to Figure $4.2 \ldots \ldots . .77$

Table 4.2 Overview of study participants. Table 4.2 corresponds to Figure 4.2.

Table 4.3 Independent samples t-test between the estimated and reference SOSs 83

Table 4.4. Examples of locations of deviations in cropping schedules in irrigated rice fields served by Ir. Djuanda reservoir in West Java detected using time-series remote sensing data. Table 4.4 corresponds to Table 4.2 and Figure 4.7. ....

Table 4.5 Example of coping strategies to flood and water-deficit events that influence cropping schedules. ............................................ 93

Table 4.6. Hazard, vulnerability, and disaster impacts in irrigated rice fields served by Ir. Djuanda (Jatiluhur) reservoir in West Java................. 100

Table 5.1 Variables used in this study ........................................ 115

Table 5.2 Number of respondents in the present study $(n=132) \ldots \ldots \ldots \ldots . \ldots 116$

Table 5.3. Actual and potential resilience categorized into very low-high resilience level......................................................... 117

Table 5.4 Percentages of response per question items ....................... 121

Table 5.5 Independent-samples t-test of low and high resilience scores differentiated by households characteristics (Mean \pm Standard Deviation; $\mathrm{n}=132$ ) 122

Table 5.6. Regression analysis of factors influencing the resilience of farmers to natural hazards in irrigated rice fields in Subang district, West Java 125

Table 5.7 Mean differences (Mean \pm Standard Error) between resilience groups $(p<.05)$. Mean differences are obtained when the mean of a group in a row is subtracted from the mean a group in a column. 


\section{List of abbreviations}

\begin{tabular}{|c|c|}
\hline ANOVA & Analysis Of Variance \\
\hline BPBD & $\begin{array}{l}\text { Badan Penanggulangan Bencana Daerah } \\
\text { (Regional Disaster Management Agency) }\end{array}$ \\
\hline BPS & $\begin{array}{l}\text { Badan Pusat Statistik } \\
\text { (The Indonesian Central Bureau of Statistics) }\end{array}$ \\
\hline DOY & Day of Year \\
\hline DPA & $\begin{array}{l}\text { Divisi Pengelolaan Air } \\
\text { (Water Management Division of PJT II) }\end{array}$ \\
\hline DPS & Dry Planting Season \\
\hline EMDAT & Emergency Event Database \\
\hline EOS & End of Season \\
\hline FAO & Food and Agriculture Organization \\
\hline FN & False Negative \\
\hline FP & False Positive \\
\hline EVI & Enhanced Vegetation Index \\
\hline IFRC & International Federation of Red Cross and Red Crescent \\
\hline IPCC & Intergovernmental Panel on Climate Change \\
\hline IRRI & International Rice Research Institute \\
\hline KKCD & $\begin{array}{l}\text { Kepala Kantor Cabang Dinas } \\
\text { Head of Aaricultural Office at the sub-district level }\end{array}$ \\
\hline MODIS & Moderate Resolution Imaging Spectroradiometer \\
\hline MLSWI & Modified Land Surface Water Index \\
\hline NDVI & Normalized Difference Vegetation Index \\
\hline NDWI & Normalized Difference Water Index \\
\hline OECD & Organization for Economic Co-operation and Development \\
\hline PJT II & $\begin{array}{l}\text { Perusahaan umum Jasa Tirta II } \\
\text { (Jasa Tirta II State-owned company) }\end{array}$ \\
\hline POPT & $\begin{array}{l}\text { Pengamat Organisme Pengganggu Tanaman } \\
\text { (Pest analysts extension ffficers) }\end{array}$ \\
\hline RMSE & Root Mean Square Error \\
\hline $\mathrm{R}^{2}$ & Coefficient of Determination \\
\hline RFAI & $\begin{array}{l}\text { Rice Fields with Flooding and Rice Fields with Agronomic } \\
\text { Inundation }\end{array}$ \\
\hline SDPA & $\begin{array}{l}\text { Sub-divisi Pengelolaan Air } \\
\text { (Water management sub-division of PJT II) }\end{array}$ \\
\hline SOS & Start of Season \\
\hline SPSS & Statistical Package for the Social Sciences \\
\hline TN & True Negative \\
\hline TP & True Positive \\
\hline UN & United Nations \\
\hline UNISDR & United Nations International Strategy for Disaster Reduction \\
\hline USDA & United States Department of Agriculture \\
\hline VCI & Vegetation Condition Index \\
\hline WPS & Wet Planting Season \\
\hline
\end{tabular}




\section{Chapter 1 Introduction}

\subsection{Risk of natural hazards in irrigated rice fields: the need for studies}

The world population is expected to reach 8.9 billion in 2050 (UN 2004). The growing population challenges the rice agricultural sector to design strategies for maintaining food security. In 2014, approximately 163 million ha rice fields were harvested worldwide and around 742 million tons rice paddy produced globally. Around $91 \%$ of global rice production were from Asia, and around $30 \%$ of the global rice crop was harvested in Southeast Asia alone (Faostat 2014). It is predicted that an additional rice production of 116 million tons is needed to meet the demand of the growing population in 2035 (Seck et al., 2012).

Irrigated rice fields deliver the majority of rice production. Irrigated rice fields (hereafter referred to as rice fields, unless stated otherwise) provide a higher productivity compared to that of rain-fed rice fields (Grisp 2013, Cesari De Maria et al., 2017). Irrigated rice fields contribute to around $55 \%$ and $75 \%$ of global harvested rice areas and rice production, respectively (Dobermann and Fairhurst 2000, Bouman et al., 2007a). Irrigation systems enable the cultivation of more than one crop per year, with production reaching up to 1518 tons/ha/year compared to 1-3 tons/ha/year of single-crop rain-fed or upland rice fields (Dobermann and Fairhurst 2000, Redfern et al., 2012). Partly because of variations in solar radiation, rice production in wet and dry planting seasons may reach 5-6 tons/ha and 7-8 tons/ha in the tropical region, respectively (Dobermann and Fairhurst 2000, Deng et al., 2015).

Globally, an increasing number of disaster events in many rice-producing regions are reported, threatening livelihoods of millions of people and jeopardizing global food security (Paul and Rasid 1993, Pandey et al., 2007, FAO 2015, Singh and Singh 2015). For example, analyzing the EMDAT (Emergency Event Database) data from 1971-2010, Thomas et al., (2014) mentioned that hydro-meteorological disasters in Asia-Pacific countries were related to the increase in population and precipitation anomaly and temperature-related climatological disasters. Furthermore, rice fields in Southeast Asia are also highly prone to natural hazards (Abe et al., 2014, Okazumi et al., 2014, Kotera et al., 2016). It is reported that there is an increasing water scarcity in irrigated rice fields because of competing water users (Bouman et al., 2007b, Pandey et al. 2007). Kouadio et al., (2012) also mentioned that flood events in six Southeast Asia countries from 2007 to 2011 have affected 25 million people and caused regional economic losses, reaching up to 4.6 billion USD. 
There are several reasons why studies related to disaster risk reduction (DRR) in rice fields are needed. Firstly, a pressing demand to reduce damages and losses from disaster events exists. Natural hazards threaten livelihoods of millions of farmers, jeopardize the continuity of sectors that supply inputs to or rely on the output of rice farming, and potentially stall or destroy hardfought development gains. Smallholder and underprivileged farmers are those who frequently suffer the most from devastating disaster impacts in rice fields. DRR aims to reduce potential damages from disaster events. DRR provides concepts and practices for analyzing and managing causal factors of disaster risk. The efforts may include, but not limited to, lessening the vulnerability of people and property, managing the environment, or improving preparedness for adverse events (UNISDR 2009b). Secondly, studies related to DRR are likely to contribute to the advancement of science and progress in disaster risk management practices. The perspective of DRR is likely to be beneficial for systematically understanding determinants of risk in the context of rice agriculture. Instead of solely attributing damages to the magnitude of natural hazards, the risk analysis has also incorporated vulnerability into evaluation processes, acknowledging human influences on potential damages and losses, providing reasons why small-moderate disaster events may cause different consequences in rice fields in space and time (Marulanda et al., 2011). Recently, the integration of resilience concept into disaster studies opens a new perspective for viewing the ability of households or communities to face the unexpected disaster events. In practice, DRR in rice fields is about making informed decisions at different management levels, such as on-the-farm, households, community, and national. Finally, local stakeholders and national policymakers frequently desire information from DRR studies to reduce potential devastating disaster impacts in rice fields. Information about disaster risk is essential for supporting national policies and programs on environmental management and rural development as well as for facilitating discussions among researchers, policy makers, field officers, and farmers. In this regard, the concept and practice of DRR help to understand interactions between environmental and socioeconomic processes (Twigg 2004) and how the interrelationships may potentially lead to disastrous events (UNISDR 2009a).

The United Nations considered potential impacts of disaster events in the attainment of the 2030 Agenda for Sustainable Development Goals (SDG), particularly under the first goal: end poverty. It is stated in Target 1.5 that by 2030, nations must 'build the resilience of the poor and those in vulnerable situations and reduce their exposure and vulnerability to climate-related extreme events and other economic, social and environmental shocks and disasters' (UN 2017). Studies related to reducing potential disaster impacts in rice fields are relevant to the first goal. Also, the studies support the accomplishment of the second goal: zero hunger (UN 2017). Target 2.4 stated that by 2030, the world community has to 'ensure sustainable food production 
systems and implement resilient agricultural practices that increase productivity and production, that help maintain ecosystems, that strengthen capacity for adaptation to climate change, extreme weather, drought, flooding and other disasters and that progressively improve land and soil quality.'

Conducting studies for reducing potential disaster impacts in rice fields are not without challenges. Firstly, investigating the disaster risk in rice fields requires the understanding of interactions among determinants of risk and dynamics between environmental processes and human activities (UNISDR 2009a, Cardona et al., 2012). It is increasingly recognized that the relationship among factors constructing determinants of risk is not straightforward and highly varied in different contexts in space and time. Secondly, the resilience concept connects disaster risk studies with broader disciplines and potentially stimulates ideas and practices for DRR to move forward; however, the definition and scope of resilience and determinants of risk and are still a matter of debate (e.g., natural or social science) (Cutter 2016). Terminologies and concepts vary, depending on the disciplinary background, perspective, and problem focus, and consequently influence the measurement processes and potential applications. One example is related to the discussion whether the vulnerability is the opposite or one of the determinants of resilience and adaptive capacity or vice versa (Adger et al., 2005, Cutter et al., 2008, Miller et al., 2010). Another example is the discrepancy in definition and determinants of vulnerability between natural hazard and climate change scientists (Cardona et al. 2012). Thirdly, scientific terminologies are often foreign for rice agricultural stakeholders at sub-national levels. Investigators need to creatively translate sophisticated terms, such as vulnerability or resilience, to local languages and design appropriate measurement tools for capturing such concepts from local stakeholders. Fourthly, the components of risk and resilience are complex, dynamic, and geographic. They continuously change in different contexts, and their analysis is influenced by the interaction of economic, social, and environmental aspects. Ideally, the examination of risk and resilience in rice fields require a considerable amount of time-series data, which is likely to be limited in developing countries. The lack of data about dynamics in rice fields often causes limitations in risk and resilience analyses. Finally, the multi-faceted and -level nature of risk components and resilience requires guiding conceptual frameworks that incorporate local aspects for their measurement, which is frequently scarce for the context of irrigated rice fields.

The most extensive areas of irrigated rice fields in Southeast Asia are found in Indonesia, followed by Vietnam, Myanmar, and Thailand (Mutert and Fairhurst 2002). Indonesia is known as the third-largest rice producer in the world (De Desarrollo Asiático 2006). The rice production reached approximately 70 million tons, and around 13.7 million ha rice fields were harvested in 2014 
(BPS 2017). Rice is the source of livelihoods for millions of households in Indonesia. The agricultural crop sub-sector accounted for $10.26 \%$ national GDP of Indonesia in 2014, having decreased from 10.99\% in 2010 (CervantesGodoy and Dewbre 2010). The absorption of labors from the agricultural sector was the highest, contributing to approximately 35.76 million workers or $30.27 \%$ of total absorbed laborers in 2014 (Kementan 2015).

Irrigated rice fields in Indonesia are severely affected by recurrent disaster impacts associated with non-extreme and extreme weather variabilities (Amien et al., 1996, Naylor et al., 2001). Flooding during wet seasons and water-deficit events during dry seasons are one of the seasonal scourges to smallholder farmers in many rice-producing provinces in Indonesia, jeopardizing the livelihoods of millions of farmers and national food security. Lassa (2012) estimated that total crop areas affected by flood and drought events from 2003-2008 in Indonesia reached up to approximately 3.9 million ha. Surprisingly, studies related to disaster events in irrigated rice fields are still lacking in Indonesia. In this respect, studies are urgently needed to fill the knowledge gap and reduce potential disaster impacts in irrigated rice fields in Indonesia.

\subsection{Disaster and disaster risk}

For the last two decades, there has been a focus shift from responding to disaster events toward reducing disaster risk, with the aim to achieve a substantial reduction in losses in lives, health, and assets of communities, businesses, and countries (Montz and Tobin 2011, UN 2015). It is increasingly acknowledged that a disaster risk always precedes the disaster occurrences (UNISDR 2009a). Disaster risk results from the complex interaction of exposure, vulnerability, and hazards (Turner et al., 2003, UNISDR 2009b). Furthermore, with the reports of increasing damages and losses and changes in frequency and magnitude of natural hazards due to the changing trends of environmental and socioeconomic processes, it is realized that resilience is essential for reducing disaster risk. Efforts for resilience building aim to enhance the ability of communities or development sectors at large to absorb, accommodate, and recover from unexpected hazardous physical events while increasing their capacity to face future disaster events.

This thesis defines disasters as 'the severe alteration in the normal functioning of a community or a system due to hazardous physical events interacting with vulnerable social conditions, leading to widespread adverse human, material, economic, or environmental effects' (Lavell et al., 2012). The term of hazardous physical events is used interchangeably with natural hazards and denotes that the disaster may be of natural, socio-natural, and anthropogenic origins (UNISDR 2009b). 
This thesis emphasizes on obtaining knowledge related to the hazard, vulnerability, and resilience for reducing potential disaster impacts, focusing on flooding and water-deficit events in irrigated rice fields. Brief elaborations on hazard, vulnerability, and resilience are provided in the following subsections. This thesis does not in particular concentrate on hazards of biological origins, such as rat, golden apple snail, bird, brown plant hopper, or other pest and disease outbreaks. However, their contributions to damages and disruptions in rice farming practices are recognized and frequently cited throughout the studies to provide a full perspective on the risk of natural hazards in irrigated rice fields.

\subsubsection{Hazard}

Studies related to natural hazards has gone through development processes until its present forms. The early research on natural hazards focused on the description of physical processes and their spatial distribution and impacts. The studies considered nature as the sole causes of adverse events (Montz and Tobin 2011). Researchers have studied extreme events (Easterling et al., 2000, Goswami et al., 2006) and the interaction among natural hazards in space and time (Wu et al., 2014, Gill and Malamud 2016). Along the way, scholars begin to use insights about physical processes to focus more on solving societal problems by understanding the interaction between natural and human environments (White 1945, Montz and Tobin 2011). Research on natural hazards expands, incorporating other determinants of risk, such as the vulnerability (Cutter and Finch 2008) or resilience of communities (Klein et al., 2003, Twigg 2007, Zhou et al., 2010, Alexander 2013).

This study views hazards as dangerous physical events that may cause loss of life, injuries or other health impacts, as well as damages to properties, infrastructures, livelihoods and services, social and economic disruptions, and environmental damages (UNISDR 2009b). Several characteristics can be used to categorize the nature of hazard events, including the type, potential magnitude, frequency of occurrence, seasonal pattern, duration, speed of onset, availability of warning system, location and spatial extent (Pine 2009). The severity of natural hazards may be determined by physical processes (Tao et al., 2013); however, from the disaster risk reduction perspective, it is currently recognized that trends in vulnerability also determine potential impacts of natural hazards (UN 2009). Furthermore, impacts of natural hazards may affect individual households (idiosyncratic), or they can be quite localized, impacting households in rural areas (covariate), or they may occur over several tens of thousands of kilometers impacting a country (systemic) (OECD 2009). 


\subsubsection{Vulnerability}

Vulnerability is a complex and dynamic concept. It consists of various aspects, including physical, economic, social, and environmental. Scholars from different disciplines propose definitions to capture the broad aspect of vulnerability (Timmerman 1981, Dow 1992, Wisner et al., 2003), often using various terms, including predisposition (Cardona 2004), susceptibility (Parry et al., 2007), sensitivity (Luers et al., 2003), or lack of capacity (Birkmann 2006). Also, studies have proposed conceptual frameworks to describe vulnerability, such as the Pressure And Release (PAR) model (Wisner et al. 2003) or the BBC (Birkman Bogardi Cardona) model (Birkmann and Fernando 2008). Authors also distinguished vulnerability either as an outcome (O'brien et al., 2004) or a process (Turner et al. 2003, Wisner et al. 2003). To understand vulnerability, one requires the comprehension of potential impacts of natural hazards and underlying conditions, including economic, social, and environmental aspects that make people unable to reduce the risk of natural hazards (Birkmann 2006). The drivers of vulnerabilities may take many forms, including the uncontrolled urbanization ( $\mathrm{Li}$ et al., 2016), poverty (Akter and Mallick 2013, Azeem et al., 2016), environmental degradation (Warner et al., 2010), or poor governance (Corfee-Morlot et al., 2011). Daily social interactions (Morrow 1999) and lack of access to resources and livelihood options may also generate vulnerability.

The dynamic and complex nature of vulnerability requires different perspectives and multi-disciplinary approaches for its understanding and measurement (Gardoni et al., 2016). Although the vulnerability assessment ideally requires comprehensive approaches (Cardona 2004), because of its complexity, the evaluation has been conducted using a single condition (e.g., economic or physical) or the combination of several conditions (e.g., socioeconomic). Thus, it is often argued that there is not a single method can comprehensively capture the nature of vulnerability (Chakraborty and Joshi 2016). Furthermore, vulnerability has been quantitatively monitored at the national and global levels using an extensive range of indicators and indices (Adrianto and Matsuda 2002, Cutter and Finch 2008). Qualitative approaches, however, are frequently used to analyze vulnerability at the sub-national (e.g., household, community) level. Vulnerability assessments at the sub-national level enable the identification of potential threats and impacts of disaster events that exist within households and communities (Fang et al., 2016). Vulnerability assessments at the local level need to capture root causes, dynamic pressures, and unsafe conditions that lead to vulnerability (Wisner et al. 2003) and position localities at the broader context (Birkmann 2006) to strategically design measures to address vulnerability (Bolin and Stanford 1998). 
The susceptibility to disaster impacts is frequently associated with particular groups of people, such as the poor people and disabled, and within the vulnerable group, people also show different levels of vulnerability (Morrow 1999, Cardona et al. 2012, IPCC 2014). Affected by the same hazard intensity, individuals and regions may experience different degrees of damages (Chatenoux and Peduzzi 2007) and perform varying levels of ability to recover from adverse conditions (Marre and Renaud 2011). Furthermore, it is increasingly recognized that people can be exposed and not vulnerable to natural hazards at the same time (Cardona et al. 2012). For example, some affluent communities who live in coastal areas that are prone to flooding and hurricane may have financial assets or insurance mechanisms, or be able to mobilize their social capital that enables them to rapidly recover from the devastating impacts of the natural hazards (Cutter and Gall 2007, Cutter 2016).

This study provides information that is useful for understanding vulnerability in irrigated rice fields from two unique perspectives: physical vulnerability (Chapter 2) and the progression of vulnerability (Chapter 3 ). The former focuses on irrigated rice fields while and the latter relates to farmers. Firstly, physical vulnerability is defined as the degree of damage to an object exposed to a given level of hazard intensity (Westen et al., 2011). Figure 1.1 shows that physical vulnerability is often expressed using vulnerability curves (range from $0-1$ ) that display the relation between the hazard intensity and degree of damage for elements at risk. It can be seen that vulnerability curves are able to incorporate various types hazards as well as spatial and temporal variations of different elements at risk. This study focuses on flood hazards with rice fields as elements at risk. Secondly, this study recognizes vulnerability as characteristics and circumstances of a community, system or asset that make it susceptible to the damaging effects of a hazard (UNISDR 2009b). Figure 1.2 shows that vulnerability may change from its root causes to unsafe conditions. It can be seen that the progression of vulnerability is multi-level and dimensional. Root causes are the set of processes in society, including economic, demographic, and political, that influence the distribution of resources and exercise of power. Dynamic pressures are associated with the contemporary or direct manifestation of root causes. The particular forms in which the vulnerability of people or system is expressed in space and time jointly with natural hazards are termed as unsafe conditions (Wisner et al. 2003). Root causes are 'translated' into unsafe conditions by dynamic pressures. This progression is likely to increase potential damages and losses from natural hazards. 
Risk: probability of losses

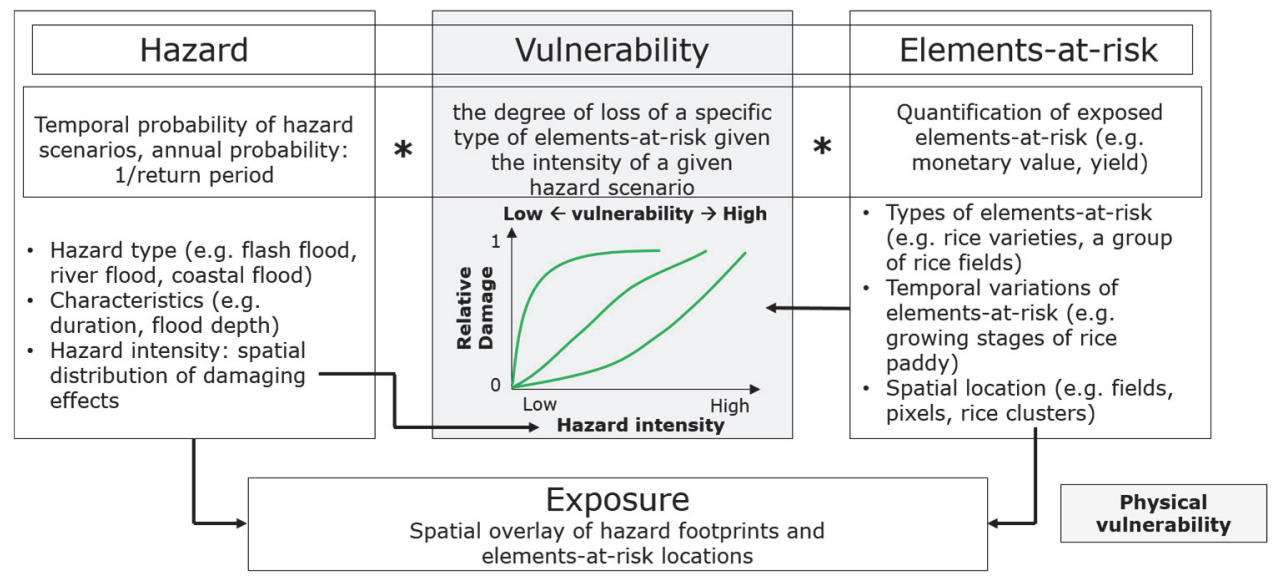

Figure 1.1 Framework of physical vulnerability (modified from Westen et al. 2011) 


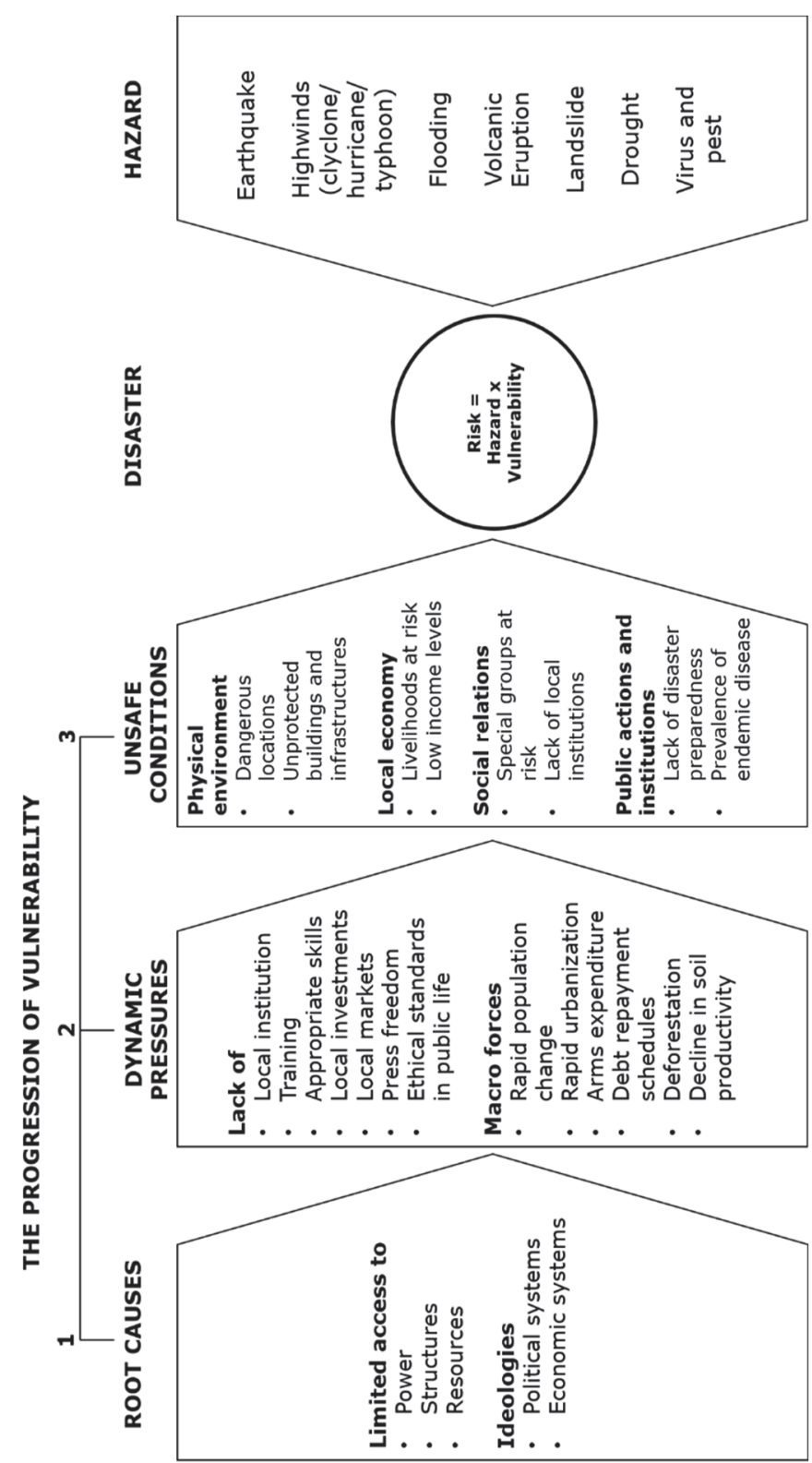

Source: Wisner, Blaikie, Cannon and Davis (2004). At Risk: Natural Hazards, People's Vulnerability, and Disasters, $2^{\text {nd }}$ edition, Routledge, New York.

Figure 1.2 Pressure and Release (PAR) model

\subsubsection{Resilience}

Resilience has gained its currency among scholars in the discipline of disaster risk reduction because of the need to enhance the capacity of a community or a system to face unexpected disaster events (Zhou et al. 2010). Resilience is 
recognized as either a desired system property (Kerner and Thomas 2014) or an umbrella concept to reduce the potential damages and losses that are associated with the trends in exposure and vulnerability (Klein et al. 2003). Resilience concept stems from the ecological discipline (Holling 1973, Holling 1986). It is then applied to social science (Timmerman 1981, Dovers and Handmer 1992, Adger 2000), social-ecological discipline (Carpenter et al., 2001, Folke et al., 2003), and natural hazards (Zhou et al. 2010, Fekete et al., 2014, Weichselgartner and Kelman 2015). Increasingly, scholars have contributed insights to advance resilience building in practice, such as the disaster resilience of 'Loss-Response' of location (DRLRL) (Zhou et al. 2010). Weichselgartner and Kelman (2015) mentioned the need to move away from the descriptive resilience concept to the normative agenda by emphasizing structural social-political processes and the differences between ecosystems and societies.

Similar to vulnerability, the broad, complex, context and location specifics, and multi-level aspects of resilience necessitate various assessment methods and interdisciplinary approaches (Constas et al., 2014). In this respect, the quantitative and qualitative approaches complement each other to illustrate the tangible and intangible features of resilience (Birkmann and Wisner 2006). Through prescribe procedures, the quantitative method provides a reliable observation on exposed and vulnerable elements-at-risk, while qualitative means capture and supply a more detailed narrative of human perceptions (Constas et al. 2014). Also, the subjective data have been proven useful to capture the characteristics of resilience communities or systems (Maxwell et al., 2015, Béné et al., 2016).

Resilience is interpreted differently among natural and social disciplines, which affect its measurement and application in practice. On the one hand, resilience has been broadly defined as the ability of a system, community or society exposed to hazards to resist, absorb, accommodate to, and recover from the effects of a hazard in a timely and efficient manner, including through the preservation and restoration of its essential basic structures and functions (UNISDR 2009b). Resilience also encompasses the capacity to learn from the past experiences or to 'bounce forward' to face future natural hazard occurrences (Manyena 2011). On the other hand, the focus of resilience may only be on one of its desired system properties, such as the ability to recover or the ability to prepare for future adverse events. Specifically, this research focuses on the recovery aspect of resilience. In this study, resilience is defined as the ability of farmers to recover from recurrent impacts of natural hazards. It is assumed that resilient households recover faster from adverse disaster impacts compared to less resilient households. 


\subsection{Research problem and objectives}

Natural hazard occurrences have caused substantial damages and losses to irrigated rice fields. However, to the best of our knowledge, fewer studies formulate the dynamics explicitly using the perspective of disaster risk reduction. This thesis is conducted in irrigated rice fields in West Java, one of the rice-producing regions in Indonesia. Several studies have provided invaluable information for monitoring changes and analyzing disruptions that have been continuously affecting farming practices in the study area. The research encompassed various topics, such as the monitoring and evaluation of rice cropping patterns (Sudana et al., 1982, Uchida 2010), mapping flooding (Yulianto et al., 2015) or drought (Darmawan et al., 2014, Surmaini et al., 2014, Aulia et al., 2016) events, characterizing non-extreme and extreme weather events (Amien et al. 1996, Naylor et al. 2001, Qian et al., 2010, Nuryanto et al., 2016), and investigating the characteristic of rice pests and diseases (Holz and Sioe 1965, Kusmayadi et al., 1990, Tristiani et al., 2003, Brown et al., 2010, Sudarmaji et al., 2010). This thesis addresses this research gap by producing knowledge related to hazard, vulnerability, and resilience in irrigated rice fields. Figure 1.3 shows that each chapter connects with and support other chapters to provide insights on the interactions between natural environment and socioeconomic processes in from the disaster risk reduction perspective. This study uses various tools, such as remote sensing and qualitative content analyses to capture dynamics of irrigated rice fields (e.g., cropping patterns, farming practices) in space and time. Overall, this thesis aims to answer the research question: 'How can disaster impacts in irrigated rice fields be reduced?' To this end, this thesis also aims to provide inputs for reducing the potential impacts of disaster events and advance science and the practices of disaster risk reduction in irrigated rice fields. Specific subobjectives are defined to respond the research question:

- to determine the vulnerability to flooding in irrigated rice fields.

- to distinguish between rice fields with flooding and rice fields with agronomic inundation using time-series MODIS imageries.

- to investigate the progression of vulnerability from rice fields to farmers

- to analyze factors influencing the resilience of farmers to natural hazards in irrigated rice fields. 


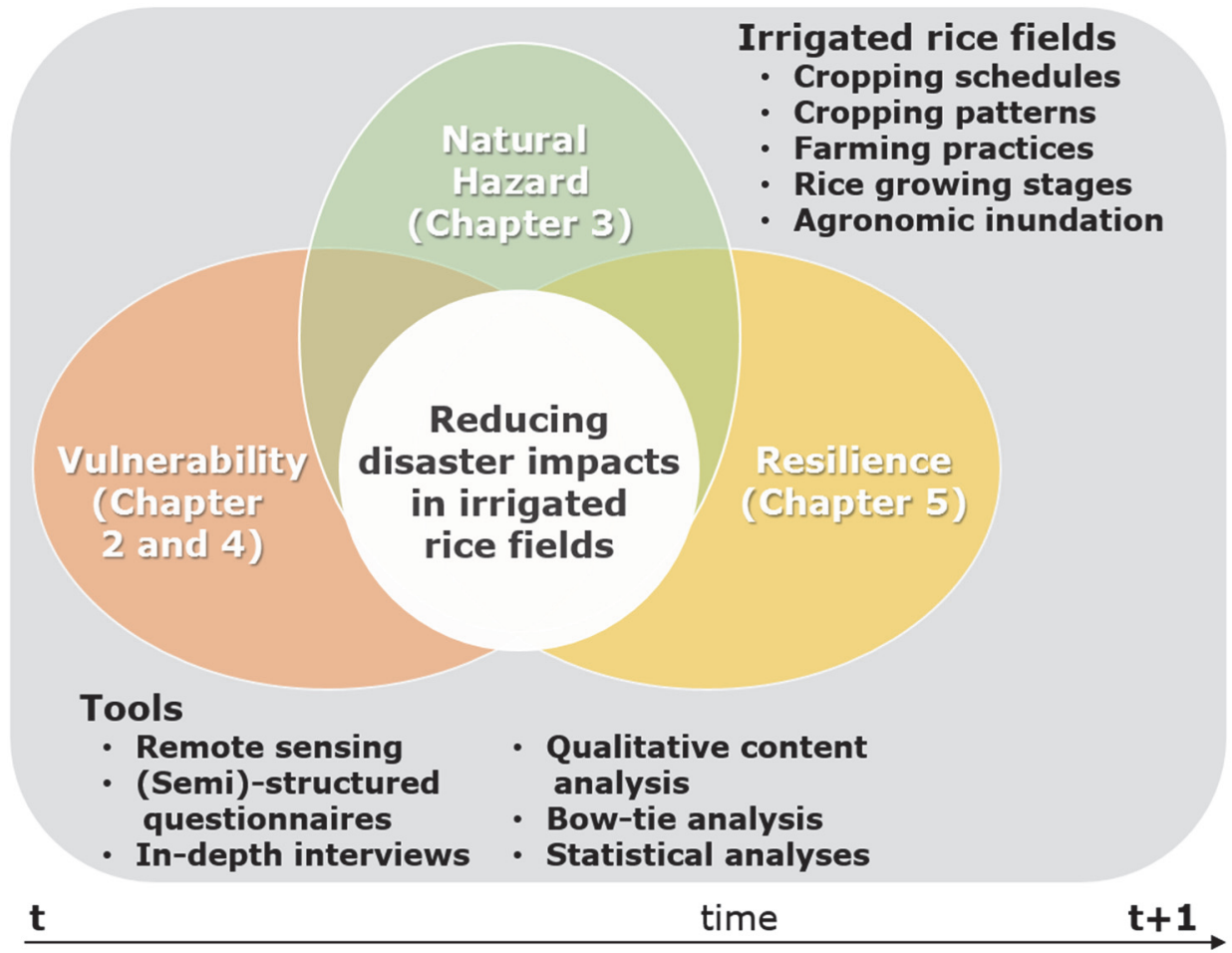

Figure 1.3 Context and components of the study

\subsection{Study areas}

Known as Indonesia's national rice-production regions, irrigated rice fields in four districts of West Java, including Karawang, Subang, Bekasi, and Indramayu, were selected as the study area, as shown in Figure 1.4 (Van Valkenburg 1936, Panuju et al., 2013). The areas of irrigated rice fields in the districts are approximately $37 \%$ of the total area of rice fields in West Java (Statistik 2012). The study area is situated in the humid tropical climate zone and experiences two seasons: wet and dry seasons (Yulianto et al. 2015, Yanto et al., 2016). Although average annual rainfall $(2000 \mathrm{~mm})$ is quite high (Juwana et al., 2016), it is mainly distributed from December to March and tends to spread over the middle and southern regions of West Java (Qian et al. 2010, Nuryanto et al. 2016). Several irrigation systems exist to serve the massive demand for water for the whole year (Ravesteijn 2002). The most extensive area of irrigated rice fields is served by a state company (Perusahaan Umum Jasa Tirta II - PJT II) where water flows from the multipurpose Ir. Djuanda (Jatiluhur) reservoir in the Purwakarta district to irrigate rice fields (approximately 240,000 ha) (Loebis and Syariman 1993). Rice fields in the Ir. Djuanda reservoir command area are regulated by a cropping calendar and irrigation schedules (Husin et al., 1995, Uchida 2010), as shown in Table 1.1. 
Other rice fields are served by local water resources, such as reservoirs, rivers, or deep wells. These rice fields are not obliged to follow official planting schedules like those of rice fields served by Jatiluhur reservoir; however, the national agricultural office suggests cropping calendars as a reference for rice cultivation (http://katam.litbang.pertanian.go.id/).

A double-irrigated rice cropping pattern is commonly adopted by farmers (Kusmayadi et al. 1990, Statistik 2012). The official wet planting season is from October to March and the dry planting season starts from April to September, taking the periods of 150 and 135 days, respectively. However, planting dates for wet and dry planting seasons often differ between years because of the interactions among irrigation management, socioeconomic, and environmental processes. Delays in planting dates at the upper parts may influence the planting dates of farmers in the lower parts of irrigation channels due to the nature of cropping calendar and irrigation schedules.

Flooding and water-deficit events are frequently reported in these riceproducing regions due to the variabilities in extreme and non-extreme weathers, especially in swampland (deep or semi-deep) rice fields located near coastal areas (Amien et al. 1996, Naylor et al. 2001, Boer and Subbiah 2005, Marulanda et al. 2011, Daruati et al., 2013, Darmawan et al. 2014, Yulianto et al. 2015, Setiawan et al., 2016). The peaks of flooding and water-deficit events are usually from the beginning of January to the end of February and from the beginning of August to the end of September, respectively (As-Syakur et al., 2013, Schollaen et al., 2013, Siswanto et al., 2016). The potential impacts of flooding and water-deficit events to rice paddies are partly determined by the growing stages of rice paddy during flood events, characteristics of flood hazards (e.g., depth, duration), and coping capacity of farmers. The impacts of flooding may range from small yield reductions to complete harvest failures if the flooding occurs during vegetative and generative phases, respectively. During flood submergence, the transport of oxygen from leaves to roots ceases, and plants stop growing (Bailey-Serres et al., 2012). During dry planting seasons, water-deficit events may occur due to lack of access to irrigation water. Rice fields located far from irrigation channels frequently experience this challenge. Water-deficit events may be exacerbated by poor irrigation management and infrastructures. Similar to flooding, the potential impacts of water-deficit events (e.g., planting or harvest failure) partly depend on the rice growing stage during disaster events. Furthermore, irrigated rice fields in the study area are sensitive to the recurring pattern of ENSO (El NiñoSouthern Oscillation), the anomalies in sea-surface temperature and sea-level pressure (Amien et al. 1996, Naylor et al. 2001, Surmaini et al. 2014). ENSO is characterized by El-Niño and La-Niña, which refers to warming and cooling periods, respectively. The extent of rice field areas suffering from water-deficit 
events is greater during strong La-Niña and El-Niño years, respectively (Harger 1995, Naylor et al. 2001, Surmaini et al. 2014).

Studies have been continuously conducted to improve the resistance of rice crops to flooding and water-deficit events (Miro and Ismail 2013). For example, several flood tolerance rice varieties (e.g., SUB1A, SNORKEL) are claimed to be able to survive for approximately two weeks during complete submergence, using strategies such as quiescence, elongation, and escape (Singh et al., 2009, Singh et al., 2011b, Mickelbart et al., 2015). Rice varieties that are resistant to flooding and water-deficit events have also been introduced to farmers. However, farmers in the irrigated rice fields in West Java prefer to plant high-yielding rice varieties and adapt to flood risk. For example, farmers whose rice fields located in flood-prone areas (e.g., near coastal areas) cope with flooding events by delaying wet season planting dates, waiting for the rainfall intensity to weaken or ponding water to subside. 

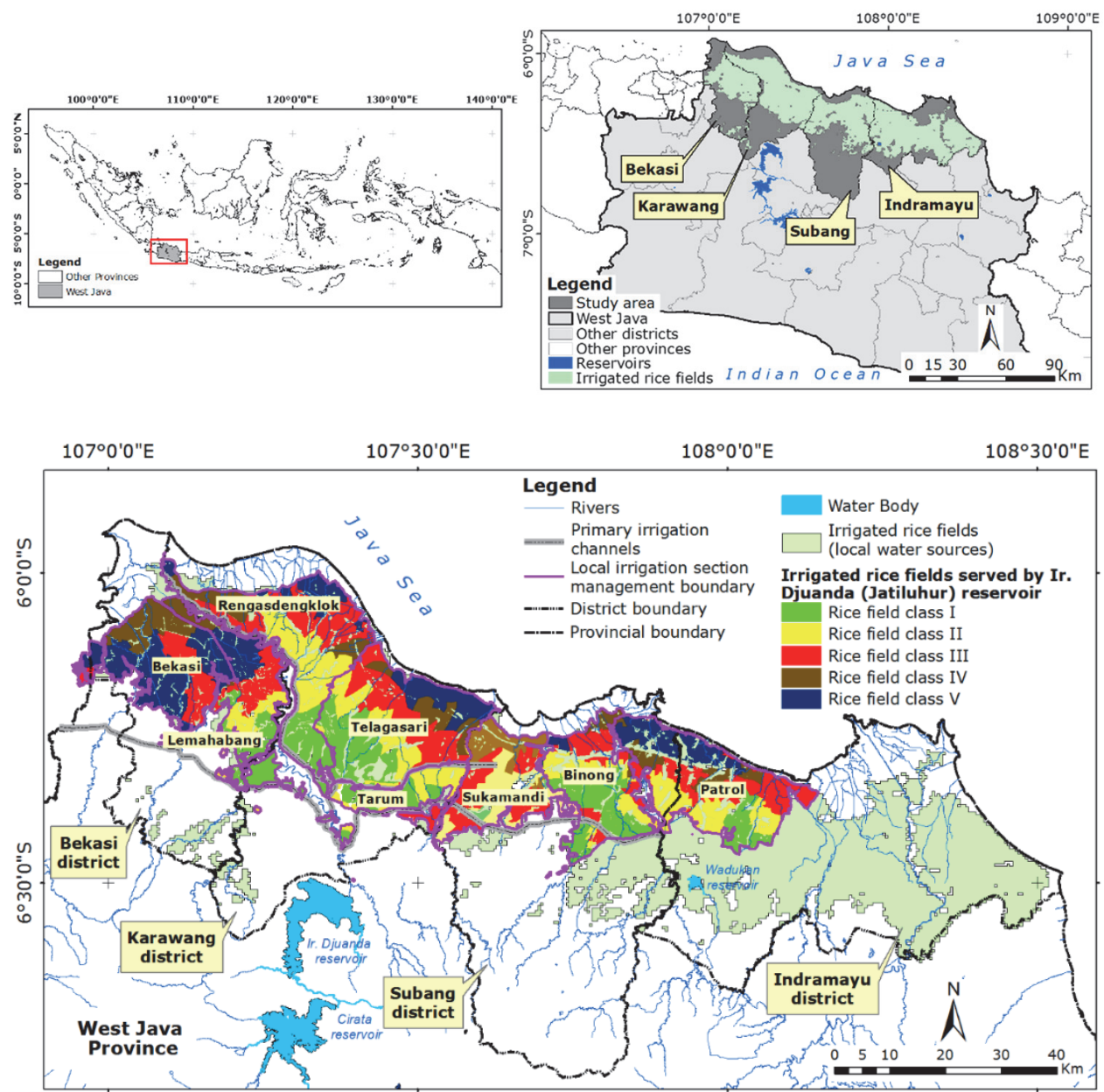

Figure 1.4 Study areas: Bekasi, Karawang, Subang, and Indramayu districts. Water for irrigation in vast rice field areas is distributed from Ir. Djuanda reservoir and managed by Perusahaan Umum Jasa Tirta II. Other irrigated rice fields are served by local water sources (e.g., reservoirs, rivers, wells). 
Table 1.1. Official cropping calendar for irrigated rice fields under Ir. Djuanda (Jatiluhur) reservoir command area. T: tillage (30 days); P: planting (15 days); G: growth (30 days); F: flowering (45 and 30 days in wet and dry planting seasons, respectively); $\mathrm{M}$ : maturation (30 days); "blank space": fallow period (farmer can use rice fields for planting cash crops); D: irrigation channel drying. In practice, farmers adjust planting dates according to perceived environmental and socio-economic factors.

\begin{tabular}{|c|c|c|c|c|c|c|c|c|c|c|c|c|c|c|c|c|c|c|c|c|c|c|c|c|}
\hline $\mathrm{Ri}$ & \multicolumn{12}{|c|}{ Wet planting season (rendeng) } & \multicolumn{12}{|c|}{ Dry planting season (gadu) } \\
\hline $\begin{array}{l}\mathrm{ce} \\
\mathrm{fi}\end{array}$ & \multicolumn{2}{|c|}{ Oct } & \multicolumn{2}{|c|}{ Nov } & \multicolumn{2}{|c|}{ Dec } & \multicolumn{2}{|c|}{ Jan } & \multicolumn{2}{|c|}{ Feb } & \multicolumn{2}{|c|}{ Mar } & \multicolumn{2}{|c|}{ Apr } & \multicolumn{2}{|c|}{ May } & \multicolumn{2}{|c|}{$\begin{array}{c}\text { Jun } \\
\mathrm{e}\end{array}$} & \multicolumn{2}{|c|}{ July } & \multicolumn{2}{|c|}{ Aug } & \multicolumn{2}{|c|}{$\begin{array}{c}\text { Sep } \\
t\end{array}$} \\
\hline $\begin{array}{c}\text { d } \\
\text { cl } \\
\text { as } \\
\text { s }\end{array}$ & $\mathrm{I}$ & $\begin{array}{l}\text { I } \\
\text { I }\end{array}$ & $\mathrm{I}$ & $\begin{array}{l}\text { I } \\
\text { I }\end{array}$ & $\mathrm{I}$ & $\begin{array}{l}\text { I } \\
\text { I }\end{array}$ & $\mathrm{I}$ & $\begin{array}{l}\text { I } \\
\text { I }\end{array}$ & $\mathrm{I}$ & $\begin{array}{l}\text { I } \\
\text { I }\end{array}$ & I & $\begin{array}{l}\text { I } \\
\text { I }\end{array}$ & $\mathrm{I}$ & $\begin{array}{l}\text { I } \\
\text { I }\end{array}$ & I & $\begin{array}{l}\text { I } \\
\text { I }\end{array}$ & I & $\begin{array}{l}\text { I } \\
\text { I }\end{array}$ & $\mathrm{I}$ & $\begin{array}{l}\text { I } \\
\text { I }\end{array}$ & $\mathrm{I}$ & $\begin{array}{l}\text { I } \\
\text { I }\end{array}$ & I & $\begin{array}{l}\text { I } \\
\text { I }\end{array}$ \\
\hline I & $\mathrm{T}$ & $\bar{T}$ & $P$ & G & $\mathrm{G}$ & $\mathrm{F}$ & $\mathrm{F}$ & $\mathrm{F}$ & $M$ & $M$ & $\mathrm{~T}$ & $\mathrm{~T}$ & $P$ & $\mathrm{G}$ & $\mathrm{G}$ & $\mathrm{F}$ & $\mathrm{F}$ & $M$ & $M$ & & & & & $\mathrm{D}$ \\
\hline II & & $\mathrm{T}$ & $\mathrm{T}$ & $P$ & $\mathrm{G}$ & $\mathrm{G}$ & $F$ & $F$ & $F$ & $M$ & $M$ & $\mathrm{~T}$ & $\mathrm{~T}$ & $P$ & $\mathrm{G}$ & $\mathrm{G}$ & $F$ & $F$ & $M$ & $M$ & & & & $D$ \\
\hline $\begin{array}{c}\text { II } \\
\text { I }\end{array}$ & & & $\mathrm{T}$ & $\mathrm{T}$ & $P$ & $\mathrm{G}$ & $\mathrm{G}$ & $F$ & $F$ & $\mathrm{~F}$ & $M$ & $M$ & $\mathrm{~T}$ & $\mathrm{~T}$ & $P$ & $\mathrm{G}$ & $\mathrm{G}$ & $F$ & $F$ & $M$ & $M$ & & & $D$ \\
\hline IV & & & & $\mathrm{T}$ & $\mathrm{T}$ & $P$ & $\mathrm{G}$ & $\mathrm{G}$ & $F$ & $F$ & $F$ & $M$ & $M$ & $\mathrm{~T}$ & $\mathrm{~T}$ & $P$ & $\mathrm{G}$ & G & $\mathrm{F}$ & $F$ & $M$ & $M$ & & D \\
\hline $\mathrm{V}$ & & & & & $\mathrm{T}$ & $\mathrm{T}$ & $P$ & $\mathrm{G}$ & $\mathrm{G}$ & $\mathrm{F}$ & $F$ & $\mathrm{~F}$ & $M$ & $M$ & $\mathrm{~T}$ & $\mathrm{~T}$ & $P$ & $\mathrm{G}$ & $\mathrm{G}$ & $F$ & $F$ & $\mathrm{M}$ & $M$ & D \\
\hline
\end{tabular}

Source: Perusahaan Umum Jasa Tirta II

\subsection{Structure of the thesis}

The thesis consists of six chapters. Chapters 2-5 addresses specific research gaps. The chapters, apart from the introduction and synthesis, have been written as stand-alone sections. Thus, there may be an overlap in the sections of Introduction and Method in each chapter.

Chapter 1 presents the background of research, research problem and objectives, a brief description of the study area, and the structure of the thesis. A brief overview of the concept of disaster risk, components of risk, and resilience is also given in this chapter.

Chapter 2 determines the vulnerability to flooding in irrigated rice fields from remote sensing and ground truth. Previous studies that estimate the physical vulnerability frequently neglect the spatial and temporal components of rice fields. Chapter 2 addresses this gap by mapping rice cropping patterns using hyper-temporal 8-day 500-m spatial resolution remote sensing imageries. Cropping patterns are generated from the spatial distribution and growing stages of rice fields. After combining cropping patterns and vulnerability curves, one can determine the spatial and temporal variations of physical vulnerability to flooding in irrigated rice fields.

Chapter 3 concerns about the hazard aspect of risk. This chapter discusses the need for a clear distinction between hazardous flooding and non-hazardous agronomic inundation and the necessity of ancillary ground information for distinguishing between the two using time-series remote sensing imageries. Previous studies claimed to have successfully detected flooding, one of the 
problems causing disruptions in cropping schedules, in irrigated rice fields using time-series remote sensing imageries (Yulianto et al. 2015, Kotera et al. 2016). However, scholars fail to recognize that surface water in irrigated rice fields may be associated with either non-hazardous irrigation water or hazardous flood events. It is argued that there is a need to distinguish between the two before detecting flooding in irrigated rice fields using remote sensing. Chapter 4 investigates this issue and proposes a method to make a distinction between rice fields with flooding and rice fields with agronomic inundation.

Chapter 4, similar to Chapter 2, is related to vulnerability. Chapter 3 focuses specifically on identifying unsafe conditions in irrigated rice fields using the concept of the progression of vulnerability (Wisner et al. 2003). Firstly, the chapter analyzes the deviation of cropping schedules from the official cropping calendar. Then, this chapter innovatively demonstrates that reasons for disruptions in cropping schedules can be used to trace unsafe conditions that may increase vulnerability.

Chapter 5 concentrates on resilience. Several studies have investigated factors influencing the resilience of farmers to natural hazards in rice-producing regions using different perspectives, such as the ability to absorb changes or cope with disaster events (Keil et al., 2007, Nguyen and James 2013, Arouri et al., 2015). However, to our understanding, fewer studies investigate factors influencing the resilience of farmers to natural hazards, focusing on the recovery aspect in irrigated rice fields in West Java, Indonesia. Chapter 5 addresses this knowledge gap with the dry planting season 2015 and wet planting season 2016 as the study period. Focusing on the recovery aspect, Chapter 5 analyzes factors that influence the resilience of farmers to natural hazards. The factors can act as a 'shortcut' for understanding the ability of farmers to recover from disaster impacts.

Finally, Chapter 6 summarizes all the findings from Chapters 2-5 with the specific aim to pinpoint efforts that can be performed to reduce the potential disaster impacts in irrigated rice fields in West Java. 


\section{Chapter 2 Mapping cropping patterns in irrigated rice fields in West Java: Towards mapping vulnerability to flooding using time-series MODIS imageries ${ }^{1}$}

\subsection{Introduction}

\subsubsection{Background}

Despite the growing rice demand, many rice-producing regions increasingly suffer from flood hazard occurrences worldwide (Okazumi et al. 2014, Gumma et al., 2015, List and Coomes 2017). For example, USDA (2011) reported that heavy monsoon rainfall and typhoons caused flooding in 2.6 million ha rice fields stretching from Burma to the Philippines (6\% of total rice areas) during September and October 2011. The impacts of flood disaster events on rice production may range from a small reduction in yield quality and harvested areas, crop failures, to massive economic losses and food insecurity (Lou et al., 2012, Chau et al., 2013, Zhang et al., 2015a).

Information on the vulnerability to flooding is essential for estimating potential damages from flooding events. Broadly, vulnerability refers to the characteristics and circumstances of a community, system, or asset that make it susceptible to the damaging effects of a hazard (UNISDR 2009b). Vulnerability encompasses different dimensions, such as physical, economic, social, and environmental, and the dimensions vary accordingly depending on the exposed elements-at-risk (Cardona et al. 2012, Van Westen and Woldai 2012). In irrigated rice fields (hereafter referred to as rice fields), the vulnerability to flooding may be determined by the interactions among environmental conditions (e.g., weather, locations), socioeconomic settings of farming communities (e.g., irrigation schedules, farming group decisions), and rice growth stages (e.g. seedling, flowering) during flood events. These conditions also indicate that the vulnerability to flooding in rice fields varies in space and time. Due to its complexity, the vulnerability assessment often focuses on a particular elements-at-risk and emphasizes on the physical aspect. In this regard, the vulnerability is defined as the degree of damage to an object (e.g., irrigated rice fields) exposed to a given level of hazard intensity (e.g., flood depth or duration) and often expressed using vulnerability curves (Van Westen and Woldai 2012). Additional datasets, such as the damaged

\footnotetext{
${ }^{1}$ This chapter is based on: Sianturi, Jetten and Sartohadi, 2018. Mapping cropping patterns in irrigated rice fields in West Java: Towards mapping vulnerability to flooding using time-series MODIS imageries. International Journal of Applied Earth Observation and Geoinformation 66, 1-13.
} 
yields and market price of yields, are required to derive the potential damages or losses in monetary values (Okazumi et al. 2014, Kwak et al., 2015).

Two challenges arise to exemplify the physical vulnerability to flooding in irrigated rice fields (hereafter referred to as 'vulnerability'): the growth stages of rice fields in space and time and the availability of spatial and temporal data. The first is related to the spatial and temporal variations of rice growth stages. Irrigated rice fields are not only regulated by irrigation schedules or cropping calendars but also highly influenced by socioeconomic and environmental processes, causing simultaneous variations in growth stages at the irrigation system level. For example, rice fields belong to farmers located near primary irrigation channels may already be at the harvesting stage while those located at the tail end of irrigation channels may still be at the transplanting stage, or often the latter experiences delays in planting dates because of irregularities in the irrigation distribution. The second challenge is about the availability of data for deriving the vulnerability. The vulnerability can be derived from various data sources from the local to national level. At the national level, the agricultural statistical data may be widely available and can provide an overview of the general condition of a rice cropping system. However, the data may differ in quality between government agencies (Knapp and Kruk 2010) and offer low-resolution vulnerability information, potentially obscuring significant variations at the local level. At the sub-national level, the elementsat-risk data, such as farming assets or rice field maps, may not be readily available, and the concern about the consistency and quality of data exists (Nicholls 1995). Additionally, the available data about rice fields are also often lack of spatial and temporal dimensions (Bie 2004), raising difficulties for the integration with hazard data. Thus, field observations are frequently needed to collect data on rice fields, which often require enormous financial, time, and human resources (Dalal-Clayton and Dent 1993).

The aforementioned challenges for mapping the vulnerability may be addressed by generating cropping patterns. A cropping pattern is a spatial and temporal arrangement of crops in rice fields (Manjunath et al., 2015). Cropping patterns result from the decision of farmers to optimize the use of resources (e.g., irrigation schedules, weather) (Serra and Pons 2008). Cropping patterns possess spatial and temporal information that captures the responses of rice fields to a range of environmental and socioeconomic processes, including natural hazard occurrences (Xiao et al., 2005, Sakamoto et al., 2007, Boschetti et al., 2009, Sun et al., 2009, Gumma et al., 2011). Information on cropping patterns, generated by combining a rice field distribution and phenology metrics (Nguyen et al., 2011), offers insights about the vulnerability and can be used to monitor flood impacts in irrigated rice fields (Sakamoto et al., 2005, Sakamoto et al. 2007, Kotera et al., 2014). The rice field distribution provides spatial information and can be utilized as a baseline to monitor the increase or 
decrease in rice field areas. The phenology metrics deliver insights about growth stages and are beneficial for obtaining temporal information on irrigated rice fields. Additionally, because of its spatial and temporal characteristics, cropping patterns can also capture disruptions or anomalies in rice fields, that is, when the ongoing cropping pattern deviates from the historical cropping pattern (Patel et al., 2012, Zhang et al., 2014, Kuenzer et al., 2015). For example, the occurrences of natural hazards in irrigated rice fields, such as flooding or drought, may delay 'normal' cropping schedules (Naylor et al. 2001), decrease cropping intensities (Hoque et al., 1982), and reduce the available planting time (Kotera et al. 2014).

Hyper-temporal remote sensing offers potential as a useful tool for monitoring changes and deriving cropping patterns in irrigated rice fields (Ehrlich and Tenerelli 2013). Hyper-temporal-remote sensing refers to a continuous longterm earth observation using high temporal resolution remote sensing imageries (Piwowar et al., 1998). The advantage is provided by the extensive areal coverage and the frequent visit of coarse-moderate spatial resolution passive remote sensors, such as MODIS $(250 \mathrm{~m}-1 \mathrm{~km})$, which enable the continuous monitoring of vegetation's physiological and biochemical states (Huete et al., 1997, Huete et al., 2002). Previous studies have increasingly proven the usefulness of hyper-temporal remote sensing data for monitoring rice agriculture areas, including mapping the spatial distribution (Xiao et al. 2005, Xiao et al., 2006, Zhao et al., 2015), extracting phenology metrics (Lieth 1974, Sakamoto et al. 2005, Boschetti et al. 2009, Motohka et al., 2009), mapping cropping patterns (Uchida 2010, Nguyen et al. 2011, Peng et al., 2011, Manjunath et al. 2015), and detecting anomalies (Verbesselt et al., 2010, Atzberger 2013, Rembold et al., 2013). Researchers frequently use vegetation indices, such as the Normalized Difference Vegetation Index (NDVI) or Enhanced Vegetation Index (EVI), to monitor the condition of vegetation on the earth's surface (Evrendilek and Gulbeyaz 2008, Qiu et al., 2013, Son et al., 2014). However, the use of EVI is often preferred than that of NDVI because the former is more responsive to biophysical variables, such as the leaf area and canopy coverage (Gao et al., 2000, Huete et al. 2002).

This study aims to generate a method to determine the vulnerability to flooding in irrigated rice fields using EVI derived from hyper-temporal 8-day 500-m spatial resolution remote sensing imageries (Figure 0.1 ). This study is part of a broader research in which the socioeconomic aspects are also investigated. This study is limited to physical vulnerability. In this study, we do not use any flood model to simulate flood hazards but only provide a method for estimating the vulnerability to flooding. The vulnerability can be coupled with flood hazards using hydraulic parameters, such as depth and velocity. This study emphasizes the use of cropping patterns as one of the inputs for mapping vulnerability and does not focus on the comprehensive interpretation of 
conditions when rice fields are most vulnerable. The susceptibility of rice fields to flood events is different from that of other natural hazards, such as waterdeficit events or strong winds. In doing so, EVI is used to produce the spatial distribution and phenology metrics of irrigated rice fields. The former and latter can be used to derive cropping patterns. Thus, cropping patterns can illustrate the spatial and temporal variations of vulnerability for a specific year. Previous studies estimating vulnerability frequently neglect the spatial and temporal components of rice fields (Kwak et al. 2015). In reality, cropping patterns vary in space and time, influenced by physical and socioeconomic factors. Furthermore, it is worth mentioning that cropping patterns were derived from time-series 8-day 500-m spatial resolution MODIS imageries (MOD09A1) in this study. The use of the moderate spatial resolution suggests that this study cannot provide a detail field recognition of an individual parcel of irrigated rice fields. Thus, the elements-at-risk of the present study is a group of rice fields (approximately $25 \mathrm{ha}$ ). It is expected that the results of the study can be used by rice agricultural stakeholders, such as water managers, extension, and disaster risk reduction officers to timely monitor changes and design effective strategies to reduce the potential damages and losses from flood hazards in irrigated rice fields.

Risk: probability of losses

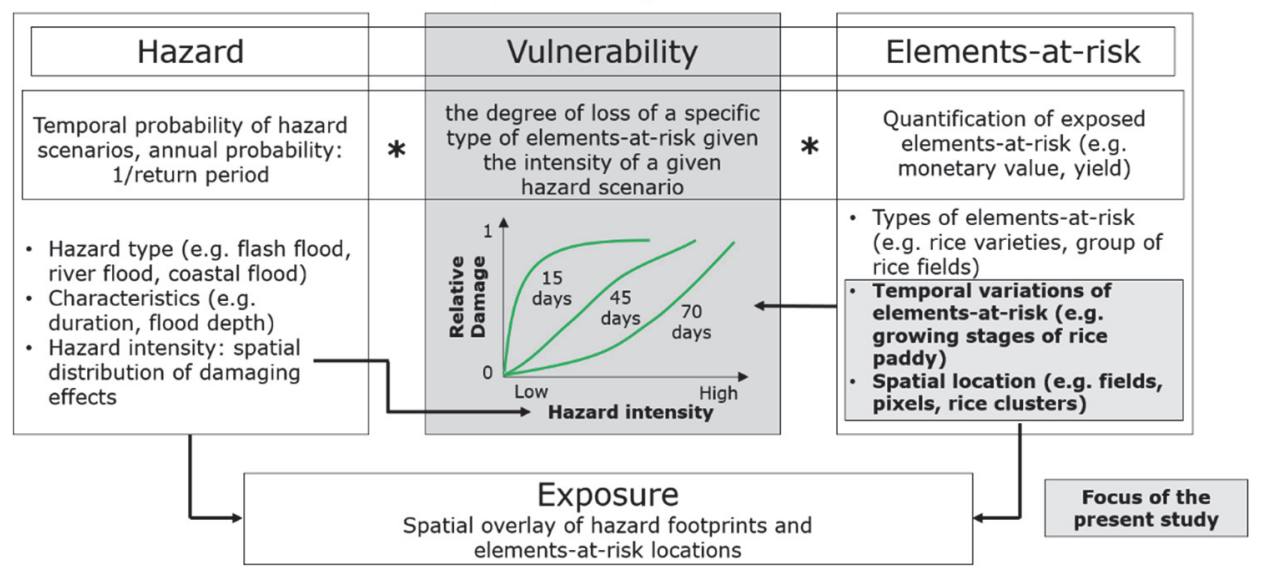

Figure 0.1. Framework for estimating vulnerability to flooding in irrigated rice fields (slightly modified from Van Westen and Woldai (2012)). Vulnerability curves are derived from the relative damages of rice growing stages at varying hazard intensities.

\subsubsection{Study Area}

\section{A. Geographic Location}

West Java is a province of Indonesia located between $5^{\circ} 50^{\prime}-7^{\circ} 50^{\prime}$ South Latitude and $104^{\circ} 48^{\prime}-108^{\circ} 48^{\prime}$ East Longitude. It is bounded by the Java Sea and the Special Province of Jakarta to the North, the Central Java province to the East, the Indian Ocean to the South, and the Banten province to the West. 
Rice yields produced from this province contribute about $17 \%$ to the national rice production (Gustoni 2013). Four northern districts of West Java, including Karawang, Subang, Bekasi, and Indramayu, are well known as Indonesia's national rice production regions (Van Valkenburg 1936, Panuju et al. 2013). The topography is dominantly flat (Bernsten and Rachim 1982), and the dominant land use is irrigated rice fields. The irrigated rice fields in the four main rice-producing districts of West Java were selected as the study area (Figure 2.2). The areas of irrigated rice fields in the districts are approximately $37 \%$ of the total area of rice fields in West Java (Statistik 2012).

The study area experiences two seasons: wet and dry seasons and is situated in the humid tropical climate zone (Yulianto et al. 2015, Yanto et al. 2016). This seasonal variation is directly related to the geographic location of Indonesia, between the Pacific and Indian oceans and Asian and Australian continents. Average rainfall is approximately $2000 \mathrm{~mm}$ per year (Juwana et al. 2016). Irrigated rice fields in the study area are at risk of flooding during wet planting seasons and water-deficit events during dry planting seasons. For example, at least 20,000 ha irrigated rice fields in Karawang district were flooded during the flood event in March 2010 (Yulianto et al. 2015). The peaks of flooding and water-deficit events are usually from the beginning of January to the end of February and from the beginning of August to the end of September, respectively (As-Syakur et al. 2013, Schollaen et al. 2013, Siswanto et al. 2016). Furthermore, irrigated rice fields are sensitive to the recurring pattern of ENSO (El Niño-Southern Oscillation) (Amien et al. 1996, Naylor et al. 2001, Surmaini et al. 2014). ENSO is characterized by anomalies in the sea-surface temperature and sea-level pressure (Southern Oscillation). El-Niño and La-Niña refer to warming and cooling periods, respectively. The extent of flooding and water-deficit events is partly associated with the severity of these climatic variabilities.

\section{B. Irrigation management and cropping pattern}

Several irrigation systems exist to serve the massive demand of water for irrigated rice fields in the study area for the whole year (Ravesteijn 2002). Although average annual rainfall ( $2000 \mathrm{~mm}$ ) is quite high (Juwana et al. 2016), it is mainly distributed from December to March and tends to spread over the middle and southern regions of West Java (Qian et al. 2010, Nuryanto et al. 2016). A large area of irrigated rice fields is served by a state company (Perusahaan Umum Jasa Tirta II - PJT II) where water flows from a multipurpose Ir. Djuanda (Jatiluhur) reservoir in the Purwakarta district to a vast area of irrigated rice fields (approximately 240,000 ha) (Loebis and Syariman 1993). Rice fields in the Ir. Djuanda reservoir command area are served by a complex irrigation system regulated by a cropping calendar and scheduled irrigation distribution (Husin et al. 1995, Uchida 2010). Other rice fields are served by local water resources, such as smaller reservoirs, rivers, or deep 
wells. Although these rice fields are not obliged to follow official planting schedules like those served by the Jatiluhur reservoir, the national agricultural office suggests cropping calendars as a reference for rice cultivation (http://katam.litbang.pertanian.go.id/). In this regard, the complexity of irrigation management partly depends on the type of and access to water sources.

The arrangement of irrigation management in rice fields served by the Ir. Djuanda reservoir is as follows. The irrigation water distribution is divided into five zones where the zones closest to the main irrigation channels (e.g., rice field class I) receive water first and zone $V$, generally located near coastal areas, receives water last. For example, irrigation water is distributed to rice field classes I and II on October 1-15 for wet planting seasons and on March 1-15 for dry planting seasons and on October 16-31 for wet planting seasons and on March 16-31 for dry planting seasons, respectively (Table 2.1). Formerly, the third and fourth weeks of September were scheduled for a complete drying of irrigation channels to enable the maintenance of irrigation infrastructures and to terminate the rice pest and disease proliferation. Nowadays, the drying is performed partly (only in secondary channels) to support other water users, such as factories and drinking water companies. Three regional water regulators (Divisi Pengelolaan Air - DPA) manage the distribution of irrigation water from primary irrigation channels to rice fields. These water regulators are aided by eight water sections, comprised of Bekasi and Lemahabang for DPA I; Sukamandi, Rengasdengklok, Telagasari, and Tarum for DPA II; and Binong, and Patrol for DPA III (see Figure 2.2).

A double-irrigated rice cropping pattern is commonly adopted by farmers (Kusmayadi et al. 1990, Statistik 2012). Locally, the first and second planting seasons are known as rendeng (hereafter referred to as wet planting season) and gadu (hereafter referred to as dry planting season), respectively. The wet planting season is from October to March and the dry planting season starts from April to September, taking the periods of 150 and 135 days, respectively. The national agricultural agency suggests rice farmers use the period after the dry season harvesting until the next wet season planting for fallow or cultivating cash crops (e.g., leek, groundnut, green beans) to halt rice pest and disease reproductions. However, planting dates for wet and dry planting seasons often differ between years because of the interplay among the irrigation management, farming practices, and socioeconomic and environmental processes. For example, although water managers distribute irrigation water according to the official cropping calendar, and the extension officers advise farmers to follow the stipulated planting dates, farmers often adjust planting dates according to their perceptions of the conditions during the whole growing seasons, such as the production and price risks. It is worth repeating that the delays in planting dates of rice fields at the upper part of 
irrigation channels may influence the cropping schedules of rice fields located in the lower part due to the nature of cropping calendar.
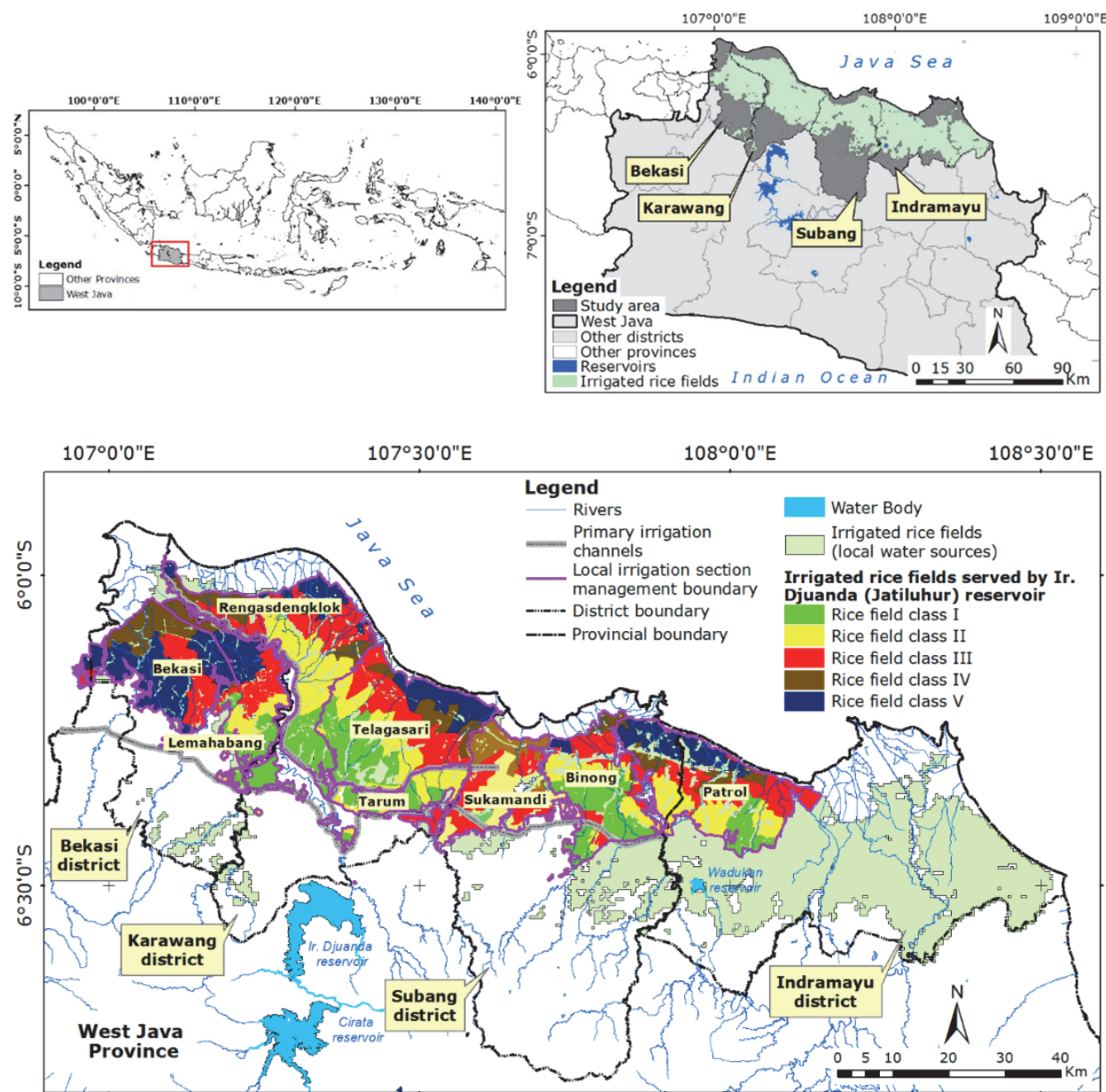

Figure 2.2. Study areas: Irrigated rice fields located in Bekasi, Karawang, Subang, and Indramayu districts. Water for irrigating rice fields are distributed from Ir. Djuanda reservoir and is managed by Perusahaan Umum Jasa Tirta II. Other irrigated rice fields are served by local water sources (e.g., reservoirs, rivers, deep wells). 
Table 2.1. Official cropping calendar for irrigated rice fields under Ir. Djuanda (Jatiluhur) reservoir command area. T: tillage (30 days); P: planting (15 days); G: growth (30 days); F: flowering (45 and 30 days in wet and dry planting seasons, respectively); $\mathrm{M}$ : maturation (30 days); "blank space": fallow period (farmer can use rice fields for planting cash crops); D: irrigation channel drying. In practice, farmers adjust planting dates according to perceived environmental and socio-economic factors.

\begin{tabular}{|c|c|c|c|c|c|c|c|c|c|c|c|c|c|c|c|c|c|c|c|c|c|c|c|c|}
\hline $\mathrm{Ri}$ & \multicolumn{12}{|c|}{ Wet planting season (rendeng) } & \multicolumn{12}{|c|}{ Dry planting season (gadu) } \\
\hline $\begin{array}{l}\mathrm{ce} \\
\mathrm{fi}\end{array}$ & \multicolumn{2}{|c|}{ Oct } & \multicolumn{2}{|c|}{ Nov } & \multicolumn{2}{|c|}{ Dec } & \multicolumn{2}{|c|}{ Jan } & \multicolumn{2}{|c|}{ Feb } & \multicolumn{2}{|c|}{ Mar } & \multicolumn{2}{|c|}{ Apr } & \multicolumn{2}{|c|}{ May } & \multicolumn{2}{|c|}{$\begin{array}{c}\text { Jun } \\
\mathrm{e}\end{array}$} & \multicolumn{2}{|c|}{ July } & \multicolumn{2}{|c|}{ Aug } & \multicolumn{2}{|c|}{$\begin{array}{c}\text { Sep } \\
t\end{array}$} \\
\hline $\begin{array}{c}\text { d } \\
\text { cl } \\
\text { as } \\
\text { s }\end{array}$ & $\mathrm{I}$ & $\begin{array}{l}\text { I } \\
\text { I }\end{array}$ & $\mathrm{I}$ & $\begin{array}{l}\text { I } \\
\text { I }\end{array}$ & $\mathrm{I}$ & $\begin{array}{l}\text { I } \\
\text { I }\end{array}$ & $\mathrm{I}$ & $\begin{array}{l}\text { I } \\
\text { I }\end{array}$ & $\mathrm{I}$ & $\begin{array}{l}\text { I } \\
\text { I }\end{array}$ & I & $\begin{array}{l}\text { I } \\
\text { I }\end{array}$ & $\mathrm{I}$ & $\begin{array}{l}\text { I } \\
\text { I }\end{array}$ & I & $\begin{array}{l}\text { I } \\
\text { I }\end{array}$ & I & $\begin{array}{l}\text { I } \\
\text { I }\end{array}$ & $\mathrm{I}$ & $\begin{array}{l}\text { I } \\
\text { I }\end{array}$ & $\mathrm{I}$ & $\begin{array}{l}\text { I } \\
\text { I }\end{array}$ & I & $\begin{array}{l}\text { I } \\
\text { I }\end{array}$ \\
\hline I & $\mathrm{T}$ & $\bar{T}$ & $P$ & G & $\mathrm{G}$ & $\mathrm{F}$ & $\mathrm{F}$ & $\mathrm{F}$ & $M$ & $M$ & $\mathrm{~T}$ & $\mathrm{~T}$ & $P$ & $\mathrm{G}$ & $\mathrm{G}$ & $\mathrm{F}$ & $\mathrm{F}$ & $M$ & $M$ & & & & & $\mathrm{D}$ \\
\hline II & & $\mathrm{T}$ & $\mathrm{T}$ & $P$ & $\mathrm{G}$ & $\mathrm{G}$ & $F$ & $F$ & $F$ & $M$ & $M$ & $\mathrm{~T}$ & $\mathrm{~T}$ & $P$ & $\mathrm{G}$ & $\mathrm{G}$ & $F$ & $F$ & $M$ & $M$ & & & & $D$ \\
\hline $\begin{array}{c}\text { II } \\
\text { I }\end{array}$ & & & $\mathrm{T}$ & $\mathrm{T}$ & $P$ & $\mathrm{G}$ & $\mathrm{G}$ & $F$ & $F$ & $\mathrm{~F}$ & $M$ & $M$ & $\mathrm{~T}$ & $\mathrm{~T}$ & $P$ & $\mathrm{G}$ & $\mathrm{G}$ & $F$ & $F$ & $M$ & $M$ & & & $D$ \\
\hline IV & & & & $\mathrm{T}$ & $\mathrm{T}$ & $P$ & $\mathrm{G}$ & $\mathrm{G}$ & $F$ & $F$ & $F$ & $M$ & $M$ & $\mathrm{~T}$ & $\mathrm{~T}$ & $P$ & $\mathrm{G}$ & G & $\mathrm{F}$ & $F$ & $M$ & $M$ & & D \\
\hline $\mathrm{V}$ & & & & & $\mathrm{T}$ & $\mathrm{T}$ & $P$ & $\mathrm{G}$ & $\mathrm{G}$ & $\mathrm{F}$ & $F$ & $\mathrm{~F}$ & $M$ & $M$ & $\mathrm{~T}$ & $\mathrm{~T}$ & $P$ & $\mathrm{G}$ & $\mathrm{G}$ & $F$ & $F$ & $\mathrm{M}$ & $M$ & D \\
\hline
\end{tabular}

Source: Perusahaan Umum Jasa Tirta II

\section{Farming practice, growth stages, flood events}

Farmers generally adopt similar farming practices although variations in planting dates exist. In practice, tillage marks the start of planting seasons. Rice seedlings are commonly sowed in a nursery bed. Then, rice paddy is usually transplanted into puddled rice fields after reaching 20-25 days in the sowing bed. Farmers frequently outsource the tillage, transplanting, and harvesting activities to labor farmers. It is common to use the services of labor farmers from other sub-districts (organized by the middlemen) if there is a shortage of local labor farmers. Most farmers still use manual hand transplanting and harvesting methods. Farmers leave rice fields fallow after harvesting. The fallow duration differs in space and time, depending on various physical (e.g., extreme weather) and socioeconomic (e.g., farming group decision) factors. Also, the selection of rice varieties influences the duration of growing seasons. Most smallholder farmers plant the rice variety of Ciherang because of the taste and high demand as staple food. Large holder farmers may plant other varieties, such as Oryza sativa glutinosa, because of their higher selling prices or local inbred rice varieties due to their potential high yields. Furthermore, farmers perform different means to manage pests or diseases in rice fields, including the intensive uses of pesticides and traditional methods and tools, both individually and in a group (e.g., synchronize planting).

The growth stages of rice paddy can be divided into three main parts, including the vegetative, generative, and ripening phases (Datta 1981, Grisp 2013). The vegetative phase starts from the germination to panicle initiation stage, taking 50-60 days after sowing. The generative phase runs from the panicle initiation 
to flowering stage, taking approximately 35 days, and the ripening phase begins from the flowering to mature grain stage, taking about 30 days.

Furthermore, flooding events are frequently reported in the study area due to the variabilities in extreme and non-extreme weathers, especially for swampland (deep or semi-deep, locally known as sawah lebak) rice fields located near coastal areas (Amien et al. 1996, Naylor et al. 2001, Boer and Subbiah 2005, Marulanda et al. 2011, Daruati et al. 2013, Darmawan et al. 2014, Yulianto et al. 2015, Setiawan et al. 2016). The impacts of flooding are partly determined by the rice growth stages during flood events, characteristics of flood hazards (e.g., depth, duration), and coping capacity of farmers. The impacts of flooding may range from a small reduction in yield quality or quantity to a complete harvest failure if flooding occurs during vegetative and generative phases, respectively. During flooding, the transport of oxygen from leaves to the roots ceases, and plants stop growing (Bailey-Serres et al. 2012). Studies have been continuously conducted to improve the flooding tolerance of rice crops (Miro and Ismail 2013). Nowadays, several flood tolerance rice varieties (e.g., SUB1A, SNORKEL) are claimed to be able to survive for approximately two weeks during complete submergence, using strategies such as quiescence, elongation, and escape (Singh et al. 2009, Singh et al. 2011b, Mickelbart et al. 2015). However, as previously mentioned, farmers in the irrigated rice fields in West Java prefer to plant high-yielding rice varieties and adapt to flood risk. For example, farmers, especially those owning fields in flood-prone locations (e.g., near coastal areas), cope with flooding events by delaying wet season planting dates, waiting for the rainfall intensity to weaken or ponding water to subside.

\subsection{Materials and Methods}

\subsubsection{Datasets and pre-processing}

Figure 2.3 shows the flowchart employed to achieve the research objective. This study specifically uses one of the land products of MODIS Terra. MODIS is one of the key instruments abroad the Terra and Aqua satellites. MODIS sensors provide a daily wide swath range $(2,330-\mathrm{km})$ observation, allowing for the monitoring of changes on the earth's surface with a high temporal resolution (1-2 days) in 36 discrete spectral bands ranging in wavelengths from $0.4 \mu \mathrm{m}$ to $14.4 \mu \mathrm{m}$. Hyper-temporal Surface Reflectance L3 8-day 500-m spatial resolution MODIS imageries (MOD09A1) were downloaded from February 2000 (DOY 49) to August 2014 (DOY 153) over the study area from the United States Geological Survey (USGS) website (http://earthexplorer.usgs.gov/). The MOD09A1 products are derived from the Level 2G MOD09GHK data with the highest observation score, lowest view angle, absence of clouds or cloud shadow and aerosol loading during an 8-day, and the data have been corrected in terms of radiometric and geometric 
(Vermote et al., 2011). The default sinusoidal projection was retained to avoid the misalignment of pixels due to re-projection. Next, the MOD09A1 data were stacked to produce time-series data (658 imageries). Then, the subset of the study area (Bekasi, Karawang, Subang, and Indramayu districts) was derived from the time-series MOD09A1. Next, the time-series Enhanced Vegetation Index (EVI) dataset was generated from the time-series MOD09A1 (Huete et al. 2002, Peng et al. 2011). EVI values range from -1 to 1 and a low EVI value indicates the lack of vegetation on the land surface. The equation to generate the EVI for this study is as follows (Huete et al. 1997, Huete et al. 2002, Sakamoto et al. 2007):

$$
\mathrm{EVI}=2.5 \times \frac{\mathrm{NIR}-\mathrm{RED}}{\mathrm{NIR}+6 \times \mathrm{RED}-7.5 \times \mathrm{BLUE}+1}
$$

where NIR is the near-infrared band (841-875 nm, Band 2); RED is the red band (621-670 nm, Band 1); and BLUE is the blue band (459-479 nm, Band 3 ). The Adaptive Savitzky-Golay filter that focuses on the upper envelope was applied to reduce the remaining noise components (e.g. aerosol or bidirectional reflectance) from the EVI dataset, resulting in the smooth temporal profiles of EVI (Jonsson and Eklundh 2002, Chen et al., 2004, Wei et al., 2012, Ali et al., 2013a, Ali et al., 2013b, Ali et al., 2014), as shown in Figure 2.4.

The time-series EVI dataset (2000-2014) was classified using an Iterative SelfOrganizing DATA (ISODATA) unsupervised classification technique (maximum iteration of 50; convergence of 0.99; diagonal axis means) with ERDAS Imagine 2013 (Pan et al., 2003, Khan et al., 2010, Singh et al., 2011a, Bie et al., 2012). The unsupervised classification method was selected because of an incomplete knowledge of the distribution of land uses in the study area. The use of the clustering method is also justified by the nature of the growing seasons in the research area. The cropping schedules are partly influenced by the cropping calendar and farmers' decisions. The latter is also related to the efforts of farmers to perform a synchronized planting to spread the risk of crop damages from rice pest and disease outbreaks (e.g., rat attacks). The ISODATA uses the minimum distance rule to calculate the class means and iteratively reclassifies pixels to new means until the threshold parameters or the maximum iteration numbers are satisfied (Tao and Gonzalez 1974, Nguyen et al. 2011). A batch of unsupervised classifications was conducted from 10100 clusters, and the divergence statistics was used to select the optimal number of classes (Swain 1973). The number of clusters is selected based on separability scores, a measure of the difference between cluster centers. The average separability score maximizes the global value of separations between clusters (Chuvieco and Huete 2009). However, the average may still include clusters that are very close together and inseparable. Therefore, the minimum separability has to be regarded as well. In practice, the optimal number of clusters occurs when the average and minimum separability scores coincide. 
In the study area, this condition happens at the number of 88 clusters, as shown in Figure 2.5. Thus, the eighty-eight cluster was selected to represent the land uses (e.g., settlements, rice fields, water bodies) (Swain 1973, Khan et al. 2010, Nguyen et al. 2011). The selection of 88 clusters is also preferable to avoid the loss of essential information because of the under-estimation of the number of classes while maintaining the relatively low number of clusters (under 100) (Nguyen et al. 2011, Bie et al. 2012).

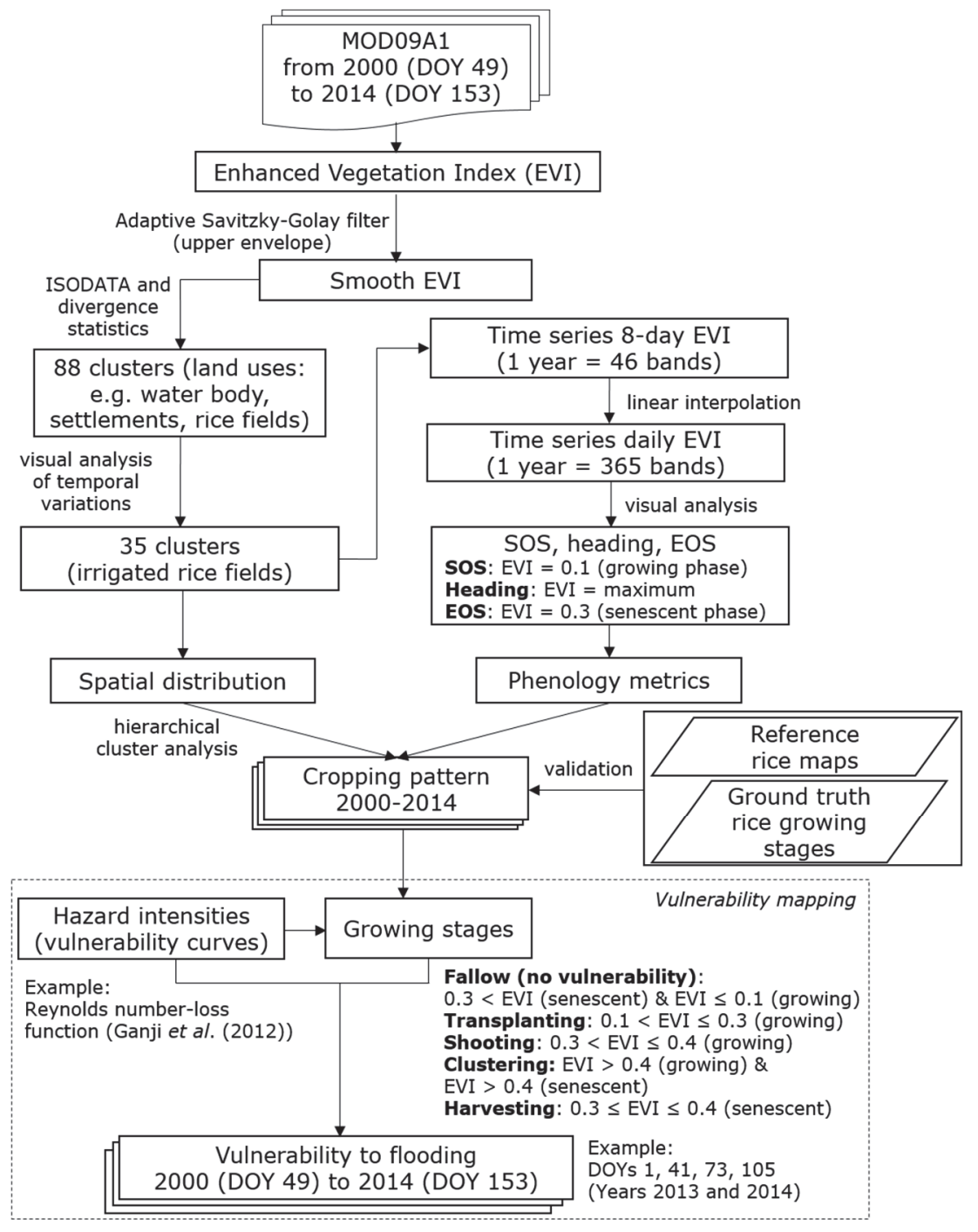

Figure 2.3. Flowchart for determining the vulnerability to flooding from time-series 8day 500-m spatial resolution MODIS (MOD09A1) imageries. Cropping pattern is one of the inputs for mapping the vulnerability to flooding in irrigated rice fields. 


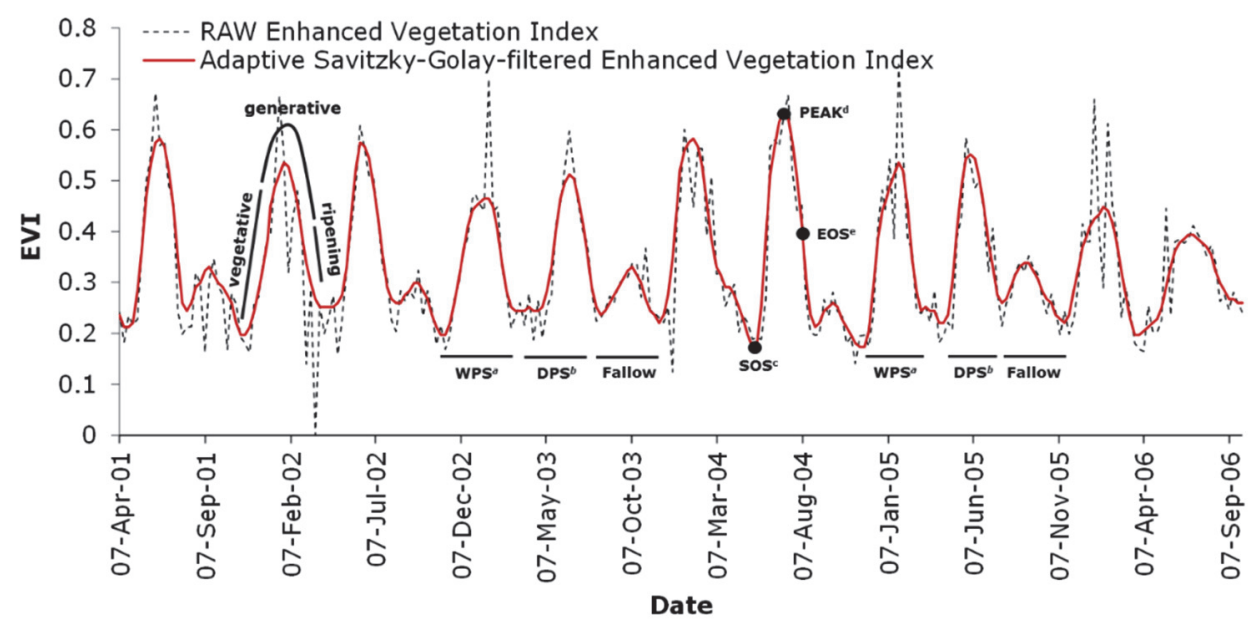

${ }^{a}$ WPS $=$ Wet Planting Season; ${ }^{b}$ DPS = Dry Planting Season; ${ }^{c}$ SOS = Start of Season; ${ }^{d}$ PEAK $=$ Heading stage $;{ }^{e}$ EOS $=$ End of Season

Figure 2.4. Smoothed time-series Enhanced Vegetation Index (EVI) using the Adaptive Savitzky-Golay filter. Illustration of rice growth phases (e.g., vegetative, generative, ripening), planting seasons (e.g., wet and dry planting seasons), and phenology metrics (e.g., start of season, heading stage, end of season) is provided.

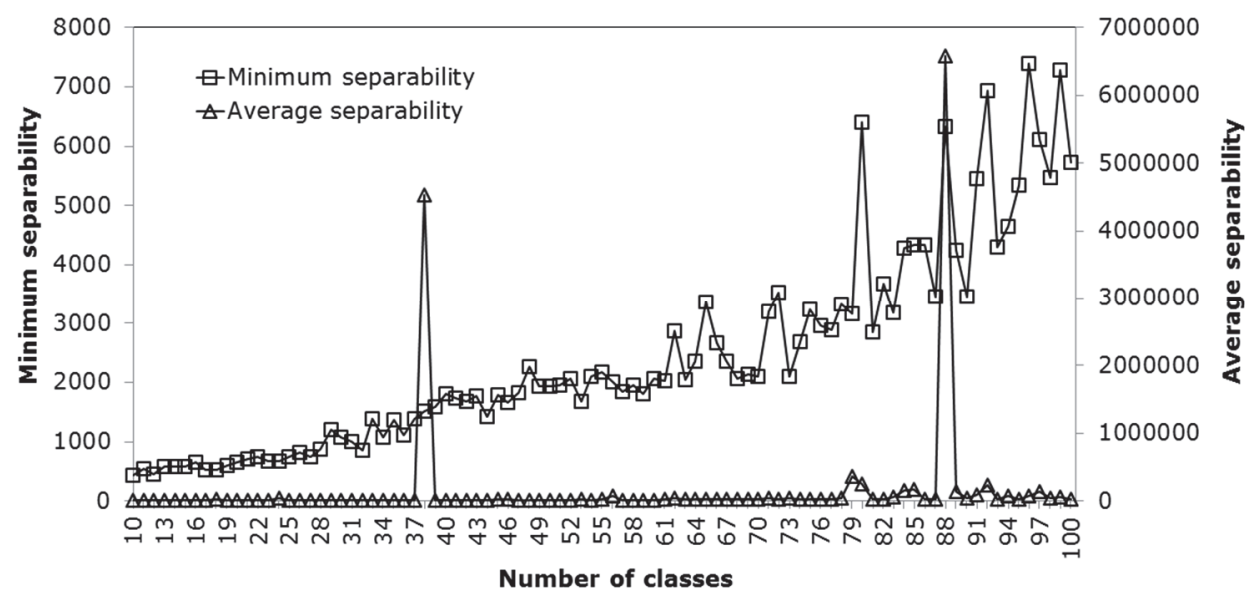

Figure 2.5. Divergence statistics (minimum and average separability scores) generated using an ISODATA unsupervised classification. Eighty-eight clusters were selected as the optimal number of clusters to represent land uses in the northern districts of West Java (Bekasi, Karawang, Subang, and Indramayu).

\subsubsection{Cropping Pattern}

\section{A. Mapping rice field distribution}

Thirty-five out of 88 clusters were manually selected to represent the spatial distribution of irrigated rice fields in the study area. The rice clusters were identified by investigating the EVI profiles that represent the growing phases 
of rice fields. Rice fields have distinctive characteristics of growing rapidly after transplanting (vegetative phase), as shown by the increase of EVI; reaching the heading stage or maturity (generative phase), signified by the peak of EVI; entering the senescence phase, marked by the decrease of EVI; entering the fallow phase; and eventually restarting the whole growing process from the vegetative phase (see Figure 2.4) (Toan et al., 1997, Xiao et al. 2005, Xiao et al. 2006, Zhang et al., 2015b). Furthermore, the small patches of rice clusters that are adjacent to or located in the middle of settlement areas were not included in the further analyses as the EVI profiles are likely to be influenced by the buildings' presence. Next, the thirty-five rice clusters were grouped into eleven general units using a hierarchical cluster analysis method to represent the gradient of cropping schedules. The agglomeration of rice clusters into the smaller groups may add understandings about the interaction among rice clusters. The Ward method and Euclidian distance interval measure were used in the hierarchical cluster analysis (Ward 1963, Gauch and Whittaker 1981, Ali et al. 2013b). The hierarchical cluster analysis was performed using SPSS (Statistical Package for the Social Science).

\section{B. Extracting phenology metrics}

Phenology metrics, including the Start of Season (SOS), heading stage (PEAK), and End of Season (EOS), were extracted from the rice clusters to obtain the time component of rice fields. In practice, the SOS and EOS are the transplanting and the harvesting periods, respectively. The heading stage is the period 55-60 days after transplanting. Firstly, the median values (50 percentile) of the time-series EVI (658 imageries) were derived for each rice cluster ( 35 clusters). Next, the 14-year time-series median values were pooled and averaged per DOYs, resulting in the historical data. The 8-day historical average data (46 imageries, 1 image is an 8-day period) were linearly interpolated to generate a daily time-series EVI (365 imageries). Next, the DOYs for SOS, PEAK, and EOS were manually extracted from the daily timeseries EVI by visually investigating thresholds. The following criteria were used to determine the phenology metrics. The SOS is the DOY when the EVI value is 0.1 . If the EVI profiles do not have values lower than 0.1 throughout a cropping season, the DOY when the EVI is at the minimum value is used as the SOS. The heading stage is the DOY when the EVI is at the maximum value. The growing season is considered a failure if the maximum EVI value during a cropping season is not higher than 0.35 . The EOS is the DOY when the EVI value reaches 0.3 during a senescent phase. The selection of the thresholds was performed using a trial and error approach based on the prior information on the dates of growth phases in the study area, gained after the fieldwork. 


\subsubsection{Mapping vulnerability to flooding}

The vulnerability to flooding in irrigated rice fields is the degree of damage during varying rice growth stages given various flood hazard intensities. The vulnerability assessment thus requires information on the hazard intensity, degree of damage, and rice growth stages. This study uses the results of Ganji et al., (2012) to support the attempt of utilizing rice cropping patterns for mapping the vulnerability to flooding. Ganji et al. (2012) performed laboratory tests on a rectangular flume (length $=10 \mathrm{~m}$; width $=0.3 \mathrm{~m}$; height $=0.45 \mathrm{~m}$ ) to investigate several hydraulic parameters for flood loss estimations at various rice growth stages, including the periods of after transplanting, shooting, clustering, and harvesting. They were able to derive vulnerability curves for varying intensities of hydraulic parameters at different growth stages. This study mainly focuses on the Reynolds number because the authors concluded that the Reynolds number, a dimensionless parameter, is the most effective parameter for simulating the flood physical-factor loss function (Figure 2.6). Ganji et al. (2012): "In fluid dynamics, the combination of the effects of inertia force and viscosity is used for the analysis of submerged bodies. [...] the Reynolds number could be considered as the most effective hydraulic parameter for deriving the loss function. In fact, the Reynolds number is a dimensionless form of [height*velocity] in open channels." The higher the Reynolds number, the stronger the force of flooding to damage rice plants. Also, they suggested the use of a logarithmic function to represent the Reynolds number versus loss (Table 2.2).

The rice growth stages and their spatial distribution are generated in the present study. The rice growth stages (fallow-harvesting) are classified into five classes, namely the transplanting, shooting, clustering, harvesting, and fallow. Fallow is the periods after rice harvesting and before rice sowing and transplanting. Farmers do not cultivate rice fields during fallow periods, so there is no elements-at-risk (therefore no vulnerability) in rice fields during this stage. The number of farmers that plant cash crops is often negligible. The 'fallow' class is when $0.3<$ EVI (senescent) and EVI $<0.1$ (growing). The transplanting periods, with $0.1 \leq \mathrm{EVI} \leq 0.3$, belong to the 'transplanting' class. The 'shooting' class is when $0.3<$ EVI $\leq 0.4$. The periods from the stem elongation to milk stages, with the EVI $>0.4$ from the growing to senescent phase, are grouped into the "clustering" class. Finally, the periods when $0.3 \leq$ EVI $\leq 0.4$ during the senescent phase, mostly during the ripening phase, are categorized into the 'harvesting' class. The present study assumes that there is no difference in the rice variety, and the whole study area is exposed similarly to flood hazards.

Figure 2.6 exhibits the vulnerability curves derived from the Reynolds number at the transplanting, shooting, clustering, and harvesting stages. To interpret Figure 6 , one can assume a kinematic viscosity of $10^{-4} \mathrm{~m}^{2 / \mathrm{s}}$, which means that 
the Reynolds number translate into velocity*depth by dividing the $X$-axis value by 10,000 . For instance, for a depth of 1 meter, the transplanted rice crops will suffer damages from the velocity between around $2.4 \mathrm{~m} / \mathrm{s}$ and $4 \mathrm{~m} / \mathrm{s}$. It can be seen that the onset of damages at the shooting and harvesting stages is around the Reynolds number 23,000. The rice fields with transplanting and harvesting stages are completely damaged at the Reynolds numbers around 42,000 and 90,000 , respectively. The clustering stage starts to suffer from damage at the Reynolds number around 57,000, suggesting that the more mature and clustered the rice fields, the lower the vulnerability level. It is plausible since the more mature or the more grouped the rice plants, the stronger the stem of and the more resistance exerted by rice plants against the flood flow. Figure 2.6 also displays that, after being plotted in the relative damage-hazard intensity graph, the transplanting, shooting, harvesting, and clustering stages show very high, high, moderate, and low vulnerability levels, respectively. The growth stages do not have equal growing lengths, suggesting that rice fields experience certain vulnerability levels for different periods of time. As an example, these levels are depicted on the vulnerability maps in the years 2013 and 2014. The spatial distribution and phenology metrics derived from time-series MODIS imageries enable the demonstration of the vulnerability in space and time. For example, rice fields may experience a very high vulnerability level for around 30 days in accordance with the length for growing from the transplanting to shooting stage.

Table 2.2. Equation for Reynolds number $(x)$ - loss $(y)$ function for rice paddies at various growth stages

\begin{tabular}{cc}
\hline Growth stage & Logarithmic function \\
\hline Transplanting & $y=189.4 * \ln (x)-1,915.7$ \\
Shooting & $y=86.83 * \ln (x)-868.2$ \\
Clustering & $y=71.54 * \ln (x)-783.84$ \\
Harvesting & $y=69.76 * \ln (x)-699.25$
\end{tabular}

Source: Ganji et al. (2012) 


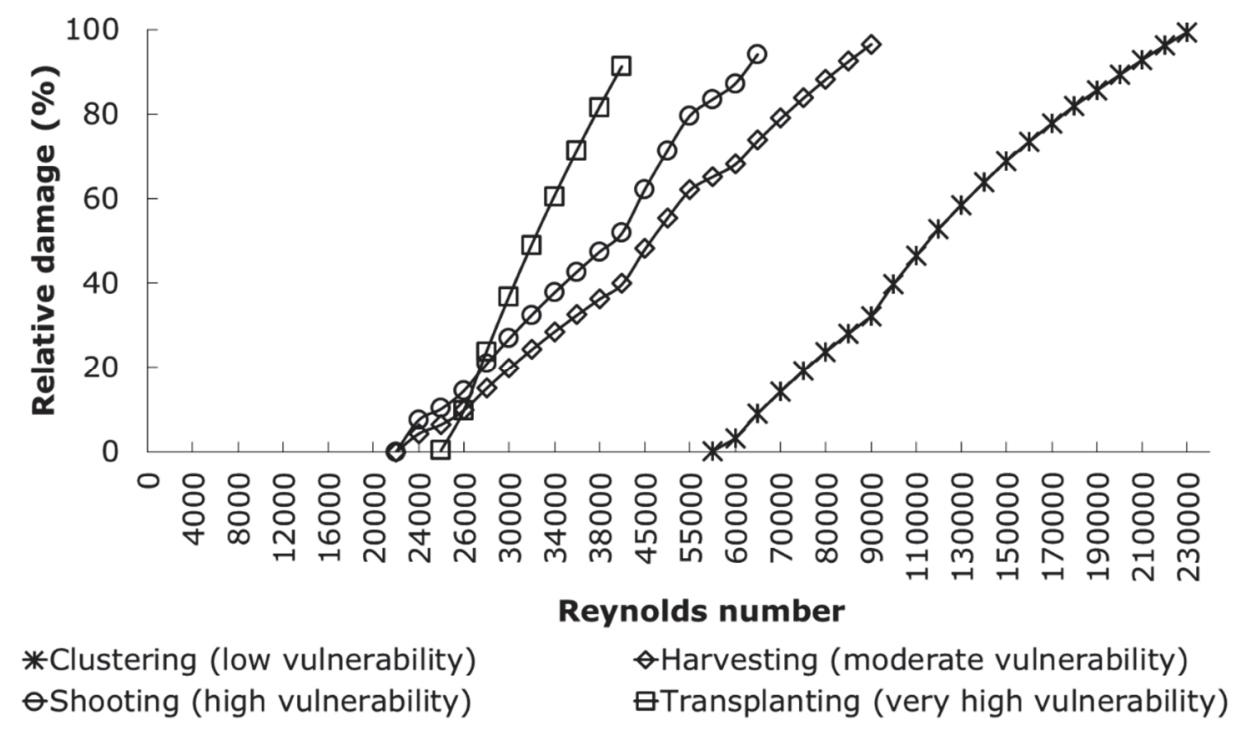

Figure 2.6. Vulnerability curves derived from the Reynolds number. Clustering, harvesting, shooting, and transplanting classes belong to the low, moderate, high, and very high vulnerability levels, respectively. Figure 2.6 corresponds to Figure 9. Source: Ganji et al. (2012)

\subsubsection{Accuracy Assessment}

The accuracy of rice field areas and phenology metrics derived from MODIS imageries was assessed using secondary and primary data, respectively. Fieldworks were conducted from October to November 2014 and from December 2014 to January 2015 to obtain the data. The primary data are the dates of rice growth stages obtained from interviews with farmers. The secondary data, such as the maps of official administrative boundaries, rivers, irrigation channels, roads, and rice fields were collected from local government, agricultural, and irrigation management offices.

The areas of rice fields generated from MOD09A1 were compared with the areas of rice fields derived from the reference maps at the sub-district level. Two reference maps were used (Figure 2.7). One is a rice field map (vector format) obtained from the Ministry of Agriculture of Republic of Indonesia (hereafter referred to as Agricultural Statistics). The other one is a land use map of Java (raster format) derived from ALOS PALSAR in 2010 (hereafter referred to as ALOS PALSAR) obtained from the Ministry of Public Works of Republic of Indonesia. The areas of rice fields were extracted from the ALOS PALSAR. Both reference maps were resampled into a 500-m spatial resolution using the nearest neighborhood operation. All rice field maps are converted into the Geographic projection for the comparison. The accuracy of the rice field distribution was assessed using the coefficient of determination $\left(R^{2}\right)$. 
The observed phenology metrics were assessed using the ground truth data at the pixel level. The locations and dates of rice growth stages, including the transplanting (1-7 days after transplanting, number of rice pixels or $n=61$ ), heading (55-65 days after transplanting, $n=46$ ), and harvesting (85-95 days after transplanting, $n=49$ ), were recorded using a hand-held Global Position System (GPS) and are used as the reference data for the SOS, heading stage (PEAK), and EOS, respectively. The accuracy of the estimated phenology metrics was assessed using the Root Mean Square Error (RMSE). The equation for deriving the RMSE is as follows:

$$
R M S E=\frac{1}{n} \sum_{i=1}^{n}\left(y_{i}-x_{i}\right)^{2}
$$

where $y_{i}$ and $x_{i}$ are the observed and estimated values, respectively.

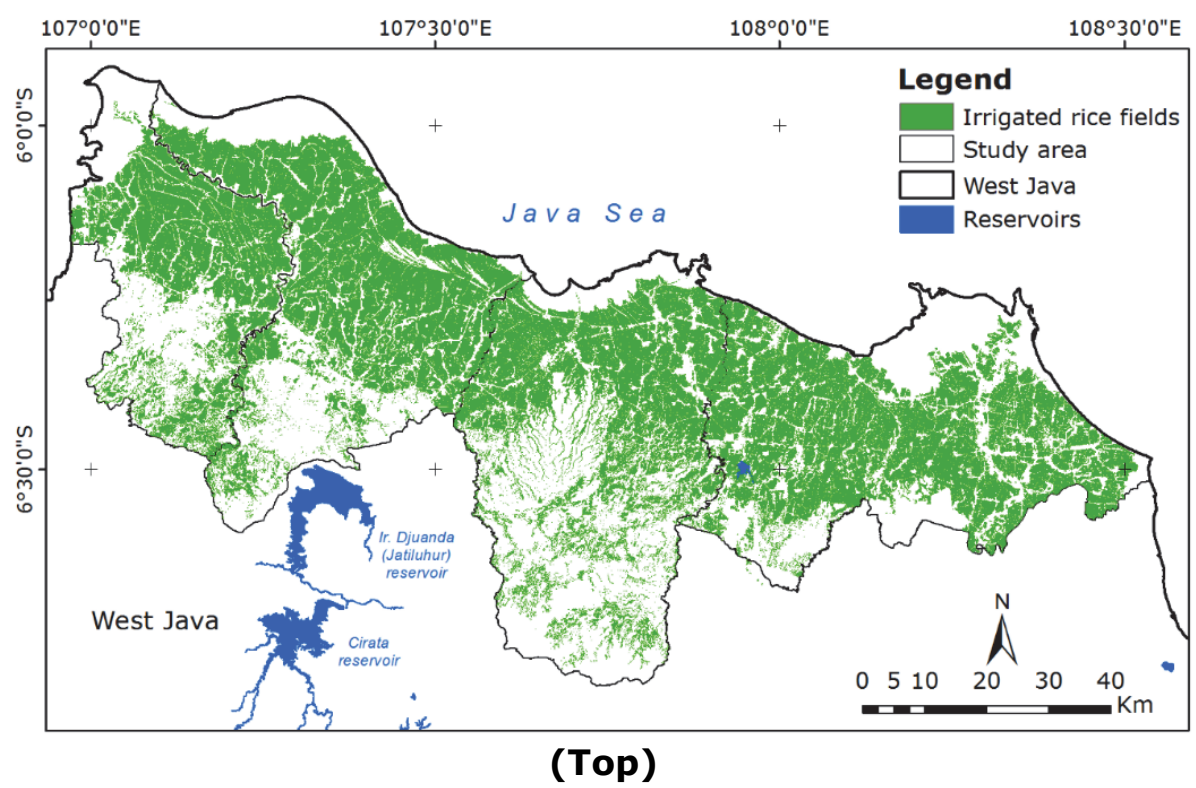




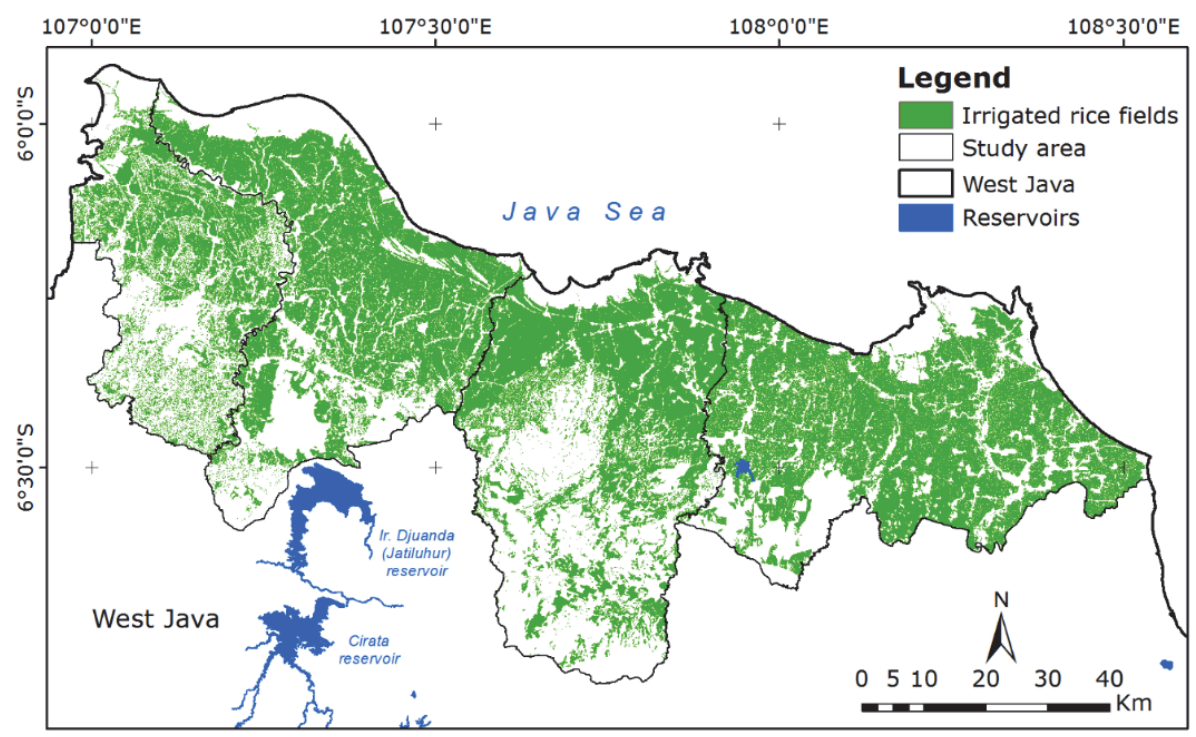

(Bottom)

Figure 2.7. Reference rice field maps. Areas of irrigated rice fields are derived from (Top) Agricultural Statistics and (Bottom) ALOS PALSAR. Source: (Top) Ministry of Agriculture and (Bottom) Ministry of Public Works of Republic of Indonesia.

\subsection{Results and discussion}

\subsubsection{Cropping pattern}

Cropping patterns were generated from the rice spatial distribution and phenology metrics. Figure 2.8 shows the spatial distribution of irrigated rice fields in West Java. The irrigated rice fields are the mosaics of thirty-five rice clusters derived from the time-series EVI collected over 14 years. The high temporal resolution enables the identification of irrigated rice fields despite the moderate 500-m spatial resolution of MODIS imageries. It can be seen that the pattern of rice clusters seems not to follow any particular administrative boundaries. Furthermore, Table 2.3 shows the phenology metrics derived from the time-series EVI from 2000 to 2014. For the past 14 years, the SOS ranges from the first week of November to the third week of March for wet planting seasons and from the end of March to the second week of August for dry planting seasons. The EOS ranges from the first week of March to the second week of June and from the last week of May to the first week of November for wet and dry planting seasons, respectively. The duration of rice growth during dry planting seasons is approximately $97 \pm 8$ days (after transplanting), fewer days shorter than that of wet planting seasons ( $110 \pm 16$ days after transplanting). This condition is associated with the variations in the solar radiation and temperature between dry and wet seasons (Grisp 2013, Deng et al. 2015, Huang et al., 2016, Wang et al., 2016). The fallow durations from 
the end of dry planting seasons (EOS $\mathrm{dry}$ ) to the start of wet planting seasons (SOS wet $_{\text {) }}$ and from the end of wet planting seasons (EOS wet) to start of dry planting season (SOS dry) are $116 \pm 25$ and $42 \pm 19$ days, respectively (Table 2.4). Grouped using the Hierarchical Cluster Analysis, the rice clusters depict elongated horizontal shapes that show the gradient of wet season planting dates. The planting dates increase from south to north and from west to east as rice fields located farther from the Ir. Djuanda reservoir. The closer the rice clusters to the coastal areas, the later the planting dates, partly reflecting the influence of irrigation schedules on cropping patterns. However, the patterns of wet season planting dates may not be similar with those of dry planting seasons, perhaps because of the irregularities in the implementation of cropping calendars.

The cropping patterns generated in this study offer more detail information on rice planting schedules compared to those of official cropping calendars (see Table 2.4). These cropping patterns can be served as a baseline to monitor variations in cropping schedules. The comparison between the cropping patterns and official irrigation schedules for rice fields served by Ir. Djuanda (Jatiluhur) reservoir revealed that the ongoing cropping schedules performed by most farmers deviate from the official cropping calendar. For example, the official cropping calendar suggests that two cropping seasons should be completed by the end of September. In practice, farmers whose rice fields served by the PJT II start dry planting seasons later than the stipulated cropping calendar. Another example can be observed from the duration of fallow. Farmers performed longer fallow periods during both wet and dry planting seasons compared to those of the official cropping calendar (see Table 2.4). The differences between the actual and official planting dates are greater as rice clusters located closer to coastal areas. It is likely that the discrepancies are partly associated with flooding events and coping strategies to flood hazards. 


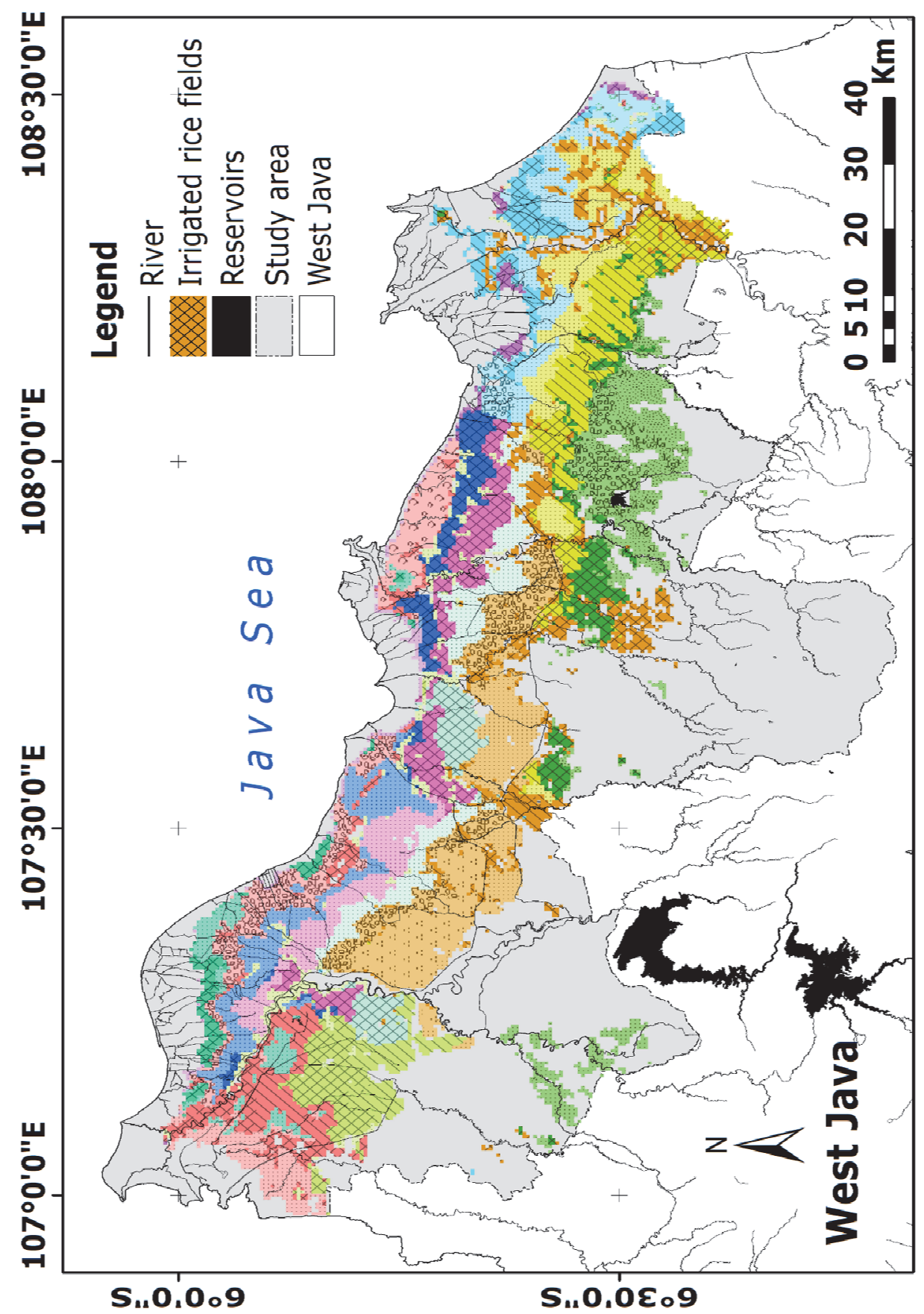

Figure 2.8. Spatial distribution of irrigated rice fields in the northern districts of West Java, represented by thirty-five rice clusters. Grouped using the hierarchical cluster analysis, rice clusters show elongated shape representing a gradient of wet season planting dates. Figure 2.8 corresponds to Table 2.3 . 
Table 2.3 Generalized phenology metrics (Mean \pm Stdv, in DOY \pm days) for rice clusters in irrigated rice fields in the northern region of West Java. Table 2.3 corresponds to Figure 2.8 .

\begin{tabular}{|c|c|c|c|c|c|c|c|c|}
\hline \multirow{3}{*}{$\begin{array}{l}\text { Map } \\
\text { Unit }\end{array}$} & \multirow{3}{*}{$\begin{array}{c}\text { Rice } \\
\text { Cluster }\end{array}$} & \multirow{3}{*}{$\begin{array}{c}\text { Area } \\
\left(\mathrm{km}^{2}\right)\end{array}$} & \multicolumn{6}{|c|}{ Phenology Metrics (MODIS) } \\
\hline & & & \multicolumn{3}{|c|}{ Wet Planting Season } & \multicolumn{3}{|c|}{ Dry Planting Season } \\
\hline & & & SOS $^{a}$ & PEAK ${ }^{b}$ & EOS $^{c}$ & sos & PEAK & EOS \\
\hline \multirow{4}{*}{$\mathbf{A}$} & & 139.25 & $309 \pm 21$ & $41 \pm 15$ & $89 \pm 16$ & $93 \pm 14$ & $143 \pm 13$ & $194 \pm 19$ \\
\hline & & 119 & $321 \pm 26$ & $25 \pm 18$ & $81 \pm 21$ & $89 \pm 18$ & $145 \pm 14$ & $200 \pm 14$ \\
\hline & & 115.5 & $321 \pm 14$ & $33 \pm 16$ & $72 \pm 18$ & $89 \pm 14$ & $141 \pm 13$ & $181 \pm 13$ \\
\hline & & 143.75 & $328 \pm 13$ & $41 \pm 15$ & $80 \pm 13$ & $105 \pm 12$ & $157 \pm 13$ & $200 \pm 10$ \\
\hline \multirow{5}{*}{ B } & & 179.25 & $313 \pm 10$ & $19 \pm 11$ & $61 \pm 7$ & $105 \pm 11$ & $161 \pm 13$ & $201 \pm 13$ \\
\hline & 36 & 167.75 & $325 \pm 13$ & $29 \pm 10$ & $72 \pm 8$ & $121 \pm 15$ & $185 \pm 13$ & $221 \pm 20$ \\
\hline & & 175 & $329 \pm 9$ & $41 \pm 12$ & $77 \pm 15$ & $129 \pm 13$ & $193 \pm 14$ & $232 \pm 14$ \\
\hline & & 178.5 & $337 \pm 14$ & $41 \pm 11$ & $90 \pm 8$ & $113 \pm 9$ & $173 \pm 10$ & $220 \pm 8$ \\
\hline & & 145.5 & $349 \pm 11$ & $53 \pm 10$ & $97 \pm 11$ & $121 \pm 12$ & $189 \pm 13$ & $228 \pm 8$ \\
\hline \multirow{3}{*}{ C } & & 112.25 & $315 \pm 31$ & $65 \pm 30$ & $101 \pm 35$ & $165 \pm 38$ & $233 \pm 36$ & $261 \pm 36$ \\
\hline & & 82 & $333 \pm 32$ & $57 \pm 23$ & $87 \pm 32$ & $141 \pm 30$ & $209 \pm 28$ & $244 \pm 28$ \\
\hline & 39 & 105.75 & $349 \pm 16$ & $69 \pm 13$ & $115 \pm 15$ & $161 \pm 16$ & $229 \pm 17$ & $270 \pm 17$ \\
\hline \multirow{2}{*}{ D } & & 105.75 & $333 \pm 16$ & $45 \pm 12$ & $89 \pm 12$ & $153 \pm 18$ & $217 \pm 20$ & $251 \pm 15$ \\
\hline & 2 & 176 & $353 \pm 14$ & $53 \pm 13$ & $96 \pm 13$ & $149 \pm 14$ & $213 \pm 14$ & $251 \pm 15$ \\
\hline \multirow{3}{*}{ E } & & 118.25 & $337 \pm 11$ & $41 \pm 13$ & $83 \pm 11$ & $117 \pm 13$ & $173 \pm 13$ & $214 \pm 12$ \\
\hline & & 150.5 & $341 \pm 14$ & $41 \pm 14$ & $78 \pm 12$ & $105 \pm 9$ & $161 \pm 12$ & $199 \pm 10$ \\
\hline & & 192.25 & $343 \pm 16$ & $53 \pm 12$ & $90 \pm 25$ & $121 \pm 11$ & $177 \pm 12$ & $214 \pm 9$ \\
\hline \multirow{5}{*}{$\mathbf{F}$} & & 58.25 & $345 \pm 15$ & $65 \pm 18$ & $92 \pm 20$ & $125 \pm 5$ & $185 \pm 4$ & $211 \pm 8$ \\
\hline & & 30 & $29 \pm 21$ & $77 \pm 19$ & $110 \pm 22$ & $142 \pm 14$ & $205 \pm 9$ & $228 \pm 10$ \\
\hline & & 73.75 & $15 \pm 15$ & $77 \pm 14$ & $110 \pm 15$ & $145 \pm 13$ & $201 \pm 13$ & $234 \pm 14$ \\
\hline & & 129.25 & $26 \pm 13$ & $61 \pm 12$ & $100 \pm 15$ & $129 \pm 12$ & $187 \pm 12$ & $220 \pm 10$ \\
\hline & & 39.5 & $34 \pm 23$ & $93 \pm 18$ & $132 \pm 15$ & $153 \pm 19$ & $209 \pm 20$ & $236 \pm 18$ \\
\hline \multirow[t]{2}{*}{ G } & & 183 & $345 \pm 13$ & $65 \pm 13$ & $105 \pm 14$ & $161 \pm 12$ & $225 \pm 13$ & $261 \pm 14$ \\
\hline & & 140.25 & $28 \pm 14$ & $69 \pm 15$ & $108 \pm 15$ & $180 \pm 19$ & $233 \pm 17$ & $270 \pm 18$ \\
\hline \multirow[b]{2}{*}{ H } & & 172 & $24 \pm 13$ & $85 \pm 16$ & $126 \pm 16$ & $200 \pm 19$ & $253 \pm 15$ & $293 \pm 16$ \\
\hline & & 113 & $27 \pm 16$ & $73 \pm 19$ & $117 \pm 17$ & $179 \pm 18$ & $233 \pm 17$ & $275 \pm 19$ \\
\hline \multirow{5}{*}{ I } & & 79.5 & $35 \pm 41$ & $97 \pm 39$ & $134 \pm 44$ & $188 \pm 29$ & $257 \pm 35$ & $298 \pm 33$ \\
\hline & & 134 & $47 \pm 17$ & $105 \pm 21$ & $144 \pm 17$ & $209 \pm 17$ & $265 \pm 17$ & $296 \pm 18$ \\
\hline & & 125.5 & $25 \pm 13$ & $107 \pm 11$ & $150 \pm 11$ & $189 \pm 11$ & $249 \pm 16$ & $294 \pm 18$ \\
\hline & & 88.25 & $32 \pm 17$ & $113 \pm 19$ & $144 \pm 14$ & $193 \pm 15$ & $257 \pm 16$ & $288 \pm 16$ \\
\hline & 37 & 98.75 & $47 \pm 12$ & $127 \pm 9$ & $165 \pm 11$ & $X^{d}$ & $x$ & $x$ \\
\hline \multirow[b]{2}{*}{ J } & & 30.25 & $28 \pm 21$ & $105 \pm 20$ & $126 \pm 18$ & $X$ & $x$ & $x$ \\
\hline & 31 & 32.5 & $46 \pm 20$ & $113 \pm 22$ & $132 \pm 21$ & $x$ & $x$ & $x$ \\
\hline \multirow{2}{*}{ V } & 43 & 76.75 & $52 \pm 17$ & $123 \pm 11$ & $159 \pm 11$ & $209 \pm 14$ & $269 \pm 14$ & $307 \pm 15$ \\
\hline & & 48.5 & $77 \pm 17$ & $129 \pm 16$ & $160 \pm 14$ & $225 \pm 16$ & $273 \pm 16$ & $302 \pm 16$ \\
\hline
\end{tabular}

aSOS = Start of Season; ${ }^{\mathrm{b} P E A K}=$ heading stage; ${ }^{\mathrm{a}} \mathrm{EOS}=\mathrm{End}$ of Season; ${ }^{\mathrm{d} X} \mathrm{X}=$ no planting, planting or harvest failure. Periods from EOS to SOS in wet and dry planting seasons are fallow. The style of Table 2.3 was adopted from Nguyen et al. (2011). 
Table 2.4 Duration (Mean \pm Stdv, in days) between phenology metrics. Variation is the average of all clusters (rounded).

\begin{tabular}{c|c|c|c|c|c|c|c}
\hline \multicolumn{2}{l}{ Wet planting season (WPS) } & \multicolumn{2}{|c|}{ Dry planting season (DPS) } & \multicolumn{2}{|c}{ Fallow } \\
\cline { 5 - 7 } SOS $^{a}-$ & SOS- & PEAK - & SOS- & SOS- & PEAK- & EOS-SOS & EOS-SOS \\
EOS $^{c}$ & PEAK $^{b}$ & EOS & EOS & PEAK & EOS & EOS-DPS & EOS \\
\hline $110 \pm 16$ & $71 \pm 15$ & $38 \pm 7$ & $97 \pm 8$ & $59 \pm 6$ & $37 \pm 7$ & $116 \pm 25$ & $42 \pm 19$ \\
\hline
\end{tabular}

${ }^{\mathrm{a} S O S}=$ Start of Season; ${ }^{\text {bPEAK }}=$ heading stage $;{ }^{\mathrm{c}} \mathrm{EOS}=$ End of Season

Cropping patterns capture the variations in the duration of cropping seasons, calculated from the start of wet planting season to the end of dry planting season (see Figure 2.9.A-I). For example, the duration of two cropping seasons in cluster 21 is at least 50 days longer than that of clusters 17 and 25 in $2002 / 2003$ because farmers in class 21 exercise a longer fallow period after wet planting seasons. Variations in the duration of cropping seasons result from the difference in farming decisions (e.g., rice variety, fallow period), which are likely to result in complex irrigation water management.

Cropping patterns show variabilities of cropping performance in space and time. Rice fields with lower access to irrigation water show a more irregular cropping pattern than that of rice fields with good access to irrigation water (compare Figure $2.9 \mathrm{H}$ and $\mathrm{J}$ ). Another example is that rice fields in cluster 21 display decreasing performances for at least eight consecutive cropping seasons from 2007 to 2010 (see Figure 2.9C). The performance of rice fields is likely related to the combination of environmental and human factors (Stuart et al., 2016, Guilpart et al., 2017, Silva et al., 2017).

Cropping patterns can capture the disruption in planting dates. Rice fields, such as those in clusters 37,41 , and 31 , often cannot pursue dry planting seasons, and frequently can only practice a single-cropping pattern in the last 15 years (see Table 2.3). These rice clusters are swampland rice fields, located near coastal areas (see Figure 2.8), far from the primary irrigation canals, and consequently, have less access to irrigation water. These rice fields also often suffer from flood events due to the accumulation of surface runoff from the upper regions during rainy seasons (see Chapter 3 ). The impacts of flood events are greater during La-Niña year (Naylor et al. 2001). Recently, a flood event in January 2014 caused a severe delay in wet season planting dates, such as those in clusters 41 and 26 (see Figure 2.9J-K). Farmers in cluster 26 resort to delaying planting dates until the end of February, waiting for flooding to subside before attempting wet planting seasons; however, the same length of delay in wet season planting dates are not experienced by farmers in cluster 41 (see Table 2.3). Delays in wet season planting dates consequently force farmers in cluster 26 to accept delays in dry season planting dates and face a higher risk of planting or harvest failure due to lack of access to irrigation water (see Table 2.3). At the same time, there are rice fields located close to coastal 
areas that are frequently affected by flood events but do not suffer from waterdeficit events during dry planting season (see Table 2.3) because of good access to irrigation water, such as those in cluster 43.

Several findings can be extracted from the disruption in cropping patterns. Firstly, different vulnerability to natural hazards exists among rice fields in the study area. Rice fields may be vulnerable to flood events; however, the same rice fields may not have the same vulnerability level to water-deficit events and vice versa. For example, rice fields in cluster 17 are not prone to flood and water-deficit events. On the contrary, at the same time, rice fields in cluster 41 are prone to both flood and water-deficit events during rainy and dry planting seasons, respectively. Secondly, it seems that the management of rice fields and natural hazards determines the variation in vulnerability. The disruption in cropping patterns in rice fields in upper regions have a 'domino effect' to rice fields in lower regions, especially those located in the same irrigation channels. Furthermore, natural hazards may modify the vulnerability to future disaster events. Flood events in wet planting seasons may have an influence on access to irrigation water in dry planting seasons. The finding also implies the importance of the temporal window of analysis in disaster risk analysis. For example, further analysis of vulnerability to natural hazards in irrigated rice fields may require at least two cropping seasons to obtain full perspectives about the dynamics in irrigated rice fields.

\subsubsection{Vulnerability to flooding}

Figure 2.10 shows the maps of vulnerability to flooding in irrigated rice fields in West Java derived from the cropping patterns and vulnerability curves. The transplanting, shooting, harvesting, and clustering stages are classified into very high, high, moderate, and low vulnerability classes, respectively (see Figure 2.6). As an example, the maps are generated for different DOYs in the years 2013 and 2014 to illustrate the influence of irrigation schedules on the vulnerability. The maps show that rice fields were mostly in the transplanting and fallow periods at the beginning of January (DOY 1) in 2013 and 2014, having very high and no vulnerability levels, respectively (Figure 2.10A-B). Most rice fields located in the southern and middle parts of the study area were at the clustering and transplanting classes, with the low and very high vulnerability levels, respectively during the DOY 41 in 2013 and 2014 (Figure 2.10C-D). During the DOY 73, rice fields situated in the southern part grew from the clustering class to the harvesting and fallow classes, changing the vulnerability level from low to moderate and no vulnerability levels (Figure 2.10E-F). Later, rice fields in the southern region were in the fallow period during the DOY 105 in 2013 and 2014, consequently having no vulnerability. It is worth repeating that the present study used the Reynolds number as the hazard intensity parameter to exemplify the vulnerability levels. The degree of damage at different growth stages results from the resistance of rice plants to 
the flow of flood water. The uses of other flood parameters, such as the depth, duration, velocity, may generate different vulnerability maps since each hydraulic parameter affects rice plants in various ways.

Figure 2.10 reveals that cropping patterns are also able to provide information on the shift in the vulnerability to flooding. Rice fields, especially those located near coastal areas often suffer from recurrent flood events due to the accumulation of surface runoff from the upper regions during wet seasons. The extent of flood impacts is greater during strong La-Niña years (Naylor et al. 2001). Farmers who own rice fields in these flood-prone areas frequently resort to delaying planting dates until the end of February, waiting for rainfall intensity to weaken or flooding to subside before attempting wet planting seasons. Recently, these rice fields suffered from an extreme flooding event in the January 2014, causing delays in the wet season planting date. Farmers were not able to perform rice sowing or transplanting activities due to prolonged flood events. The events cause a shift in planting dates in the affected rice fields during the wet planting season 2013/2014. The shift changed the 'normal' vulnerability level, leading to either an increase or decrease in the vulnerability to flooding in the areas of origin and other rice fields. It can be seen that the vulnerability in rice fields located in the northern part of the study area differs between the year 2013 and 2014. Since farmers delay the wet season planting dates, the areas of rice fields with no vulnerability were higher during DOY 41 in 2014 compared to that in 2013. Consequently, the areas of rice fields with high-very high and moderate vulnerability classes were higher during the DOYs 73 and 105 in 2014 compared to those in 2013, respectively (Figure 2.10E-H). This illustration suggests the importance of spatial and temporal perspectives to understand the vulnerability to flooding in irrigated rice fields. 


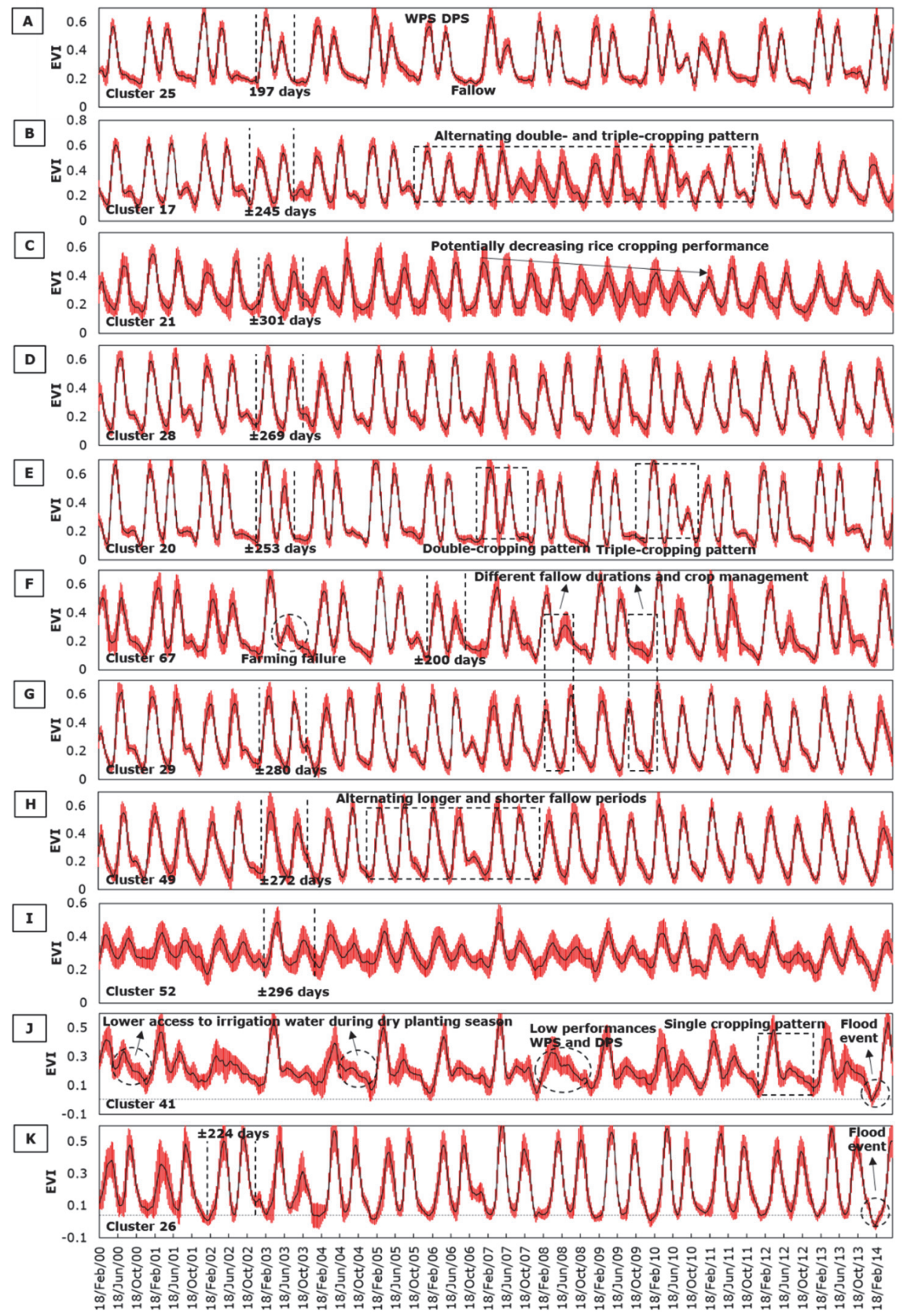

Figure 2.9 Cropping patterns in irrigated rice fields in West Java. A rice cluster is used to represent the rice cluster groups (Letter A-K) generated from the hierarchical cluster analysis. Figure 2.9 corresponds to Figure 2.3. 

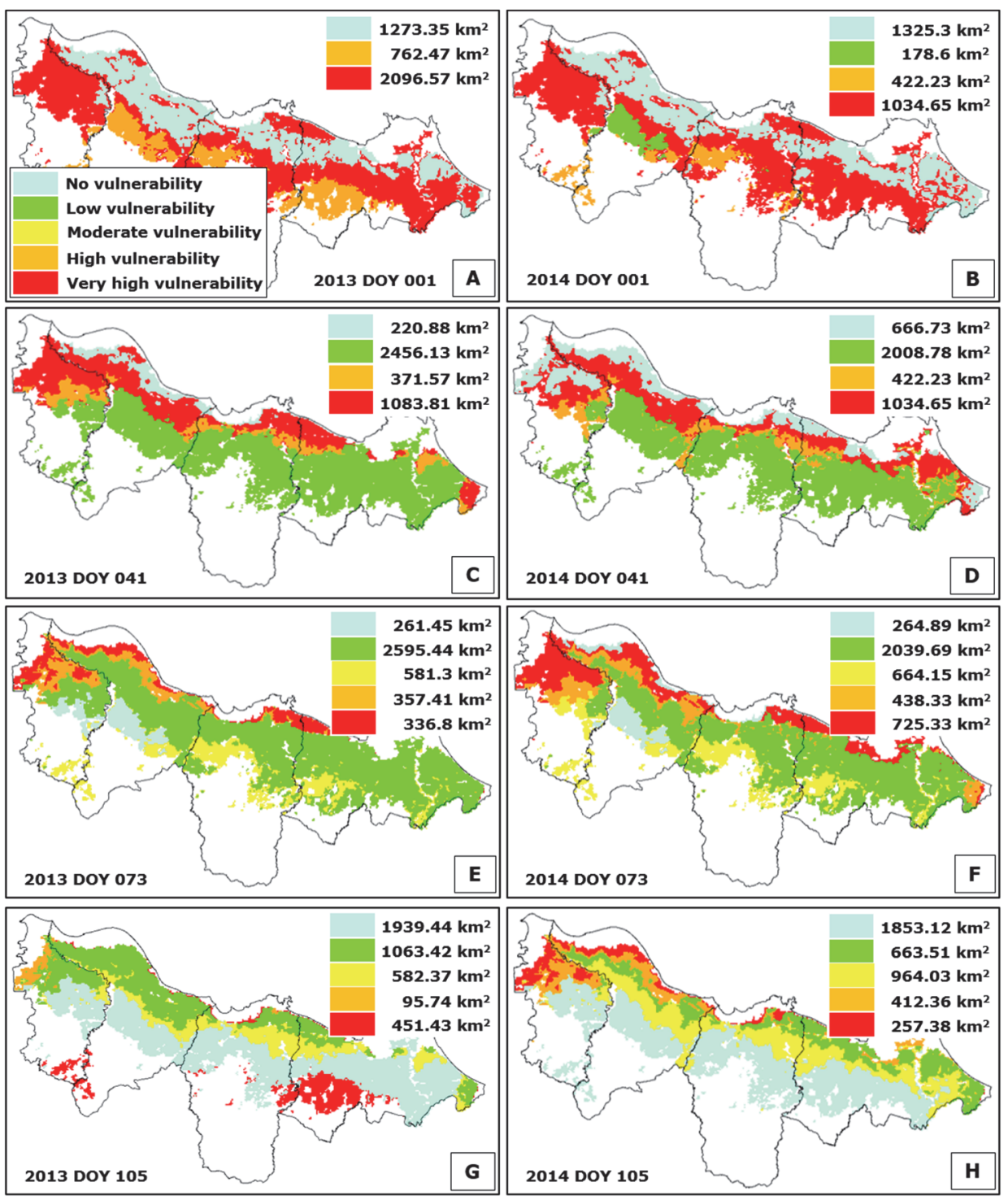

Figure 2.10. Vulnerability to flooding in irrigated rice fields varies in space and time. Fallow, clustering, harvesting, shooting, and transplanting stages belong to the no, low, moderate, high, and very high vulnerability levels. Figure 2.10 corresponds to Figure 2.6 .

\subsubsection{Accuracy Assessment}

The areas of irrigated rice fields between MOD09A1 and ALOS PALSAR and MOD09A1 and Agricultural Statistics were compared to validate the spatial distribution of rice fields. The comparisons showed consistent results with $R^{2}$ $=0.81$ and 0.93 for MOD09A1 and ALOS PALSAR and MOD09A1 and 
Agricultural Statistics, respectively, as demonstrated in Figure 2.11. Furthermore, Figure 2.12 shows a one-to-one comparison between the estimated and observed DOYs of phenology metrics. The estimated RMSEs for SOS $(n=61)$, PEAK $(n=46)$, and EOS $(n=49)$ are 9.21, 9.29, and 9.69 days, respectively. Since the RMSE values are almost similar to the MODIS data source (8-day interval), it can be concluded that the estimated phenology metrics were sufficient to represent rice growth stages in irrigated rice fields in the study area.

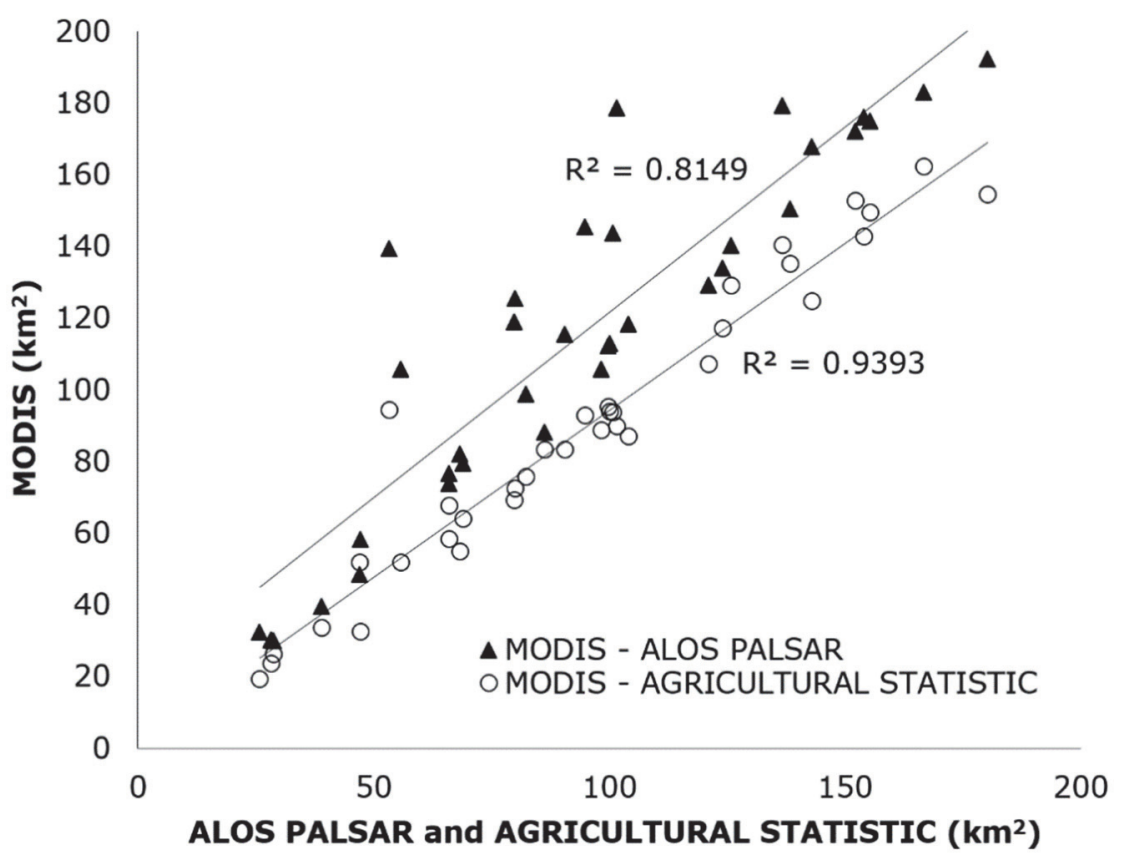

Figure 2.11. Comparison between the estimated and observed areas of irrigated rice fields derived from MOD09A1 and ALOS PALSAR and MOD09A1 and Agricultural Statistics. 


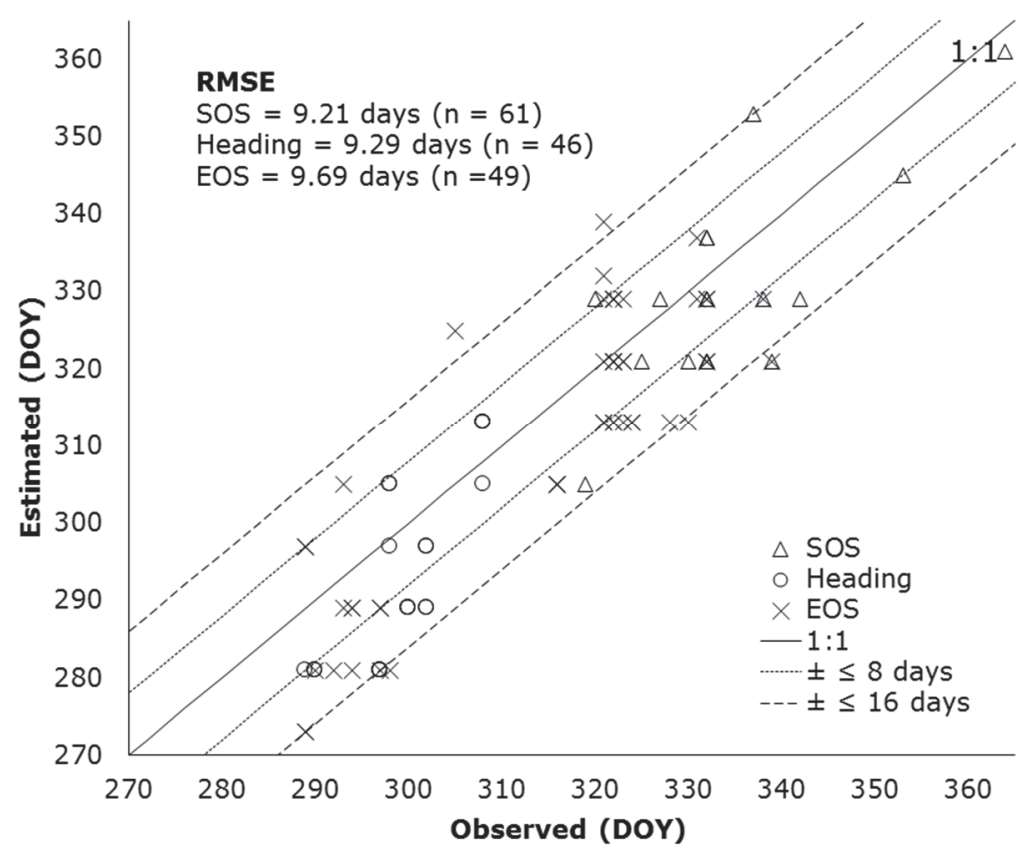

Figure 2.12 One-to-one comparison between estimated and observed DOYs of phenology metrics.

\subsection{Conclusion}

This study has successfully generated a method to determine the vulnerability to flooding in irrigated rice fields using the Enhanced Vegetation Index (EVI) derived from time-series 8-day 500-m spatial resolution MODIS imageries (MOD09A1) in irrigated rice fields in West Java. Coupling the vulnerability curves and cropping patterns, this paper has demonstrated that the vulnerability varies in space and time. Cropping patterns were generated by combining the spatial distribution and the phenology metrics, where the former and the latter provide spatial and temporal information, respectively. Cropping patterns can also capture the shift in the vulnerability that may lead to either an increase or decrease in the degree of damage in the rice fields of origin and other rice fields. Furthermore, the comparisons of rice field areas between MOD09A1 and ALOS PALSAR and MOD09A1 and Agricultural Statistics showed consistent results with $R^{2}=0.81$ and $R^{2}=0.93$, respectively. The estimated and observed DOYs of phenology metrics produced sufficient results, with RMSES $=9.21,9.29$, and 9.69 days, for SOS, heading stage, and EOS, respectively. Using the method presented in this study, one can estimate relative damages provided available information on flood depth and velocity, for instance from a flood model. Water managers and extension and disaster risk officers can use the cropping patterns and vulnerability maps for in-depth 
discussions of designing effective planting dates, irrigation water management, flood risk reduction strategies.

Some further studies are proposed. This study used moderate $500-\mathrm{m}$ spatial resolution MODIS imageries to determine the vulnerability to flooding in irrigated rice fields. The use of time-series remote sensing datasets with a higher spatial resolution (e.g., Proba-V or combinations of Sentinel-2 and Landsat series) may improve the results of the study. Furthermore, some reasons for variations in cropping patterns, such as the irrigation management and flooding events, have partly been identified; however, other socioeconomic and environmental factors that influence cropping schedules and potentially disrupt the continuation of farming practices remain to be explored. 


\section{Chapter 3 Distinguishing between Flooding and Agronomic Inundation in Irrigated Rice Fields: A case study from West Java}

\subsection{Introduction}

\subsubsection{Background}

A robust flood detection method is crucial for deriving accurate information about flood hazards and designing effective strategies to reduce potential damages of flood disasters (Smith 1997, Plate 2002, Klijn et al., 2015). Several studies have documented applications of spectral indices for detecting surface water in rice fields using remote sensing imageries. Spectral indices are a single band or combination of bands that is able to distinguish target objects as a consequence of specific physical differences captured in spectral behavior. Water indices, such as NDWI (Normalized Difference Water Index) (Gao 1996, Mcfeeters 1996) or MLSWI (Modified Land Surface Water Index) (Kwak et al., 2014), are commonly used as tools to detect water bodies on the earth's surface. Moreover, vegetation indices, such as the Normalized Difference Vegetation Index (NDVI) and Enhanced Vegetation Index (EVI), are frequently used to detect surface water in rice fields (Xiao et al. 2006, Nguyen et al. 2011). Similar to NDVI, EVI is highly correlated with variations in the canopy background (Rouse et al., 1974, Gao et al. 2000). EVI minimize the saturation and soil noise problems of NDVI by incorporating the blue spectral band for adjusting atmospheric noise and is thus more sensitive to high biomass and differences in the canopy than NDVI (Huete et al. 1997, Miura et al., 2001, Huete et al. 2002). However, the requirement of the blue band seems to limit the range of sensors that can be used for generating EVI. Studies have been conducted on constructing EVI with two bands, using only red and nearinfrared wavelengths, to respond to this limitation (Jiang et al., 2008).

Recently, researchers have been increasingly using the NDVI or EVI as a tool for detecting spatiotemporal flooding on the earth's surface, including in rice fields (Sakamoto et al. 2007, Islam et al., 2010, Nguyen et al. 2011, Martinis et al., 2013, Son et al., 2013). Sakamoto et al. (2007) detected flooding with time-series 8-day 500-m spatial resolution MODerate resolution Imaging Spectroradiometer (MODIS) imageries (MOD09A1) within the Cambodia and Vietnamese Mekong Delta. They suggested using EVI $\leq 0.1$ ( $\left.R^{2}: 0.77-0.97\right)$. Next, investigating flood-affected rice fields in Chao Phraya River delta in Thailand using MOD09A1, Son et al. (2013) also suggested that flooded areas can be detected with EVI < 0.1 (Overall Accuracy: 84.1\%-97.9\%; Kappa coefficient: 0.62-0.82). Following Sakamoto et al. (2007), Islam et al. (2010) applied EVI $\leq 0.1$ derived from MOD09A1 imageries for mapping flood events in Bangladesh ( $\left.R^{2}: 0.96\right)$. Martinis et al. (2013) who designed a fully automatic 
multi-scale flood monitoring system also used MODIS-derived EVI $\leq 0.1$ for delineating flooded areas $\left(R^{2}: 0.56-0.91\right)$. The thresholds designated were derived from the observation of temporal profiles of 'pure' pixels from different land uses or specific objects of interest. The use of EVI $\leq 0.1$ (or other values) for identifying flooding in rice fields is thus based on the assumption that the critical value of 0.1 is the condition where hazardous surface water (e.g., flooding) is detected by remote sensors (Ji et al., 2009). It is worth noticing that the use of a fixed threshold may lead to an over-estimation or underestimation of flood-affected areas because the coarse resolution satellite imageries are influenced by mixed pixels (Ji et al. 2009). Sanyal and Lu (2004) mentioned that the dynamics in the albedo of water bodies and bare soil are determined by the concentration of sediment in flooding and high soil moisture content. Thus, threshold values used for delineating between land and surface water might differ during monsoon seasons from dry season values. Several approaches have been proposed to overcome the issue, such as selecting locally-adapted thresholds (Xiao et al. 2005, Ji et al. 2009, Peng et al. 2011, Powell et al., 2014), calibrating a general threshold for different locations (Boschetti et al., 2014), or implementing iterative and adaptive water extraction mechanisms for obtaining surface water areas (Qiao et al., 2012).

Two types of surface water can be identified in irrigated rice fields. On the one side, surface water refers to deliberate inundation or non-hazardous surface water, which is part of cropping practices (Xiao et al., 2002, Massey et al., 2014, Qin et al., 2015, Dong et al., 2016). On the other side, surface water refers to physical events or hazardous surface water that is likely to cause crop damages, harvest failures, or disruptions in farming practices (Chau et al. 2013, Mandal 2014, Coomes et al., 2016). A clear distinction between surface water due to farming practices and a natural hazard is needed to limit the detection of 'false positives.' In this study, any deliberate inundation or nonhazardous surface water to support farming activities (e.g., tillage, rice transplanting) is referred to as agronomic inundation, while any non-deliberate inundation or hazardous surface water in rice fields that potentially disrupts agricultural practices and causes crop damages is called flooding. The present study argues that an overestimation and misinterpretation may arise if spectral indices (EVI or other indices) with a hard threshold ( 0.1 or other values) without additional local farming information is directly used to detect floodaffected rice fields. An attempt to distinguish between flooding and agronomic inundation using time-series of remote sensing imageries is needed to detect spatiotemporal flooding in irrigated rice fields.

The objective of this study is to develop a method to distinguish between Rice fields with hazardous Flooding and rice fields with Agronomic Inundation (hereafter referred to as RFAI) using time-series remote sensing imageries and additional ground information. By doing so, the method can detect hazardous 
flooding in irrigated rice fields. The study area is irrigated rice fields in West Java, a main rice production area of Indonesia. We use the time-series EVI derived from MOD09A1 for identifying rice field areas and develop the flood detection method. The information on farming practices is obtained through a large number of interviews with farmers, extension officers, and water managers. We analyze EVI profiles in locations with known flooding. We test EVI $\leq 0.1$ and, if possible, give improved criteria for flood detection in irrigated rice fields. In this respect, the duration of land preparation and transplanting activities is used as a parameter to develop the method for detecting flooding. The methods are tested by comparing wet planting seasons 2013/2014 (a year with known flooding) and 2014/2015 (a dry year) in terms of flood extent and temporal evolution. An important assumption is that hazardous flooding is all surface water that is not 'normal' according to common farming practices. We assume that the long-term average of EVI (15 years) represents a normal situation per pixel. An accuracy assessment is performed to evaluate the quality of the derived flood maps.

\subsubsection{Study Area}

The study area is an intensive rice production area in West Java, Indonesia, that depends on irrigation systems (Figure 3.1). West Java has humid tropical climate and experiences two seasons: wet and dry seasons that start from October to March and from April to September, respectively. Farmers mainly adopt a double-cropping pattern (rice-rice-fallow), with the periods of wet and dry planting seasons conform to wet and dry seasons. Although the average annual rainfall reaches up to $2000 \mathrm{~mm}$, the majority of rainfall is distributed mainly in the middle and southern parts of the province from December to March (Qian et al. 2010, Nuryanto et al. 2016).

Irrigation systems are required to help maintain stable rice production throughout the years. The Ir. Djuanda reservoir serves the largest irrigation system (approximately 240,000 ha), managed by a state company Perusahaan Umum Jasa Tirta (PJT) II (http://www.jasatirta2.co.id/). An official cropping calendar is created by the ministry of agriculture to regulate irrigation schedules for rice fields under Ir. Djuanda command area. The implementation of a double-rice cropping cycle and irrigation schedules result in complex cropping patterns, with south-north and west-east gradients of planting dates (Sianturi et al., 2018). However, closely knit farmer communities adjust their schedules based on logic and perceived socioeconomic and environmental factors, resulting in a complex patchwork of rice growth stages. It is possible at any moment of the year to find all growth stages of rice in the area. Furthermore, rice fields that are not under Ir. Djuanda command area use water from local sources to irrigate rice fields (e.g., reservoirs, rivers, wells). Although these rice fields are not entitled to follow any official cropping calendar, the national agricultural office suggests seasonal cropping schedules. 
Recently, an extreme flooding event with varying depths and durations occurred in January 2014, afflicting irrigated rice fields in the study area. The flooding event damaged fields and rice crops and caused delays in planting dates. Swampland (deep and semi-deep) rice fields located in the northern regions of study area suffered the most during this adverse event. These rice fields frequently have bowl-shaped topography, low-lying areas, and are associated with inadequate drainage channels. Thus, flood duration was longer than other rice fields because surface run-off (e.g., rainfall, irrigation water, river discharge) accumulates in these rice fields. Also, strong river flow caused a dike failure in Cipunagara river in Pamanukan sub-district on January 18, 2014, allowing river water to submerge adjacent swampland rice fields. Also, stakeholders needed to reconstruct the river levees and rice field embankments before starting rice cultivation. Rice fields with flooding (dike failure and swampland) are represented by the red dot (V) in Figure 3.1A or black rectangle in Figure 3.1B. 


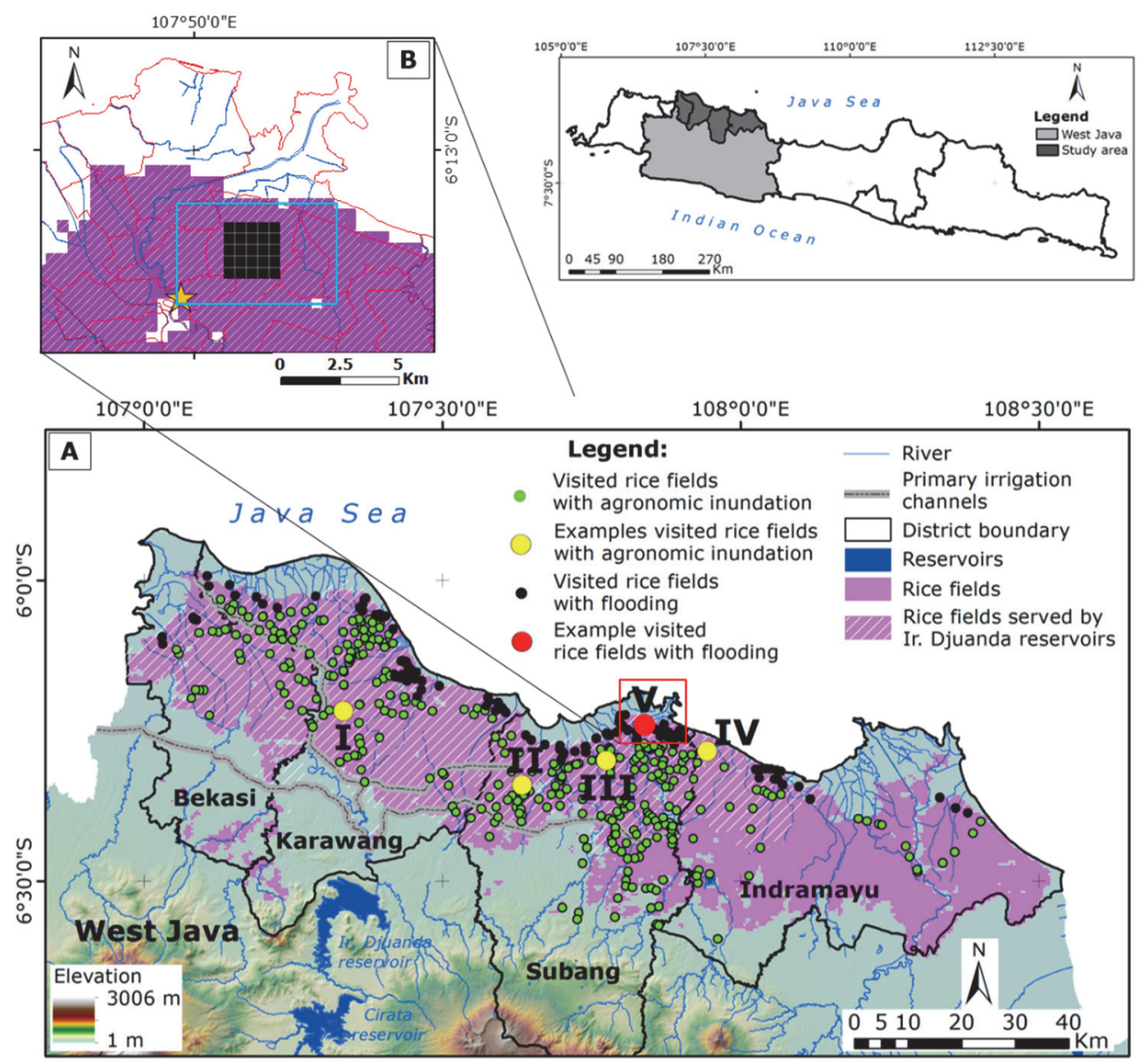

Figure 3.1 (A) Study areas: Irrigated rice fields (purple) in Bekasi, Karawang, Subang, and Indramayu districts (black line). Green dots and black dots represent visited rice fields with agronomic inundation and flooding, respectively. Yellow dots (I-IV) and a red dot (V) represent examples of rice fields with agronomic inundation and flooding, respectively. Yellow dots and the red dot correspond to Figure 3.2. (B) Blue rectangle represents swampland rice fields affected by the dyke failure on January 18,2014 . Yellow star marks the location of the dyke failure (inset). Conditions in the black rectangle in Figure 3.1B are explained in Table 3.1.

\subsection{Methods}

\subsubsection{Pre-processing}

The Terra satellite carrying the MODIS sensor was launched in December 1999. The Level 3 atmospherically corrected 8 -day 500-m spatial resolution MODIS imageries (MOD09A1) from 2000 (DOY 49) to 2015 (DOY 255) were used for this study. MOD09A1 data were stacked to produce a time-series dataset. The study area, including Karawang, Subang, Bekasi, and Indramayu districts, was derived from the dataset. The default sinusoidal projection was retained to avoid the misalignment of pixels during the data pre-processing. A time-series 
Enhanced Vegetation Index (EVI) dataset was derived from the time-series MOD09A1 using the formula (Huete et al. 2002, Sakamoto et al. 2007, Son et al. 2013):

$$
\mathrm{EVI}=2.5 \times \frac{\mathrm{NIR}-\mathrm{RED}}{\mathrm{NIR}+6 \times \mathrm{RED}-7.5 \times \mathrm{BLUE}+1}
$$

where NIR, RED, BLUE are the near-infrared ( $841-875 \mathrm{~nm})$, red $(621-670 \mathrm{~nm})$; and blue (459-479 $\mathrm{nm}$ ) bands, respectively. The EVI dataset was de-noised using the Adaptive Savitzky-Golay filter focusing on the upper envelope to smooth and enable the observation of spectral profiles (Nguyen et al. 2011, Ali et al. 2013a, Ali et al. 2014). The filter has been used for estimating phenology metrics using 8 day $500 \mathrm{~m}$ spatial resolution in irrigated rice fields in West Java with reasonable accuracy (RMSEs $=9.21,9.29$, and 9.69 days for the Start of Season, heading stage, and End of Season, respectively). Low and high EVI values represent a scarce and dense vegetation cover, respectively. Low positive or even negative EVI values also signify free-standing water (e.g., rivers, lakes, floods).

From the dataset, the time-series EVI from 2000 (DOY 49) to 2014 (DOY 153) was analyzed using the Iterative Self-Organizing DATA (ISODATA) unsupervised classification to generate rice field areas (Khan et al. 2010, Bie et al. 2012). The unsupervised classification is selected because of the lack of information about the spatial distribution of land uses in the study area. The complete procedures of pre-processing and analysis to derive the rice field areas were elaborated in Sianturi et al. (2018). The rice field area is used as a mask during the whole analysis.

\subsubsection{Field data collection}

The data collection was divided into two phases. In the first phase (OctoberNovember 2014), farmers, extension officers, and water managers $(n=85)$ were interviewed to obtain information about the cropping calendar, irrigation management, reasons for initiating cropping seasons, variations of surface water in irrigated rice fields, and natural hazards (flood or water-deficit events). The green dots in Figure 3.1. A show rice fields with agronomic inundation visited during the fieldwork. The variations in cropping schedules and surface water duration during land preparation and transplanting activities in these rice fields with agronomic inundation are exemplified by yellow dots (I-IV).

In the second phase (January-February 2015), the fieldwork aim was to provide inputs for developing a method to distinguish RFAI. The focus was on rice fields experiencing flooding: the swampland rice fields and rice fields affected by dyke failures. Recurrent flood events occur mainly in the 
swampland rice field during wet planting seasons, in part, due to its bowlshaped topography. Also, high tide occurrence frequently prolongs the flood duration in these rice fields. In January 2014, swampland rice fields located throughout the northern part of the study area were severely flooded. Furthermore, river dyke failures may occur during wet planting seasons partly due to heavy rainfall, high river discharge, and poor river levee conditions.

Rice fields in villages, Pamanukan Sebrang (Pamanukan sub-district), Bobos, Pangarengan (Legonkulon sub-district), and Rancadaka (Pusakanagara subdistrict) in Subang district (see Figure 3.1B) were selected as rice fields with flooding to develop a method for distinguishing RFAI. Two reasons were used to select the areas of hazardous flooding.

1) Direct evidence (dyke breach): Rice fields in these villages were affected by flooding due to a dyke failure on January 18,2014 . The same rice fields did not experience any flood events from January to February 2015. Farmers and extension officers mentioned a stark contrast between low and high rainfall intensities during 2014/2015 and 2013/2014 wet seasons, respectively.

2) Physical conditions: These are swampland rice fields. Often, farmers who own swampland rice fields resort to coping with the risk of flooding by delaying the wet planting season until the end of February. The strategy is performed because it is almost impossible for farmers to drain ponding water from irrigated rice fields to hasten the start of rice cultivation during flooding periods. In other words, the start of wet planting seasons in these irrigated rice fields is partly controlled by physical conditions (e.g., rainfall, topography).

Table 3.1 compares conditions of RFAI in the selected locations from January to February in wet planting seasons $2013 / 2014$ and 2014/2015. The conditions were obtained through interviews with farmers. Rice fields were flooded from DOY 17 to DOY 57 in 2014. On the contrary, similar rice fields did not experience any flood event during the same period in 2015. 
Table 3.1. Conditions of rice fields with flooding and rice fields with agronomic inundation in Bobos and Pangarengan villages (Legonkulon sub-district) in the wet planting season 2014 (wet year) and 2015 (dry year). Table3.1 corresponds to Black dot (V) in Figure

\begin{tabular}{|c|c|c|c|}
\hline $\begin{array}{c}\text { Dates } \\
\text { (wet planting season } \\
2014 \text { - wet year) }\end{array}$ & $\begin{array}{l}\text { Rice Field } \\
\text { Condition } \\
\text { (Interview) }\end{array}$ & $\begin{array}{c}\text { Dates } \\
\text { (wet planting season } \\
2015 \text { - dry year) }\end{array}$ & $\begin{array}{l}\text { Rice Field Condition } \\
\text { (Fieldwork) }\end{array}$ \\
\hline 17 January (DOY 017) & Flooding & 17 January (DOY 017) & Fallow \\
\hline 25 January (DOY 025) & Flooding & 25 January (DOY 025) & Fallow \\
\hline 2 February (DOY 032) & Flooding & 2 February (DOY 032) & Fallow \\
\hline $\begin{array}{c}10 \text { February (DOY } \\
041 \text { ) }\end{array}$ & Flooding & $\begin{array}{c}10 \text { February (DOY } \\
041 \text { ) }\end{array}$ & Tillage \\
\hline $\begin{array}{c}18 \text { February (DOY } \\
049 \text { ) }\end{array}$ & Flooding & $\begin{array}{l}18 \text { February (DOY } \\
049)\end{array}$ & Tillage \\
\hline $\begin{array}{c}26 \text { February (DOY } \\
057 \text { ) }\end{array}$ & Flooding & $\begin{array}{l}26 \text { February (DOY } \\
057 \text { ) }\end{array}$ & Tillage \\
\hline
\end{tabular}

\subsubsection{Distinguishing between flooding and agronomic inundation}

This section aims to elaborate methods, EVI $\leq 0.1$ and EVI40, tested to distinguish between rice field with flooding and rice fields with agronomic inundation. Firstly, EVI $\leq 0.1$ is tested for detecting hazardous surface water in the study area. The time-series EVI $\leq 0.1$ was generated from the EVI dataset. Periods when flood events were recorded during the wet planting season from DOY 337 (2013) to DOY 49 (2014) and the periods when no flood events were reported during the dry planting season from DOY 137 (2014) to DOY 217 (2014) were used as test periods. Periods in between, from DOY 49 (2014) to DOY 137 (2014), are mixed conditions where flooding was still present in swampland rice fields.

Secondly, the time-series EVI40, an extension of time-series EVI $\leq 0.1$ after incorporating the duration of land preparation and transplanting activities, was tested to distinguish between flooding and agronomic inundation (hence detecting flooding) in the study area. Farmers in the study area need approximately 40 days for the land preparation activities, including maturing rice seedlings, tillage, and rice transplanting (hereafter referred to as EVI40). Most farmers employ farm labors for transplanting rice fields. The use of transplanting machine is not common in the study area. In practice, tillage and transplanting processes may take longer due to various reasons, including the irregularity in the irrigation distribution, inadequate rainfall intensity, lack of labor farmers, or planting delay to ensure a synchronize planting and distribute the risk of rat attacks. Furthermore, it is worth mentioning that the $\mathrm{EVI}=0.1$ value coincides with the crop establishment (transplanting) period (Sianturi et al. 2018). EVI can also detect flooding when rice plants are present irrigated rice fields if the flood water completely submerges rice fields. However, timeseries remotely-sensed data with moderate resolutions limitedly may only detect flooding impacts on delays in cropping schedules. In the study area 
setting, delays in planting dates may results in irregularity in irrigation management and asynchronous cropping schedules, among others.

Table 3.2 shows the duration of flooding and agronomic inundation in irrigated rice fields derived from EVI profiles from 2000/2001 to 2014/2015. The duration is the difference between transplanting dates and the date when agronomic inundation or flooding first detected. In the last 15 years, rice fields with agronomic inundation experiences $21 \pm 9$ to $30 \pm 9$ days of surface water during land preparation and transplanting activities. EVI $\leq 0.1$ less than 40 days ( $n$ or number of pixels=1287) consistently represents rice fields with agronomic inundation. This result is likely due to the similarity of farming practices (tillage, seedling preparation, transplanting) in the study area. On the other hand, rice fields with flooding (swampland rice fields and flooded rice fields due to dike failure) exhibit EVI $\leq 0.1$ longer than 40 days. Rice fields with flooding were submerged from $83 \pm 22$ to $95 \pm 20$ days during the wet planting season 2014.

Figure 3.2 shows EVI profiles derived from $5 \times 5$ adjacent rice pixels in $2013 / 2014$ and long-term average (LTA) in RFAI. The use of $5 \times 5$ pixels is justified as farming practices and surface water dynamics are relatively similar in neighboring irrigated rice fields. Five EVI profiles are purposefully selected to clarify the differences in surface water duration for rice fields with flooding (1 EVI profile) and rice fields with agronomic inundation (4 EVI profiles) based on the fieldwork. The selection of $4 \mathrm{EVI}$ profiles for the latter is also to indicate variations in cropping schedules in the study area. Similar to Table 3.2, Figure 3.2 consistently shows that the duration of flooding detected using the timeseries EVI $\leq 0.1$ is longer than that of agronomic inundation. It can be seen also that the duration of flooding due to the dike failure in January 2014 was longer than that of long-term average (2000-2015) ponding swampland rice fields.

Figure 3.2 shows that surface water in irrigated rice fields is not always detectable using time-series EVI $\leq 0.1$ derived from moderate resolution imageries, revealing the influence of mixed pixels resulting from environmental conditions and human decisions on EVI profiles. Farmers have dissimilarities in decisions related to cropping schedules. Additionally, the relative elevation of rice fields and drainage conditions cause differences in the duration of water in irrigated rice fields. These different conditions may result in varying degree of mixed pixels, influencing EVI profiles detected by remote sensing imageries. It is worth repeating that, the more dominant the presence of surface water in irrigated rice fields due to specific farming practices, the lower the EVI value and the easier surface water to be detected using EVI $\leq 0.1$. On the contrary, when plants cover rice fields, EVI values are relatively high. Thus, flooding 
events can be easily detected in irrigated rice fields during transplanting and fallow periods unless flood events submerge rice fields.

Several examples are presented to elaborate why EVI $\leq 0.1$ may not always be able to detect surface water in irrigated rice fields. Firstly, farmers with access to irrigation water and good drainage conditions have more flexibility in managing planting dates compared to those located at the tail end of irrigation channels. For the former, water excess in rice fields can be drained, reducing the risk of flooding. These farmers may also perform triple rice-cropping pattern without fallow periods. On the contrary, the influence of geographic locations and lack of access to irrigation water are more dominant in rice fields near coastal areas and in swampland rice fields. Persistent ponding water in irrigated rice fields may reduce mixed pixel problems from irregularity in planting dates and result in stronger surface water signals. It can be seen that Figure 3.2 demonstrates that rice fields located closer to primary irrigation channels (e.g., Rawamerta rice class I and Patokbeusi rice lass III) have higher minimum EVI values compared to those that located near coastal areas (Tambakdahan rice class II and Sukra rice class I. Secondly, it is related to variations in farmers' coping mechanisms to environmental conditions. As previously mentioned, farmers with lack of access to irrigation water during dry planting season may perform quick rice cultivation after wet season harvest, skipping the fallow period. These conditions cause some rice fields almost always covered by rice plants or stubble.

Table 3.2. Duration (Mean \pm Stdev, in days) of surface water (agronomic inundation and flooding) in irrigated rice fields per year derived from EVI from 2000/2001 to 2014/2015 ( $n=$ number of pixels). Duration is the difference between transplanting date (SOS ${ }^{a}$ ) and the date when agronomic inundation or flooding first detected.

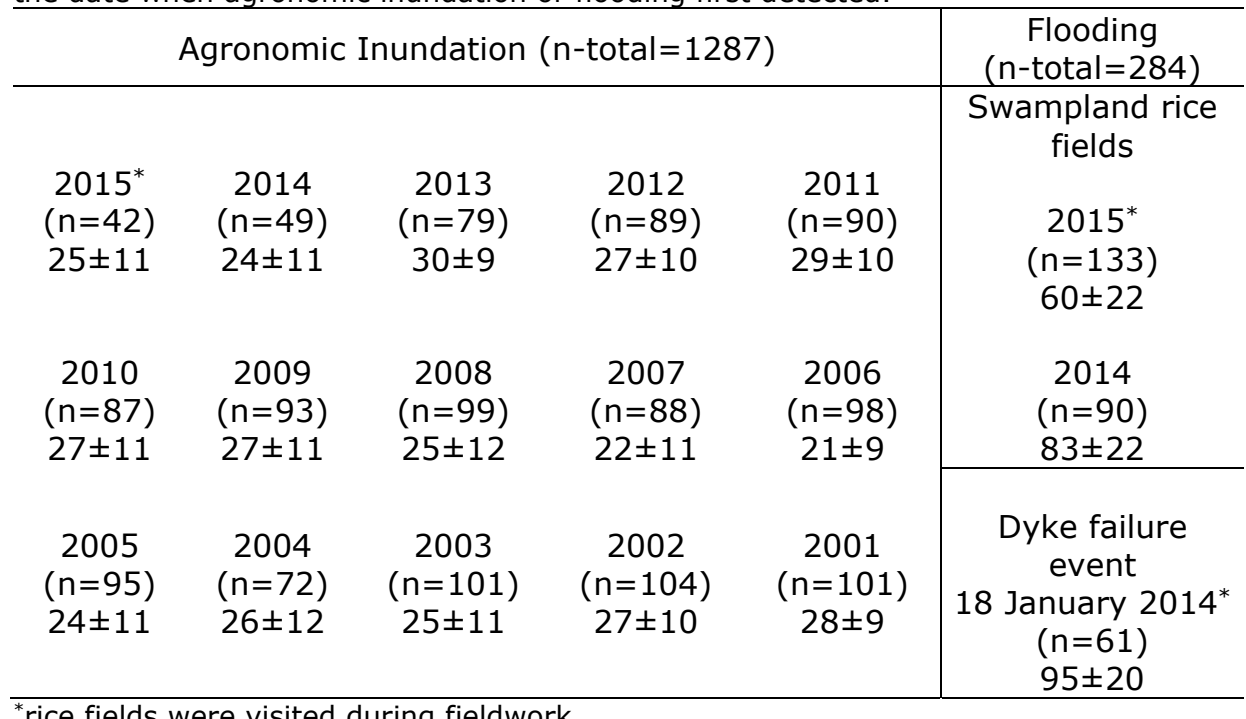



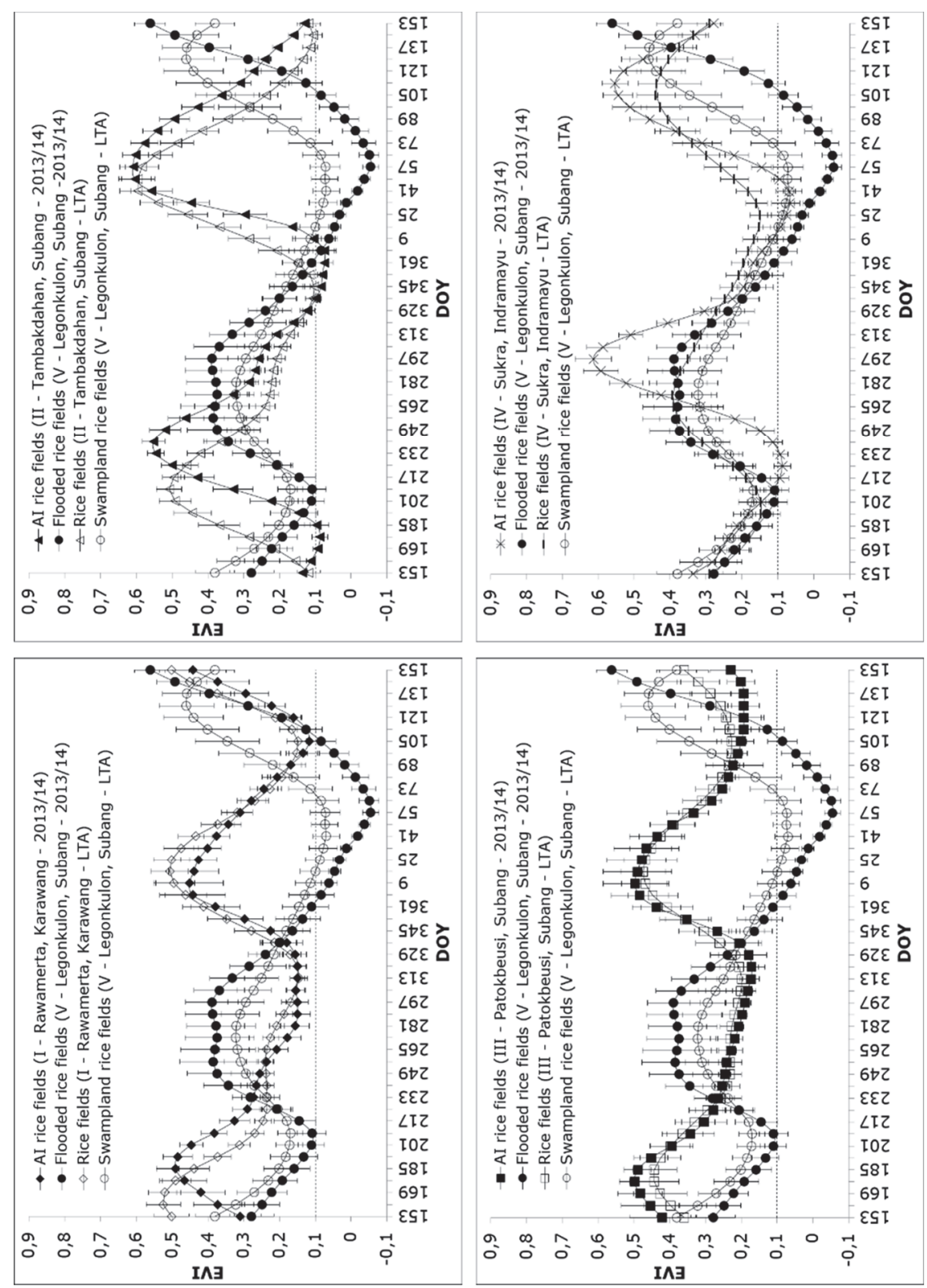

Figure 3.2. EVI profiles (average of $5 \times 5$ pixels) in rice fields with flooding and rice fields with agronomic inundation in 2013/2014 and LTA (2000-2015). Each dot represents an 8-day MOD09A1. Lines with solid- and non-filled markers represent rice fields with flooding and rice fields with agronomic inundation, respectively. Symbols I-IV correspond to the yellow dots and the $\mathrm{V}$ red dot in Figure 3.1A. AI stands for Agronomic Inundation. LTA stands for Long-term Average. 


\subsubsection{Accuracy assessment}

An accuracy assessment is performed to assess the quality of flood maps derived using EVI40. The duration of rice maturing in seedling beds before being transplanted, approximately 25 days, is selected as the parameter to assess the flood maps. The underlying assumption is that farmers suffer from the delay in planting dates from flood events in irrigated rice fields during the wet planting season 2013/2014. The 25-day duration also allows farmers to cope with flooding, for example by purchasing matured rice plants or replanting rice seedlings. In this respect, an evaluation matrix based on the Start of Season (SOS) is developed for accuracy assessment, as shown in Table 3.3. The SOS is one of the phenology metrics and is considered as the moment when farmers transplant rice fields. The SOS criteria follow the work of Sianturi et al. (2018). The SOS is defined as the period when the EVI value reaches 0.1 during growing phases. The growing phase is the periods from the minimum to peak value (heading stage). If the lowest EVI value throughout cropping seasons is higher than 0.1 (e.g., due to mixed pixels), the minimum value is selected as the SOS. Also, if more than one EVI values ( 0.1 or minimum) are the same, the last DOY is selected as the SOS. It is worth mentioning that the DOY for the SOS is analyzed manually according on the aforementioned condition to ensure the correctness of DOYs. As an example, this study focuses only on evaluating the flooding event in the wet planting season 2013/2014.

Within the evaluation matrix, a flood pixel is considered as True Positive when the difference in the SOS of flooded rice fields during the wet planting season $2013 / 2014$ and long-term average (2000-2015) is $>25$ days. For example, if the planting dates in the wet planting season 2013/2014 is DOY 75 (possibly delayed due to the flooding event) while the long-term average planting date is DOY 45 , then the pixel is labeled as flooded rice fields. The agronomic inundation pixels are considered as True Negative if the difference in the SOS of rice fields with agronomic inundation during the wet planting season $2013 / 2014$ and long-term average is $\leq 25$ days.

Table 3.3 shows the methods used to assess the estimated flood maps derived using EVI40, including the precision (positive predictive value), recall (sensitivity), specificity, false positive rate, false negative rate, negative predictive value, accuracy (Congalton 1991, Foody 2002, Campbell and Wynne 2011), and F1 score (Li and Guo 2014). The precision measures the quality of positive findings among all identified positive results while the recall is a measure of completeness of the results among possible identified positive results. The absence of type I (no false positive) and type II (no false negative) errors correspondents to maximum precision and recall scores, respectively. Results with high specificity values will accurately detect rice fields with agronomic inundation from all possible rice fields with agronomic inundation pixels. A false positive rate (type I error) estimates the likelihood of rice fields 
with agronomic inundation pixels that are incorrectly identified as rice fields with flooding. On the contrary, a false negative rate (type II error) measures the likelihood of rice fields with flooding that is incorrectly identified as rice fields with agronomic inundation. In contrast to the precision, the negative predictive value is the proportion of true negative among all identified negative results. Accuracy is the total number of correctly classified pixels divided by all test pixels. Accuracy is useful in symmetric datasets where the number of false positives and false negatives is relatively similar. An F1 score is the harmonic average of precision and recall, where 1 (or $100 \%$ ) and 0 (or $0 \%$ ) are the best and worst values, respectively. A higher F1 score indicates a high predictive power of a classification procedure. Unlike the accuracy, the F1 score works best if the data have an uneven class distribution. Pixels for the accuracy assessment were randomly selected from RFAI in 2013/2014 and 2014/2015.

Table 3.3. Evaluation matrix to assess estimated flooded rice pixels derived using $\mathrm{EVI}_{40}$.

\begin{tabular}{|c|c|c|}
\hline \multicolumn{3}{|c|}{ Method and formula } \\
\hline $\begin{array}{l}\text { True Positive: flooding is } \\
\text { correctly identified as flooding; } \\
\quad \text { SOS }^{a}-\operatorname{SOS}_{z}^{b}>25 \text { days }\end{array}$ & $\begin{array}{l}\text { True Positive Rate } \\
\text { or Sensitivity or } \\
\text { Recall: } \\
\mathrm{TP}^{d} /\left(\mathrm{TP}+\mathrm{FN}^{e}\right)\end{array}$ & $\begin{array}{l}\text { Positive Predictive } \\
\text { Value or Precision: } \\
\text { TP / (TP +FP) }\end{array}$ \\
\hline $\begin{array}{l}\text { False Positive: agronomic } \\
\text { inundation is incorrectly } \\
\text { identified as flooding; } \\
\qquad \operatorname{SOS}_{\mathrm{y}}{ }^{c}-\mathrm{SOS}_{z}>25 \text { days }\end{array}$ & $\begin{array}{l}\text { False Positive } \\
\text { Rate: } \\
\text { FP / (FP+TN) }\end{array}$ & $\begin{array}{c}\text { Negative Predictive } \\
\text { Value: TN / } \\
(\mathrm{TN}+\mathrm{FN})\end{array}$ \\
\hline $\begin{array}{l}\text { True Negative: agronomic } \\
\text { inundation is correctly identified } \\
\text { as agronomic inundation; } \\
\qquad \mathrm{SOS}_{\mathrm{y}}-\mathrm{SOS}_{\mathrm{z}} \leq 25 \text { days }\end{array}$ & $\begin{array}{l}\text { True Negative } \\
\text { Rate } \\
\text { or Specificity: } \\
\text { TN }^{f} /\left(\mathrm{FP}^{g}+\mathrm{TN}\right)\end{array}$ & $\begin{array}{c}\text { Accuracy: } \\
(\mathrm{TP}+\mathrm{TN}) / \\
(\mathrm{TP}+\mathrm{FP}+\mathrm{TN}+\mathrm{FN})\end{array}$ \\
\hline $\begin{array}{l}\text { False Negative: flooding is } \\
\text { incorrectly identified as } \\
\text { agronomic inundation; } \\
\qquad \operatorname{SOS}_{x}-\operatorname{SOS}_{z} \leq 25 \text { days }\end{array}$ & $\begin{array}{l}\text { False Negative } \\
\text { Rate: } \\
\text { FN / (FN+TP) }\end{array}$ & $\begin{array}{c}\text { F1 Score: } \\
\text { 2TP / } \\
(2 \mathrm{TP}+\mathrm{FP}+\mathrm{FN})\end{array}$ \\
\hline
\end{tabular}

\subsection{Results and Discussion}

\subsubsection{EVI $\leq \mathbf{0 . 1}$ for distinguishing between RFAI}

Figure 3.3 shows time-series surface water maps detected using EVI $\leq 0.1$ during the wet planting season 2013/2014 and dry planting season 2014 . Surface water detected during the wet planting season 2013/2014 includes both rice fields with flooding and with agronomic inundation. On the contrary, surface water detected during the dry planting season 2014 was rice fields with agronomic inundation as no flood events were reported by farmers, extension officers, and water managers. 
EVI $\leq 0.1$ can detect the movement of both non-hazardous agronomic inundation and hazardous flooding during planting seasons, reflecting the influence of irrigation schedules on rice cultivation. This finding provides evidence that EVI $\leq 0.1$ is not able to discriminate RFAI in the study area. This finding is not in line with studies mentioning that EVI $\leq 0.1$ can be used to detect spatiotemporal flooding on the land surface, including in irrigated rice fields (Sakamoto et al. 2007, Islam et al. 2010, Yan et al., 2010, Martinis et al. 2013, Son et al. 2013). A plausible explanation may be related to differences in the irrigation management and farming practices. This finding suggests that the analysis may open to misinterpretation if one directly uses spectral indices (e.g., vegetation, water) to directly detect flooding in the study area. In this study region, ancillary information is required to enable the discrimination between hazardous and non-hazardous surface water.

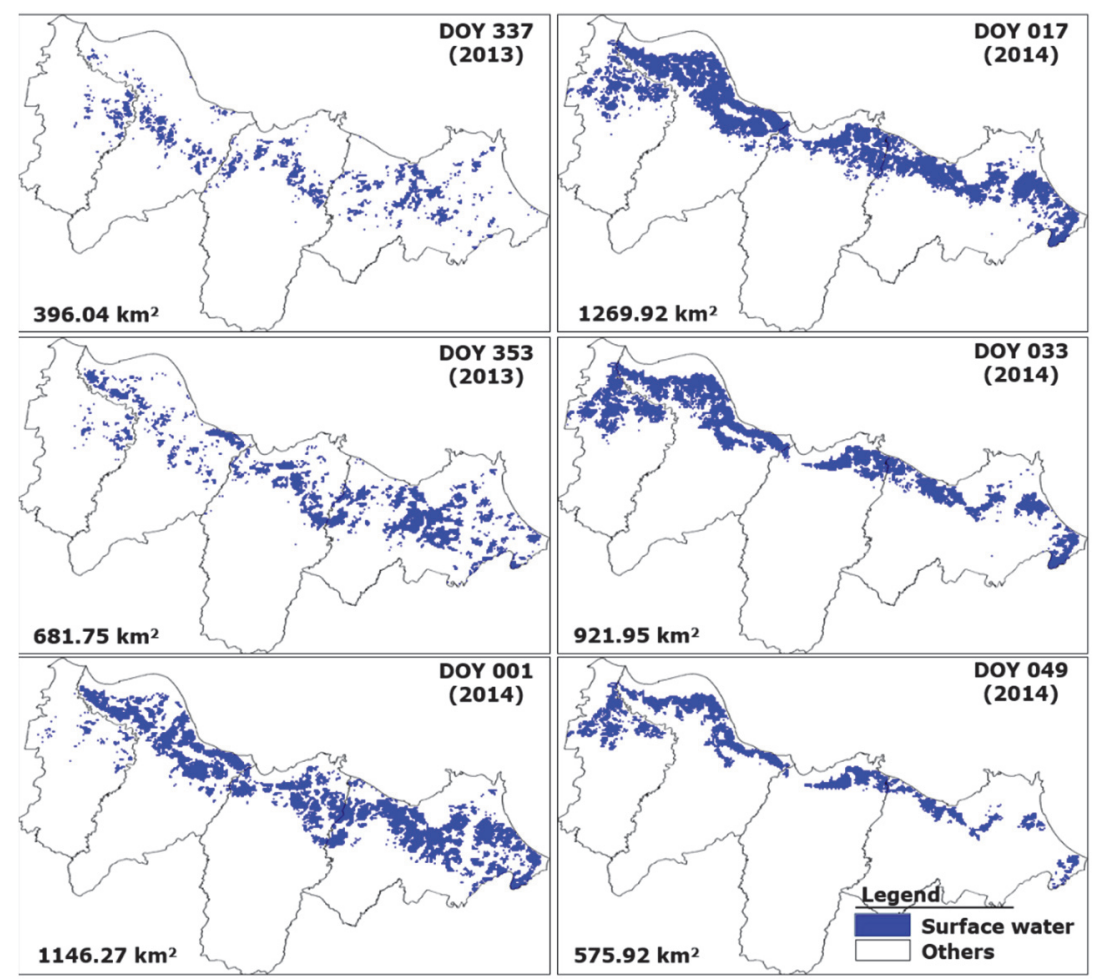

(Top) 


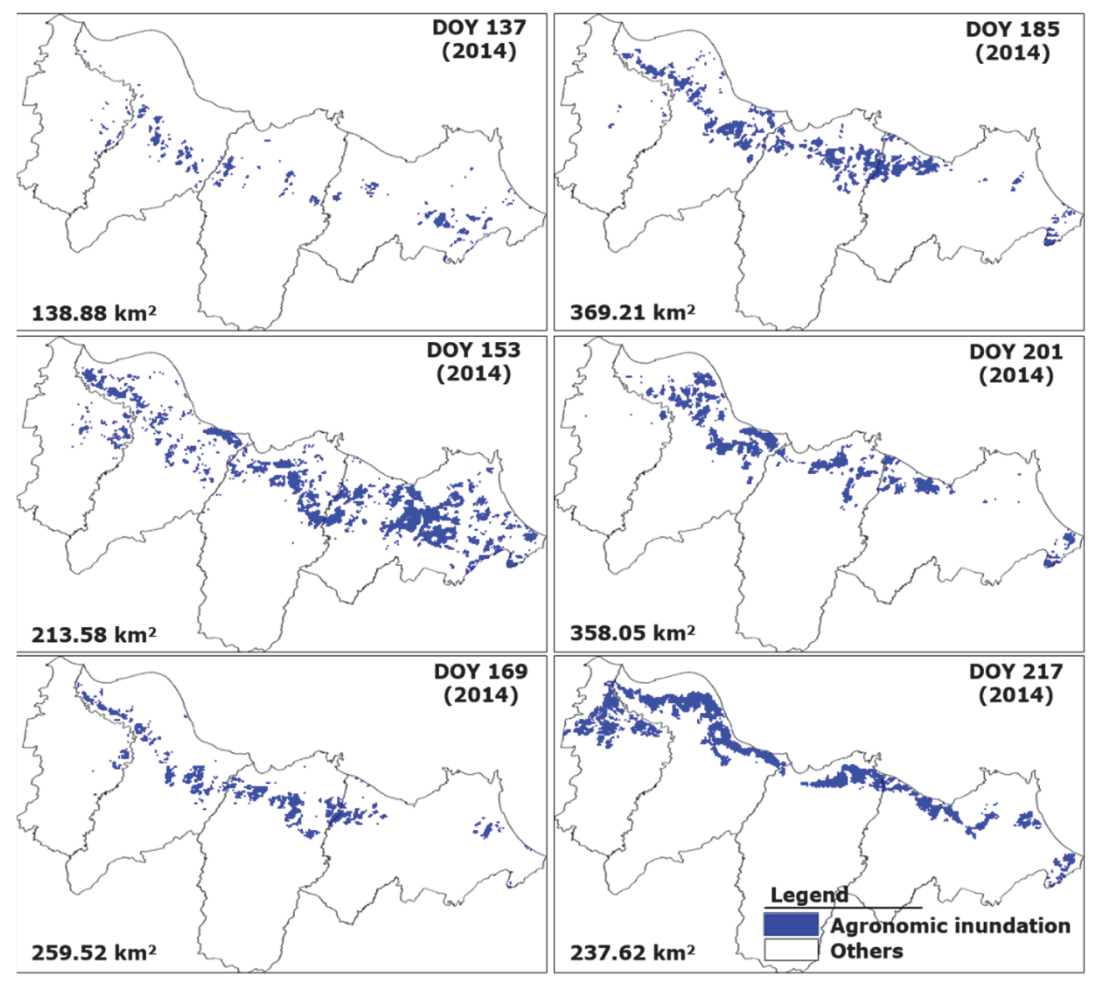

(Bottom)

Figure 3.3 Time series of surface water maps generated using EVI $\leq 0.1$ in irrigated rice fields in West Java. (Top) wet planting season: DOY 337 (2013) - 49 (2014). (Bottom) dry planting seasons DOY 137- 217 (2014). Value at the left corner of each figure is the area of surface water in $\mathrm{km}^{2}$. Rice field areas presented in Figure 3.1 is used as a mask.

\subsection{2. $\mathrm{EVI}_{40}$ for distinguishing between RFAl}

Figure 3.4 illustrates time series of surface water maps produced using EVI $\leq$ 0.1 (Figure 3.4A) and of flood maps generated from $\mathrm{EVI}_{40}$ (Figure 3.4B) for DOY 337-49 during wet planting seasons 2013/2014 and 2014/2015 in the focus area (see Figure 3.1B). Figure 3.4A demonstrates that EVI $\leq 0.1$ cannot distinguish between flooding and agronomic inundation in rice fields. On the contrary, Figure $3.4 \mathrm{~B}$ can show that flooding occurred at the beginning of January (DOY 1 ) in 2014 in the focus area. EVI40 detect rice fields with flooding by eliminating the areas of rice fields with agronomic inundation. Furthermore, Figure 3.4C exhibits the areas of rice fields with flooding detected using EVI40 aggregated from DOY 337 to 129 in 2013/2014 and 2014/2015. EVI40 exposes the areas of rice fields affected by flooding during the wet planting season $2013 / 2014$. It can be seen that flooding occurred in swampland rice fields during the wet planting season 2014/2015. A plausible reason is an accumulation of surface runoff in swampland rice fields. Additionally, a caution should be taken while interpreting the classification results of EVI40. The field 
observation around DOY 033 in 2015 exposed that flooding in the rice fields (Figure 3.4B, green circle) was river water deliberately channeled to rice fields to support tillage and an early start of the wet cropping season. This finding suggests that there are situations, mainly influenced by human activities, where the threshold of 40 days is inaccurate.
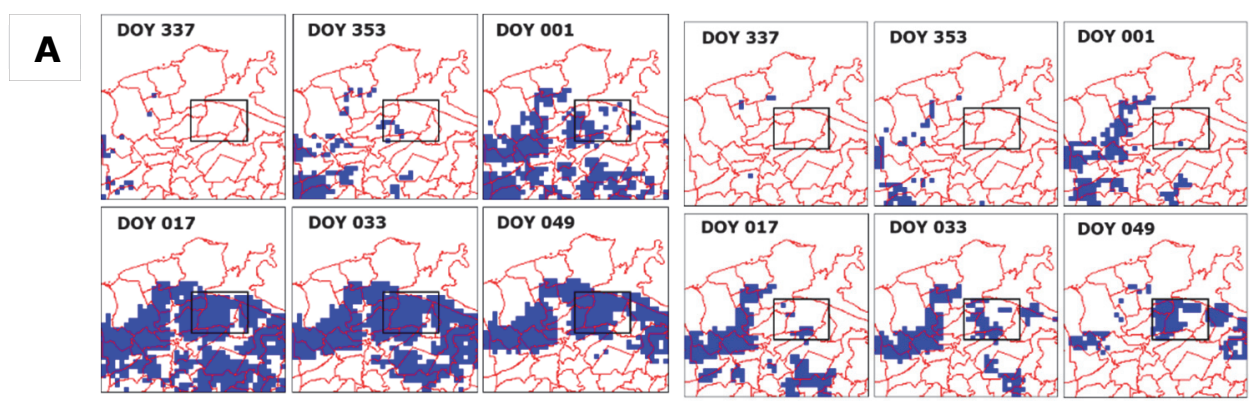

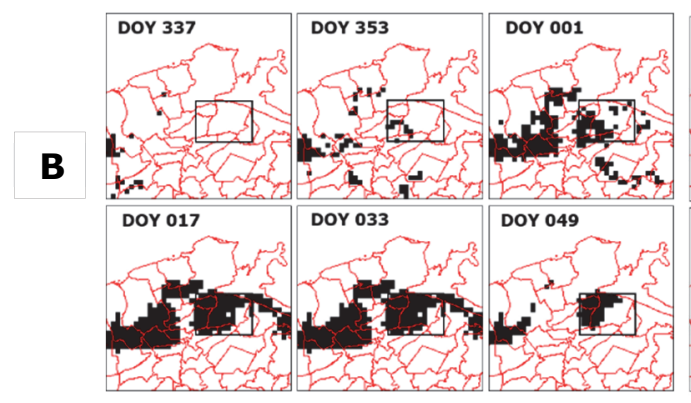

$(2013 / 2014)$

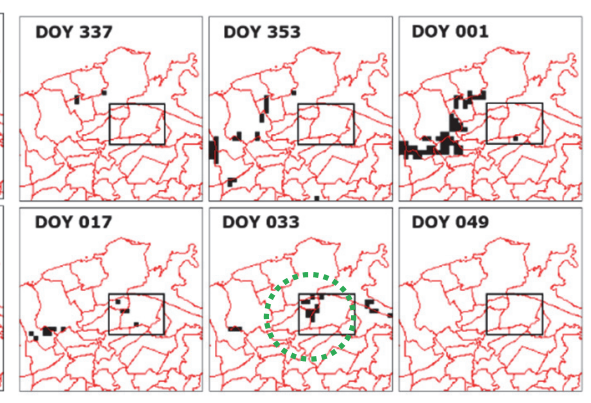

(2014/2015)

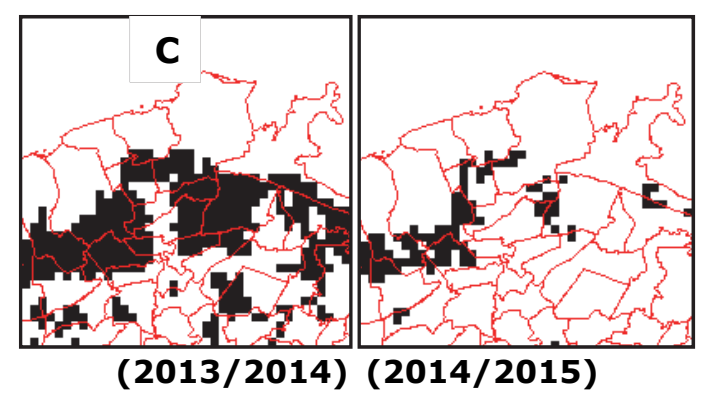

Figure 3.4 Rice fields with (A) surface water detected using EVI $\leq 0.1$ (blue) and (B) with flooding detected using $\mathrm{EVI}_{40}$ (black). Black rectangle represents rice fields affected by a dyke failure on January 18,2014 . Dotted green circle is misclassified flooded rice fields. (C) Total area rice fields with flooding detected using $\mathrm{EVI}_{40}$ in $2013 / 2014$ and 2014/2015. Figure 3.4 corresponds to Figure 3.4B. 


\subsubsection{Comparisons of surface water areas}

Figure 3.5 displays time series of surface water areas detected using EVI $\leq 0.1$ and of flooded rice fields identified using EVI40 during 2013/2014, 2014/2015, and long-term average. It is worth repeating that flooding in irrigated rice fields may take forms of longer ponding water (e.g., swampland rice fields) or shorter flash flooding (e.g., dyke breach). The duration and extent of flooding partly results from irrigation management dynamics, cropping schedules, weather variabilities, and inadequate drainage infrastructures. The areas of surface water are the largest in the beginning of January and July for wet and dry planting seasons, respectively. Compared to those of 2014/2015 and longterm average (2000-2015), EVI $\leq 0.1$ and EVI40 detect more extensive areas of surface water (DOY 1-89, t-test: $p<.05$ ) and flooding (DOY 1-89, t-test: $\mathrm{p}<.05$ ) in $2013 / 2014$, respectively. It is likely that the dike failure event in January 2014 increased the areas of flooded rice fields during the wet planting season 2013/2014. On the contrary, the areas of surface water (DOY 1-89, ttest: $p>.05$ ) detected using EVI $\leq 0.1$ and flooding (DOY 1-89, t-test: $p>.05$ ) using the EVI40 in the wet planting season $2014 / 2015$ are relatively similar to those of the long-term average (2000-2015).

Furthermore, Figure 3.5 demonstrates that the areas of surface water detected using the EVI $\leq 0.1$ are lesser in dry planting seasons compared to those in wet planting seasons. Several plausible explanations are present for this condition. Firstly, this result is related to greater water availability (irrigation water, rainfall, river discharge) and access to irrigation water for irrigating rice fields during wet planting seasons compared to that of dry planting seasons, indicating that not all farmers can perform double-rice cropping pattern in the study area. Secondly, it may be related to differences in the land preparation method after fallow between dry and wet planting seasons. After long dry season fallow, rice fields require a massive amount of water and longer inundation duration to fill cracks in soil at the onset of wet planting seasons. On the contrary, farmers may directly perform land preparation on the onset of dry planting seasons, approximately after one month fallow. Thirdly, some farmers in the Indramayu district may perform quick dry planting seasons directly after the first harvest in order to take advantages of soil moisture and intermittent rainfall at the end of wet seasons. These reasons causes differences in soil, water, and vegetation conditions between two seasons, influencing the strength and persistence of signal as captured by remotelysensed data.

It is also worth noticing that Figure 3.5 shows that small areas of rice fields with agronomic inundation are incorrectly detected as rice fields with flooding (False Positive) using EVI40 during the dry planting season 2014 (black arrow). Several possible reasons exist for the False Positives. Firstly, the misclassification pixels may be related to the dynamics of tidal flood intrusion 
in irrigated rice fields. The saltwater intrusion in rice fields through river channels is more likely to occur during dry planting seasons because the river discharge to push the intrusion of sea tide to river channels downstream is limited. The distinction between fresh and sea water in irrigated rice fields is out of the scope of this study. Secondly, the misclassification may be influenced by mixed pixels. The locations of the misclassified pixels mostly are near coastal areas and are adjacent to fish ponds (not shown). It is likely that the reflectance values are influenced by the variations of surface water in fish ponds. Thirdly, misclassified flood pixels may be associated with variations in ponding surface runoff in swampland rice fields. In practice, however, the existence of irrigation water in swampland rice fields is temporary and can be regarded as negligible provided the considerable need for water to support farming practices during dry planting seasons.

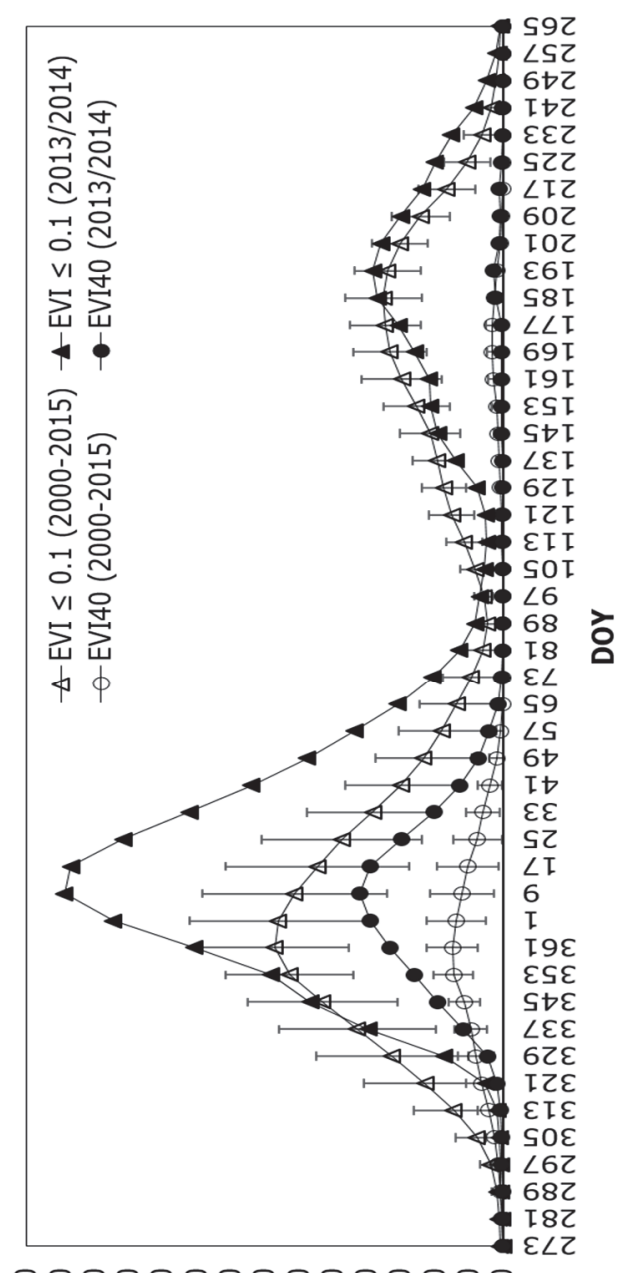

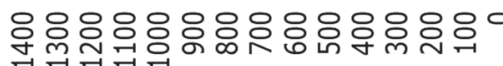

$$
\text { (zسب) eәd }
$$

Figure 3.5 Time series of total rice fields with surface water areas $\left(\mathrm{km}^{2}\right)$ derived from EVI $\leq$ 0.1 and with flooding using $\mathrm{EVI}_{40}$ in 2013/2014, 2014/2015, and long-term average (2000-2015). Black arrow points to misclassified flood pixels (False Positive) detected using $\mathrm{EVI}_{40}$ during dry planting seasons 2014 and 2015. 
Figure 3.6 shows the maps of flood duration produced using EVI40 during DOY $1-89$ in wet planting seasons $2013 / 2014$ and $2014 / 2015$. The period of DOY $1-$ 89 is purposefully selected due to the following reasons. Firstly, although Figure 3.5 demonstrates that the increase in flood area starts from the beginning of December 2013 (DOY 337), most farmers agree that flooding started at the beginning of January 2014 (thus DOY 1 is selected). This information is used to avoid the 'grey periods' when surface water that submerges swampland rice fields can be considered either hazardous or nonhazardous. On the one hand, ponding water during fallow periods can be regarded as hazardous if flooding disrupts cropping schedules. On the other hand, flood events may be considered non-hazardous as farmers may be accustomed to flooding occurrences within acceptable duration and extent. Secondly, farmers suffered from the flood event mentioned various wet season planting dates. The delays partly regulated by the differences in the flood duration. For example, farmers located at the tail end of irrigation channels in Legonkulon sub-districts (see Figure 3.1B) reported that the start of wet planting season was from the middle of March to the beginning of April 2014 (DOY 89).

Figure 3.6 shows that the areas of flooded rice fields in 2013/2014 are more extensive than those in 2014/2015 (t-test: $p<.05$, from DOY 3372013 to DOY 89 2014, see also Figure 3.5). Rice fields with the most extended flood duration are located mostly in swampland rice fields in the northern part of the study area. It is worth repeating that these rice fields have relatively low elevations and are associated with inadequate drainage systems, causing difficulties for ponded surface runoff to drain. Additionally, flooding that occurs during wet planting seasons can be exacerbated by the high tide that slows the flood retreat or brings sea water into rice fields. Furthermore, total flooded rice field areas in 2014/2015 and long-term average are relatively similar (see Figure 3.5). However, the extent and duration of flooding in $2014 / 2015$ may not represent the flood extent and duration of long-term average (2000-2015). The reason is related to the elaboration of farmers that low rainfall surprisingly occurred during the wet planting season 2014/2015 compared to other years. 


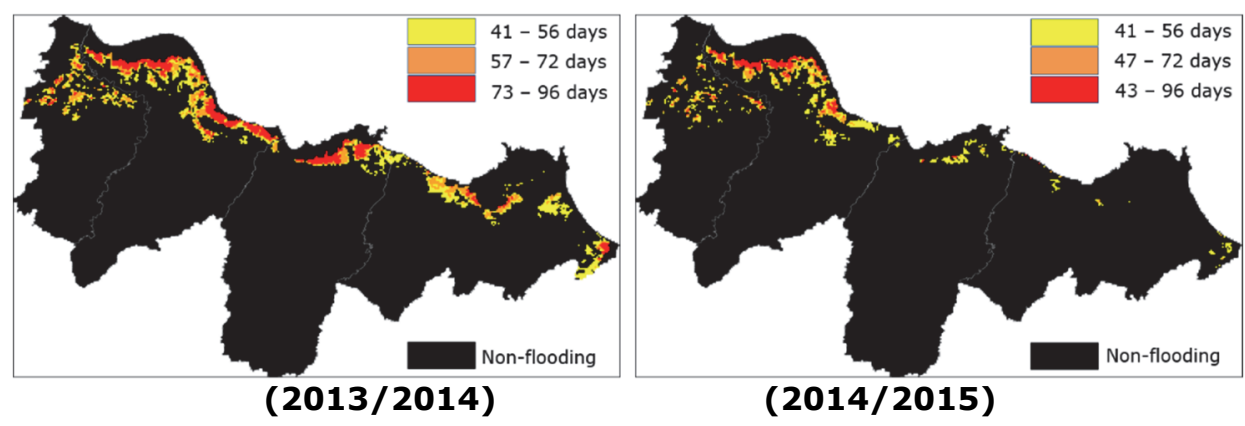

Figure 3.6 Maps of flood duration generated using $\mathrm{EVI}_{40}$ during wet planting seasons (DOY 1-89) in 2013/2014 and 2014/2015.

\subsubsection{Accuracy assessment}

Table 3.4 shows accuracy assessment for flood maps produced using EVI40 during DOY 1-89 in the wet planting season 2013/2014. Using the Start of Season as an indicator, the comparison of planting dates between wet planting season 2013/2014 and long-term average (2000-2015) shows that the accuracy and $\mathrm{F} 1$ scores are $75.96 \%$ and $81.74 \%$, respectively. The accuracy and $\mathrm{F} 1$ scores are partly related to the influences of the natural environment (e.g., geographic location), human decisions (e.g., irrigation management and inadequate drainage systems), and mixed pixels. The likelihood of accurately detecting flooding in rice fields is relatively high, with True Positive Rate $82.49 \%$. It can thus be inferred that flooding water mostly originates from ponding surface water. The ability of the test to correctly identified agronomic inundation within rice fields with agronomic inundation is $63.72 \%$. Furthermore, the False Positive Rate suggests that the likelihood that rice fields with agronomic inundation are incorrectly detected as rice fields with flooding is $36.28 \%$. The True Negative and False Positive Rates may be related to farmers' behavior in managing irrigation water. The likelihood of rice fields with flooding are incorrectly detected as rice fields with agronomic inundation (False Negative Rate) is $17.51 \%$. A plausible explanation is likely related to the coping capacity of farmers. Some farmers might be able to mobilize resources to reduce the flood impact on planting dates. Another reason might be due to mixed pixel problems associated with moderate spatial resolution of MOD09A1. Finally, the likelihood that detections are actually flooding or agronomic inundation given the positive and negative results are $81 \%$ (Positive Predictive Value) and $65.99 \%$ (Negative Predictive Value), respectively. 
Table 3.4. Results of accuracy assessment (\%) for rice fields with flooding detected using $\mathrm{EVI}_{40}$ during the wet planting season $2013 / 2014$. The wet planting season $2013 / 2014$ is compared to long-term average (2000-2015)

\begin{tabular}{ccc}
$\begin{array}{c}\text { Number of } 5 \times 5 \\
\text { pixels } \\
(\mathrm{n}=1918)\end{array}$ & Methods \\
\hline True Positive: 1032 & $\begin{array}{c}\text { True Positive Rate or } \\
\text { Sensitivity or Recall: } \\
82.49 \%\end{array}$ & $\begin{array}{c}\text { Positive Predictive } \\
\text { Value or Precision: } \\
81 \%\end{array}$ \\
False Positive: 242 & $\begin{array}{c}\text { False Positive Rate } \\
\text { or Fall out: } 36.28 \%\end{array}$ & $\begin{array}{c}\text { Negative Predictive } \\
\text { Value: } 65.99 \%\end{array}$ \\
True Negative: 425 & $\begin{array}{c}\text { True Negative Rate } \\
\text { or Specificity: } 63.72 \% \\
\text { False Negative Rate } \\
\text { or Miss Rate: } 17.51 \%\end{array}$ & Accuracy: $75.96 \%$ \\
False Negative: 219 & F1 Score: $81.74 \%$ \\
\hline
\end{tabular}

\subsection{Conclusion}

The present study has emphasized the need for a clear distinction on the nature of surface water in irrigated rice fields, whether it is hazardous or nonhazardous for the farmers. Previous studies have frequently been using EVI $\leq$ 0.1 derived from time-series remote sensing imageries to detect spatiotemporal flooding in irrigated rice fields. This study found that a sole use EVI $\leq 0.1$ derived from time-series MODIS 8 -day $500-\mathrm{m}$ spatial resolution (MOD09A1) is not sufficient to distinguish between rice fields with flooding and agronomic inundation in irrigated rice fields in West Java, Indonesia. EVI $\leq 0.1$ detects agronomic inundation and flooding at the same time during wet planting seasons. Furthermore, a new threshold called EVI40 has been developed, which is an extension of EVI $\leq 0.1$ with the maximum duration of 40 days of surface water allocated for land preparation and transplanting activities. This study has demonstrated that EVI40 could overcome the overestimation of flood areas suffered by EVI $\leq 0.1$ by reducing the detection of areas of rice fields with agronomic inundation. The flooded areas are mostly detected in swampland rice fields in the northern regions of the study areas, which is in line with the interviews with farmers, extension officers, and water managers. This study proposes that one may not able to ascertain whether surface water in irrigated rice fields is hazardous without defining the nature of surface water, prior information on flood event locations, or by solely relying on EVI $\leq 0.1$ (or other vegetation or water indices). This study proposes that the addition of 40 -day duration to EVI $\leq 0.1$ is needed if one aims to detect flooding events in irrigated rice fields using time-series imageries with moderate spatial resolution.

Using the Start of Season (SOS) to evaluate the areas of rice fields with flooding, the scores of accuracy and F1 for EVI40 are $75.96 \%$ and $81.74 \%$, respectively. The results of EVI40 are partly influenced by environmental processes (e.g., geographic location) and human decisions (e.g., irrigation 
management or poor drainage systems). Additionally, the mixed pixels may contribute to the accuracy of the areas of rice fields with flooding detected by EVI40.

Several limitations of the study are also identified. Firstly, the long-term average EVI is sensitive to outlier values resulting from various environmental and socioeconomic factors. For example, frequent extreme wet years and a change in irrigation management policy may influence the identification of SOSs from long-term average EVI profiles. However, the use of long-term average time-series EVI as a reference for 'normal' farming practices is justified provided that farmers, extension officers, and water managers may have different perceptions on normal cropping schedules. Secondly, this study used unsupervised clustering method to generate rice field areas, assuming that the areas are not changing within analysis periods. Further studies that incorporate changes in rice cultivation areas through wet and dry planting seasons may improve the results. Thirdly, EVI40 can only discriminate flooding from agronomic inundation if surface water has persistently covered rice fields for at least 40 days. Consequently, the method cannot detect flash flood or other fast-moving flood events in irrigated rice fields. The 40-day threshold is determined based on the duration land preparation and transplanting activities. Thus, an adjustment in the period may be required before the method can be used in other rice producing regions with land preparation and transplanting duration different from that of the study area. Fourthly, this study uses moderate spatial resolution imageries to derive flood areas. The use of higher spatial resolution is expected to increase the study result. Despite the limitations, EVI40 has successfully distinguished rice fields with flooding from rice fields with agronomic inundation in irrigated rice fields in West Java. The results from this study can be used by agricultural or disaster risk management institutions for improving management of and reducing flood risk in irrigated rice fields. 


\section{Chapter 4 Towards understanding vulnerability: Investigating disruptions in cropping schedules in irrigated rice fields in West Java $^{2}$}

\subsection{Introduction}

The vulnerability of farmers to natural hazards (hereafter referred to as vulnerability) may partly be explained by unsafe conditions (Wisner et al. 2003), such as unsustainable farming practices (Best 1988) or low cooperation among agricultural stakeholders (Bahta et al., 2016). Vulnerability refers to the characteristics and circumstances of a community, system, or asset that make it susceptible to the damaging effects of a hazard (UNISDR 2009b). According to the Pressure and Release (PAR) model (Figure 4.1), the origin of unsafe conditions may be traced back to the dynamic pressures and root causes of vulnerability (Wisner et al. 2003). Unsafe conditions are the specific forms in which the vulnerability of people is expressed in space and time in conjunction with natural hazards (Wisner et al. 2003). Unsafe conditions may reduce the capacity of farmers to prevent, mitigate, or recover from impacts of natural hazard occurrences (Adger 2006). However, identifying unsafe conditions are not without challenges. Firstly, unsafe conditions may be determined by many reasons, including farming practices (Daléus et al., 1988, Cardona 2005), the community coordination (Liverpool-Tasie 2014), and irrigation water availability (Uphoff and Wijayaratna 2000, Hoang et al., 2006), among others. Secondly, rice agricultural stakeholders may have different perceptions about dynamics in rice fields from researchers (Nguyen et al., 2016). Researchers need to translate terms such as the 'unsafe conditions' or 'vulnerability' into the daily language of stakeholders (Cicourel 1964, Seidman 2006). There exists a need to locate a common ground so that researchers can provide suggestions to address unsafe conditions and reduce the vulnerability in irrigated rice fields.

In the context of scheduled irrigated rice fields, disruptions in cropping schedules may be used as a 'common language' to understand mechanisms of how unsafe conditions may increase the vulnerability. On the one hand, extension officers and water managers regulate the implementation of an official cropping calendar and irrigation distribution to achieve the rice

\footnotetext{
${ }^{2}$ This chapter is based on: Sianturi, R.; Jetten, V. Towards understanding vulnerability: Investigating disruptions in cropping schedules in irrigated rice fields in West Java. International Journal of Disaster Risk Reduction. 28. 2018. Riswan S. Sianturi ; Willem Nieuwenhuis and V. G. Jetten, " Seasonal parameter extraction of paddy rice fields in West Java using multi-temporal MODIS imagery datasets ", Proc. SPIE 9637, Remote Sensing for Agriculture, Ecosystems, and Hydrology XVII, 963703 (October 14, 2015); doi:10.1117/12.2194999; http://dx.doi.org/10.1117/12.2194999
} 
production target. On the other hand, farmers may adjust planting dates according to their perceptions of physical and socioeconomic conditions to maximize productivity from their rice fields. Previous studies have identified causes that potentially influence rice cropping schedules in irrigated rice fields, broadly categorized into physical, technical, and socioeconomic factors (Hoque et al. 1982). The former is related to the geographic location where rice fields are cultivated, such as soil texture and moisture-holding capacity, topography, and non-extreme and extreme weather variabilities (Datta 1981, Malla et al., 1982). The latter may manifest in natural hazards, such as flooding (Sakamoto et al. 2007, Kotera et al. 2014) and drought (Birthal et al., 2015). The technical factor is related to water availability or irrigation management (Warburton. et al., 1999, Sudarmaji et al. 2010), and other technologies that can be used to support farming practices, such as rice varieties or labor farmers (Bernsten and Rachim 1982). Finally, socioeconomic factors encompass a broad range of social and economic conditions from the local to global level, including agricultural policies or regulations (Pan et al., 2014). 


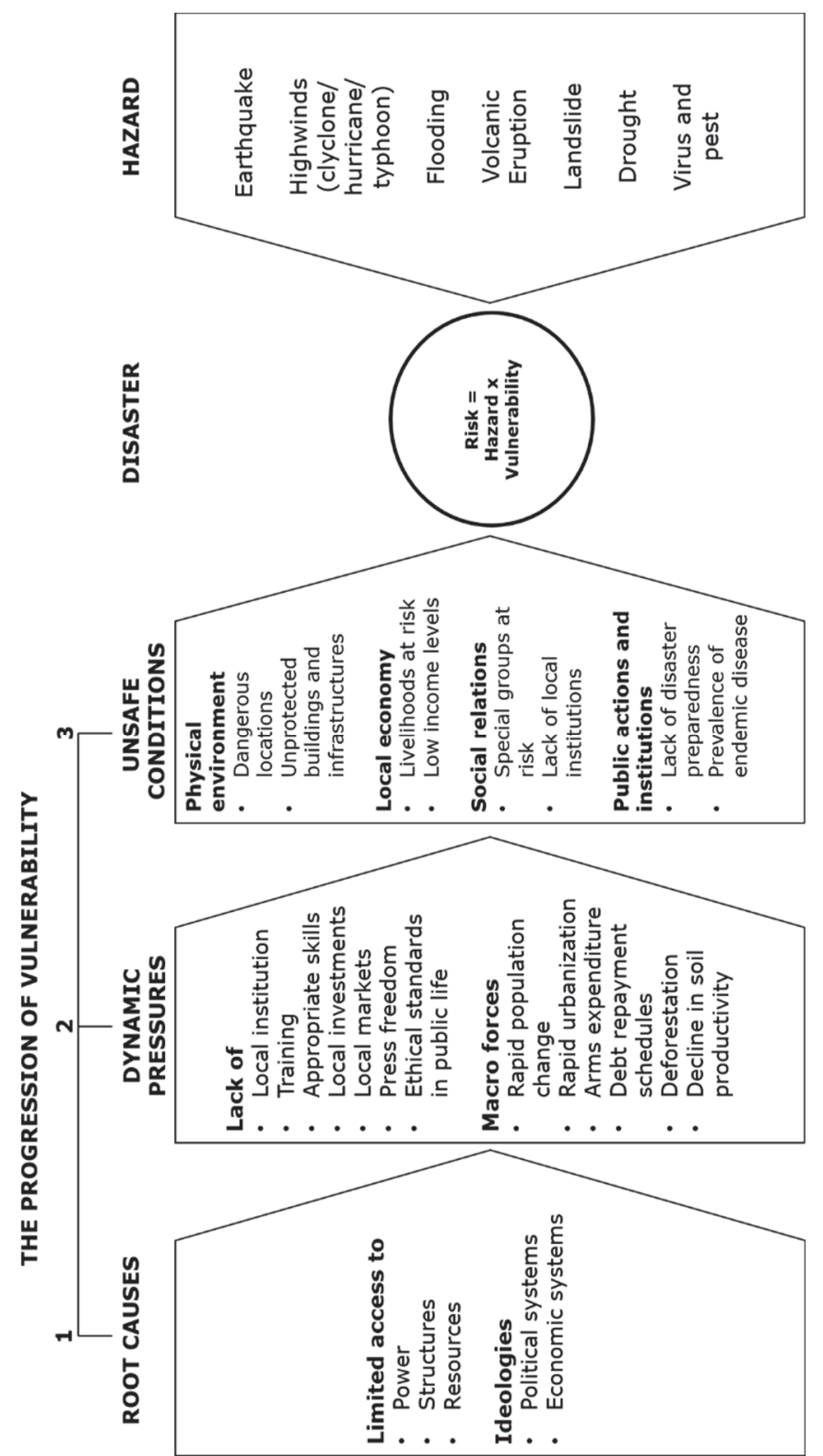

Source: Wisner et al. (2003). At Risk: Natural Hazards, People's Vulnerability, and Disasters, $2^{\text {nd }}$ edition, Routledge, New York.

Figure 4.1 Pressure and Release (PAR) model

The present study mainly focuses on irrigated rice fields served by a multipurpose Ir. Djuanda (Jatiluhur) reservoir (e.g., hydroelectric power generation, water supply, irrigation) under the management of Perusahaan umum Jasa Tirta II (PJT II) in West Java, Indonesia (Figure 4.2). The construction of the 
reservoir and development of irrigation systems since 1967 have improved agricultural productivity, marked by the change from a single- to the doublerice cropping cycle (http://jasatirta2.co.id/). Since then, the irrigation committee, currently consisting of the ministry of agriculture, provincial government, Balai Besar Wilayah Sungai Citarum (Citarum river basin office), and Dinas Pendayagunaan Sumber Daya Air (water resource management office) of West Java, and Perusahaan umum Jasa Tirta II (state company PJT II), have suggested a cropping calendar to satisfy irrigation water demand for the vast rice fields (approximately 240,000 ha) during wet and dry planting seasons. The cropping calendar is a recommendation of cropping schedules for farmers and a guide for PJT II in distributing irrigation water to rice fields (Table 1.1). The calendar was designed based on the operational pattern of the reservoir and seasonal periods of wet (October-March) and dry (AprilSeptember) seasons. The calendar also serves as a method to stop rice pest and disease reproduction, maintain soil fertility, and determine labor requirements, among others. Annually, the government of West Java and PJT II pass an official cropping schedule after discussing the draft of the cropping calendar with the irrigation committee. The calendar is disseminated among stakeholders (e.g., farmers, extension officers, local government) through various means, such as village meetings or mosque announcers. The irrigation committee conducts two weekly meetings at the sub-district level (minggon) to discuss the implementation of the cropping calendar.

The cropping calendar suggests that irrigation water is distributed to each rice field class according to stipulated schedules to ensure equal access and to avoid massive irrigation water demand due to concurrent planting dates (Table 4.1). Rice field classes categorize rice fields according to periods of receiving irrigation water. Rice field classes are determined by PJT II partly based on the locations and access of rice fields relatively to primary irrigation channels. Rice fields class I are located closer to primary irrigation channels and receive water first, while rice fields classes $V$ mostly are located at the tail end of irrigation channels and receive water last (Table 4.1). The amount and timing of water channeled to rice fields classes I to $V$ during wet and dry planting seasons is regulated according to the data of PJT II on rice field areas. However, irregularities in the amount and timing of water distributed to rice fields are present, especially during dry planting seasons, due to many factors, including water needs in other rice fields and sectors (e.g., electricity generation, drinking water). Thus, irrigated rice fields may not be given water priority during limited water resources, for example during an El-Niño period. Three regional water divisions (Divisi Pengelolaan Air - DPA) manage the distribution of irrigation water from primary to secondary irrigation channels (off-farm). Eight sub-division offices aid these division offices, comprising Bekasi and Lemahabang for DPA I; Sukamandi, Rengasdengklok, Telagasari, and Tarum for DPA II; and Binong, and Patrol for DPA III. From tertiary channels to rice 
fields (on-farm), the irrigation distribution is managed by farmer groups (P3A/Mitra Cai). Additionally, the primary irrigation channels were scheduled for a complete drying in September for maintenance and halting rice pest reproductions (Table 1.1); however, nowadays, the drying is performed mainly in secondary irrigation channels due to increasing water users (e.g., drinking water, factories).

The implementation of the cropping calendar frequently faces constraints in the study area. As previously mentioned, extension officers and water managers perform their duties according to the official cropping calendar while farmers who have more access to irrigation water may modify planting dates to maximize their rice production. There are no sanctions in terms of financial or water right cuts if farmers do not conform to the regulation. The efficiency of irrigation management decreases if farmers do not perform the cropping calendar. Also, incentives are non-existent if farmers follow the cropping calendar. Furthermore, the cropping calendar has existed for more than three decades as a guide for regulating planting and irrigation schedules in vast rice fields areas. The calendar was strictly regulated during the old order era (before 1998), contributing partly to rice availability and price stability. Nowadays, some farmers still consider the calendar in their farming practices. In contrast, cropping schedules in other rice fields deviate from the stipulated calendar. This irregularity in planting dates is likely to influence the availability of water. For example, a delay in planting dates in rice fields class I may lead to a delay in planting dates in rice fields classes II to V. Although the delay in rice fields class I may mean more water is available, farmers in other areas may not necessarily perform rice cultivation based on irrigation water availability. Some farmers may only start planting seasons if farmers in previous rice classes have cultivated rice fields to avoid problems in irrigation water schedules during growing seasons. The unsafe conditions that arise are therefore in part caused by the irregularity in irrigation water distribution.

This study aims to investigate disruptions in cropping schedules to understand unsafe conditions that contribute to the vulnerability of farmers to natural hazards in irrigated rice fields served Ir. Djuanda (Jatiluhur) reservoir in West Java. The primary goal is to provide insights on reducing the vulnerability. Firstly, we evaluate the deviation of ongoing cropping schedules from the official cropping calendar using time-series remote sensing data. As an indicator of the cropping schedule, we use the Start of Season (transplanting date) because this can be detected from variations in rice cover. The maps of deviations of long-term average (LTA) planting dates from the official cropping calendar are provided. Secondly, we explore reasons for disruptions in cropping schedules using an in-depth interview and qualitative content analysis. Using the first two results, we provide examples of locations and periods of the reasons. Thirdly, we demonstrate the progression from potential causes of 
disruptions to adverse disaster impacts using a Bow-Tie analysis. Using the result of the Bow-Tie analysis, we identify unsafe conditions that potentially increase the vulnerability. Finally, we suggest ways to reduce the vulnerability based on the results. The findings can be used as an input by extension officers, water managers, and disaster risk reduction officers for designing pathways for reducing the vulnerability of farmers to natural hazards.

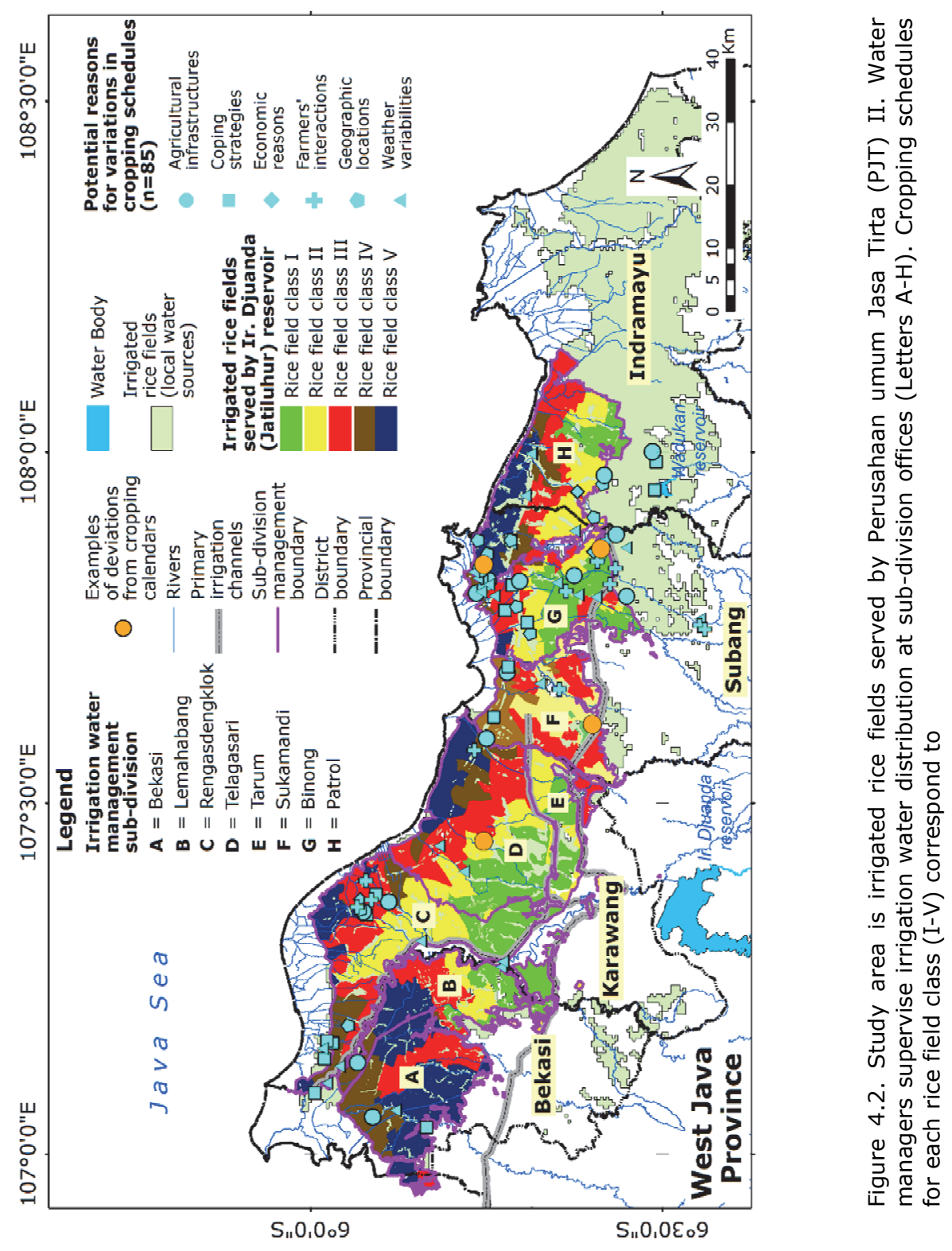


Table 4.1. Official cropping calendar for irrigated rice fields served by Ir. Djuanda (Jatiluhur) reservoir. Farmers may adjust planting dates according to perceived environmental and socioeconomic factors. Letter $\mathrm{P}$ (Planting) is the reference Day of Year (DOY) for the Start of Season (SOS). Rice field classes in Table 4.1 corresponds to Figure

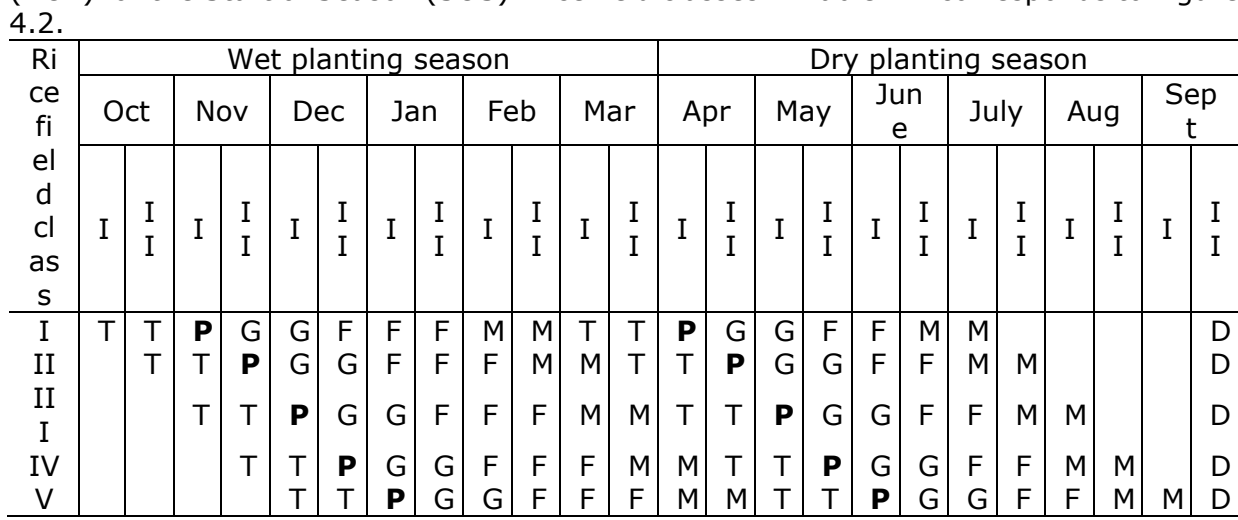

T: tillage (30 days); P: planting (15 days); G: growth (30 days); F: flowering (45 and 30 days in wet and dry planting seasons, respectively); M: maturation (30 days); "blank space": fallow period; D: irrigation channel drying. Source: Perusahaan Umum Jasa Tirta II

\subsection{Materials and methods}

\subsubsection{Remote sensing analysis}

A remote sensing analysis was performed to obtain information about the deviation of ongoing cropping schedules from the official cropping calendar in space and time. MODerate-resolution Imaging Spectroradiometer (MODIS) 8 day $500 \mathrm{~m}$ spatial resolution imageries (MOD09A1) from 2000-Date Of Year (DOY) 49 to 2015-DOY 225 were downloaded from the United States Geological Survey (USGS) website (http://earthexplorer.usgs.gov/) over the study area. The MOD09A1 data were stacked to produce a time-series dataset, and the study area was a subset of the dataset. A time-series Enhanced Vegetation Index (EVI) dataset was generated from the time-series MOD09A1 dataset. The formula for deriving the EVI is as follows:

$$
\mathrm{EVI}=2.5 \times \frac{\mathrm{NIR}-\mathrm{RED}}{\mathrm{NIR}+6 \times \mathrm{RED}-7.5 \times \mathrm{BLUE}+1}
$$

where NIR is the near-infrared band (841-875 nm, Band 2); RED is the red band (621-670 nm, Band 1); and BLUE is the blue band (459-479 nm, Band 3). The Adaptive Savitzky-Golay filter focusing on the upper envelope was performed to reduce the remaining noises and to smooth the time-series EVI dataset (Jonsson and Eklundh 2002, Chen et al., 2004, Wei et al., 2012, Ali et al., 2013a, Ali et al., 2013b, Ali et al., 2014). The 8 day time-series EVI (1 year $=46$ imageries) is interpolated into daily time-series EVI ( 1 year $=365$ imageries). 
The Start of Season (SOS) is used to obtain the DOY when farmers start rice cultivation. In practice, the SOS indicate the period when farmers start rice transplanting. The use of SOS to investigate the deviation in cropping schedules is preferred than other phenology metrics, such as the heading stage or end of season, because adverse events may damage rice cultivation during growing periods, reducing yield quantity and quality or causing harvest failures. Sianturi et al. (2018) estimated the SOS using MOD09A1 showed a reasonable result with Root Mean Square Error (RMSE) of 9.21 days. The unit analysis for deriving the SOS is rice field classes (I-V). EVI values in all pixels within a rice field class is averaged. The SOSs were derived from the timeseries EVI data for each rice field class within each water sub-division for both wet and dry planting seasons manually. The periods of wet and dry planting seasons were identified and used as a time boundary to discriminate between wet and dry planting seasons. Normally, the periods of wet and dry planting seasons are from October to March and from April to September, respectively. The DOY when the EVI value reaches 0.1 at the beginning of each planting season was derived from the time-series EVI. If the minimum EVI value throughout a cropping season is higher than 0.1 because of the influence of mixed pixels, the DOY of the lowest value (through) is selected as the SOS, as shown in Figure 4.3. Furthermore, the areas of rice fields served by Ir. Djuanda reservoir were also obtained from Sianturi et al. (2018) in the form of a raster dataset. The authors mapped irrigated rice fields in four northern districts of West Java (Bekasi, Karawang, Subang, Indramayu) using MOD09A1 with $R^{2}=$ 0.81-0.93.

The procedure for obtaining samples (N) for the DOY of the SOS is as follows. This study uses EVI data from 2000 to 2015, so there are at least 15 SOSs for each wet and dry planting season. Eight water sub-divisions are present in the study area (see Figure 4.2). Each water sub-division comprises rice field classes. The samples are obtained from all pixels in each rice field class (I-V). Some water sub-divisions have five rice field classes while others may have only 3 or 4 rice field classes. The total number of samples of SOS for the t-test is the multiplication of the number of years (e.g., 15 years) and the number of similar rice field classes in all water sub-divisions at each planting season (wet and dry planting seasons). For example, the rice field class III exists in all water sub-divisions. So the number of SOS sample for each wet and dry planting season is 120 . The inclusion of all pixels in a rice field class is to avoid the sample bias associated with the difference in the areas of water subdivisions. The estimated SOS derived from MOD09A1 were compared with the reference SOS using a t-test to investigate whether the ongoing planting dates deviate from the official cropping calendar. The null hypothesis $\left(H_{0}\right)$ : there is no difference between the estimated and the reference SOSs in each rice field class. The reference SOS is the official cropping calendar stipulated by the provincial government of West Java and PJT II for each rice field class. The 
DOYs of the reference SOSs for the wet and dry planting seasons in each rice field class are as follows: Class I, DOY 305 and DOY 91; Class II, DOY 320 and DOY 106; Class III, DOY 335 and DOY 121; Class IV, DOY 350 and DOY 136; and Class V, DOY 1 and DOY 152, respectively (see Table 1.1). It is worth mentioning that this study used the earliest DOYs during planting periods as the references SOS, leading to maximum deviation duration.

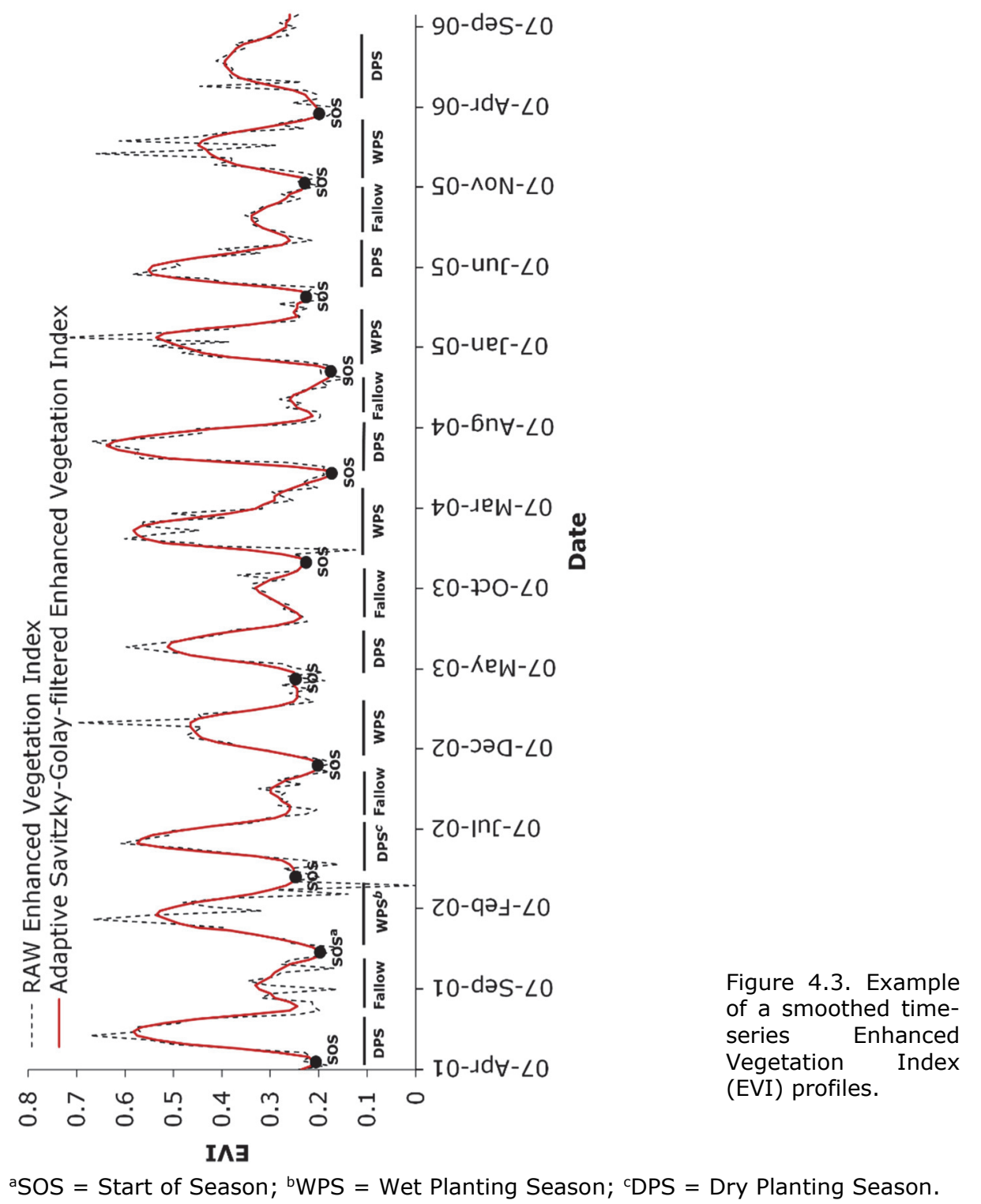




\subsubsection{Interviews}

Field interviews (85 respondents in total) were conducted from October to November 2014, and from January to February 2015 to obtain information on reasons for irregularities in cropping schedules. Practically, it is not possible to collect actual data on a wide range of conditions (e.g., the length of damaged irrigation channels) and activities (e.g., the amount of pesticide uses per cropping season) from different stakeholders in the study area. In this regard, in-depth interviews offer the advantages to capture perceptions of rice agricultural stakeholders about disruptions in cropping schedules (Cicourel 1964, Seidman 2006). The respondents include farmers, extension officers, and water managers. The primary question used as the guideline to probe reasons for disruptions in cropping schedules was 'why is the cropping schedule irregular?' The most dominant answers per respondent were presented per category in Figure 4.2. However, the demonstration should not be compared between districts provided a respondent may deliver more than one answer, and a specific weight was not given to responses during the data collection. It is expected that responses to the particular question may reveal unsafe conditions and their contribution to the vulnerability of farmers to natural hazards. The follow-up questions were varied based on the interviewees' responses and tailored according to the roles of the respondents, whether as farmers, extension officers, or water managers. The primary investigator was the lead author and was present during whole data collection processes. The interviews were conducted in Bahasa Indonesia and further translated into English for publication purposes. The interviews were recorded to reduce information loss. Before the end of each interview, the responses were reviewed. The contents were also cross-checked with other stakeholders in other interview sessions to address ambiguous and unclear answers and to produce robust data. Table 4.2 shows the number of respondents interviewed at each district in the study area.

This study applies both purposive and random sampling methods. Extension officers were purposively selected, but other respondents, including farmers and water managers, were randomly selected. The extension officers were pest analysts (POPT - Pengamat Organisme Pengganggu Tanaman) and the head of agricultural branch offices at the sub-district level (KKCD-Kepala Kantor Cabang Dinas). These extension officers directly interact with farmers, water managers, and village leaders on their daily routine. Huts where farmers usually gather were visited, and one of the farmers was asked as a representative for the interview. The interviews may be conducted on a oneon-one or as a group. In many occasions, the interviews are performed as a group. Usually, farmers appointed a person who is considered knowledgeable about the areas as their representative. Other farmers are free to join the discussions and to share their opinion during the interview process directly. The water management offices, including the sub-division level (SDPA-Sub- 
Divisi Pengelolaan Air), division level (DPA), and Ir. Djuanda reservoir, were also visited. Except for the DPA and Ir. Djuanda offices, the same procedures as those applied to farmers were conducted for gaining information from stakeholders at the sub-division level of the water management offices. It is worth mentioning that during the period of the study, the provincial disaster management office (BPBD-Badan Penanggulangan Bencana Daerah) was nonexistent in the study area. The tasks of disaster risk reduction and management are delegated to governmental agencies, according to the responsibilities of the departments. For example, the damage assessment from flooding or water-deficit events in irrigated rice fields is executed under the duty of the ministry of agriculture, performed by extension officers. Furthermore, the present study also includes examples of locations and timeseries EVI profiles for reasons of disruptions. The lead author obtained a specific reason and its approximate locations (e.g., villages or sub-districts) during interviews. Then, the lead author visited the locations, confirmed the particular farming practices with farmers living in the surrounding areas, and noted the coordinates.

Table 4.2 Overview of study participants. Table 4.2 corresponds to Figure 4.2 .

\begin{tabular}{c|ccccc}
\hline & Karawang & Subang & Bekasi & Indramayu & Total \\
\hline Farmers & 13 & 29 & 3 & 7 & 52 \\
Water Managers & 2 & 5 & 1 & - & 9 \\
Extension officers & 7 & 16 & 1 & 1 & 24 \\
Total & 22 & 50 & 5 & 8 & 85 \\
\hline
\end{tabular}

\subsubsection{Qualitative content analysis and Bow-Tie analysis}

This study used a conventional qualitative content analysis to scrutinize 85 responses from semi-structured in-depth interviews (Bos and Tarnai 1999, Bengtsson 2016, Neuendorf 2016). The text data were qualitatively evaluated using an inductive approach due to lack of established frameworks for guiding what factors should be included or excluded in the study area (Elo and Kyngäs 2008). The analysis was started using a coding strategy. The coding strategy means to use certain labels to categorize the responses. The process involves two-step procedures, including open coding and selective coding. In the former, the texts are labeled into abstract groups, while in the latter, the labels are categorized into themes and used to summarize the data (Burnard 1991). These categories represent reasons for disruptions in cropping schedules perceived by the stakeholders.

Next, a Bow-Tie analysis is used to visualize relationships from potential causes, a top event, and consequences (Figure 4.4). The Bow-Tie analysis is a risk evaluation method used for demonstrating causal and consequence relationships in risk scenarios (Gerkensmeier and Ratter 2016). The components of the Bow-Tie include hazards, causes, preventive barriers, top 
events, recovery barriers, consequences, escalation factors, and escalation factor barriers (Cockshott 2005). A hazard is an activity or process that potentially causes harm. Hazards are normal farming activities that can turn into a disaster if control over them is lost. Causes are possible reasons for a top event. For example, cropping schedules can be delayed because of a flooding event. Preventive barriers are measures that can be performed to stop causes escalating into a top event. A top event is a point in time when a control over a hazard is lost, for example when cropping schedules are disrupted. A top event indicates the analysis focus (e.g., disruption in cropping schedules). A top event is a common ground to facilitate communication between researchers and stakeholders. During a top event, there is no damage involved, and recovery barriers can be performed to stop a top event turning into consequences. Consequences are undesirable events caused by a top event. Escalation factors are conditions that inhibit the effectiveness of barriers. Escalation factor barriers are measures that can be performed to manage escalation factors. It is worth mentioning that the present study does not particularly define thresholds for particular elements of the Bow-Tie analysis, such as when potential causes may manifest into a top event or preventive barriers are considered effective. The Bow-Tie analysis is generated from the interview results. Thus, the progression from potential causes, a top event, to consequences purely relies on the authors' interpretation of respondents' perceptions.

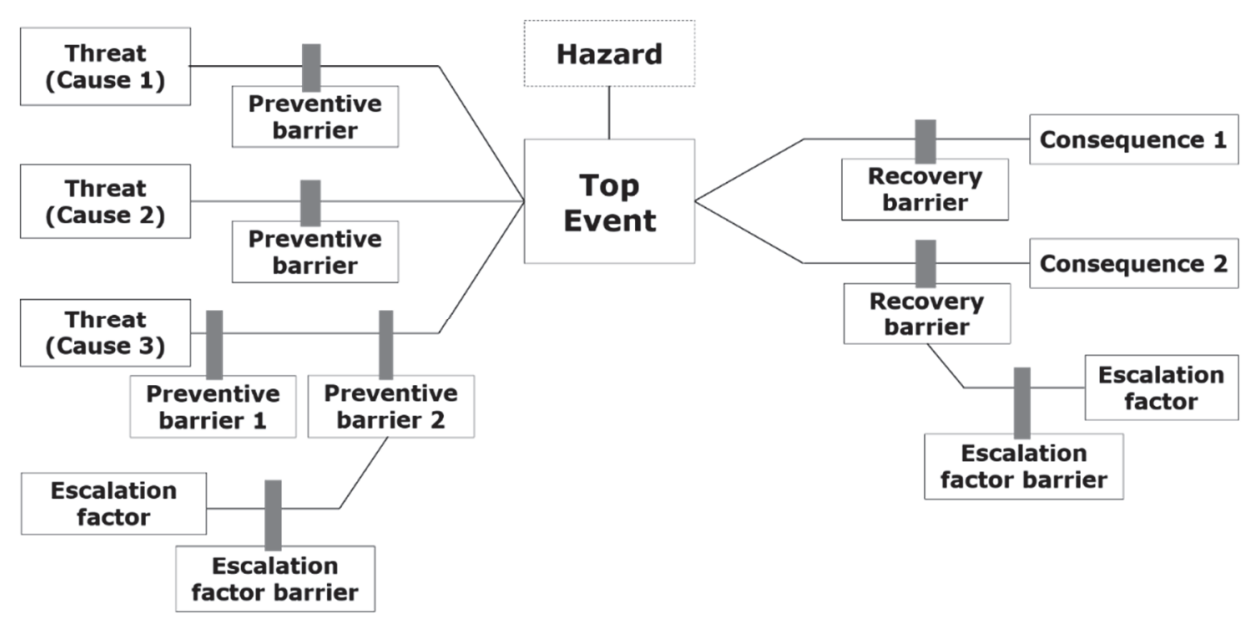

Figure 4.4 Bow-Tie analysis diagram. Elements include hazards, causes, preventive barriers, top events, recovery barriers, consequences, escalation factors, and escalation factor barriers. 


\subsection{Results}

\subsubsection{Deviation from official cropping calendar}

Stakeholders, including farmers, extension officers, and water managers, reported that planting dates in the majority of irrigated rice fields deviate from the official cropping calendar during both wet and dry planting seasons:

... in reality, there are delays in planting dates, and most planting dates agglomerate in the periods of rice fields with classes III and IV.

This finding was corroborated by the t-test result that found significant differences between the estimated and reference SOSs for each rice field class during wet and dry planting seasons, as shown in Table 4.3. Thus, the null hypothesis $\left(\mathrm{H}_{0}\right)$ was rejected. Furthermore, observing the column of mean differences of the t-test, it is apparent that the deviation of ongoing cropping schedules from the official cropping calendar in wet planting seasons is smaller than that of dry planting seasons for each rice class. The reason is partly related to lower access to irrigation water during dry planting seasons compared to that during wet planting seasons. Additionally, the delay in wet season planting dates may contribute to the delay in dry season planting dates. Table 4.3 also shows that the mean differences between the estimated and reference SOSs in rice field classes IV and $V$ are higher than those in rice field classes I, II, and III. A plausible reason may be related to the accumulation of delays in planting dates from rice fields located closer to primary irrigation channels to rice fields located at the tail end of irrigation channels.

Table 4.3 Independent samples t-test between the estimated and reference SOSs

\begin{tabular}{|c|c|c|c|c|c|c|c|}
\hline $\begin{array}{l}\text { Rice } \\
\text { Field } \\
\text { Class }\end{array}$ & $\begin{array}{l}\text { Planting } \\
\text { Season }\end{array}$ & $N$ & $\begin{array}{c}M \pm S D \\
(D O Y \pm \text { days })\end{array}$ & $t$ & $d f$ & \multicolumn{2}{|c|}{$\begin{array}{c}\text { Mean } \\
\text { Difference } \\
\text { (days) }\end{array}$} \\
\hline \multirow[t]{2}{*}{ I } & $\mathrm{DPS}^{a}$ & 105 & $115 \pm 25^{* * *}$ & 9.69 & 104 & 24 & \\
\hline & WPS $^{b}$ & 105 & $319 \pm 25^{* * *}$ & 5.84 & 104 & & 14 \\
\hline \multirow[t]{2}{*}{ II } & DPS & 105 & $134 \pm 21^{* * *}$ & 13.52 & 104 & 28 & \\
\hline & WPS & 105 & $332 \pm 21^{* * *}$ & 6.16 & 104 & & 12 \\
\hline \multirow[t]{2}{*}{ III } & DPS & 120 & $154 \pm 30^{* * *}$ & 12.01 & 119 & 33 & \\
\hline & WPS & 120 & $353 \pm 27^{* * *}$ & 7.25 & 119 & & 18 \\
\hline \multirow[t]{2}{*}{ IV } & DPS & 105 & $186 \pm 25^{* * *}$ & 20.73 & 104 & 50 & \\
\hline & WPS & 105 & $16 \pm 27^{* * *}$ & 11.98 & 104 & & 31 \\
\hline \multirow[t]{2}{*}{ V } & DPS & 75 & $200 \pm 24^{* * *}$ & 17.73 & 74 & 49 & \\
\hline & WPS & 75 & $33 \pm 28^{* * *}$ & 9.80 & 74 & & 32 \\
\hline
\end{tabular}

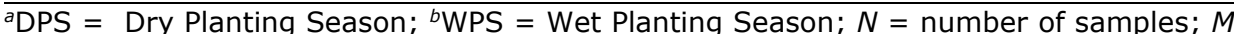
$\pm S D=$ Mean \pm 1 Standard Deviation; $t=\mathrm{t}$-test; $d f=$ degree of freedom; ${ }^{* * *}$ significant at $p<.001$.

Figure 4.5 shows the maps of deviations of long-term average (LTA) planting dates (2000-2015) from the official cropping calendar during wet and dry planting seasons. The planting dates in the majority of rice fields tend to 
deviate from the stipulated planting dates. Areas that deviate more than 15 days during wet and dry planting seasons are around $60 \%$ and $80 \%$, respectively. The delay in planting dates tends to increase as rice fields located further from the primary irrigation channels. Furthermore, around $5.6 \%$ rice fields located at the tail end of irrigation channels cannot pursue rice cultivations during dry planting seasons. One of the reasons is likely related to lack of access to irrigation water during dry planting seasons.

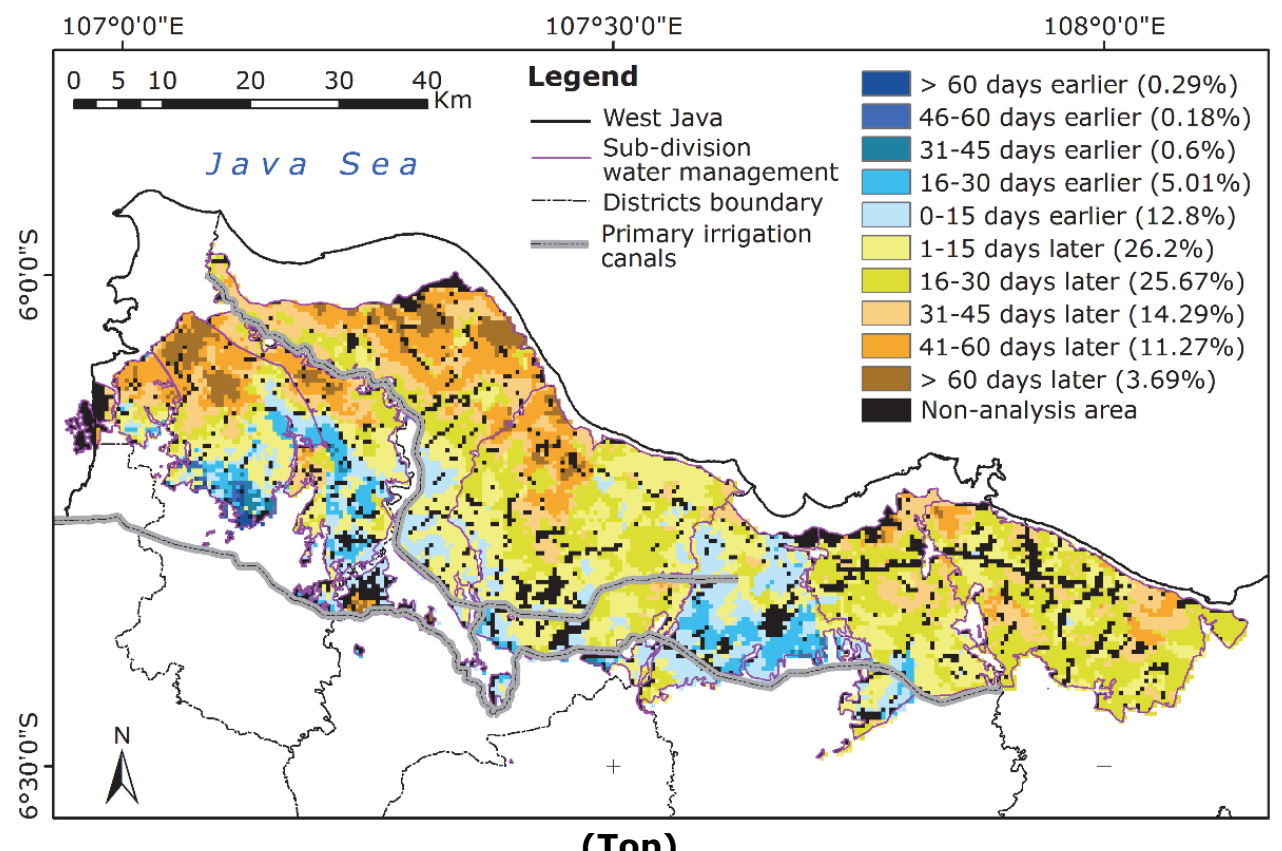

(Top) 


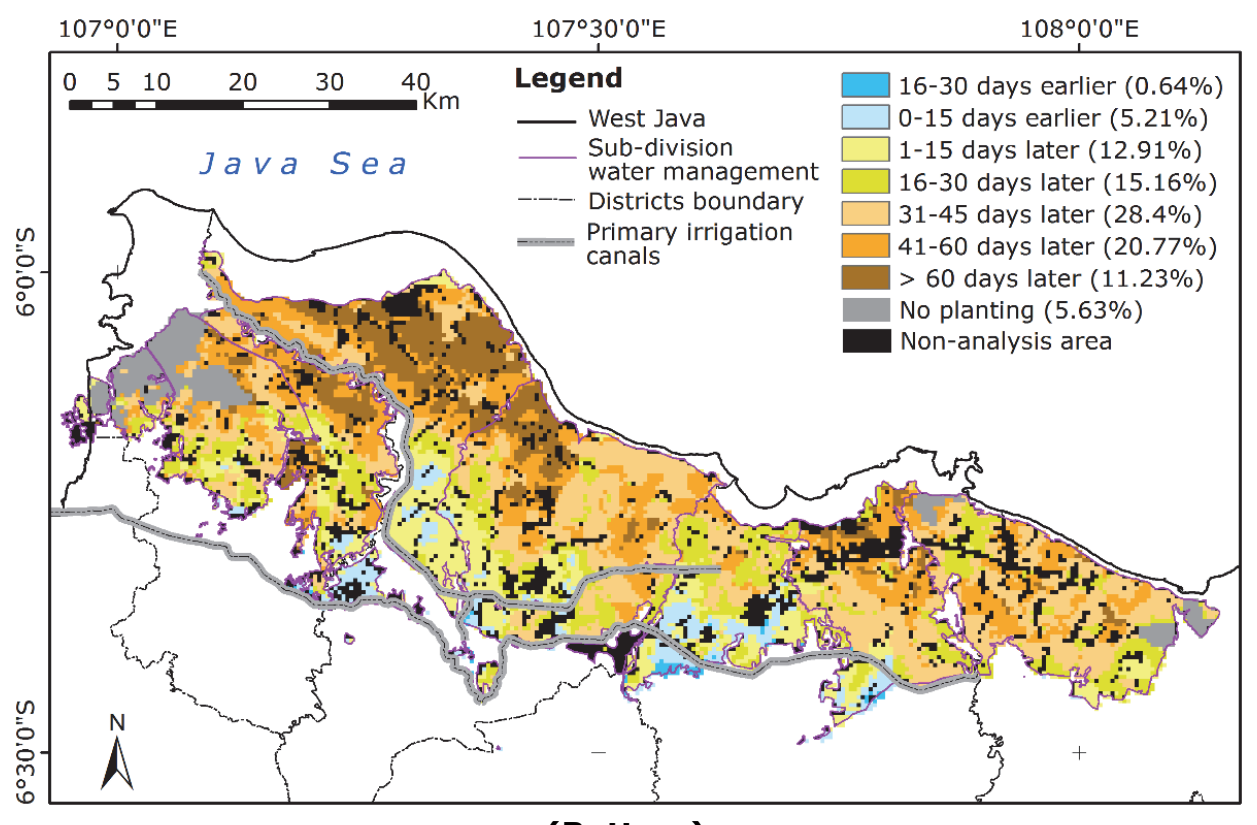

(Bottom)

Figure 4.5. Deviation (days) of long-term average (2000-2015) planting dates from the official cropping calendar in irrigated rice fields served by Ir. Djuanda reservoir during (top) wet and (bottom) dry planting seasons

Figure 4.6 shows deviations (days) of long-term average (2000-2015) planting dates from the official cropping calendar at the sub-district level in four districts in the study area. The difference in deviations between wet and dry planting seasons varies per sub-district. Several sub-districts can perform rice cultivation earlier than the stipulated schedules, such as Cibitung in Bekasi district or Pabuaran and Pagaden in Subang district. One of the plausible reasons is that rice fields have high access to irrigation water, allowing farmers to adjust planting dates. Some sub-districts, for example in Indramayu district, shows that delays during dry planting seasons are shorter than those of wet planting seasons. Farmers cope with difficulties in irrigation distribution during dry planting seasons by performing quick dry season planting dates to take advantages of occasional rainfall that still occur at the end of wet seasons. Furthermore, it can be seen that the deviation in dry planting seasons is longer than that of wet planting seasons in the majority of sub-districts in each district. Delays in dry planting seasons are the highest in Muaragembong, Pedes, Pamanukan, and Sukra sub-districts for Bekasi, Karawang, Subang, and Indramayu districts, respectively. These sub-districts are located at the tail end of irrigation channels with low access to irrigation water during dry planting seasons. 


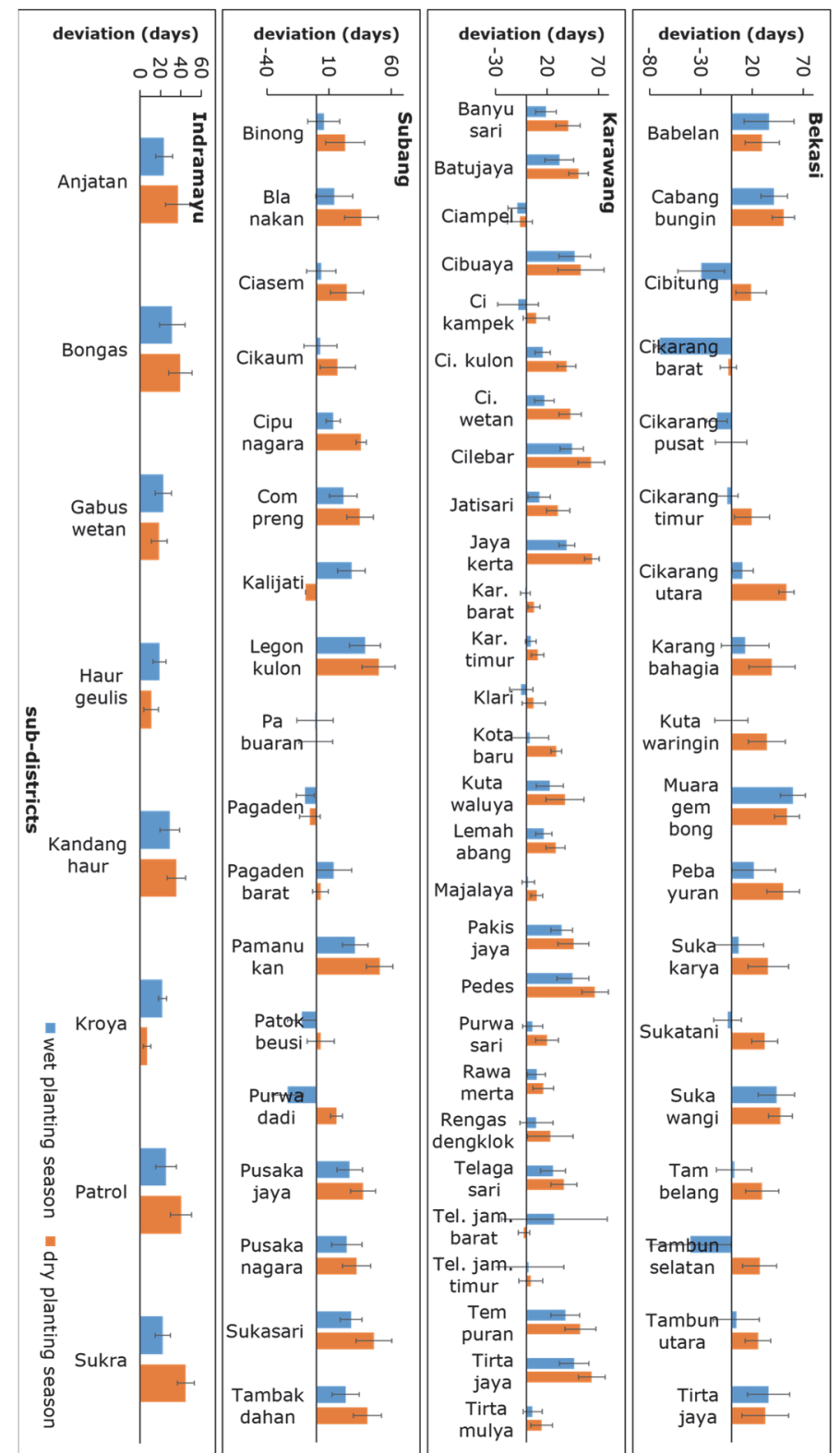

Figure 4.6. Deviations (days) of long-term average planting dates (2000-2015) from the official cropping calendar in irrigated rice fields served by Ir. Djuanda reservoir in four rice-producing districts of West Java.

\subsubsection{Reasons for disruptions in cropping schedules}

Six categories emerge from the qualitative content analysis as reasons for disruptions in cropping schedules in the study area, including economic motives, weather variabilities, geographic locations, coping strategies, 
farmers' interactions, and agricultural infrastructures. These reasons are not watertight, but interrelated to some extent with others. It is worth mentioning that this study does not aim to take side to any group. Some reasons may benefit a particular farmer group and at the same time cause harmful effects to other rice fields. Instead, this paper reveals the progression how potential causes may turn into disruptions in cropping schedules and result in adverse events to provide information for reducing the vulnerability in the study area.

\section{A. Economic motives}

As expected, economic motives are identified as one of the prominent reasons that influence disruptions in cropping schedules. Two forms of non-compliance associated with economic motives were identified, including the intentional delay in planting dates and the irregularities in cropping patterns. Farmers in both categories are likely to own rice fields with good access to irrigation water and are thus able to rely less on rainfall during wet and dry planting seasons. It seems that the abolition of regulation for the annual complete drying of irrigation channels in September provides time independence for farmers to tailor their cropping schedules.

The first category is farmers who deliberately delay their planting dates. It is found that some farmers in rice fields class I decide to delay land preparation and rice transplanting activities from October-November to NovemberDecember. Farmers and extension officers in Compreng and Binong subdistricts, Subang district, and Anjatan sub-district, Indramayu district $(n=5)$ mentioned that one of the reasons for delaying planting dates is to avoid difficulties of harvesting and post-harvesting activities during the peak of wet seasons in January and February (see Table 4.4A, Figure 4.7A):

... farmers are afraid; if the harvesting period is in February, the (heavy) rain is still present. Farmers want to harvest in drier months to avoid the difficulties in harvesting and drying harvested yields. When rice yields are not of high quality (e.g., damaged by rainfall), the (market) price gets lower. Intermediaries also have more difficulties in visiting and taking rice paddies from rice fields; consequently, rice paddies will not be easy to sell;

Farmers $(n=9)$ also deliberately adjust the period of harvesting in their respective rice fields so that it does not coincide with great harvest periods in other sub-districts. This strategy maximizes the selling price of harvested yields.

... if farmers follow the (official) cropping calendar of the PJT II, the price of rice yields is lower. If rice paddies are planted in January and harvested in April, the price is higher, because rice fields in Pagaden, Rancasari, Binong sub-districts have already been harvested. 
The second category is farmers who adopt irregular cropping patterns. Cropping schedules become inconsistent as farmers who have good access to irrigation water adopt intensive cropping patterns, including the alternating double- and triple-rice cropping cycle and the continuous triple-rice cropping cycle. For example, farmers in the Pabuaran sub-district (rice field class I), Subang district continuously practice the triple-rice cropping cycle without fallow periods $(n=13)$. Farmers in the Binong sub-district (rice field class I), Subang district perform the alternating double- and triple-rice cropping cycle $(n=3)$ (see Table 4.4B, Figure 4.7B) mentioned:

... farmers in this area (Binong) cultivate rice fields without a specific fallow period. There is no term for a delay from the official cropping calendar. We (farmers) count it per year. There used to be fallow periods after harvesting. Now, farmers choose to plant again after harvesting ... in one year we harvest two times, and in two years we can harvest five times. It used to be four harvests in two years ...

It seems that the intensive cropping pattern is one of the strategies for profit maximization. This strategy may be related to tenure of rice fields. Farmers reported that rice fields are commonly rented with an annual payment. Tenant farmers (guntai) thus make efforts to maximize profit from each planting season:

... farmers used not to rent their rice fields. Even though the area is more than ten bouw or bahu $\left( \pm 70,000 \mathrm{~m}^{2}\right)$, the owners themselves do or employ other farmers the entire cropping practices. Now, rice fields are mostly rented (guntai). The rent price per bahu is $\pm R p .15$ 22 million ( $\pm € 1,000-1,500)$ per year. The payment should be in cash because many people want to rent rice fields ...

Furthermore, it is likely that the irregularity in cropping patterns, in part, causes massive water demand during dry planting seasons in irrigated rice fields located further down the irrigation system. Respondents $(n=51)$ reported insufficient irrigation water for cultivating rice fields during dry planting seasons. Rice field classes IV and $\mathrm{V}$ risk of suffering from water shortages the most as the start of dry planting seasons in these rice field classes is often shifted into the peak of dry seasons in July and August (see Table 4.4C, Figure 4.7C). For example, some farmers who own rice fields belong to class $V$, such as in Bobos, Karangmulya, Patimban, and Rancadaka villages, Subang district, and Sukra and Patrol villages, Indramayu district, reported that they are unable to pursue dry planting seasons because of lack of access to irrigation water. The persistent irrigation water shortages during dry planting seasons in water-deficit prone rice fields may also be partly related to the 'urbanization' along irrigation networks. Respondents $(n=26)$ mentioned that the decrease in access to irrigation water might be related to the increase of water users. Previous studies have mentioned that population growth and urban 
development have influences on access to irrigation water (Strauß 2011, Bao and Fang 2012). One of the farmers mentioned:

...water deficits happen during dry months because water is used by upper rice fields and other users (southern regions). Only they who have access to water can cultivate rice fields during dry planting seasons.

Table 4.4. Examples of locations of deviations in cropping schedules in irrigated rice fields served by Ir. Djuanda reservoir in West Java detected using time-series remote sensing data. Table 4.4 corresponds to Table 4.2 and Figure 4.7.

\begin{tabular}{cccll}
\hline ID & Latitude & Longitude & \multicolumn{1}{c}{ Reasons } & \multicolumn{1}{c}{ Likely Factors } \\
\hline A & -6.4125 & 107.8623 & $\begin{array}{l}\text { Delay in wet season planting } \\
\text { dates }\end{array}$ & Economic motives \\
B & -6.4000 & 107.6123 & $\begin{array}{l}\text { Alternating double- and } \\
\text { triple-cropped irrigated rice } \\
\text { fields }\end{array}$ & Economic motives \\
C & -6.2458 & 107.8401 & $\begin{array}{l}\text { (a) Delay in wet season } \\
\text { planting dates because of } \\
\text { severe flooding events. } \\
\text { (b) Planting failure due to } \\
\text { lack access to irrigation water } \\
\text { during dry planting seasons. } \\
\text { Change of control from the } \\
\text { central government on } \\
\text { cropping schedules }\end{array}$ & $\begin{array}{l}\text { Coping strategy, Weather } \\
\text { variability, }\end{array}$ \\
Geographic location, & Farmers' interaction \\
D & -6.2458 & 107.4461 infrastructure \\
\hline
\end{tabular}

\section{B. Weather variabilities}

Weather variabilities are intuitively one of the critical reasons that influences cropping schedules. Weather variabilities can be categorized into non-extreme and extreme events. The former refers to regular seasonal weather changes and the latter refers to events that likely result in flooding and water deficits in rice fields. Firstly, non-extreme weather events play a role in supporting land preparations. Farmers do not start the tillage until irrigation water to sustain wet planting seasons is perceived sufficient. Farmers $(n=12)$ mentioned that a sufficient amount of rainfall is needed to complement irrigation water to support synchronous tillage or quick planting during wet planting seasons:

Water discharge from irrigation channels is small. To start wet planting seasons, farmers need a significant amount of water for tillage. After fallow, cracks in dry soil is wide. If irrigation water discharge is low, it might require one week to fill cracks in 1-2 Ha rice fields. If rainfall is present, tillage can be performed together and faster.

The concerted planting is likely associated with strategies to reduce or spread the risk of crop damages resulting from rat, pest, disease, or bird attacks during growing periods. This finding is coherent with that of previous studies mentioning that farmers adjust planting dates to avoid crop damages from bird and rat attacks (Bernsten and Rachim 1982). Additionally, extension officers 
mentioned that delays in planting dates might also be connected to the habit of farmers that exorbitantly pond rice fields with irrigation water before tillage and rice transplanting. This particular practice is partly related to the weed control mechanism (Ampong-Nyarko and Datta 1991, Islam and Molla 2001). Nonetheless, this finding is coherent and, at the same time, adds insights to the conclusion of Sawano et al., (2008) who mentioned that the cropping calendar was well expressed as a function of cumulative precipitation from the onset of wet seasons.

Secondly, extreme weather variabilities, resulting in flooding and water-deficit events, cause severe impacts to rice fields (Naylor et al. 2001, Surmaini et al. 2014). During a strong La-Niña year, the areas of rice fields affected by flooding are likely larger than those of non-extreme year. Higher river discharge during extreme weather years may cause dike failures in main rivers or their tributaries. For example, farmers reported that the dike of Cipunagara river failed in January 2014, and a flood event occurred in rice fields that were at the time of a fallow period (see Table 4.4C, Figure 4.7C). According to farmers, the flood event in January 2014 was the most extreme since the 1980s. Farmers, water managers, and extension officers $(n=17)$ in Subang district reported:

Flooding often occurs in January and February. Usually, there is no flood in March; flood occurs only until the end of February. Flooding in 2014 was the worst;

Flooding happened due to the dike breach in January 2014;

Farmers mentioned that noticeable impacts of flooding and water-deficit events are economic damages and time losses (Thieken et al., 2008, Merz et al., 2010, Hallegatte 2014). Damages or losses can be discriminated into either direct or indirect effects. Direct economic damages are closely associated with growing stages of rice fields during disasters. The more mature rice plants affected by disaster events, the higher the potential financial losses experienced by farmers. An example of indirect economic damages is related to the inability of farmers to pursue dry cropping seasons because of the insufficient growing time, lack of financial capital, or lack of economic feasibility. Farmers often need to expend additional costs for continuing rice cultivation after disruptions in cropping schedules. Furthermore, respondents $(n=67)$ agree that flooding events result in delays in wet planting seasons, and cause losses in available planting time. It is likely that the longer the duration of flooding events, the longer the delay in wet season planting dates, which subsequently results in late dry season planting dates, and partly contributes to the insufficient planting time for pursuing dry planting seasons. Interestingly, farmers in rice fields class $\mathrm{V}$ mentioned that smaller flooding events tend to cause a greater asynchronous planting date compared to that of larger flood events. This pattern is plausible because a large number of farmers simultaneously cannot 
practice rice cultivation when rice fields are affected by an extensive flood event:

... after small flooding events, the similarity in planting dates among rice fields is lesser. However, after a large flood event, the similarity in planting dates are greater.

Another example of indirect losses is related to social unrest. Water competitions frequently arise when rice fields located in different classes need a massive amount of water at the same time during dry planting seasons. The competition frequently happens among farmers who own rice fields in the same irrigation channels. However, it seems that the water competition is fiercer among farmers with different rice field classes or sub-districts.

\section{Geographic locations}

Geographic locations emerge as one of the issues that potentially disrupts cropping schedules. This factor is associated with the spatial characteristics of rice fields and access to irrigation water. Respondents $(n=15)$ mentioned that the rice agroecosystem in the study area could be distinguished into two categories: normal (sawah darat) and swampland (deep and semi-deep) rice fields (sawah lebak). Sawah darat has good access to irrigation water during both wet and dry planting seasons compared to that of sawah lebak. Swampland rice fields mostly are located near coastal areas, at a relatively low elevation, far from primary irrigation channels, have poor drainage and irrigation infrastructures, and scheduled last to receive irrigation water. Swampland rice fields are often, but not always, associated with the rice field class $V$. These characteristics, partly, make these rice fields prone to flooding and water-deficit events during wet and dry planting seasons, respectively. Surface runoff accumulates in low-lying rice fields and is frequently difficult to drain during wet planting seasons partly because of inadequate drainage systems. Respondents $(n=21)$ described that farmers resort to exercising late wet season planting dates, waiting accumulated water to subside or evaporate: ... when farmers plant in December or January, seedling beds are often destroyed by flooding. Thus, the planting time is usually delayed until the end of February.

Interestingly, the perception of farmers about access to irrigation water seems to influence planting dates. Frequently suffered from water-deficit events during dry planting seasons, farmers decide to neglect or completely abandon the cropping calendar. For example, farmers in Babelan sub-district, Bekasi cultivate rice fields based on water availability either from irrigation or river channels, especially during dry planting seasons. An extension officer of Babelan mentioned that the irrigation water schedule is irregular, and farmers completely do not follow the cropping calendar: 
Farmers in Babelan cultivate rice fields according to water availability; farmers do not follow the cropping calendar... Planting dates depend on water availability ... Farmers in Pantai Hurip, Hurip Jaya, and Muara Bakti villages plant whenever water is available and not saline ... irrigation water for Bekasi is inadequate...

\section{Coping strategies}

Coping strategies emerge as a reason that potentially disrupts cropping schedules. Coping strategies are the ability of farmers to face and manage adverse conditions that afflict their farming practices (UNISDR 2009b). Coping strategies are connected with the weather variability factor. Table 4.5 lists coping strategies employed by farmers to reduce potential impacts of flooding and water-deficit events in irrigated rice fields during wet and dry planting seasons, respectively. It is worth mentioning that the list is not exhaustive and only includes coping strategies that directly affect planting dates. In reality, farmers exercise a broad range of coping strategies at the household or community level to reduce potential impacts of disaster events on their livelihoods. For example, farmers may work as farm labors in other villages, migrate temporarily to bigger cities (e.g., Jakarta) and work in non-farming sectors, or ask more remittances from relatives abroad.

It seems that the decision for pursuing particular measures to reduce disaster impacts on rice cultivation may result from the perception of farmers about natural hazards and availability of resources. For example, farmers in Kebondanas, Subang district use hydro pumps to obtain water directly from irrigation channels or rivers as a reaction to water-deficit events during dry planting seasons. The possible measures may also be inspired by individual experiences or discussions among stakeholders (musyawarah). The collective stakeholders' actions seem to enhance the results of the selected strategies. For instance, farmers in Pangarengan village, Subang district may dam a river or divert used irrigation water to water-deficit rice fields. Depending on water availability, stakeholders (e.g., water managers, extension officers, and farmers) may tailor water distribution and strictly employ continuous supervisions until irrigation water reaches the designated rice fields to cope with emergency situations during dry planting seasons (giring gilir).

It is worth noting that farmers may not be able to perform any corrective strategies if natural hazard impacts surpass the coping capacity of farmers. For example, farmers could not perform any coping strategies to initiate rice cultivation according to regular cropping schedules during the dike failure event in Pamanukan sub-district, Subang district in January 2014:

In January 2014, it was impossible for farmers to do any measures due to extreme flooding; 
Planting dates were delayed in flooded rice fields. Farmers can only wait for flooding to subside...

Table 4.5 Example of coping strategies to flood and water-deficit events that influence cropping schedules.

\begin{tabular}{|c|c|}
\hline Flooding (wet planting season) & Water deficit (dry planting season) \\
\hline $\begin{array}{l}\text { - Collective decision to pursue normal } \\
\text { planting and face the risk of being } \\
\text { affected by flood events }(n=4) \\
\text { - Delaying wet season planting dates } \\
\text { ( } n=16 \text { ) } \\
\text { - Having a longer vegetative phase in } \\
\text { seedling beds, approximately } 30-40 \\
\text { days } \\
\text { ( } n=4 \text { ) } \\
\text { - Making seedling beds in a higher } \\
\text { elevation fields ( } n=5 \text { ) } \\
\text { - Pumping water out from flooded rice } \\
\text { fields ( } n=15 \text { ) } \\
\text { - Strengthening river dykes with soils, } \\
\text { sand sacks, and bamboo ( } n=14 \text { ) } \\
\text { - Fixing the dyke failures and rice field } \\
\text { embankments } \\
\text { ( } n=13 \text { ) } \\
\text { - Seed re-sowing and rice plants } \\
\text { re-transplanting ( } n=22 \text { ) } \\
\text { - Looking for wild rice plants or buying } \\
\text { extra rice plants for re-planting } \\
\text { ( } n=12 \text { ) } \\
\text { - Planting earlier than normal } \\
\text { cropping schedules ( } n=5 \text { ) }\end{array}$ & $\begin{array}{l}\text { - Starting early dry planting seasons } \\
\text { to take advantage of water } \\
\text { availability and remaining soil } \\
\text { moisture ( } n=6 \text { ) } \\
\text { - Pursuing normal planting and face } \\
\text { the risk of being affected by water- } \\
\text { deficit events ( } n=4 \text { ) } \\
\text { - Pumping water from river or } \\
\text { irrigation channels ( } n=31 \text { ) } \\
\text { - Exercising giring gilir (overseeing } \\
\text { the water flow until it reaches the } \\
\text { designated rice fields) ( } n=7 \text { ) } \\
\text { - Damming a river or diverting and } \\
\text { reusing irrigation water from upper } \\
\text { stream rice fields ( } n=5 \text { ) } \\
\text { - Seeking assistance from local } \\
\text { government, asking for aids ( } n=7 \text { ) } \\
\text { - Not pursuing dry planting season* } \\
\text { ( } n=4 \text { ) }\end{array}$ \\
\hline
\end{tabular}

\section{E. Farmer's interactions}

Farmer's interactions are also found to play a role in determining cropping schedules. In this context, farmers' interactions refer to daily interplay between farmers and rice agricultural stakeholders that potentially influences cropping schedules. The scope of the interactions can range from the local to national level, both formally and informally. Items that belong to farmers' interactions include stakeholders' meetings, community events, perceptions of risk of rat attacks, local belief systems, and government controls.

Stakeholder meetings or community events may influence rice planting dates. Respondents $(n=10)$ mentioned that stakeholders in every sub-districts conduct a two-weekly meeting (rapat minggon) to exchange ideas or discuss issues related to farming conditions in their respective sub-districts. The participants consist of, but not limited to, village officers, water managers, 
farmer group representatives, and extension officers. The issues conversed may comprise the cultivation planning, coping strategies to flooding and water deficit events, or condition of agricultural infrastructures. Community events such as Islamic holidays or the election of village leader may also influence planting dates $(n=4)$.

The perception of the risk of rat attacks among farmers influences planting dates during wet and dry planting seasons. Respondents $(n=11)$ explained that both smallholder and large holder farmers are aware of the threat of rat attacks (e.g., rattus argentiventer) that potentially damage their rice cultivation. The problem of rat attacks in West Java has been discussed in previous studies (Holz and Sioe 1965, Tristiani et al. 2003, John 2014). It is found that smallholder and large holder farmers are reluctant to initiate rice cultivation because of the risk of being damaged by rat attacks, and tend to wait until other farmers start cropping seasons. Smallholder farmers mentioned that they prefer to wait for synchronous planting to minimize the risk of being attacked by rats, pests, or diseases during growing periods:

... there was a commando for rice cultivation, now the influence of farmer groups or extension officers on farmers' decisions is weaker. Farmers tend to work individually for self-profit. In fact, farmers seem to wish rats, pests, or diseases afflict rice plants of other farmers who planted first. If the latter is not attacked by rats, pests, or diseases, then the former will follow to cultivate rice fields. If the contrary occurs, then farmers wait a little while for cultivating rice fields.

In this regard, 'local champions' (e.g., respected leaders or large holder farmers) play a role in determining planting dates. It is found that social cohesion, directed by local leaders, among smallholder farmers tend to play a major role in guiding cropping schedules in some villages; while in other villages large holder farmers are the one who tends to navigate planting dates. This finding is coherent with that of previous studies mentioning the influence of social capital (Alam et al., 2016) and key persons in directing the community efforts to coping with disaster impacts (Liu et al., 2008).

Also, the local belief system is found to influence cropping schedules. This finding is not surprising as local beliefs or local wisdom is prevalent and exercised as guidelines for managing rice cultivation in many rice-producing regions in Southeast Asia (Lansing et al., 2009). Respondents $(n=14)$ described that farmers in several villages (e.g., Compreng sub-district) choose not to perform rice transplanting in the first three weeks of May (kemeian). The farmers believe that the growth of rice plants will not be optimal if planting dates are set within the period. A polarized belief was identified in the study area about kemeian: 
... Farmers in this area (Blanakan sub-district) believe in kemeian. Farmers do not make seedling beds until the middle of May. Much crop diseases emerge in May, causing the plants in seedling beds stay small...;

... farmers in swampland rice fields affected by flooding (also Blanakan sub-district) do not follow kemeian;

... farmers in Legonkulon sub-district do not agree with kemeian ...

Furthermore, cropping schedules may also be influenced by the change in the rice agricultural control from the central government $(n=14)$. Before 1998 (new order era), the rice agricultural system was strictly regulated by a topdown approach (Lukas 2013). Farming practices and inputs, such as planting dates or crop varieties, were tightly controlled by the central government. After 2000 (regional autonomy era), the strict regulation of farming practices from the central government loosened. It seems that farmers perceive that they gain greater independence in managing their farming practices. One of the respondents mentioned that the years from 1998 to 2001 marked the change in cropping schedules. However, analyzing the time-series remotely-sensed data in Telagasari village, Karawang district, it is found that the shift of planting dates was started in the wet planting season in 2003 (see Table 4.4D, Figure 4.7D). It seems that this opportunity was also used by farmers to adjust planting and harvesting dates to more favorable conditions. On the other side, nonetheless, farmers in the rice fields class $V$ frequently associate the change of government control as one of the reasons for the water shortage events during dry planting seasons:

... during the new order era, flood duration in swampland rice fields (sawah lebak) might reach two months; however, farmers could still plant two times. Irrigation water was available during dry planting seasons, but now irrigation water does not reach this area (rice field class $V)$.

\section{F. Agricultural infrastructure}

It is found that agricultural infrastructures potentially influence cropping schedules. Agricultural infrastructures encompass physical resources for supporting rice cultivation, including the conditions of irrigation, drainage networks and river channels, rice varieties, and farming labors, among others.

Respondents $(n=28)$ mentioned that many drainage and river channels located close to coastal areas suffer from narrowing and shallowing. The sediment transported from upper stream areas may have a role in the narrowing and shallowing processes of drainage or river channels. Farmers and extension officers also mentioned that the disappearance of the irrigation, river, and drainage channels is partly due to the conversion of these networks into rice fields, fish ponds, or settlements. The deteriorating conditions of irrigation and 
drainage networks partly contribute to disruptions in irrigation water distribution, leading to the irregularities in planting dates. Also, poorly maintained drainage and river channels may prolong flood depth and duration in rice fields, causing a longer delay in wet season planting dates. Respondents $(n=53)$ frequently reported spilled water due to the inadequate capacity of irrigation channels to convey irrigation water to rice fields:

... water shortages happen in Tanjung Tiga village (Blanakan subdistrict, Subang district) ... the capacity of irrigation channels is not adequate for the water flow, the embankment of irrigation channels is low, drainage channels are shallow and narrow ... the water spills along the channels. Irrigation water cannot reach the designated rice fields.

Furthermore, rice varieties also influence cropping schedules $(n=13)$. Large holder and tenant farmers prefer to plant rice varieties with a longer growing duration (135-150 days), such as Oriyza sativa Glutinosa (beras ketan), while smallholder farmers prefer to plant shorter growing duration rice varieties (115-125 days), such as Oryza sativa Poaceae (Ciherang). Rice plants harvested by the former is mainly for sale while the yield harvested by the latter is aimed for self-consumption. Farmers who prefer rice paddies with longer growth periods tend to practice early transplanting to ensure synchronous harvesting with those planting shorter growth period rice varieties. It seems that the selection of rice varieties is also, in part, influenced by the tenure and market price. One of the farmers mentioned that the market price of longer growth duration rice varieties is higher than that of shorter growth duration rice varieties:

... the cost of renting rice fields is expensive and is mostly based on the market price of beras ketan (Oriyza sativa Glutinosa). So, farmers who rent rice fields prefer to plant the beras ketan variety ...

Farmers $(n=3)$ mentioned that the availability of labor farmers influence cropping schedules. A shortage of labor farmers for rice transplanting frequently occurs because of the concurrence between great harvesting and transplanting periods. Labor farmers prefer harvesting to transplanting jobs because of the higher income of the former than the latter. Furthermore, it is found that farmers commonly make an informal contract with labor farmers (mediated by middleman) to secure workers for tillage, transplanting and harvesting activities. However, it seems that the 'ownership' of specific working areas by labor farmers may increase the risk of delays in planting dates. A tillage labor may perform land preparation activities for a vast area of rice fields. Additionally, farmers often must adjust the tillage and transplanting dates to the tight schedule of labor farmers. Studies mentioned that the problem of labor shortages in rural areas are associated with the increase of off-farm employment and improvement of rural transports to urban areas, enabling the annual or monthly basis migration (Collier et al., 1982). 


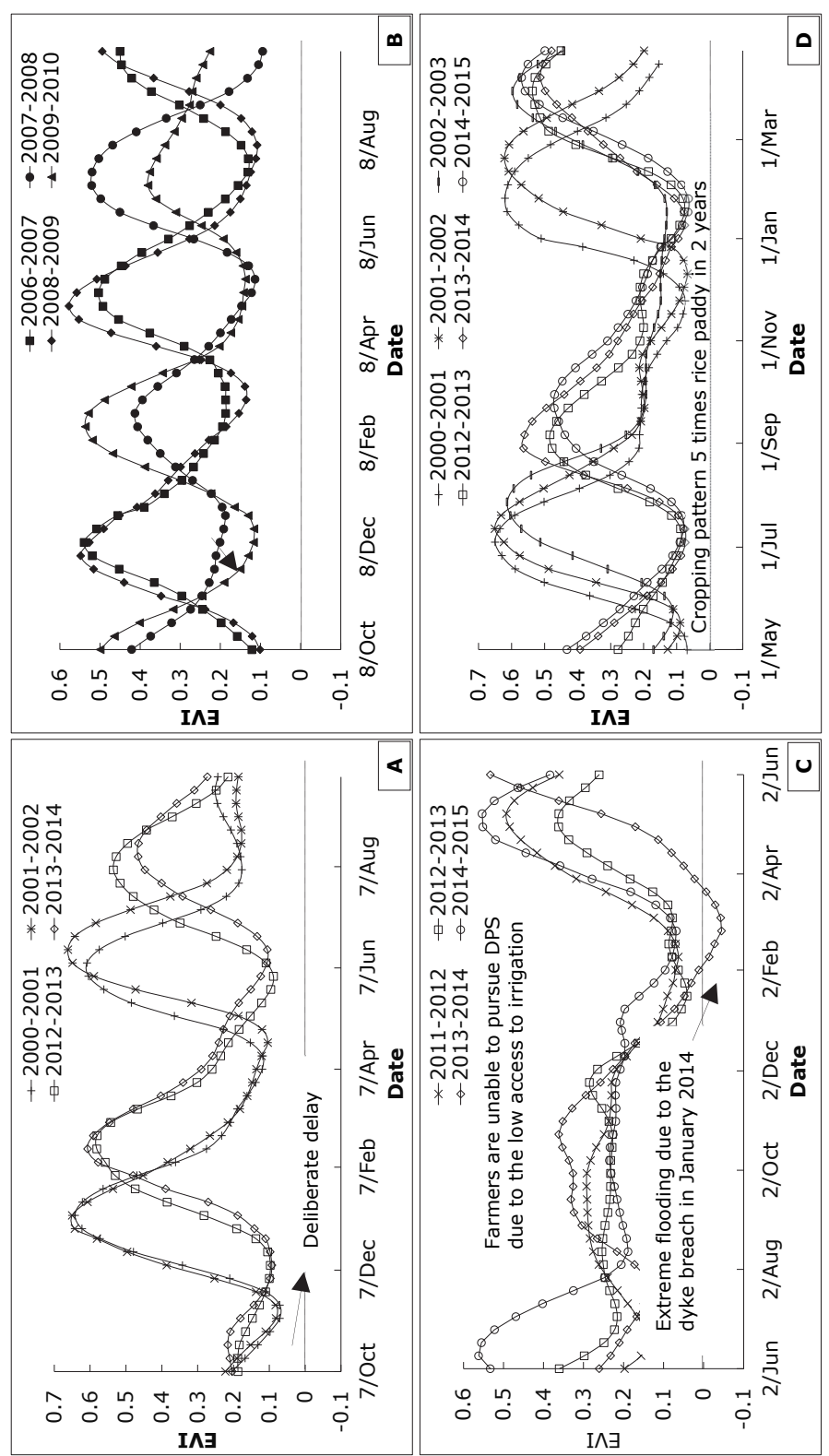

Figure 4.7 Examples of reasons for disruptions in cropping schedules derived from the time-series Enhanced Vegetation Index (EVI) dataset (average $5 \times 5$ pixels). (A) Delay in planting dates until the middle of December (e.g. 2012/13) to avoid harvesting difficulties during wet seasons; (B) Alternating double- (e.g. 2006/07) and triple- (e.g., 2009/10) rice cropping cycle; (C) Farmers resort to delaying wet season planting dates due to flooding events; (D) Shift in cropping schedules due to a change in government control on farming practices since the wet planting season in 2003. Start of Season is when the EVI value is 0.1 during a growing phase. Reasons and locations were obtained through in-depth interviews. Figure 4.7 corresponds to Figure 4.2 and Table 4.4. 


\subsubsection{Bow Tie analysis}

Figure 4.8 shows the result of the Bow-Tie analysis with the disruption in cropping schedules as the top event. The contents of the Bow-Tie analysis were obtained from the in-depth interviews and qualitative content analysis. The Bow-Tie analysis connects and visualizes the relationship between potential causes and consequences of the top event. The potential causes are reasons for disruptions in cropping schedules, comprising economic motives, weather variabilities, geographic locations, farmers' interactions, and coping strategies. Coping strategies, efforts to reduce potential damages, appear as one of the potential causes for disruptions in cropping schedules. Some farmers may wait for flooding to subside and report the event to the local government, while other farmers with access to resources may drain water from their submerged rice fields using hydro pumps. The consequences are potential impacts if the disruption in cropping schedules materializes into disaster events, including harvest failures, yield quality and quantity reductions, and livelihood disruptions, among others.

The Bow-Tie analysis also provides foundation for identifying potential prevention or corrective barriers to reduce potential disaster impacts in irrigated rice fields. For example, as a preventive barrier, investment in the rehabilitation of river or irrigation channels may minimize the spill-over and loss of water during irrigation distribution, reducing the risk of cropping schedule disruptions. Furthermore, Figure 4.8 adds an element of intermediate events to the Bow-Tie analysis. This study particularly interested in the loss of control over the implementation of cropping schedules. The loss of control over other activities that are connected to the top event, such as farming labor availability or irrigation infrastructure conditions, is termed as intermediate events. These intermediate events may result from the ineffective implementation of preventive or corrective barriers, which may lead to the top event and consequences. It is worth noticing that Figure 4.8 does not include the escalation factor and escalation factor barrier. The inclusion of these categories may obscure the aim of the Bow-Tie analysis, which is to understand the progression from potential causes, top event, to consequences and the identification of unsafe conditions. As an example, an individual smallholder farmer may not able to afford the cost of pumping water from the closest river to rice fields (escalation factor); however, cost sharing among smallholder farmers may enable such an attempt and reduce the risk of crop damages (escalation factor barrier).

The Bow-Tie analysis exposes several insights that need to be considered to reduce the potential damages from adverse events in irrigated rice fields. Firstly, multiple potential causes exist, and they may manifest in a single or multiple consequences. This finding suggests that partial intervention on potential causes of disruption in cropping schedules may not directly result in 
a decrease in potential damages. However, comprehensive and continuous efforts to interrupt the progression from potential causes to the top event are likely reduce the vulnerability. Additionally, the progression indicates that potential causes may generate intermediate events before the actual top event occurs and materializes into consequences. This finding implies that stakeholders have opportunities to mobilize resources to perform preventive or corrective barriers before potential causes turn into disaster impacts. This result also advocates that the lack of capacity to perform preventive and corrective barriers from rice stakeholders may exacerbate potential disaster impacts. For example, flooding accumulating in low-lying rice fields may be prolonged because of poor drainage channel conditions and lack of access to hydro pumps to drain ponding water.

Secondly, the mismanagement of farming practices in rice fields may influence the outcomes of other rice fields. In other words, the vulnerability may increase because of the irregularity in cropping schedules performed by other farmers. For example, intensive triple-rice cropping cycle or irregular planting dates may generate habitat and food for rice pest and disease reproduction, jeopardizing rice cultivation in the next season or other rice areas. Another example is that farming groups may adjust their planting dates for benefits of their groups, which inevitably create water-deficit problems in other rice field classes located at the tail end of irrigation channels. Finally, the Bow-Tie analysis exposes incorrect procedures performed to address unsafe conditions in irrigated rice fields. For example, farmers use chemical pesticides or insecticides to eradicate threats of rice pest and diseases. This negative coping strategy may result in pest outbreaks due to the lack of natural enemies of rice pest and diseases. Later, farmers tend to use pesticides with higher chemical substance to suppress the increasing threats of rice pests and diseases, repeating the same loop of negative coping mechanisms.

Furthermore, the elements of the Bow-Tie analysis are categorized into natural hazards, vulnerability, and disaster impacts, as shown in Table 4.6. The BowTies analysis demonstrates that the interaction between natural hazards and vulnerability potentially materializes in a range of disaster impacts. Unsafe conditions that contribute to the increase of vulnerability of farmers to natural hazards in the study area have also been exposed. Unsafe conditions take tangible and intangible forms and may occur from the farm to national level, comprising dangerous locations, unsustainable farming activities, unsuitable coping strategies, fragile infrastructures, and inaccurate perceptions. The result clarifies the multi-dimension and multi-level nature of vulnerability (Adger 2006). Water managers, extension officers, or risk reduction officers are likely able to reduce the vulnerability of farmers to natural hazards in the study area by addressing the unsafe conditions. 
Table 4.6. Hazard, vulnerability, and disaster impacts in irrigated rice fields served by Ir. Djuanda (Jatiluhur) reservoir in West Java.

\begin{tabular}{|c|c|c|}
\hline $\begin{array}{c}\text { Hazard } \\
\text { (Chapter 3) }\end{array}$ & Vulnerability & Disaster Impacts \\
\hline 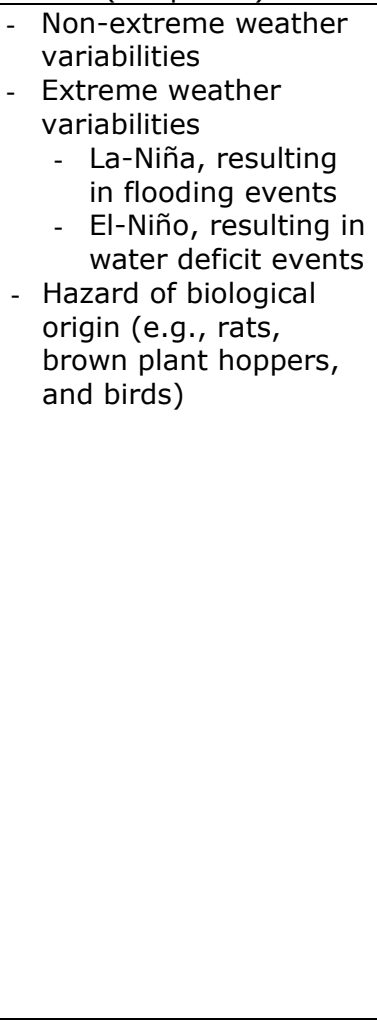 & $\begin{array}{l}\text { Unsafe conditions } \\
\text { Dangerous locations: } \\
\text { - } \quad \text { Relatively low elevation } \\
\text { compared to neighboring rice } \\
\text { fields } \\
\text { - } \quad \text { Near coastal areas } \\
\text { Unsustainable farming activities: } \\
\text { - } \quad \text { Alternating double- and } \\
\text { triple-cropping patterns } \\
\text { - Triple-cropping pattern } \\
\text { Unsuitable coping strategies: } \\
\text { - Pumping water directly from } \\
\text { main irrigation channels } \\
\text { - Water competition } \\
\text { - } \quad \text { Excessive use of chemical } \\
\text { pesticides } \\
\text { Fragile infrastructures: } \\
\text { - Inadequate and deteriorating } \\
\text { quality of irrigation, river, and } \\
\text { drainage channels } \\
\text { - } \quad \text { Lack of labor farmers } \\
\text { - } \quad \text { Government control of } \\
\text { - agriculture system } \\
\text { Local belief system }\end{array}$ & $\begin{array}{ll}\text { - } & \text { Crop damages } \\
\text { resulting in seasonal } \\
\text { yield quality and } \\
\text { quantity reductions } \\
\text { - } \quad \text { Planting failures } \\
\text { - } \quad \text { Harvest failures } \\
\text { - } \quad \text { Livelihood } \\
\text { disruptions and food } \\
\text { insecurity }\end{array}$ \\
\hline
\end{tabular}




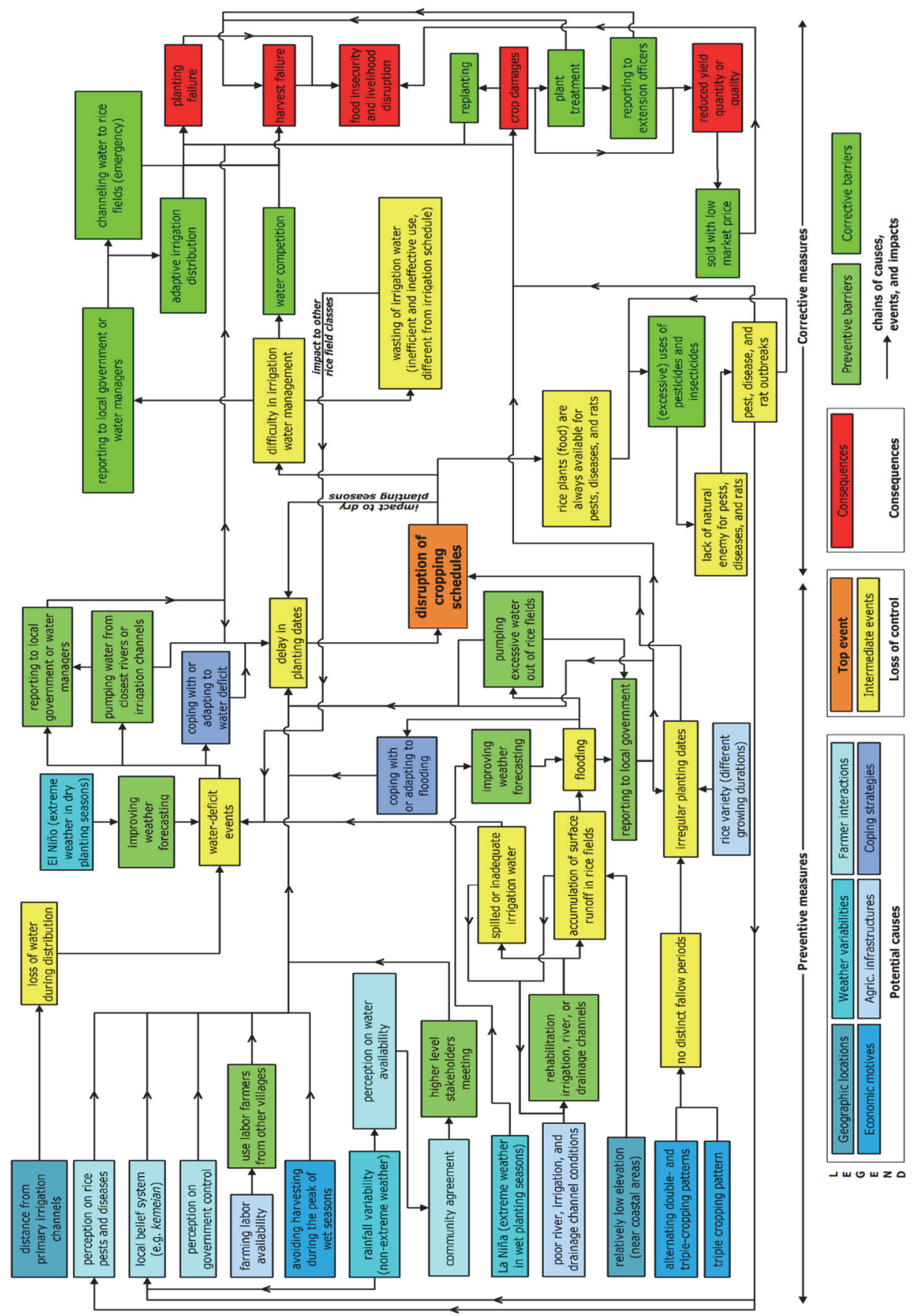

Figure 4.8 Bow-Tie analysis of reasons for disruptions in cropping schedules in irrigated rice fields served by Ir. Djuanda reservoir in West Java. Reasons comprise economic motives, weather variabilities, geographic locations, coping strategies, farmers' interactions, and agricultural infrastructures. 


\subsubsection{Reducing vulnerability to natural hazards}

This study has demonstrated that unsafe conditions play an essential role in increasing the vulnerability of farmers to natural hazards. Since reducing vulnerability may also contribute to the decrease of the risk of natural hazards, addressing unsafe conditions that result from daily on-the-farm decisions is one of the means to reduce potential impacts of natural hazards in irrigated rice fields. The following recommends ways to reduce the vulnerability of farmers to natural hazards by specifically addressing unsafe conditions in irrigated rice fields.

Addressing unsafe conditions related to economic motives can reduce the vulnerability and increasing the resilience of farmers to natural hazards. Farmers with good access to irrigation water realistically attempt to improve their livelihoods by adopting an intensive rice cropping pattern. In this respect, local government officers should improve awareness that farmers, including those who are poor and vulnerable, can progress their economic conditions through livelihood diversification, which is also likely to increase the resilience of farmers to unexpected disaster impacts (Van Den Berg 2010, Sun et al., 2012). Also, extension officers should encourage farmers to focus on sustainable rice production that does not neglect the ecological aspect, social cohesion, or compromise the ability of other farmers for cultivating rice fields (Carson 2002, Gathorne-Hardy et al., 2016). For example, instead of focusing solely on intensive rice monoculture, farmers are encouraged to adopt balanced cropping practices. One of the forms of balanced cropping practices is the adoption of a double-rice cropping cycle with fallow periods in between planting seasons. Farmers may optimize the use of rice fields for planting cash crops (e.g., onions, tomatoes, long beans) or adopting a rice-fish system. Studies have demonstrated that balanced cropping practices provide long-term benefits through ecosystem services to rice farmers in terms of pest control, nutrient cycling, and rice-fish culture, compared to intensive cropping practices (triple-rice cropping cycle) (Tong 2017). An intensive cropping practice adds one more planting season; however, it has evidently deteriorated environmental conditions surrounding rice fields and does not contribute to economic improvements of farmers (Tong 2017).

Addressing unsafe conditions associated with fragile infrastructures may improve the productivity of irrigated rice fields. For example, efforts to improve poor infrastructure conditions can secure water availability and reduce the risk of crop damages from flooding and water-deficit events during wet and dry planting seasons, respectively. Previous studies have provided evidence that improvements in irrigation performance by enhancing land and water productivity are useful for alleviating poverty in rural areas (Hussain et al., 2006, Matsuno et al., 2013). Such efforts may be performed using a range of 
structural measures, namely the construction of reservoirs or rehabilitation of irrigation channels, among others.

Furthermore, farmers often cope with impacts of natural hazard occurrences using their limited resources. However, it seems that strategies focusing on building the resilience and reducing the vulnerability of farmers to natural hazards are likely to be more effective for decreasing the potential damages and losses in the long-term (Dalgliesh et al., 2016). These efforts can also be performed using a range of non-structural measures, such as awareness programs on adverse impacts of unsuitable coping strategies, training and education on best farming practices, or livelihood diversification. Also, the adoption of insurance mechanisms can be useful for transferring the remaining risk associated with natural hazard occurrences (Pasaribu 2010).

The present study finds that farmers' interactions may contribute to unsafe conditions and lead to disruptions in cropping schedules. The coordination among stakeholders may be beneficial for addressing constraints limiting rice production and succeeding the implementation of stipulated cropping schedules for the common good. However, evidence shows that disruptions in official cropping schedules can be partly attributed to decisions of farmer groups, indicating the downside of social capital. In this respect, farmers are recognized as members of an extensive irrigation system regulated by an official cropping calendar. It seems that social capital is used as a tool to achieve objectives of a particular group while compromising the right of other farmers to have equal opportunities to irrigation water at the broader irrigation system level (Pain and Levine 2012). Extension officers, together with local government officers, should design strategies to increase the awareness of farmers of regulated irrigation distribution and cropping calendar benefits. Additionally, instead of leaving the system to work under a free market system, it seems that policy interventions are required for untangling disruptions in cropping schedules. Further studies to stimulate the compliance of farmers to the official cropping calendar are suggested.

Finally, this study emphasizes that addressing unsafe conditions requires creativity that goes beyond on-the-farm and community decisions. Reducing the vulnerability requires local stakeholders to collaborate with external stakeholders continuously. For example, information about the probability of El Niño-Southern Oscillation (ENSO) provided by the national meteorological office (BMKG-Badan Meteorologi dan Geofisika) is indispensable for supporting farmers in designing well-informed cropping plans. Given the importance of weather and farming information, the national government officials should focus on supporting access to such data, for example, by improving tools and methods for obtaining and sharing updated critical information among stakeholders. Also, extension officers or water managers may need to 
proactively learn from rice farming and water management practices that have been proven to be successful in other rice-producing regions. The officers need to be connected with research institutes, such as the International Rice Research Institute (IRRI), to obtain updated information on challenges in rice farming. At the same time, studies for improving flood- and drought-tolerant rice varieties and devising environmentally-friendly cropping practices must be continuously encouraged (Ward et al., 2014, Haefele et al., 2016, Sarangi et al., 2016). Furthermore, the availability of farming information should be supported by the ability of farmers in quantifying changes (e.g., rainfall, rice disease symptoms) and interpreting available data (Van Den Berg and Jiggins 2007, Winarto et al., 2011, Guo et al., 2015). For example, farmers can be trained to collect and interpret rainfall data through Farmer Field Schools (FFS).

\subsection{Discussion and conclusion}

This paper has successfully investigated disruptions in cropping schedules in irrigated rice fields served by Ir. Djuanda (Jatiluhur) reservoir in West Java using different analysis tools to improve understanding of the vulnerability of farmers to natural hazards. Firstly, using the time-series remotely-sensed dataset, the present study has revealed that ongoing cropping schedules are significantly different from the cropping calendar stipulated by the provincial government of West Java and PJT II during wet and dry planting seasons. In the same vein, Sianturi et al. (2018) has successfully mapped cropping patterns in northern districts of West Java and found that for the last fourteen years (2000-2014), wet and dry season planting dates in the study area may range from the first week of November to the third week of March and from the end of March to the second week of August, respectively. Thus, there have been more than five classes of planting dates performed by farmers in the last decade (see Table 1.1). The finding may also indicate that different references for planting dates exist among rice farmers. Both farmers who use the official calendar as their reference for planting dates and farmers who perform planting dates according to their habits and perceptions of socioeconomic and environmental conditions are common in the study area. On the one hand, farming practices and the efficiency in irrigation water uses need to be improved so that farmers can adapt to changing conditions and improve rice productivity. On the other hand, these results raise a question whether the official cropping calendar and irrigation distribution schedules need to be adjusted to suit changing environmental and socio-economic settings. Secondly, using responses from farmers, extension officers, and water managers, the present study has shown that disruptions in cropping schedules can be attributed to several reasons, including economic motives, weather variabilities, geographic locations, coping strategies, farmers' interactions, and agricultural infrastructures. Thirdly, this study has demonstrated using the Bow-Tie analysis that the vulnerability can be partly traced back to daily 
farming activities and socioeconomic and environmental processes. Finally, the present study has pinpointed tangible and intangible unsafe conditions that are likely to increase the vulnerability of farmers to natural hazards, including dangerous locations, unsustainable farming activities, unsuitable coping strategies, fragile infrastructures, and inaccurate perceptions. Results from this study can be used as inputs by extension officers, water managers, and disaster risk reduction officers for designing pathways for reducing the vulnerability of farmers to natural hazards. Also, it is worth mentioning that findings from this study can be used by disciplines related to rural and agricultural development in less developed and developing countries. For example, vulnerability to natural hazards is closely related to vulnerability to poverty. In fact, poverty is one of the consequences and drivers of disaster events (UNISDR 2008). Disaster events may cause loss of lives, assets, and livelihoods and, increasing the vulnerability of affected people to poverty. Poor people may resort to live in dangerous locations due to their inability to afford safe and legal living space, increasing their vulnerability to natural hazards. In this respect, efforts to address unsafe conditions are likely beneficial for confronting both issues to secure lives and livelihoods of the poor and the vulnerable (UNISDR 2008).

The present study is not without limitations. Firstly, this research used the Start of Season (SOS) as the indicator to investigate disruptions in cropping schedules. The SOS is relatively easy to recognize in the time-series profiles of EVI and precedes other phenology metrics during growing seasons. Other phenology metrics, such as the heading stage or end of season, exist and may be useful as indicators to understand disruptions in cropping schedules. Secondly, reasons for disruptions in cropping schedules and accompanying time-series EVI profiles were obtained through in-depth interviews and field visits. At the same time, the use of the Bow-Tie analysis requires investigators to carefully choose a top event that serves as a common ground and allow discussions among stakeholders. These procedures are labor intensive and time-consuming. Investigators may need to spend time staying in the study location (e.g., one cropping season), observe applied farming practices, and visit same areas several times to clarify respondents' statements. Thirdly, this research primarily utilized the responses of farmers, water managers, and extension officers for understanding unsafe conditions and suggesting ways for reducing the vulnerability of farmers to natural hazards. It is possible that other latent factors that are not revealed by this study exist considering the intricate, multi-faceted, and multi-dimensional nature of vulnerability. Thus, findings from this study should be regarded as exploratory, a guide, and a background for further in-depth studies. Despite the limitations, the present study has provided information for water managers, disaster risk reduction officers, and extension officers for devising strategies and policies for regulating cropping schedules, reducing the risk of natural hazards, and building resilient rice 
agriculture. Further studies are recommended. Studies that probe unsafe conditions in irrigated rice fields should also incorporate the perspectives of other stakeholders, such as academics or business people. Additionally, quantitative studies to monitor changes in the vulnerability of farmers to natural hazards are suggested. 


\section{Chapter 5 Factors influencing Resilience of Farmers to Natural Hazards in Irrigated Rice Fields in West Java}

\subsection{Introduction}

\subsubsection{Background}

Potential disaster damages and losses in irrigated rice fields can be reduced by building the resilience of farmers to natural hazards (UNISDR 2005, Berkes 2007). Resilience is 'the ability of a system, community or society exposed to hazards to resist, absorb, accommodate to and recover from the effects of a hazard in a timely and efficient manner, including through the preservation and restoration of its essential basic structures and functions' (UNISDR 2009b). Resilience also relates to 'the ability of systems or people to effectively respond and adapt to changing circumstances and to develop skills, capacities, behaviors and actions to deal with adversity' (IFRC 2014). Resilience is a multiscale, spatial- and temporal-specific, and dynamic concept (Constas et al. 2014, Cimellaro 2016).

Studies mentioned that resilience is influenced by factors from different aspects, including economic, social, environmental, and institutional, at different spatial and temporal scales (Keil et al. 2007, Zhou et al. 2010, Cimellaro 2016). For example, variables, such as the caste system, local knowledge, cropping calendar, natural hazard, need to be included to represent the influence of local factors on resilience (Gómez-Baggethun et al., 2012, Mavhura et al., 2013, Ranjan et al., 2015). At the household level, factors such as age, education level, landholding size, among others, are often found to contribute to the resilience of farmers to natural hazards (Jülich 2015, Udmale et al., 2015).

The multi-faceted nature of resilience requires various types of information for its analysis (Jones and Tanner 2017). Quantitative, qualitative, and subjective data complement each other to provide a detailed description on interrelationships among determinants of resilience (Jones and Tanner 2017). Researchers also used a qualitative indicator-based approach to capturing essential properties of resilience at the community level, such as risk awareness, flexibility, and learning (Twigg 2007, Becker 2014, Cimellaro 2016). Although some resilience determinants are subjective and may not be able to be generalized to a broader spatial extent, they can be made 'quantifiable' using rating scales or coding schemes (Cimellaro 2016, Jülich 2017). Due to its complexity in measurement, the knowledge of its influencing factors can be used as a 'shortcut' to build the resilience of farmers to natural 
hazards. The factors can also be used as indicators to monitor and enhance the resilience of farmers (Dixon and Stringer 2015, Douxchamps et al., 2017).

Without efforts to enhance the capacity to face unexpected hazardous events, farmers may pursue ineffective pathways to build resilience to future disaster events (Becker 2014). In reality, constraints are present, and farmers may underperform their recovery from adverse events, causing farmers to take longer recovery duration compared with their neighbors. Thus, it is essential to not only to increase the 'potential' capacity but also to enable farmers to optimally manifest their latent capacity into the ability to recover from natural hazards impacts. Using subjective data, researchers may capture the perceptions of farmers on their ex-post or 'actual' ability (Cumming et al., 2005, UNISDR 2009b) and ex-ante or 'potential' capacity (Walker et al., 2004, Becker 2014) to recover from particular adverse events. It is expected that an understanding of characteristics or circumstances that differentiate the recovery level of farmers may support the actualization of capacity into the ability to recover from natural hazard impacts.

For more than a decade, time-series MODerate resolution Imaging Spectroradiometer (MODIS) images have been providing valuable information on vegetation conditions in the earth's surface. The Vegetation Condition Index (VCI) derived from Normalized Vegetation Index (NDVI) or Enhanced Vegetation Index (EVI) has been continuously used for monitoring drought conditions in irrigated rice fields (Singh et al., 2003, Rizatus et al., 2014). The VCI compares the EVI value of a particular DOY with a range of minimum and maximum values in the long-term average year (Kogan 1995b). Thus, the VCI can be used to make a relative assessment of rice field conditions (Quiring and Ganesh 2010). The VCI has also been used in many geographical locations with different environmental settings (Kogan 1997, Jain et al., 2009).

This study aims to investigate factors that influence the resilience of farmers to natural hazards. As previously mentioned, resilience includes the ability of people to recover from disaster impacts. Using irrigated rice fields in Subang district, one of the main rice-producing districts in West Java, Indonesia, this study focuses mainly on the recovery aspect of resilience. We define resilience as the ability of farmers to recover from the recurrent impacts of natural hazard occurrences (hereafter referred to as resilience).

- Firstly, this study provides an overview of rice field conditions in space and time using the VCI during dry and wet planting seasons 2015 and 2016, respectively. Supported by a field visit in August 2016, the VCI is also used to limit the study location to villages affected by an extreme water deficit event during the dry planting season 2015.

- Secondly, this study investigates factors that influence resilience using the multiple linear regression analysis with the stepwise method. 
- Finally, this study analyzes characteristics that distinguish between farmers with different recovery levels using the Analysis Of Variance (ANOVA).

\subsubsection{Study Area}

Irrigated rice fields in the northern districts of West Java (Subang, Karawang, Indramayu, and Bekasi) are one of the primary rice-producing regions of Indonesia. Farmers mainly adopt a double rice cropping pattern. Wet and dry planting seasons start from October to March and April to September, respectively, corresponding to periods of rainy and dry seasons. The national government suggests a cropping calendar for scheduling rice cultivation in the study area (http://katam.litbang.pertanian.go.id/). Irrigation systems also exist to maintain continuous rice production. The most extensive irrigation system is served by Ir. Djuanda reservoir (http://www.jasatirta2.co.id/).

Irrigated rice fields located near coastal areas are prone to flooding and waterdeficit events during wet and dry planting seasons, respectively. Flooding occurs partly because of the low elevation and bowl-shaped topography (swampland rice fields). For example, Yulianto et al. (2015) reported that approximately 20,000 ha irrigated rice fields in Karawang district were submerged during the flood event in March 2010. High tide occurrences may exacerbate flooding duration and depth. During an extreme wet year, river dike failures may be reported. Recently, a dike breach in Cipunagara river occurred partly due to strong river discharge during the wet planting season 2014. Also, water-deficit events frequently occur partly due to extreme dry seasons (Rosanne D'arrigo et al., 2006, Aulia et al. 2016), increasing water users, and deteriorating irrigation channel conditions. Flooding and waterdeficit events reach peaks from the beginning of January to the end of February and from the beginning of August to the end of September, respectively (AsSyakur et al. 2013, Schollaen et al. 2013, Siswanto et al. 2016). The areas of irrigated rice fields affected by flooding and water-deficit events are likely to be greater during strong El-Niño and La-Niña years, respectively (Naylor et al. 2001, Surmaini et al. 2014). Boer and Subbiah (2005) mentioned that the longest dry season duration might reach up to 250 days and rainfall may range from $250-750 \mathrm{~mm}$ in the northern districts of West Java. The potential impacts of flooding and water-deficit events partly determined by rice growing stages and may range from small variations in planting dates to massive harvest failures (Sianturi et al. 2018). Furthermore, it is predicted that changing climate may increase solar radiation, maximum and minimum temperature, and rainfall, potentially reducing approximately $1 \%$ rice yields annually by 2050 in West Java (Amien et al. 1996).

The present study focuses on irrigated rice fields in villages in Subang district that suffered from a water-deficit event in the dry planting season 2015 (Figure 
5.1). The adverse event occurred partly due to a very strong El-Niño year (http://origin.cpc.ncep.noaa.gov), causing massive rice planting failures. Farmers in villages, including Karangmulya, Bobos, and Pangarengan in Legonkulon sub-district; Gempol, Mundusari, Kalentambo, Kotasari, Patimban, Pusakaratu, and Rancadaka in Pusakanagara sub-district; Pusakajaya, Kebondanas, and Karanganyar in Pusakajaya sub-district, could not pursue rice cultivation. Farmers also reported crop damages due to rice blast attacks (Magnaporthe grisea) and strong wind with rainfall during the rice booting stage and harvest period respectively in the wet planting season 2016.

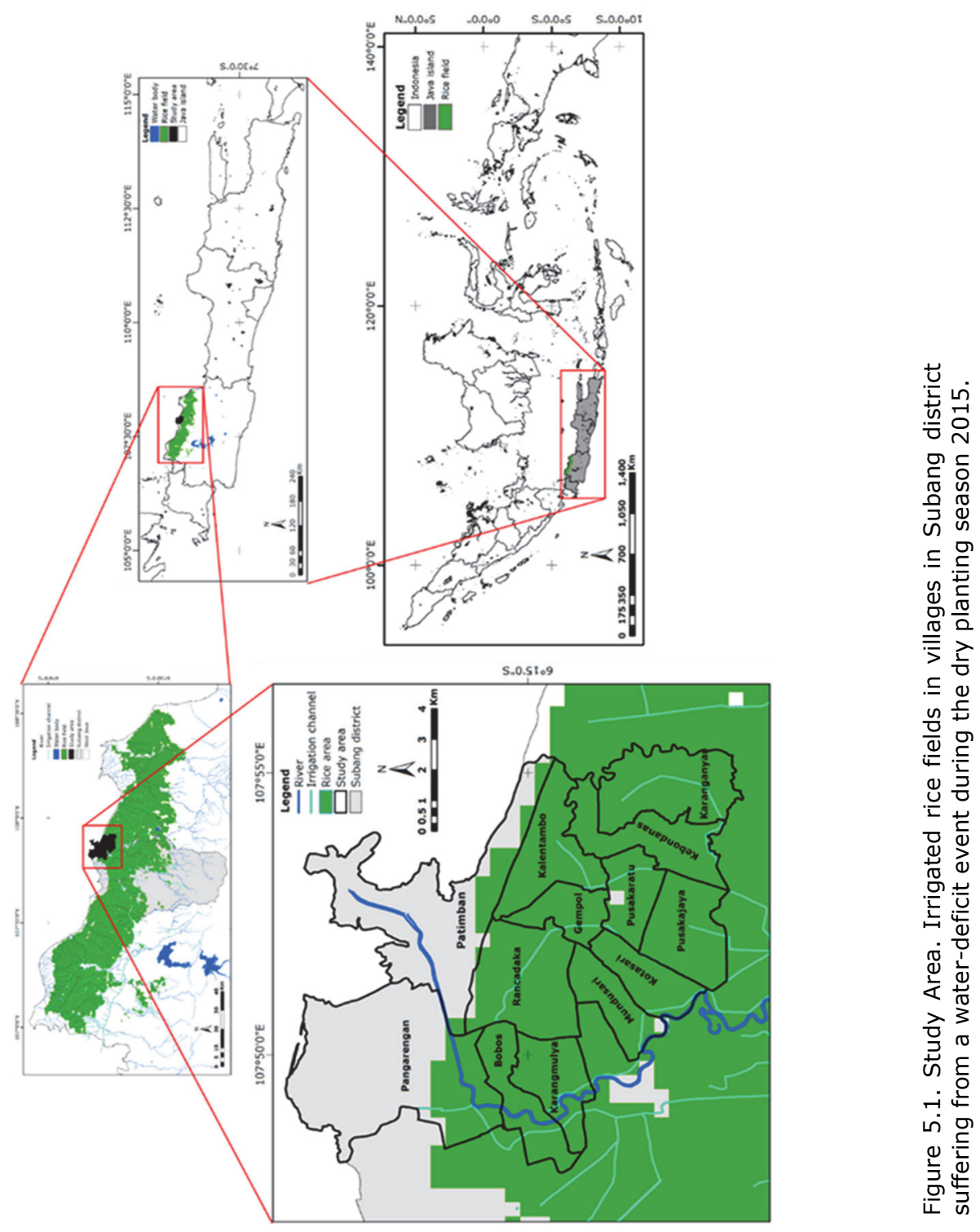




\subsection{Methods and data}

\subsubsection{Conceptual framework}

Figure 5.2 the conceptual framework used to investigate factors influencing resilience. The framework was improved from the studies of Béné et al. (2016) and Sianturi et al. (2018). Sianturi et al. (2018) mapped the cropping pattern in irrigated rice fields in West Java. Béné et al. (2016) studied the resilience of coastal fishing communities to adverse events in Fiji, Ghana, Sri Lanka, and Vietnam. The framework components used in the study are natural hazards, vulnerability, resilience, disasters, impacts, and responses. The components are features that continuously interact with each other and change in space and time. These items are variables used to construct a questionnaire investigating the resilience of farmers to natural hazards in the study area. The elaboration of each component is as follows.

The origins of hazards may be of natural, human-made, or the combinations of the natural and anthropogenic. Natural hazards refer to 'the dangerous physical events that may cause loss of life, injury or other health impacts, as well as damage and loss to property, infrastructure, livelihoods and services, social and economic disruption and, or environmental damage' (UNISDR 2009b). This study focuses on flooding and water-deficit events; however, the hazard of a biological origin associated with rat attacks, rice pests, and diseases are also considered provided their significant contributions to the reduction of rice production in the study area (Holz and Sioe 1965, Tristiani et al. 2003, Singleton et al., 2004, Sudarmaji et al. 2010, John 2014).

Vulnerability refers to 'the characteristics and circumstances of a community, system or asset that make it susceptible to the damaging effects of a hazard' (UNISDR 2009b). The vulnerability of farmers to natural hazards is partly originated from unsustainable rice farming activities. The vulnerability in the present study is represented by cropping schedule factors, including economic motives, geographic locations, weather variabilities, coping strategies, agricultural infrastructures, and farmers' interactions. The factors were the result of a qualitative study exploring unsafe conditions in irrigated rice fields served by Ir. Djuanda reservoir in West Java (in review). The study has contributed to the comprehension of the progression of vulnerability in irrigated rice fields and thus are expected to be useful for improving the understanding of resilience factors.

The interaction between natural hazards and vulnerable conditions may result in disasters. The extent of adverse events may range from the rice field to national level. The potential impacts of natural hazards in irrigated rice fields are influenced partly by responses of farmers to disaster events. These actions 
also influence vulnerability and resilience in space and time. The responses may result from on-the-farm and household decisions, which, to some extent, are influenced by decisions taken at the community level. Finally, the framework views resilience as an umbrella concept for a range of desired system properties. The elements-at-risk in the present study is potential rice production. In this regard, rice production is converted into monetary values for analysis purposes.

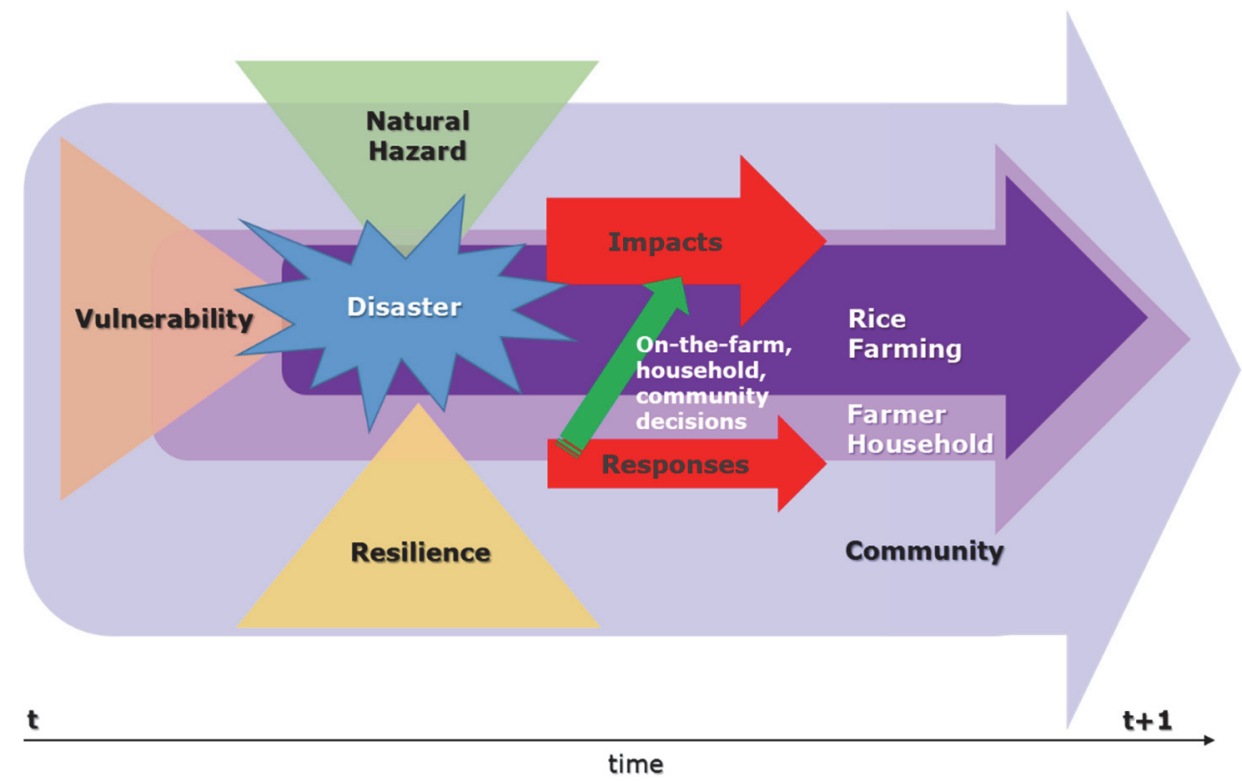

Figure 5.2 Component framework. Each component in the framework is used to construct a questionnaire for investigating factors influencing the resilience of farmers to natural hazards in irrigated rice fields.

\subsubsection{Data collection and analyses}

\section{A. Vegetation Condition Index}

Remote sensing imageries provide insights on understanding the resilience of farmers to natural hazards in irrigated rice fields (Rochon et al., 2003, Déri 2014). The Level 3 atmospherically corrected time series MODIS 8-day 500-m spatial resolution MODIS imageries (MOD09A1) from 2000 to 2016 were obtained from the United States Geological Survey (USGS) (http://earthexplorer.usgs.gov/). The time-series MOD09A1 dataset was stacked and used to derive the time-series EVI. Since EVI correlates with biophysical variables (Gao et al. 2000, Huete et al. 2002), such as the canopy structure or leaf area, it has frequently been used to monitor changes in the vegetation activities or crop phenology (Sakamoto et al. 2005, Evrendilek and Gulbeyaz 2008). The EVI was derived from the near infrared $(841-875 \mathrm{~nm})$, 
red (621-670 nm), and blue (459-479 nm) bands of MOD09A1. The formula to derive EVI is as follows:

$$
\mathrm{EVI}=2.5 \times \frac{\mathrm{NIR}-\mathrm{RED}}{\mathrm{NIR}+6 \mathrm{x} \text { RED }-7.5 \times \mathrm{BLUE}+1}
$$

The time-series EVI dataset was de-noised using the Adaptive Savitzky-Golay filter focusing on the upper envelope (Khan and Shah 2010, Ali et al. 2013b) to enable the observation of spectral profiles and diminish the remaining noise components (e.g., aerosol or bidirectional reflection).

This study uses the work of Sianturi et al. (2018) for obtaining irrigated rice field areas in the northern districts of West Java. The authors have elaborately described the procedure to derive irrigated rice fields using MOD09A1 imageries. The coefficient of determination $\left(R^{2}\right)$ of estimated rice field areas is 0.81-0.93.

Furthermore, the time-series VCI was derived from the time-series EVI dataset. The VCI was used to illustrate rice cultivation conditions during the analysis period (Kogan and Sullivan 1993, Kogan 1995a, Kogan 1997). The formula to derive the VCI is as follows (Kogan 1995a).

$$
\mathrm{VCI}=\left(E V I_{i}-E V I_{\min }\right) /\left(E V I_{\max }-E V I_{\min }\right) * 100 \%
$$

where EVIi refers to the EVI value in the particular DOY. The EVImax and EVImin refer to long-term (2000-2016) maximum and minimum EVI values, respectively (Kogan 1995b). The VCI value ranges from $0-100 \%$. Low and high VCI values indicate good and poor vegetation conditions, respectively (Dalezios et al., 2014). The range between $0-30 \%,>30-60 \%$, and $>60-100 \%$ indicates very poor vegetation, poor, and above normal vegetation conditions, respectively. It is worth mentioning that attributing the VCI $<60 \%$ in irrigated rice fields to water-deficit events without field information may mislead the result interpretation. Farmers may practice fallow, periods when rice fields are left dry and without crops after harvesting. Fieldwork was conducted in August 2016 to confirm actual rice field conditions, whether the low VCI value is associated with water-deficit events or fallow periods. It is worth mentioning that the present study mainly uses the long-term (2000-2016) VCI dataset to derive the minimum and maximum VCI values. The focus of the VCI analysis was mainly in the dry and wet planting seasons 2015 and 2016, respectively because of lack of field data about previous water-deficit events in the study area. 


\section{B. Questionnaires}

A structured questionnaire was used to gather information about factors that influence resilience. The design of the questionnaires was developed based on the conceptual framework used in the present study (see Figure 5.2). The questionnaire consists of six sections and is used to collect data related to farmers' household characteristics, farming activities, natural hazards, cropping schedule factors, quality of life dimensions, and resilience outcomes. Table 5.1 lists variables used in the present study (see Appendix for the questionnaire).

The first section is related to the characteristics of farmers' households, such as education, rice field tenure. The second section pertains to farming activities, presented from the economic, social, institutional, and individual aspects. The third section inquiries about natural hazards, such as the occurrences of flooding and water deficit events, problems of irrigation infrastructures, among others. The fourth and fifth sections are about the resilience outcome, subjective resilience, and community recovery and quality of life dimensions, respectively. The items in these sections have been elaborated thoroughly in Béné et al. (2016). In the fourth section, a question probing the number of seasons needed to recover from damages and losses suffered from the previous events (dry and wet planting season 2015 and 2016 , respectively) is added to the subjective resilience subsection. The sixth section is related to cropping schedule factors. These items are added to incorporate the influences of local factors to the analysis.

Since it is not feasible to visit all affected households, convenience sampling was used to collect data from 132 farmers in August 2016 to represent the affected households (Figure 5.2). The data collection using the questionnaire and interviews was conducted face to face in farmers' houses, accompanied by their family members. Farmers' houses were randomly visited. In several occasions, the data collection was performed in huts in rice fields. Farmers were eligible as respondents if two requirements are satisfied: (1) farmers are currently practicing rice farming, either by owning or renting rice fields (not labor farmers); (2) farmers provide consent to participate in the study. The duration of the survey was not pre-determined. The session was over when respondents completed their questionnaire. To maintain the quality of answers, the interviewer was present during the whole data collection processes and able to communicate with respondents directly. The questions were read and explained if respondents were not able to demonstrate basic reading skills, or could not comprehend the questions. The data collection processes were recorded using a voice recorder. 
Table 5.1 Variables used in this study

\begin{tabular}{ll}
\hline \multicolumn{1}{c}{ Variables } & \multicolumn{1}{c}{ Scale } \\
\hline $\begin{array}{ll}\text { 1. Farmers' household characteristics } \\
\text { - Age }\end{array}$ & \# years \\
- Farming experience & \# years \\
- Tenure of rice fields & self-owned (1) or rent (2) \\
- Areas of rice fields & \# hectare \\
- Education level & no school (1), elementary school (2), \\
& junior high school (3), senior high \\
- Income from the previous season & school (4), undergraduate or more (5) \\
- Dependent family member & \# rupiahs \\
- Farming income of the previous season & \# people \\
- Capital source of the previous season & \# rupiahs
\end{tabular}

2. Farming activities

- Cropping calendar

- Economic aspect

- Social aspect

3. Natural hazards

- Water-deficit event

- Flooding event

- Saline water intrusion

- Irrigation infrastructure problem

- River shallowing and narrowing
- Institutional aspect

- Individual aspect

- Weather variabilities disrupt harvest time in wet seasons

- Weather variabilities disrupt harvest time in dry seasons

- Rat attacks reduce harvest yields

- Brown plant hopper attacks reduce harvest yields

- Ponding water in swampland rice fields due to excessive irrigation water uses

4. Resilience outcome

Resilience score $\left(A{ }^{*} B\right)$

(A) Recovery from the past event

(B) Relative recovery from the past event compared to other farmers in the same village

Community recovery

Subjective resilience

- Capacity to handle a similar future adverse event

- Recovery time (from the previous adverse event provided optimum rice harvest)

5. Quality of life

6. Cropping schedule factors

- Economic motives

- Geographic locations

- Coping strategies

- Agricultural

infrastructures

- Weather variabilities

very disagree (1) - very agree (4)

very disagree (1) - very agree (4)

very disagree (1) - very agree (4)

no problem (0), very low (1) - very

high (4)

no problem (0), very low (1) - very high (4)

no problem (0), very low (1) - very high (4)

no problem (0), very low (1) - very high (4)

no problem (0), very low (1) - very high (4)

Min: 1 - Max: 30

have not recovered (1) - fully

recovered (6)

worst (1) - best (5)

have not recovered (1) - fully recovered (6)

worst (1) - best (5)

\# seasons (2 seasons $=1$ year)

very low (1) - very high (5)

very disagree (1) - very agree (4) 
Table 5.2 Number of respondents in the present study $(n=132)$

\begin{tabular}{clcllc}
\hline Sub-district & Village & Sample & Sub-district & Village & Sample \\
\hline Pusakanagara & Gempol & 7 & Legonkulon & Karangmulya & 11 \\
& Mundusari & 14 & & Bobos & 11 \\
& Kalentambo & 18 & & Pangarengan & 5 \\
& Kotasari & 5 & Pusakajaya & Kebondanas & 6 \\
& Patimban & 17 & & Karanganyar & 9 \\
& Pusakaratu & 7 & & Pusakajaya & 5 \\
& Rancadaka & 17 & & & \\
\hline
\end{tabular}

\section{Questionnaires}

The multiple linear regression (MLR) is used to investigate factors influencing resilience. The dependent variable is resilience scores that result from the product of the items of 'perceptions of the recovery from past events' and 'relative recovery of past events compared to other farmers in the same village' (Béné et al. 2016). In the former, farmers compared their current circumstances after being affected by adverse events relative to their perceived normal conditions. The independent variables for the MLR comprise all items from the questionnaire. The MLR is started by addressing key assumptions, such as the linearity, normality, multicollinearity, and homoscedasticity (Field 2009). The linearity assumes that there must be a linear relationship between the dependent variable and independent variables. The normality requires that errors between independent and dependent variables must normally be distributed. This assumption can be assessed using the histogram and P-P plots of normally distributed residuals. The multicollinearity necessitates that independent variables are not strongly correlated. A Variance Inflation Factor (VIF) of 1 indicates that there is no correlation among significant independent variable with the remaining independent variables. The multicollinearity can be solved by removing independent variables with high correlation. For example, the 'farming experience' item was removed from further analyses since the variable is highly correlated with 'farmer's age' item. Variables that are not included in the results table of the Multiple Linear Regression are variables removed to avoid the multicollinearity problem (see Appendix). The omitted items can be traced back to the questionnaire (see Appendix). Finally, the homoscedasticity assumes that the error variance is the same across independent variables. The assumptions of linearity and homoscedasticity can be demonstrated using a plot of standardized residuals versus predicted values that shows equally distributed points across all values of independent variables.

\section{Actual and potential aspects of resilience}

It is argued that the resilience score proposed by Béné et al. (2016) only captures the actual ability, not the potential to recover (hereafter referred to as potential resilience) from adverse events. The potential resilience is a product of two responses: subjective resilience (Béné et al. 2016) and recovery 
time. The subjective resilience refers to the capacity of farmers to handle or recover from hazardous events. The recovery time refers to the duration (year) required to recover from future similar adverse events provided that farmers successfully harvest optimum yields from their rice fields. The 'recovery time' item is different from the 'recovery from past event' item (one of the resilience score items). The latter is the current state of recovery from past adverse events.

Furthermore, the potential resilience scores are coupled with the actual resilience scores. Low and high potential and actual resilience scores are categorized into 'very low, 'low, 'moderate,' and 'high' recovery levels, as shown in Table 5.3. Each mean value of actual and potential resilience is used to distinguish between the low and high level. An ANOVA test is used to analyze whether there are any statistically significant differences between farmers with different recovery groups. The dependent variables are all items in the questionnaire used for analyzing factors influencing resilience (see Table 5.1). Next, The Hochberg and Games-Howell Post-hoc tests are performed for the variables that agree with or violate the assumption of equality of variances (Levene's test), respectively (Field 2009).

Table 5.3. Actual and potential resilience categorized into very low-high resilience level Potential resilience

\begin{tabular}{cccc}
\cline { 3 - 4 } & & Low & High \\
\cline { 3 - 4 } Actual & Low $^{a}$ & 73 & 20 \\
resilience & (very low recovery) & (low recovery) \\
& High & (moderate recovery) & (high recovery) \\
\hline
\end{tabular}

\subsection{Results}

\subsubsection{Rice field conditions}

Figure 5.3 shows rice field conditions in space and time during dry and wet planting seasons in 2015 and 2016, respectively, illustrated using the VCI. Because VCI values are relatively similar during water-deficit events and fallow (Table 5.3, top), field visits were performed to verify rice field conditions. It was found that rice fields in several villages in the northern district of Subang were severely affected by an extreme water-deficit event during the dry planting season 2015 (Table 5.3, middle). These rice fields were selected as the study area. It can be seen that poor vegetation conditions (>30-60\%) lasted for approximately ten months, starting from DOY 161 (2015) to DOY 73 (2016). Farmers could not pursue the dry planting season 2015. These rice fields suffered from lack of access to irrigation water partly due to the extreme dry season. Furthermore, farmers were able to continue rice cultivation in the wet planting season 2016 (Table 5.3, bottom). However, planting dates in 
several villages, such as Karangmulya, Bobos, and Rancadaka were delayed until approximately DOY 73 , later than those of neighboring villages. Farmers deliberately delay rice cultivation to cope with flood risk. Farmers reported crop damages due to the strong wind with rainfall at the booting stage and rice blast outbreaks during the wet planting season 2016. However, the impacts of these adverse events to vegetation conditions cannot be captured by moderate 500$\mathrm{m}$ spatial resolution MODIS imageries. Limited by its spatial resolution, the VCI may be able to capture the impacts of covariate natural hazards on rice field conditions (e.g., planting schedules), but it may not be able to detect impacts of idiosyncratic or small-scale events on rice cultivation. Additionally, the VCI may capture the periods when farmers continue rice cultivation; however, the VCI may not able to completely capture the duration for farmers to recover from adverse events. These findings support the need for investigation of factors influencing the resilience of farmers to natural hazards.

\subsubsection{Households' characteristics}

Table 5.4 shows the descriptive statistics of households' characteristics and resilience scores. The age of respondents ranges from 25 to 78 years $(M=$ $49.38 ; S D=10.27)$. All respondents are male. Sixty-one respondents $(46.2 \%)$ received an elementary degree, $28(21.2 \%)$ graduated with a secondary degree or above, and $43(32.6 \%)$ do not attend a school. A hundred and one respondents $(76.5 \%)$ own rice fields. During the wet planting season 2016, sixty-nine farmers $(46.2 \%)$ cultivated rice fields in the area of 0.7 ha or less, 49 respondents $(37.1 \%)$ managed $0.7-2.8 \mathrm{ha}$, and $14(16.7 \%)$ farmed $>2.8$ ha. Forty-eight respondents $(36.36 \%)$ have 2 or more dependent family members. Furthermore, ninety-six respondents $(72.7 \%)$ have low resilience scores (1-10 points), 33 (25\%) have moderate resilience scores (11-20 points), and $3(2.3 \%)$ have high resilience scores (21-30 points). The complete descriptive statistics for items included in the current study are presented in the Appendix section. 

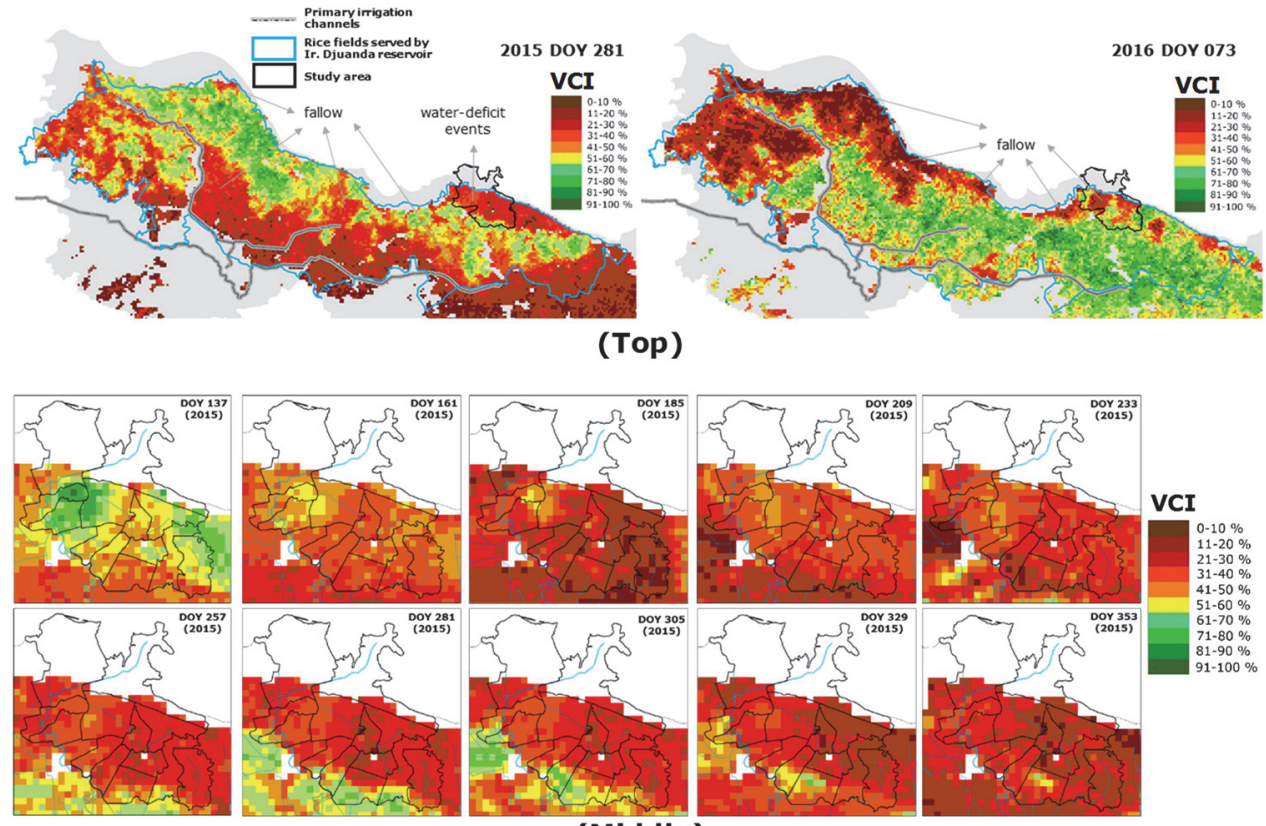

(Middle)
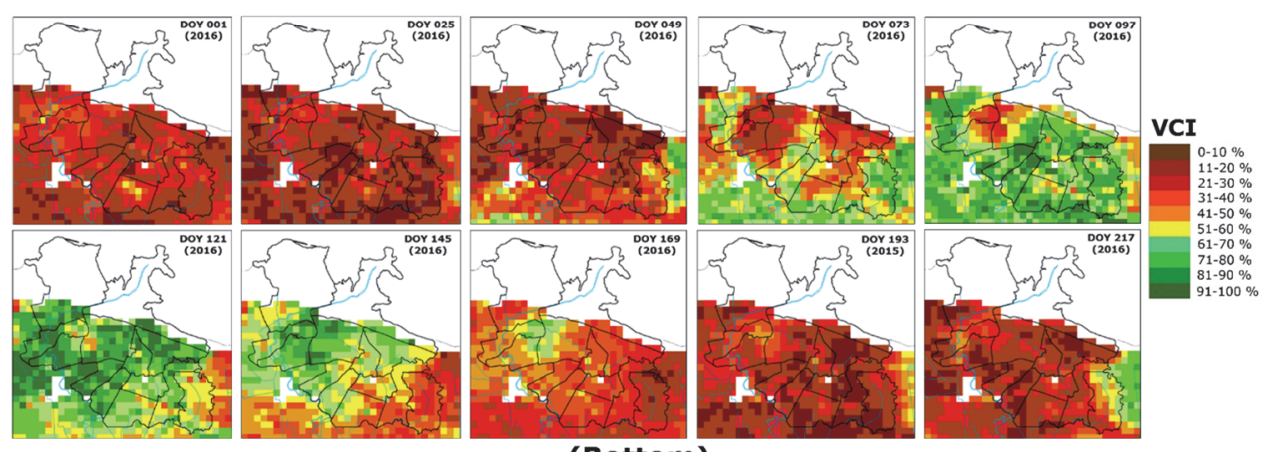

Figure 5.3. Conditions of rice fields illustrated using the Vegetation Condition Index (VCI) during the (Top) dry and wet planting seasons in the DOY 281 (2015) and DOY 073 (2016), respectively; (Middle) dry planting season 2015; (Bottom) wet planting season 2016. High VCI percentage reflects good vegetation conditions. Low VCI percentage reflects either fallow conditions or water-deficit events.

\subsubsection{Resilience scores of households}

Table 5.5 shows the differences in household characteristics between farmers with low and high resilience scores, analyzed using the Independent-samples t-test. It can be seen that there are no significant differences in the age, farming experience, rice field tenure, education, and number of dependent family member categories $(p>.05)$. On the other hand, significant differences were found in the rice field area, income during the wet planting season 2016 
$(p<.05)$ and sources of capital during wet planting season $2016(p<.001)$. The differences in resilience scores are also found in other items $(p<.05)$, including the ability to save money after selling harvests, sufficiency of income from rice farming for meeting family daily needs, access to other jobs in times of planting failures, support from extension officers, membership and participation in a farming group, irrigation infrastructure problems, influence of irrigation water to flooding in low elevation rice fields, influence of the size of rice field and flooding events on variations in cropping schedule, farming income, and resilience outcome variables (see Appendix). The results provide evidence that the economic aspect seems to have an essential role in improving the ability of farmers to recover from natural hazard impacts. The finding also indicates that household characteristics related to social, institutional, technological, and environmental aspects are relatively similar between low and high resilience groups. A plausible explanation may be related to the similarity of farming households in terms of geographic location and social settings. 
Table50.4 Percentages of response per question items

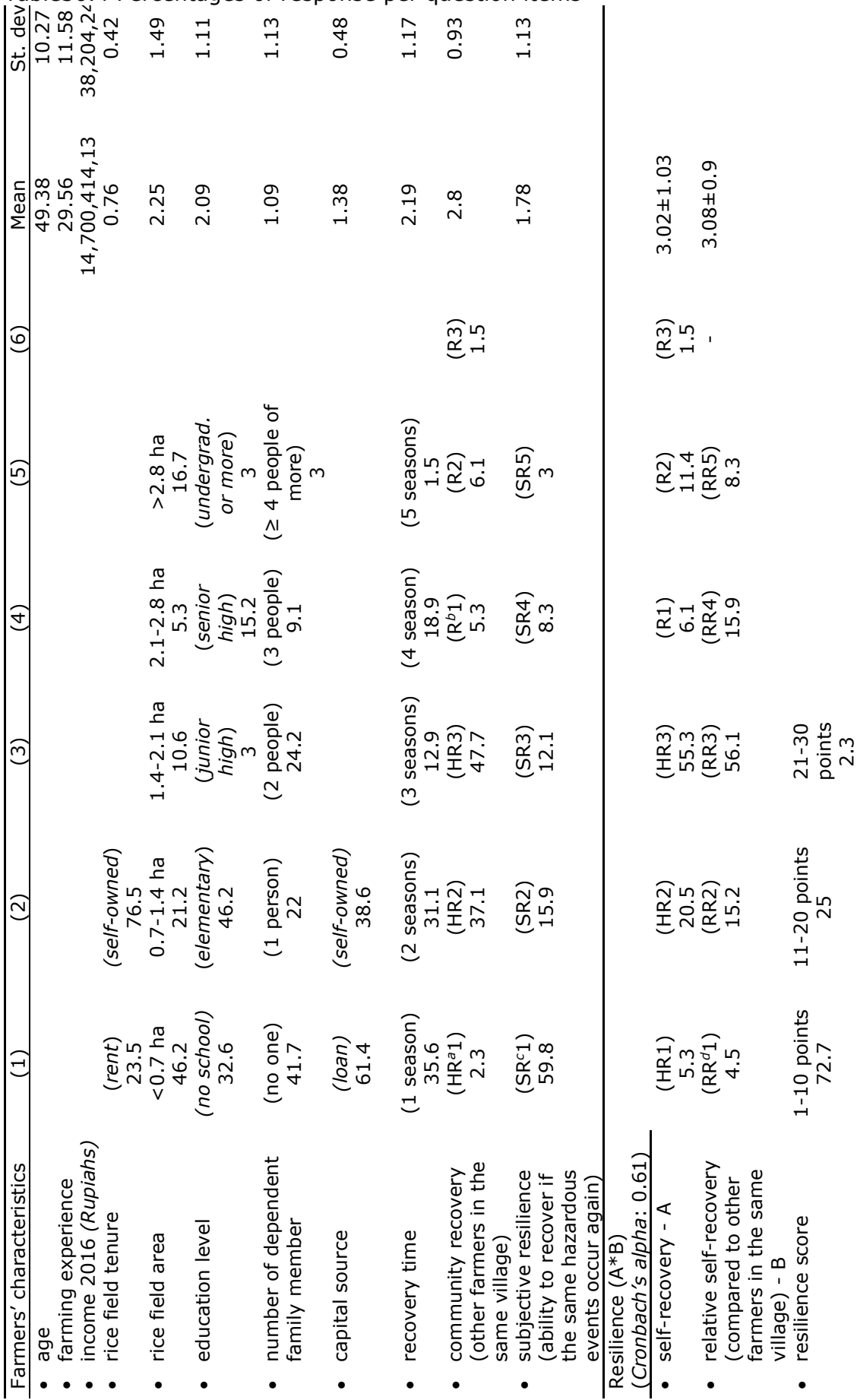

aHR: have not yet recovered; ${ }^{b} \mathrm{R}$ : recovered; ${ }^{c} \mathrm{SR}$ : subjective resilience; ${ }^{d} \mathrm{RR}$ : relative recovery. 
Table 5.5 Independent-samples t-test of low and high resilience scores differentiated by households characteristics (Mean \pm Standard Deviation; $n=132$ )

\begin{tabular}{|c|c|c|c|c|c|c|c|c|}
\hline \multirow{3}{*}{ Items } & \multicolumn{8}{|c|}{ Resilience score } \\
\hline & \multicolumn{4}{|c|}{ low } & \multicolumn{4}{|c|}{ high } \\
\hline & description & $\mathrm{n}$ & mean & std. & description & $\mathrm{n}$ & mean & std. \\
\hline - age & $>50$ years old & 60 & 9.21 & 5.64 & $<=50$ years old & 72 & 10.19 & 5.41 \\
\hline $\begin{array}{l}\text { - farming } \\
\text { experience }\end{array}$ & >30 year & 59 & 9.71 & 5.62 & $<=30$ years & 73 & 9.78 & 5.47 \\
\hline $\begin{array}{l}\text { rice field } \\
\text { tenure }\end{array}$ & rent & 31 & 8.45 & 4.57 & self-owned & 101 & 10.14 & 5.74 \\
\hline $\begin{array}{l}\text { rice field } \\
\text { area }\end{array}$ & $<=0.7$ ha* $^{*}$ & 61 & 8.6 & 4.25 & $>0.7$ ha* & 71 & 10.7 & 6.28 \\
\hline $\begin{array}{l}\text { - education } \\
\text { level }\end{array}$ & $\begin{array}{l}\text { elementary } \\
\text { school or } \\
\text { lower }\end{array}$ & 104 & 9.29 & 5.12 & $\begin{array}{l}\text { junior school or } \\
\text { above }\end{array}$ & 28 & 11.42 & 6.64 \\
\hline $\begin{array}{l}\text { number of } \\
\text { dependent } \\
\text { family } \\
\text { member }\end{array}$ & $<=1$ member & 84 & 9.3 & 5.46 & $>1$ member & 48 & 10.52 & 5.58 \\
\hline $\begin{array}{l}\text { income of } \\
\text { previous } \\
\text { season (wet } \\
\text { planting } \\
\text { season } \\
2016 \text { ) }\end{array}$ & $\begin{array}{l}<7,000,000^{*} \\
\text { rupiahs }\end{array}$ & 72 & 8.65 & 4.19 & $\begin{array}{l}>7,000,000^{*} \\
\text { rupiahs }\end{array}$ & 60 & 11.06 & 6.57 \\
\hline $\begin{array}{l}\text { - capital } \\
\text { source of } \\
\text { the previous } \\
\text { season (wet } \\
\text { planting } \\
\text { season } \\
2016 \text { ) } \\
\end{array}$ & loan** & 81 & 8.71 & 4.76 & self-owned ${ }^{* *}$ & 51 & 11.39 & 6.25 \\
\hline
\end{tabular}

\subsubsection{Regression analysis}

Several assumptions need to be met to produce a robust multiple linear regression analysis. Figure 5.4 shows the histogram and normal P-P plots of normally distributed residuals, a scatterplot of standardized residual and standardized predicted values, and a scatterplot of unstandardized predictive values and the dependent variable. The unstandardized predictive value is the combination of independent variables significantly influencing resilience (Table 5.6). The former three graphs indicate that the assumptions of linearity, normality, and homoscedasticity are met. The VIF values are approximately 1 , indicating that the multicollinearity assumption is met, as shown in Table 5.6.

Table 5.6 lists factors that are significantly correlated with resilience, including 'the ability to save money after selling harvests' (save_money), 'community recovery,' 'rat attacks reduce harvest yields' (rat reduces harvest), and 'rice field tenure.' The factors cover economic (save harvest, rice field tenure), 
social (community recovery), and environmental (rat attacks reduce harvest yields) aspects. Furthermore, Figure 5.5 shows the correlation coefficient for each variable that significantly influences resilience in the multiple linear regression analysis. Individually, the variables 'save money', 'rat reduces harvest,' and 'community recovery' are significantly correlated with the resilience score. However, individually, the variable 'rice field tenure' is not correlated with the resilience score. It seems that the 'rice field tenure' item is a suppressor variable. The suppressor variable is correlated with one or more other independent variables but has close to zero correlation with a dependent variable (Pedhazur 1982). The variable 'rice field tenure' removes the irrelevant variance from independent variables and improve the prediction of resilience. In this study, although the item is not consistent with the description of Pedhazur (1982), it increases the prediction of resilience (Adj. $R^{2}$ from .290 to .311), aligned with Mendershausen (1939). Additionally, Table 5.6 shows that the partial correlation (.193) of the variable 'rice field tenure' with the dependent variable 'normalized resilience scores' is higher than its zero-order correlation (.136), indicating that the former is a suppressor variable (Kendall and Stuart 1973). In relation to this, the argument of Ludlow and Klein (2004) is highlighted. The author argued that if the addition of a variable 'acts as', aiming to maximize predictive validity, in contrary to 'is', resulting from a hypothesis testing, a suppressor variable, 'the results were not expected, were not interpretable, and were ultimately attributed to chance, such as due to complex relationships within the independent variable correlation matrix' (Ludlow and Klein 2004). 

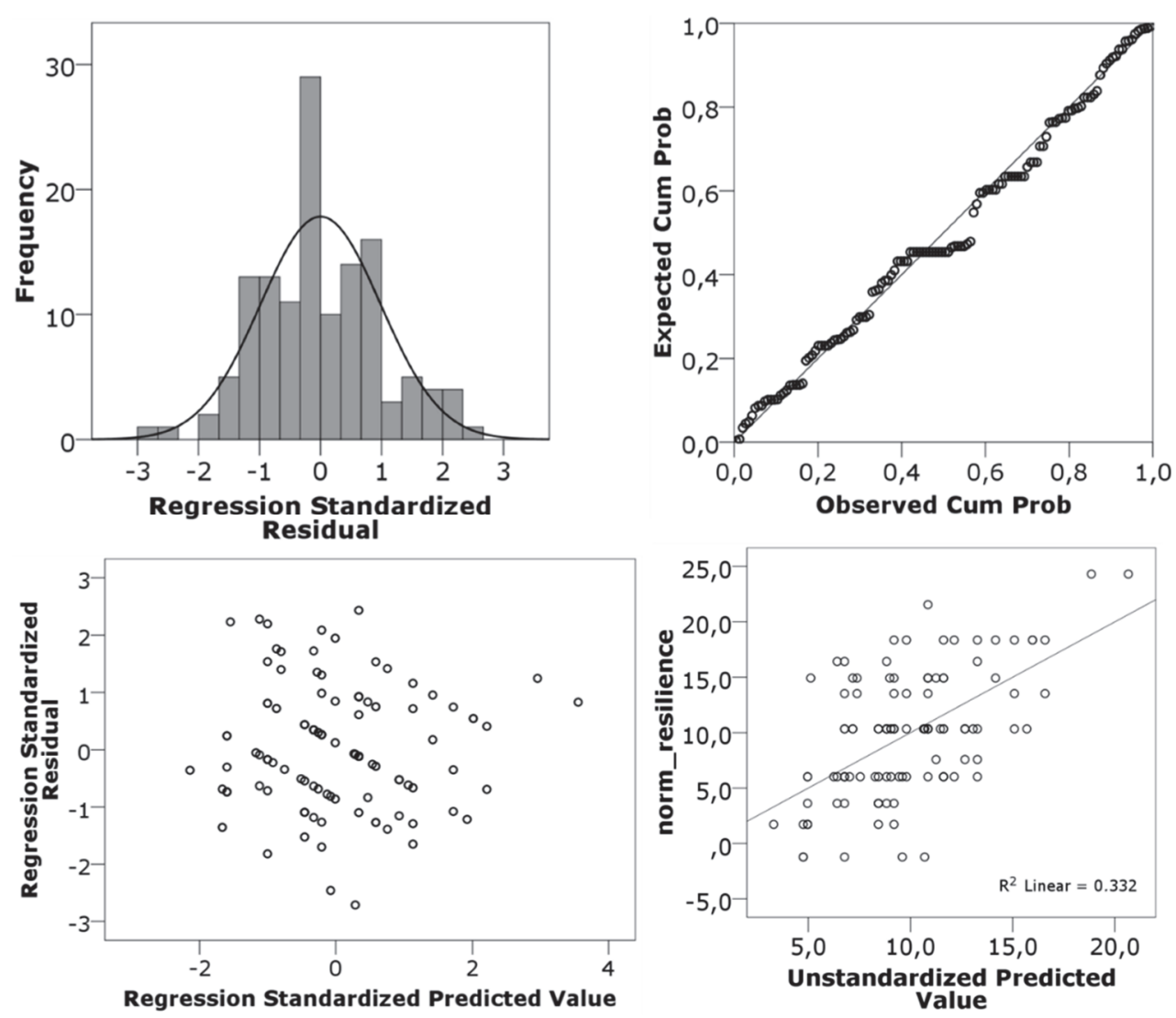

Figure 5.4. H istogram (top left), normal P-P plots (top right), scatterplot of standardized residual and standardized predicted values (bottom left), and scatterplot of independent variables and a dependent variable in the multiple linear regression (bottom right). 
Table 5.6. Regression analysis of factors influencing the resilience of farmers to natural hazards in irrigated rice fields in Subang district, West Java

\begin{tabular}{|c|c|c|c|c|c|c|c|c|c|c|}
\hline & & Unst. & Coeff. & $t$ & Sir & $\begin{array}{r}95 . \\
\text { Conf. II }\end{array}$ & $\begin{array}{l}\% \\
\text { terval }\end{array}$ & Correlat & ons & \\
\hline & Model & Beta & S.E. & $\tau$ & Sig. & $\begin{array}{l}\text { Lower } \\
\text { bound }\end{array}$ & $\begin{array}{l}\text { Upper } \\
\text { bound }\end{array}$ & $\begin{array}{l}\text { Zero- } \\
\text { order }\end{array}$ & Partial & $I F^{a}$ \\
\hline & (Constant) & -2.6 & 1.88 & -1.4 & .159 & $-6,4$ & 1,05 & & & \\
\hline & - save money & 2.477 & .532 & 4.654 & $.000^{* * *}$ & 1.424 & 3.530 & .448 & .380 & 1.08 \\
\hline A & - community & 1.614 & .435 & 3.709 & $.000^{* * *}$ & .753 & 2.475 & .387 & .311 & 1.0 \\
\hline & $\begin{array}{l}\text { - } \text { rat reduces } \\
\text { harvest }\end{array}$ & 1.609 & .729 & 2.208 & $.029^{*}$ & .167 & 3.050 & .224 & .192 & 1.01 \\
\hline & $.553 ; R^{2}=.30$ & Adi $R$ & $=.29$ & $p<.05$ & 2-tailed); & $* * * p<$ & $01(2-t$ & ailed) & & \\
\hline & (Constant) & -4.5 & 2.06 & -2.2 & $.027^{*}$ & -8.67 & -.518 & & & \\
\hline & - save money & 2.42 & .52 & 4.59 & $.000^{* * *}$ & 1.37 & 3.46 & .448 & .379 & 1.08 \\
\hline & - community & 1.66 & .43 & 3.82 & $.000^{* * *}$ & .8 & 2.51 & .224 & .217 & 1.07 \\
\hline B & $\begin{array}{l}\text { recovery } \\
\text { - } \text { rat reduces } \\
\text { harvest }\end{array}$ & 1.80 & .73 & 2.45 & $.015^{*}$ & .35 & 3.25 & .387 & .324 & 1.03 \\
\hline & $\begin{array}{l}\text { - rice field } \\
\text { tenure }\end{array}$ & 2.02 & .91 & 2.21 & $.029^{*}$ & .21 & 3.83 & .136 & .193 & 1.01 \\
\hline & $.576 ; R^{2}=.33$ & Adj. $R$ & $=.311$ & $p<.05$ & -tailed) & ${ }^{* * *} p<.0$ & 1 (2-ta & iled) & & \\
\hline
\end{tabular}

Dependent variable: normalized resilience scores. The assumptions of linearity, normality, multicollinearity, and homoscedasticity has been passed. ${ }^{a}$ VIF (Variation Inflation Factor) of 1 means that there is no correlation among independent variables.
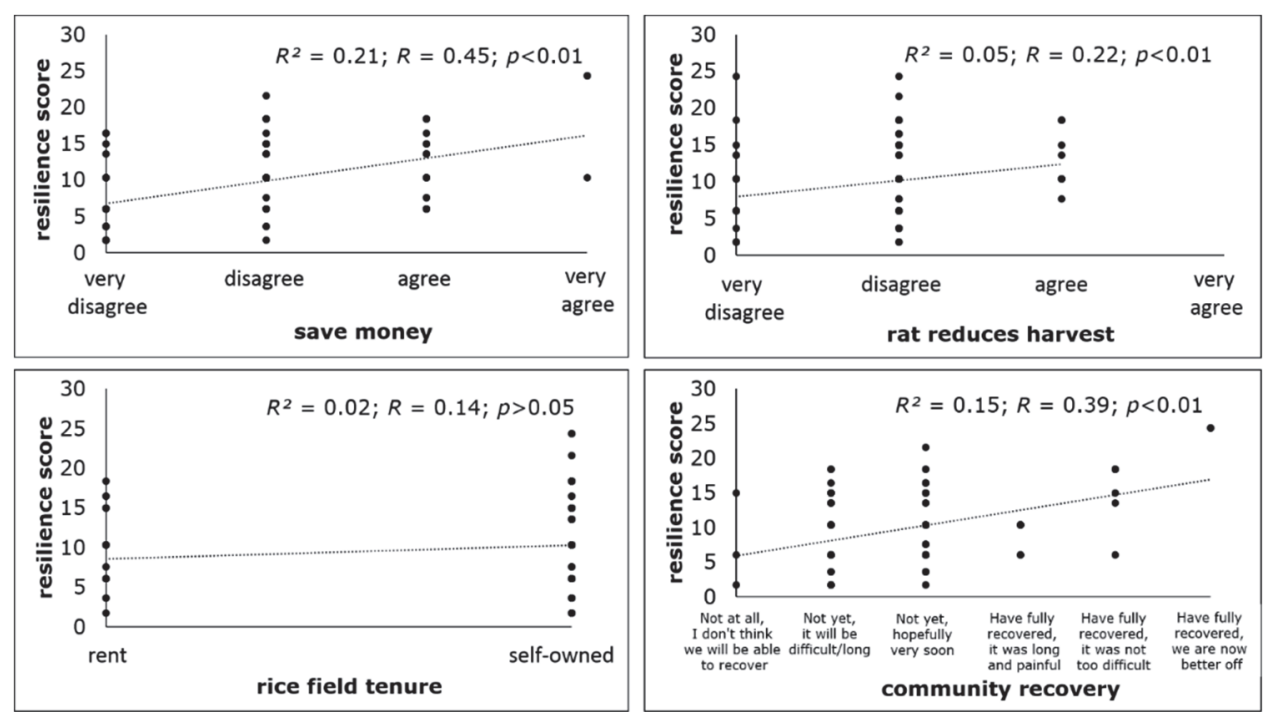

Figure 5.5. One-to-one relationship between independent variables and resilience scores

\subsubsection{Actual and potential aspects of resilience}

The resilient scores presented in the previous section capture the actual ability, not the potential capacity to recover from adverse events. In reality, farmers may underperform their potential to reduce natural hazard impacts. To understand variables that differentiate farmers with different recovery level, actual and potential resilience is coupled and categorized into four recovery 
levels, from 'very low' to 'high.' The differences among group means were analyzed using the ANOVA. A one-way ANOVA was conducted to determine if variables influencing resilience were different for households with different potential and actual resilience levels. Samples were categorized into four groups: Low actual-low potential resilience (Very Low recovery, $n=73$ ), Low actual-High potential (Low recovery, $\mathrm{n}=23$ ), High actual-Low potential (Moderate recovery, $\mathrm{n}=16$ ), High actual-High potential (High recovery, $\mathrm{n}=$ 20).

Table 5.7 lists variables that differentiate farmers with different recovery levels $(p<.05)$ according to the one-way ANOVA analysis. It can also be seen that the posthoc tests show mean differences of variables between two groups. For example, variables 'rat attacks reduce harvest', 'extension officer support to farmers,' and 'save money after selling harvests' are statistically significantly higher in the High recovery group compared to the Very Low recovery group. Surprisingly, many variables are statistically significantly different between the Low and Very Low recovery groups, such as 'skill as a farmer,' 'rat attacks reduce harvest,' 'satisfaction with farming income,' and 'rent price expensive,' among others. Table 5.7 also shows that variables that statistically significantly differentiate the groups comprise different dimensions, such as social, economic, institutional, and environmental aspects and seem to be multi-level, ranging from individual to national level. 
Table 5.7 Mean differences (Mean \pm Standard Error) between resilience groups $(p<.05)$. Mean differences are obtained when the mean of a group in a row is subtracted from the mean a group in a column.

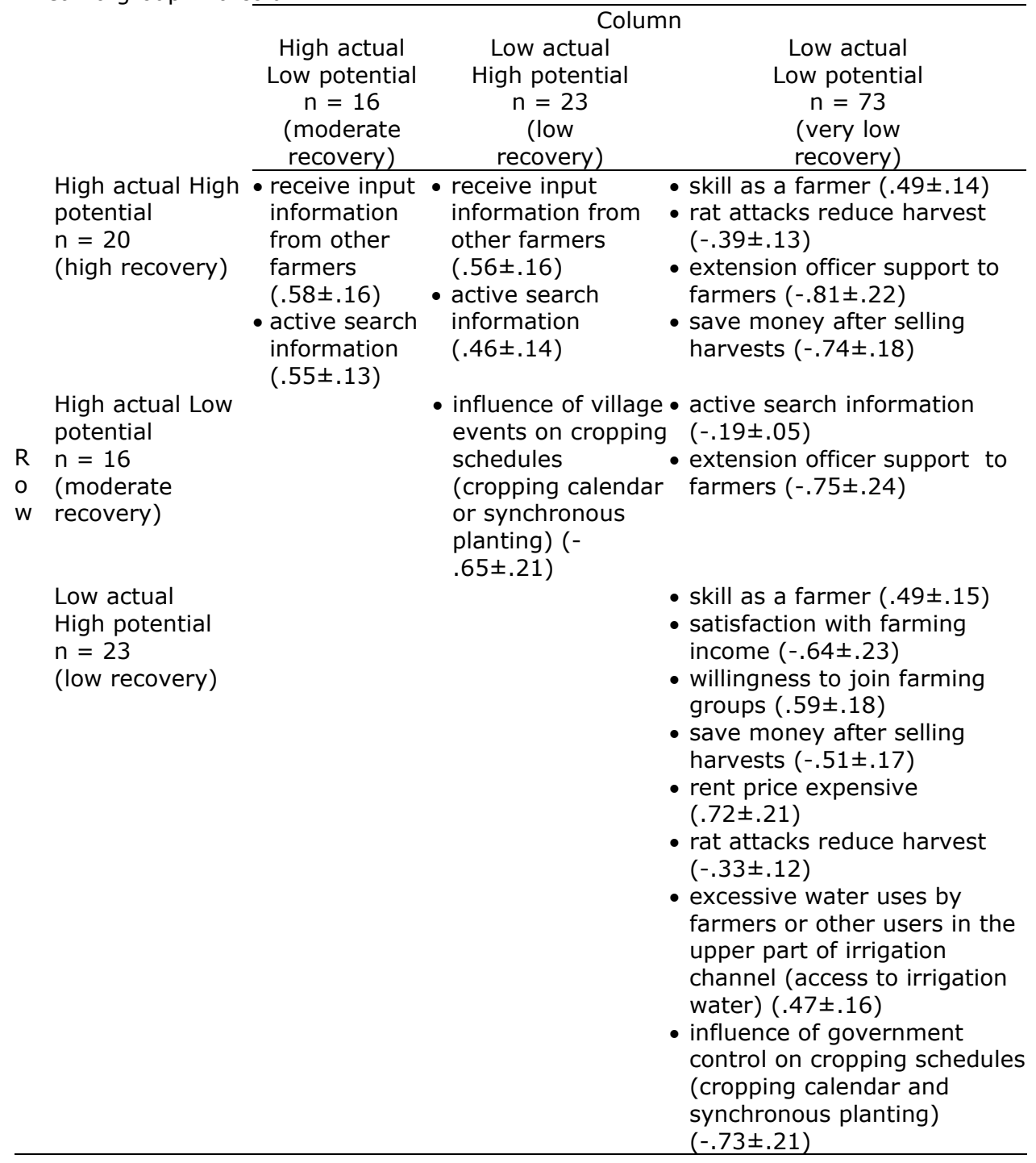

\subsection{Discussion and conclusion}

Combined with information obtained from the fieldwork, the VCI add insights to the resilience analysis. The VCI demonstrates that the scope of analysis, including the working definition and temporal and spatial scales, play roles in determining the results of resilience studies. Firstly, the working definition of resilience may also influence the result of resilience studies. For example, defining resilience as the ability of farmers to continue disrupted rice farming practices, one may conclude from the VCI in the wet planting season 2016 that 
farmers affected by the extreme water deficit event during the dry planting season 2015 are resilient. Nevertheless, the resilience study may reveal different results after incorporating the fact that farmers may use loans with high interest to support rice cultivation (Islam 2011, Barbier et al., 2016). Secondly, the temporal scale influences the resilience analysis. For example, extending the investigation period to two cropping seasons or more, the VCI implies that farmers may have other sources of financial capital for continuing rice cultivation in the wet planting season 2016 despite having no income to continue rice cultivation from the previous dry planting season 2015. Finally, the spatial scale also influences the finding of the resilience study. Although farmers could cultivate rice fields, it was found that several farmers delay the wet season planting dates until the end of February (e.g., year 2016-DOY 073) to cope with flood risk. The planting delay increases the risk of rice pest and disease attacks because farmers located in the upper part have harvested their rice fields. Overall, supported by the time-series remote sensing analysis, this study has clarified that resilience studies in irrigated rice fields not only need to consider the notions: Resilience to what? Resilience for whom? (Cutter 2016), but also it is essential to take temporal and spatial scales and the working definition into account.

Factors influencing the resilience of farmers to natural hazards include the 'save money,' 'rat attacks reduce harvest yields,' 'rice field tenure,' and 'community recovery' $(p<.05)$. This finding highlights the need to consider economic, social, environmental aspects in building resilience. Explanations are present for the results. Firstly, the save money implies that farmers have an extra financial capital to recover from disruptions after meeting the basic family needs. Secondly, the 'rat attacks reduce harvest yields' item reflects the threat of rice attacks to rice cultivation. Unlike other rice pests and diseases or natural hazards, rat damages rice fields irrespective of growing phases and planting seasons (Singleton et al., 2005). Thirdly, the 'rice field tenure' 'acts as' a suppressor variable. Although an explanation may be not required for a variable that acts as suppressor variable (Ludlow and Klein 2004), a plausible reason still exists for the finding. Farmers who own rice fields do not have to assign money for renting rice fields and can allocate their income for investing more in rice farming, for example by purchasing more lands for rice cultivation. Also, using their rice fields as collateral, farmers owning rice fields are likely to have greater access to financial capital compared with labor farmers. Finally, the 'community recovery' is found to be strongly correlated with resilience $(p<.0001)$. It is likely that the faster the community recovery, the faster the recovery of households. This result also confirms the multi-level nature of resilience (Béné et al. 2016).

Surprisingly, there are no items related to flooding or water-deficit events that are significantly correlated with resilience. Although recurrent flooding and 
water-deficit cause disruptions in farming practices, it is likely that the adverse events are not new problems to the farmers. Farmers have developed coping mechanisms to reduce the risk of water-related hazards in irrigated rice fields. It is worth repeating that this finding is supported by the VCI analysis showing that farmers can continue rice cultivation despite being frequently exposed to the risk of water-deficit event and flooding during dry and wet planting seasons, respectively. However, it is possible that the finding is particular for this study area. More studies about factors influencing the resilience of farmers to natural hazards in other irrigated rice fields are needed before a robust conclusion can be derived.

Findings on factors influencing resilience suggest that studies that mentioned a 'one-way influence' of rice fields close to primary irrigation channels over rice fields closer to the coastal area may be incomprehensive (Sianturi et al. 2018). Figure 5.6 shows inter-relationships among farming households in the study area. Rice fields are connected through socio-economic, institutional, and environmental processes. Rice fields located near coastal areas that suffer from the impacts of flooding or water-deficit events may also influence the outcomes of rice fields located close to primary irrigation channels. It is worth mentioning that the spatial extent of the interconnectedness of each process may differ. Also, the connections may result in either progress or decline in rice production. The first example is related to the reduction of harvest yields because of rat attacks. The irregularity in cropping schedules, either triggered by natural or human processes, results in asynchronous planting (Sianturi et al. 2018). This unsafe condition supports all-year food availability and increases the risk of crop damages due to rat attacks, jeopardizing rice cultivation in the whole rice fields served by Ir. Djuanda reservoir. Another example is related to the community recovery. It seems that the community recovery has a 'multiplier effect' on the recovery process of farmers' households. Farmers suffering from disaster impacts may choose to work as farm labors in other villages that are not affected by natural hazards. Farmers having access to other sources of financial capital are likely to recover faster than those who do not have such access. The faster communities recover from adverse events, the faster the availability of farming jobs (e.g., transplanting, weeding), supporting the recovery processes of other farmers. 


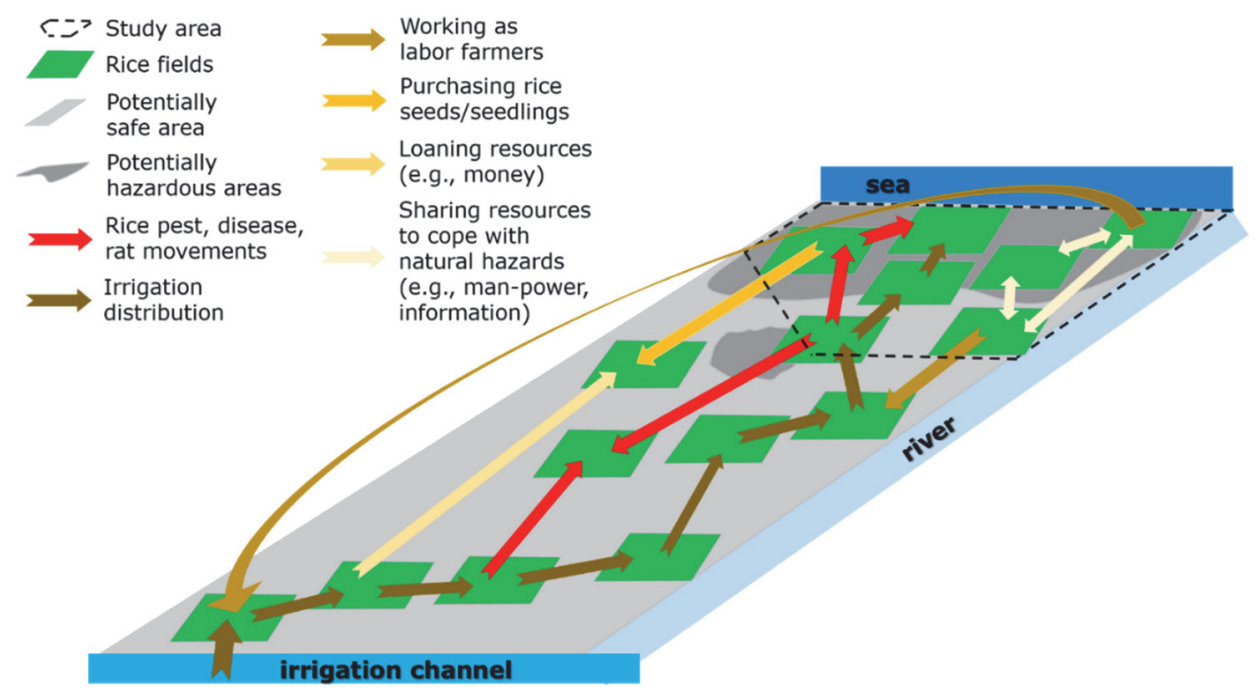

Figure 5.6. Examples of interrelationships among farming households in the study area. Rice fields are connected through socio-economic, institutional, and environmental processes.

The differences in characteristics that distinguish between farmers with different recovery levels provide insights for increasing resilience. It seems that efforts to address challenges related to access to farming information and financial capital, synchronous planting, reducing rat attacks, and farmers' skills are likely to be beneficial to empower farmers to materialize their potential into actual resilience. It is worth reminding that the multi-dimensional and level nature of variables may suggest the need for partnership and cooperation between farmers and other stakeholders (e.g., local governments and academicians). Some of the challenges can be addressed at the household and community level, while others may need government interventions through policies and programs. At the same time, it is likely that policies and programs need to be tailored to particular farming household groups. For example, the variable 'access to supports from extension officers' is statistically significantly lower in the Low recovery group compared to the Moderate recovery group, or High recovery group. Such limitation may contribute to low actual and low potential resilience since the success of rice cultivation, and reduction of multiple agricultural risks are partly determined by access to information from reliable sources. Such disadvantage may be related to the ineffective mechanism for information flow after being delivered by extension officers, influence of elite and intragroup dynamics (Liverpool-Tasie 2014), or inadequacy of the number of extension officers in each sub-district. In this regard, reaching out strategies need to be devised so that agricultural programs and advances can be disseminated equally to farming households through extension officers. Another interesting example is related to the 
variable 'skill as a farmer.' This variable is statistically significantly higher in the Very Low recovery group than in the Low or High recovery groups. This finding may reflect technical skills of the former. To be resilient, there is also a need to increase functional skills. Such efforts can be performed using various educational programs targeting farmers and extension officers, such as the Farmer Field Schools (FFS).

The results are not without limitations. It is acknowledged that farmers' responses may be influenced by personal factors (e.g., education level, cultural values). To overcome this potential bias, the participation of other farmers and family members to accompany respondents during interview sessions is encouraged. Other participants were allowed to add comments to responses provided by the main interviewee. Also, farmers may refer their answers on extreme events. Respondents were asked to center their answers to the analysis periods (dry season 2015 and wet season 2016) to maintain focus. It is expected that the arrangements may increase the reliability of the results. Furthermore, the studies were conducted in the disaster-prone irrigated rice fields served by Ir. Djuanda reservoir. Thus, the study results may not be able to be generalized to irrigated rice fields in West Java. Finally, this study mainly used farmers' responses to understand factors influencing resilience. It is expected that the inclusion of stakeholders from different background in future studies may improve the understanding of factors influencing resilience to natural hazards in the study area.

\subsection{Conclusion}

This study investigates factors that influence the resilience of farmers to natural hazards in irrigated rice fields with the focus on the recovery aspect. A structured questionnaire has been used as a tool to collect data from farmers affected by an extreme water deficit event in the dry planting season 2015 in villages in Subang district, West Java. The fieldwork and data collection were performed in August 2016.

- Firstly, the study has successfully illustrated irrigated rice field conditions using the Vegetation Condition Index (VCI) during dry and wet planting seasons in 2015 and 2016, respectively. Poor vegetation conditions, signified by low VCI values, may be associated with either fallow or waterdeficit events. Field visits are needed to differentiate between the two. It was found that farmers were able to continue rice cultivation in the wet planting season 2016 despite the planting failure due to an extreme water deficit event in the dry planting season 2015. Although the VCI may capture the periods when farmers continue rice cultivation, it may not be able to completely capture the duration for farmers to recover from adverse events. It has also been demonstrated that the scope of the 
resilience study, such as the working definition, spatial, and temporal scales may determine the results of resilience analysis.

- Secondly, the study has investigated factors that influence the resilience of farmers to natural hazards using the multiple linear regression with the stepwise method. Several factors were found to significantly contribute to the resilience, including the ability to save money after selling harvests, rat attacks reduce harvest yields, rice field tenure, and community recovery. The factors suggest that rice fields in the study area are connected not only by institutional settings but also by socioeconomic and environmental processes.

- Finally, characteristics that distinguish between farmers with different recovery levels have been analyzed using the Analysis of Variance. It seems that efforts to address challenges related to access to farming information and financial capital, synchronous planting, management of rat attacks, and farmers' skills are likely to be beneficial to empower farmers to materialize their potential into actual resilience. 


\section{Chapter 6 Synthesis}

\subsection{Introduction}

There has been a shift in focus from dealing with disaster events toward reducing disaster risk, with the aim to achieve a substantial reduction in losses in lives, health, and assets of communities, businesses, and countries (Montz and Tobin 2011, UN 2015). Disaster risk results from the complex interactions of exposure, vulnerability, and hazards (Turner et al. 2003, UNISDR 2009b). Nowadays, it is increasingly realized that resilience is essential for reducing disaster risk. It is necessary that people at risk have the ability to absorb, accommodate, and recover from unexpected hazardous physical events while increasing their capacity to face future disaster events.

Despite their essential role in maintaining food security and accelerating rural development, irrigated rice fields in many rice-producing regions in Indonesia suffer from devastating impacts of natural hazards. Nevertheless, studies aiming at reducing disaster damages and losses in irrigated rice fields are surprisingly lacking in Indonesia. To contribute to the existing body of knowledge, this thesis was conducted in main rice producing districts in West Java.

This chapter uses the results of previous chapters to synthesize and improve the understanding of dynamics in irrigated rice fields from the disaster risk reduction perspective. Firstly, this chapter summarizes and connects findings from each chapter. Then, this chapter elaborates efforts to reduce the disaster damages and losses in the study area. Finally, this chapter concludes with potential future research directions and practices to reducing disaster impacts in irrigated rice fields.

\subsection{Towards mapping vulnerability to flooding using time- series MODIS imageries: Mapping cropping patterns in irrigated rice fields in West Java}

Estimating potential damages from flooding events requires information on vulnerability to flooding. One of the challenges in mapping the physical vulnerability to flooding in irrigated rice fields is the large variability of rice growth stages in space and time. Analyzing rice growing stages is necessary to determine the vulnerability of irrigated rice fields at one moment. The challenge may be addressed by generating cropping patterns. Cropping patterns, derived from time-series MODIS imageries, capture the spatial distribution and phenology of rice fields (Figure 6.1). Combined with vulnerability curves, cropping patterns show spatial and temporal variations of physical vulnerability in irrigated rice fields. This study used the Reynolds 
number as a parameter for simulating the flood physical-factor loss function (Ganji et al. 2012). Rice plants are more vulnerable to flooding when they is less developed (Ganji et al. 2012). As shown in Figure 6.2, rice growth stages (fallow-harvesting) are classified into five classes, namely the transplanting, shooting, clustering, harvesting, and fallow. Farmers do not cultivate rice fields during fallow periods and the number of farmers that plant cash crops is often negligible. So, it is assumed that there is no elements-at-risk (therefore no vulnerability) in rice fields during this stage.

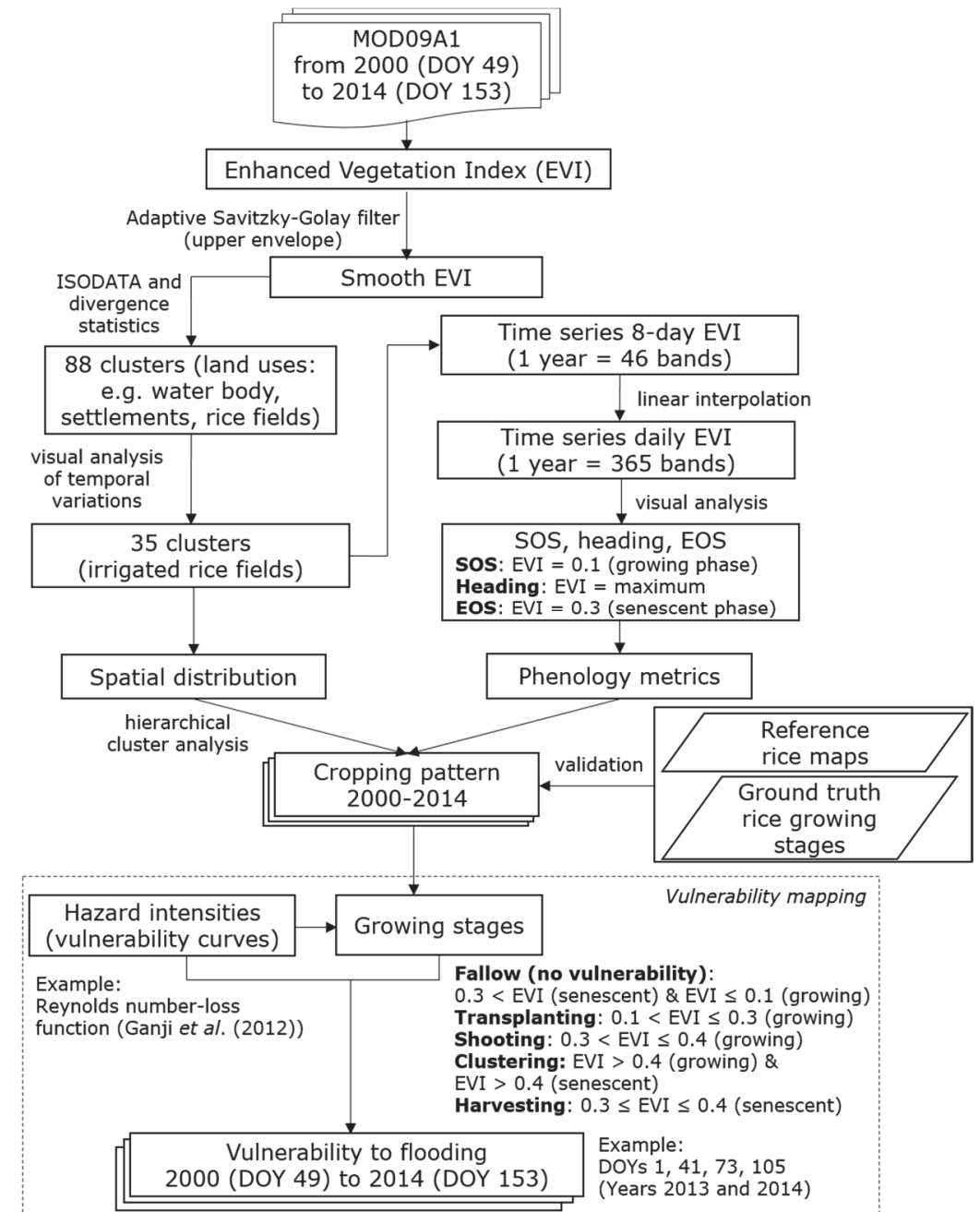

Figure 6.1. Flowchart for determining the vulnerability to flooding from time-series 8day 500-m spatial resolution MODIS (MOD09A1) imageries.

Chapter 2 successfully demonstrates that cropping patterns derived from timeseries MODIS 8-day 500-m spatial resolution remote sensing imageries can be used as one of the inputs for mapping the vulnerability to flooding in irrigated 
rice fields. The reference rice field maps and ages of rice plants after transplanting were used to validate the spatial distribution and phenology metrics of rice fields, respectively. The comparison of irrigated rice field areas between MOD09A1 and ALOS PALSAR (2010) and MOD09A1 and Agricultural Statistics showed $R^{2}$ of 0.81 and 0.93 , respectively. The estimated and observed Start Of Season, heading stage, and End Of Season respectively displayed RMSE of $9.21(n=61), 9.29(n=46)$, and $9.69(n=49)$ days, indicating at most a 10 day error in estimating these stages.

Chapter 2 has also highlighted that physical vulnerability may shift partly because of extreme weather variabilities or human-made interventions, resulting in either an increase or decrease of vulnerability (Figure 6.3). Chapter 2 was only able to attribute the disruption in cropping schedules in swampland rice fields to flood events (see also Chapter 3). Chapter 4, however, was able to fill this gap by providing a range of environmental and socioeconomic processes that may lead to disruptions in cropping schedules. 

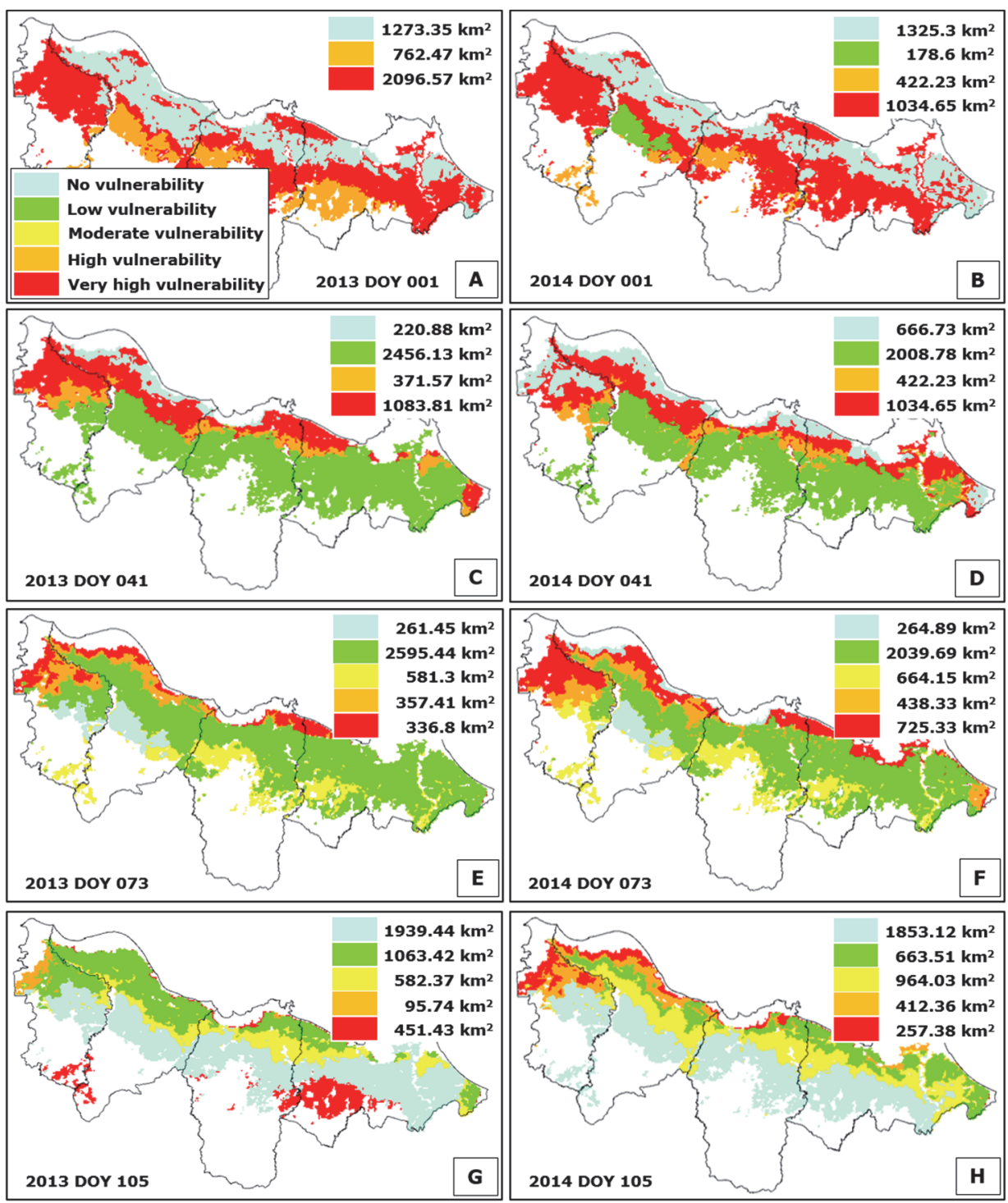

Figure 6.2. Vulnerability to potential flooding in irrigated rice fields varies in space and time. Fallow, clustering, harvesting, shooting, and transplanting stages belong to the no, low, moderate, high, and very high vulnerability levels.

\subsection{Distinguishing between flooding and agronomic inundation in irrigated rice fields}

Both agronomic inundation (non-hazardous surface water) and flooding (hazardous surface water) are present in irrigated rice fields. This condition complicates the flood detection in irrigated rice fields. Discriminating between rice fields with flooding and rice fields with agronomic inundation (RFAI) is 
necessary to detect flood hazards in irrigated rice fields. Chapter 3 aimed to distinguish between flooding and agronomic inundation in irrigated rice fields in West Java. (Sakamoto et al. 2007, Islam et al. 2010, Son et al. 2013) suggested that EVI $\leq 0.1$ can be used to detect flooding in irrigated rice fields. In this regard, the effectiveness of EVI $\leq 0.1$ for distinguishing agronomic inundation and hazardous flooding in the study area was tested. Then, EVI ${ }_{40}$, an extension of EVI $\leq 0.1$ after incorporating the duration of land preparation and transplanting activities, was developed and tested to detect flooding in irrigated rice fields.

Figure 6.3 shows that EVI $\leq 0.1$ cannot distinguish between flooding and agronomic inundation in the study area. EVI $\leq 0.1$ can detect both hazardous flooding and non-hazardous agronomic inundation. On the contrary, EVI 40 can distinguish between RFAI. EVI 40 can overcome the overestimation of rice field areas with flooding suffered by EVI $\leq 0.1$ by reducing the detection of rice fields areas with agronomic inundation. 

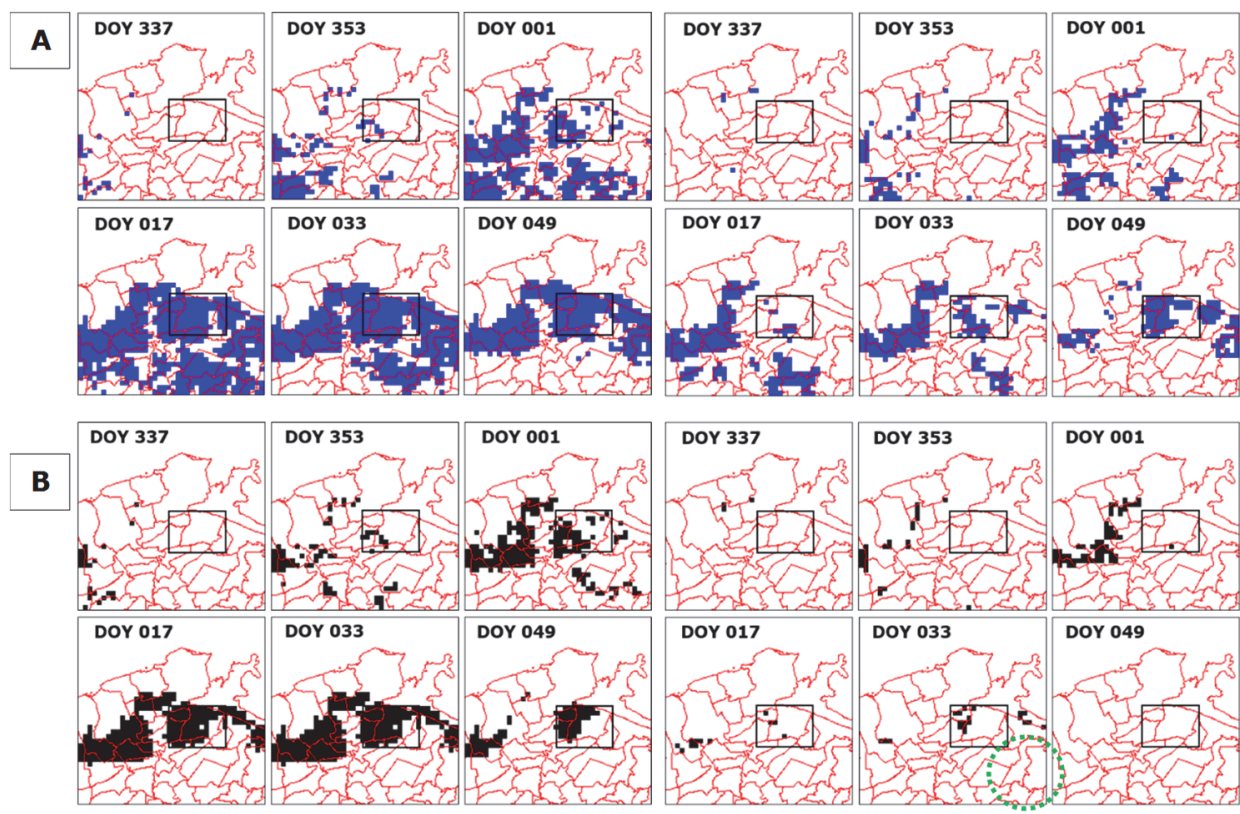

(2013/2014)

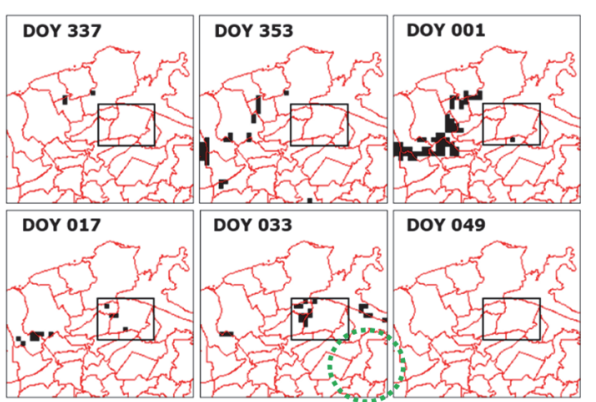

(2014/2015)
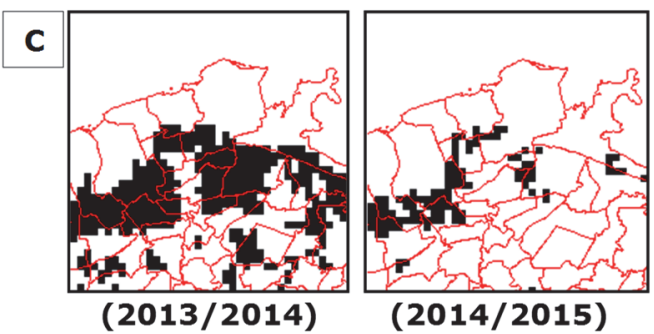

Figure 6.3 Rice fields with (A) surface water detected using EVI $\leq 0.1$ (blue) and (B) with flooding detected using $\mathrm{EVI}_{40}$ (black). Black rectangle represents rice fields affected by a dyke failure on January 18,2014 . Dotted green circle is misclassified flooded rice fields. (C) Total area rice fields with flooding detected using $\mathrm{EVI}_{40}$ in 2013/2014 and 2014/2015.

Validating the distinction between the two inundation types is challenging provided the unavailability of ground truths in the spatial format. Since other optical remotely-sensed imageries with coarse-moderate spatial resolutions (e.g., NOAA-AVHRR, SPOT-VEGETATION) share the same disadvantage with MODIS, they are not useful for validating the result of the study. At the same time, the availability of high spatial resolution satellite imageries (e.g., Landsat) during flooding periods is limited due to the heavy cloud cover. Thus, the Start of Season (SOS) was used as an alternative to validate the areas of rice fields with flooding. Assuming that flooded rice fields experience delays in cultivation, the delay in planting dates between flooded rice fields and rice fields with 'normal' cropping schedules were compared and used to validate the areas of rice fields with flooding. The use of SOS to validate the results 
showed that the Accuracy and F1 scores (Powers 2011, Li and Guo 2014) for $\mathrm{EVI}_{40}$ are $75.96 \%$ and $81.74 \%$, respectively. The results of the accuracy assessment are partly related to the influences of environmental processes (e.g., seawater intrusion), human decisions (e.g., inadequate drainage systems), and mixed pixels.

\subsection{Towards understanding vulnerability: Investigating disruptions in cropping schedules in irrigated rice fields in West Java}

Chapter 4 aimed to investigate disruptions in cropping schedules to understand unsafe conditions that contribute to the vulnerability of farmers to natural hazards in irrigated rice fields. Two considerations need to be taken into account to achieve the aim: many potential reasons for unsafe conditions and the 'vocabulary' differences between the scientific community and rice stakeholders. In this regard, disruptions in cropping schedules may be used as a 'common language' to understand mechanisms of how unsafe conditions may increase vulnerability. Likewise flooding, farmers view other hazards (e.g., water-deficit event or rat attacks) as threats to potential income from rice cultivation. Therefore, in the last two chapters, the analysis scope widens to incorporate other adverse events.

Chapter 4 has successfully investigated the disruption in cropping schedules in irrigated rice fields served by the Ir. Djuanda (Jatiluhur) reservoir in West Java. It was found that cropping schedules are different from the cropping calendar stipulated by the provincial government of West Java and Perusahaan umum Jasa Tirta II (state company) during wet and dry planting seasons, as shown in Figure 6.4. The greater the deviation from official cropping calendar, the more disorganized the on-farm management of irrigation water. Disordered planting schedules may increase the risk of rat attacks and water-deficit events. Furthermore, the disruption in cropping schedules is a complex phenomenon and is not only determined by irrigation management (see Chapter 2), flood (see Chapter 3), or water-deficit (see Chapter 5) events. It can be attributed to other several reasons, including economic motives, weather variabilities, geographic locations, coping strategies, farmers' interactions, and agricultural infrastructures. The relationships among reasons for and consequences of disruptions in cropping schedules were shown using the Bow-Tie analysis in Figure 6.5. Framing the results of the Bow-Tie analysis into the components of risk, stakeholders may obtain an overview of the relationships among hazards, exposure, vulnerability, and potential disaster impacts. This result helps to pinpoint unsafe conditions that are likely to increase the potential damages and losses from recurrent natural hazards. The unsafe conditions are categorized into dangerous locations, unsustainable 
farming activities, unsuitable coping strategies, fragile infrastructures, and inaccurate perceptions.

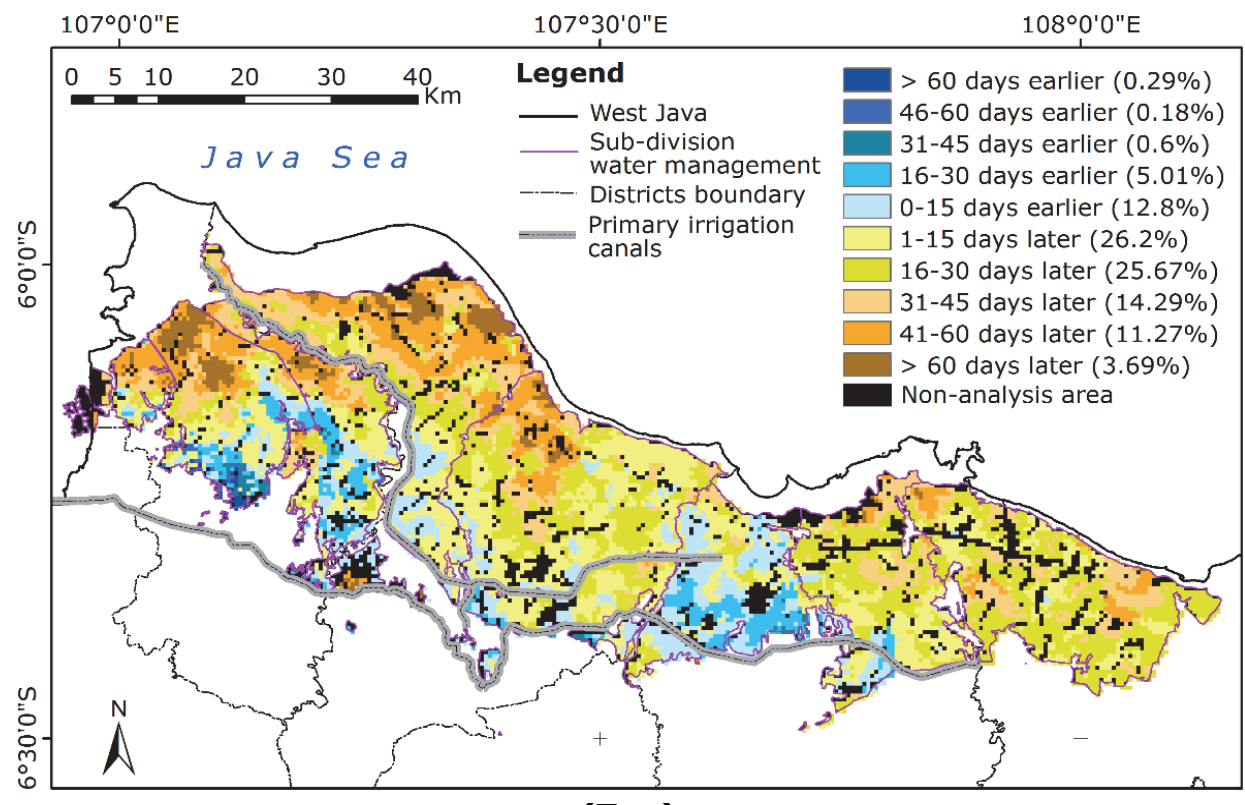

(Top)

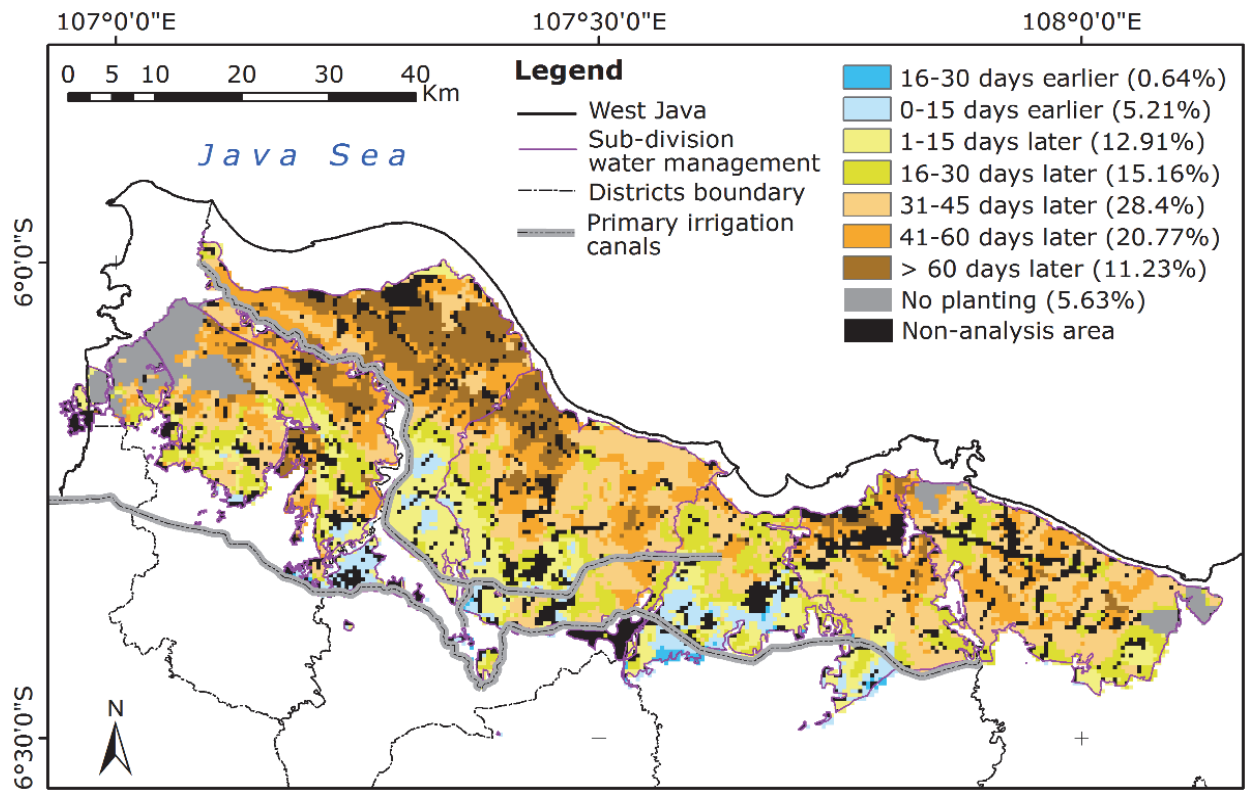

\section{(Bottom)}

Figure 6.4. Deviation (days) of long-term average (2000-2015) planting dates from the official cropping calendar in irrigated rice fields served by Ir. Djuanda reservoir during (top) wet and (bottom) dry planting seasons 
Efforts to address the unsafe conditions are likely beneficial for reducing vulnerability to natural hazards in irrigated rice fields. Addressing unsafe conditions related to economic motives can be done by livelihood diversification and balanced farming practices (double-rice cropping pattern with fallow) that focus on ecological and social cohesion aspects. Farmers may also optimize the use of rice fields for planting cash crops (e.g., onions, tomatoes, long beans) or adopting a rice-fish system. Addressing unsafe conditions associated with fragile infrastructures may be done by improving poor infrastructure conditions to secure water availability and reduce the risk of crop damages from flooding and water-deficit events during wet and dry planting seasons. Furthermore, strategies incorporating a range of non-structural measures, such as awareness programs on unsuitable coping strategy impacts, training and education on best farming practices, or livelihood diversification may be useful for building the resilience and reducing the vulnerability of farmers to natural hazards. Also, the adoption of insurance mechanisms can be useful for transferring the remaining risk of natural hazards. Reducing vulnerability requires local stakeholders to continuously collaborate with external stakeholders. The availability of farming information should be supported by the ability of farmers in quantifying changes (e.g., rainfall, rice disease symptoms) and interpreting available data. At the same time, studies for improving flood- and drought-tolerant rice varieties and devising environmentally-friendly cropping practices must be continuously encouraged. 


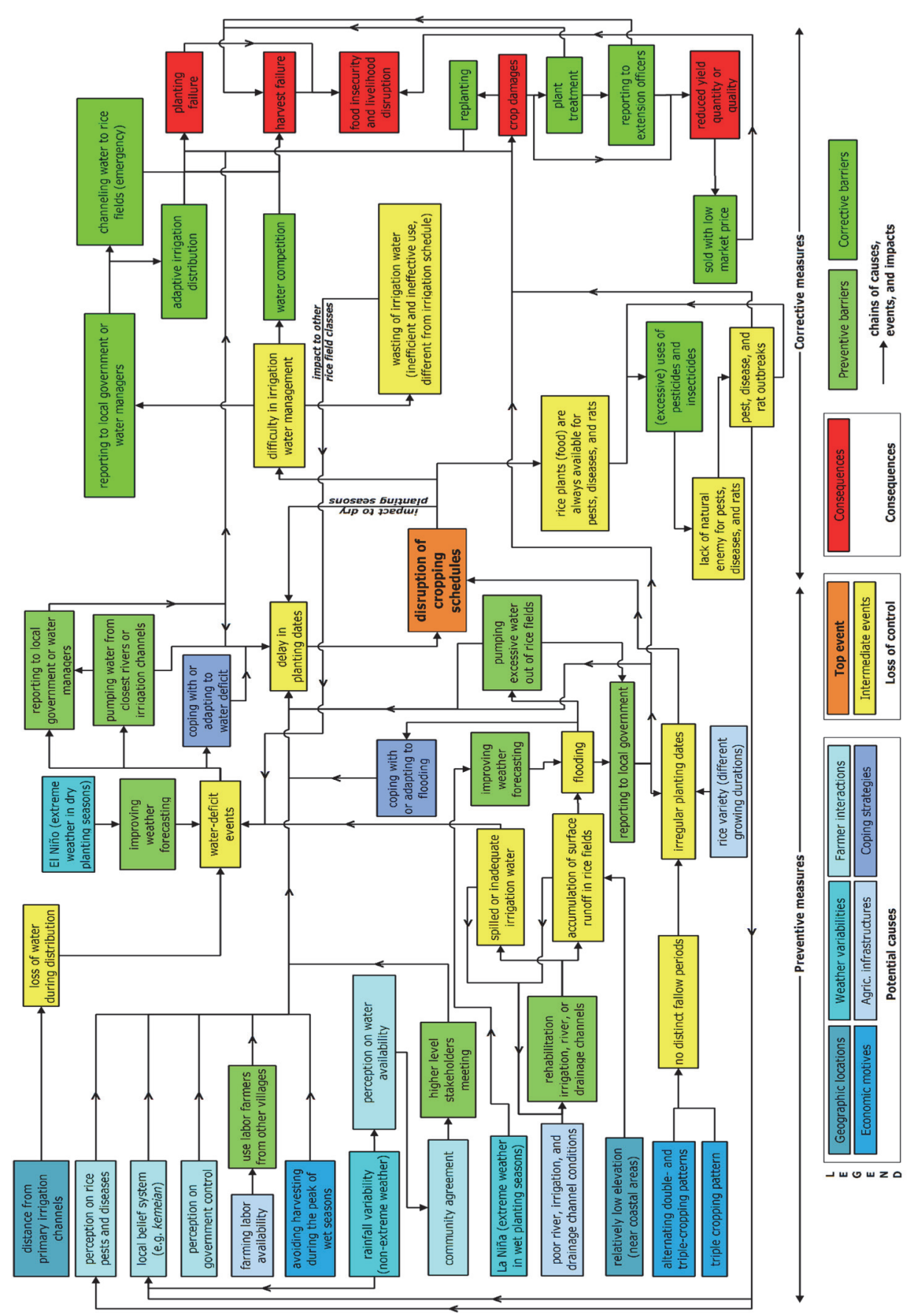

Figure 6.5 Bow-Tie analysis of reasons for disruptions in cropping schedules in irrigated rice fields served by Ir. Djuanda reservoir in West Java. Reasons comprise economic motives, weather variabilities, geographic locations, coping strategies, farmers' interactions, and agricultural infrastructures. 
Rice fields are connected through a range of socio-economic, institutional, and environmental processes. The outcomes of rice fields located near primary irrigation channels may influence those of rice fields located close to coastal areas and vice versa (Figure 6.6). Several examples are as follows. The irregularity in cropping schedules may increase the risk of crop damages due to rat attacks, jeopardizing rice cultivation in the whole rice fields served by the Ir. Djuanda reservoir. Farmers affected by adverse events may perform different coping mechanisms to reduce potential disaster impacts. Farmers may buy new seedlings to ensure synchronous planting with neighboring rice fields. Another example is related to community recovery. Farmers may work as farm labors if conditions does not allow for rice cultivation. The faster communities recover from adverse events, the faster the availability of farming jobs (e.g., transplanting, weeding), supporting the recovery processes of other farmers.

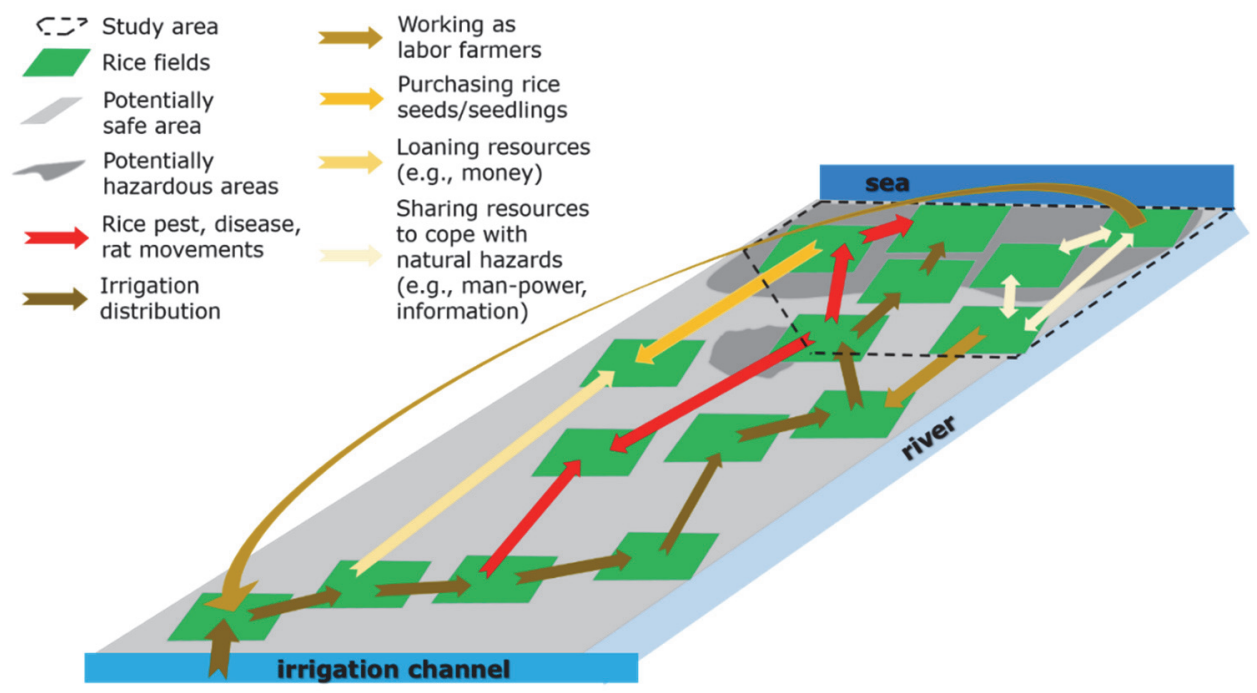

Figure 6.6. Examples of interrelationships among farming households in the study area. Rice fields are connected through socio-economic, institutional, and environmental processes.

\subsection{How can the impacts of natural hazards in irrigated rice fields be reduced?}

This study has demonstrated that irrigated rice fields in West Java suffer from recurrent disaster events during wet and dry planting seasons. The impacts of hazardous events differ seasonally depending on the severity of natural hazards and vulnerability. Additionally, it has been illustrated that farmers face crop damages from pest and disease outbreaks differently during planting 
seasons. Several points to reduce disaster risk in irrigated rice fields in West Java are highlighted based on findings in each chapter of the thesis.

Firstly, it is essential to implement a consistent cropping calendar. Regular cropping schedules are likely able to address several unsafe conditions in irrigated rice fields, such as the irregularity in cropping patterns and irrigation distribution, incidences of rice pest or disease outbreaks, and availability of farming labors. To consistently implement the official cropping calendar, rice agricultural stakeholders may need to address challenges related to economic motives, weather variabilities, geographic locations, coping strategies, farmers' interactions, and agricultural infrastructures. Addressing the challenges may require structural and non-structural measures. Structural measures can be directed to increase the access to irrigation water and reduce the severity of flood hazard, among others. Non-structural measures can be performed, for example, by improving the awareness of farmers on their vulnerability and hazards in their vicinity, accelerating the flow of farming information, increasing the capacity of weather forecasting institutions, or adopting sustainable farming practices.

Secondly, reducing potential impacts of disasters in irrigated rice fields can be conducted by resilience building. The economic aspect plays a dominant role in the recovery of farmers from disaster events at the household level in the study area. However, building resilience may require farmers to increase the overall livelihood capitals of farmers, including the social, environmental, individual, and institutional aspects. These are the resources used by farmers not only to recover, but also to prevent, cope with, or adapt to adverse events. Efforts to build resilience may involve tradeoffs between the short- and longterm benefits, such as diversifying income sources (e.g., non-rice and nonfarming), employing balanced farming practices, or improving irrigation infrastructures, among others.

Thirdly, reliable farming information, such as weather variabilities, irrigation schedules, pest and disease symptoms, or early warning, plays an essential role in reducing potential disaster impacts. Not only will it improve awareness and preparedness, but reliable information is also crucial for making informed farming decisions. In this regard, partnership among rice agricultural stakeholders (e.g., farmers, water managers, extension officers) at different management levels is crucial for improving the production, dissemination, access, and interpretation of farming information.

Finally, efforts to reduce the potential impacts of natural hazards should incorporate measures that stretch beyond the on-the-farm or household level. Focusing on the principle of sustainability (environment, social, and economy) and equality, the vision should be to improve the well-being and livelihoods of 
farmers in the whole irrigation system as well as to maintain food security. For example, the implementation of balanced cropping practices (rice-rice-fallow) is recommended compared to intensive cropping patterns (rice-rice-rice). Additionally, farming insurance may play a role in transferring the remaining risk of natural hazards. Although farming insurance has been available for farmers since the wet planting season 2016, the participation of farmer is still low during the dry planting season 2016. However, the investigation of the role of farming insurance to reduce potential disaster impacts is out of the scope of the study. Furthermore, the government plays an essential role in enacting and enforcing the public policies and regulations that aim to reduce disaster risk and build resilience. To ensure the continuity, programs to reduce disaster impacts in irrigated rice fields should be integrated into rural development policies and performed by stakeholders according to their respective roles.

\subsection{Recommendations}

\section{A. For research}

- This study used time-series 8 day $500 \mathrm{~m}$ spatial MODIS imageries to map rice cropping patterns and detect flooding and water-deficit events in irrigated rice fields in West Java. Studies that use higher spatial and temporal resolution may improve findings presented in this study. Such improvement may enable the monitoring of rice fields at a greater detail, connecting farmers and their rice fields or allowing for the validation of coarse and moderate resolution imageries. In this regard, it is necessary to continuously record farming practices and rice field conditions and relate the changes with remote sensing imageries. Also, there is a need to understand and update normal and disrupted farming practices in irrigated rice fields.

- This study has provided background for an in-depth investigation of risk and resilience determinants in the context of irrigated rice fields. Studies using panel data are useful for monitoring changes in the vulnerability, risk, and resilience of farmers to natural hazards

- This research has identified that farmers are interconnected among others through social, economic, institutional, and environmental processes. Studies that focus on the ability of farmers' households and community to mobilize livelihood capitals for reducing risk and building resilience to natural hazards are also suggested.

\section{B. For practice}

- Rice agriculture stakeholders should be open for innovation and embrace the lifestyle of 'living with risk'. The stakeholders focus needs to be shifted into reducing the risk instead of continuously dealing with disaster events.

- Differences in terms, definitions, and 'vocabulary' exist among rice agricultural stakeholders. Stakeholders must not wait until disruptions in 
farming practices occurred before coordination can be established. Farmers or other stakeholders should not conduct risk reduction strategies in isolation. This discrepancy should be seen as an opportunity to improve communication and link local knowledge and technology advancement with the focus on reducing disaster risk and increasing resilience. It is recommended that rice agricultural stakeholders strive for improving a seamless communication system at different management levels. Lack of communication, whether at the community or national level, between farmers and stakeholders may elevate the risk of natural hazards in irrigated rice fields.

- Data related to natural hazards and vulnerability and resilience in the study area are lacking, hampering efforts to reduce disaster risk in the context of rural areas and irrigated rice fields. Partnership that leads to data and technology sharing among government institutions may compensate this disadvantage. Such cooperation may also leverage the coping mechanism and adaptation strategies performed to face increasing or unexpected natural hazards.

- Methods to disseminate farming information effectively and efficiently are urgently needed. In relation to this, stakeholders should continuously improve their capacity according to the assigned roles and responsibilities to be able to substantially reduce disaster risk, face the unexpected future adverse events, and build resilience. For example, farmers may need to learn how to use the internet to access information or interpret weather data. Agricultural and weather offices should cooperate to provide timely farming information and recommendation. Public works and irrigation management offices need to collaborate to maintain irrigation channel conditions and quality services.

- It is essential that disaster risk reduction efforts be integrated with rural or rice agricultural development programs to reduce existing risk, prevent the creation of new risk, or increasing resilience to natural hazards. Additionally, it is necessary that such programs and farming information reach the poor and the vulnerable to build trust and ensure equal opportunities for improved well-being. In this regard, government officials may need to devise reaching out strategies. 


\section{Bibliography}

Abe, Sekiya, Kanemaru and Okamoto, 2014. Spatial Analysis of Flood Area and Its Impact on Rice Production on Vientiane Plain. Integrated Studies of Social and Natural Environmental Transition in Laos. S. Yokoyama, K. Okamoto, C. Takenaka and I. Hirota, Springer Japan: 119-139.

Adger, 2000. Social and ecological resilience: are they related? Progress in Human Geography 24(3), 347-364.

Adger, 2006. Vulnerability. Global Environmental Change 16(3), 268-281.

Adger, Hughes, Folke, Carpenter and Rockström, 2005. Social-Ecological Resilience to Coastal Disasters. Science 309(5737), 1036-1039.

Adrianto and Matsuda, 2002. Developing economic vulnerability indices of environmental disasters in small island regions. Environmental Impact Assessment Review 22(4), 393-414.

Akter and Mallick, 2013. The poverty-vulnerability-resilience nexus: Evidence from Bangladesh. Ecological Economics 96, 114-124.

Alam, Alam and Mushtaq, 2016. Influence of institutional access and social capital on adaptation decision: Empirical evidence from hazard-prone rural households in Bangladesh. Ecological Economics 130, 243-251.

Alexander, 2013. Resilience and disaster risk reduction: An etymological journey. Nat. Hazards Earth Syst. Sci. 13(11), 2707-2716.

Ali, de Bie and Skidmore, 2013a. Detecting long-duration cloud contamination in hyper-temporal NDVI imagery. International Journal of Applied Earth Observation and Geoinformation 24(0), 22-31.

Ali, de Bie, Skidmore, Scarrott, Hamad, Venus and Lymberakis, 2013b. Mapping land cover gradients through analysis of hyper-temporal NDVI imagery. International Journal of Applied Earth Observation and Geoinformation 23(0), 301-312.

Ali, de Bie, Skidmore, Scarrott and Lymberakis, 2014. Mapping the heterogeneity of natural and semi-natural landscapes. International Journal of Applied Earth Observation and Geoinformation 26(0), 176183.

Amien, Rejekiningrum, Pramudia and Susanti, 1996. Effects of Interannual Climate Variability and Climate Change on Rice Yield in Java, Indonesia. Water, Air, and Soil Pollution 92(1), 29-39.

Ampong-Nyarko and Datta, 1991. A handbook for weed control in rice. Manila, Philippines, International Rice Research Institute.

Arouri, Nguyen and Youssef, 2015. Natural disasters, household welfare, and resilience: Evidence from rural Vietnam. World Development 70, 59-77.

As-syakur, Tanaka, Osawa and Mahendra, 2013. Indonesian rainfall variability observation using TRMM multi-satellite data. International Journal of Remote Sensing 34(21), 7723-7738. 
Atzberger, 2013. Advances in Remote Sensing of Agriculture: Context Description, Existing Operational Monitoring Systems and Major Information Needs. Remote Sensing 5(2), 949.

Aulia, Liyantono, Setiawan and Fatikhunnada, 2016. Drought Detection of West Java's Paddy Field Using MODIS EVI Satellite Images (Case Study: Rancaekek and Rancaekek Wetan). Procedia Environmental Sciences 33, 646-653.

Azeem, Mugera and Schilizzi, 2016. Poverty and vulnerability in the Punjab, Pakistan: A multilevel analysis. Journal of Asian Economics 44, 57-72.

Bahta, Jordaan and Muyambo, 2016. Communal farmers' perception of drought in South Africa: Policy implication for drought risk reduction. International Journal of Disaster Risk Reduction 20, 39-50.

Bailey-Serres, Lee and Brinton, 2012. Waterproofing Crops: Effective Flooding Survival Strategies. Plant Physiology 160(4), 1698-1709.

Bao and Fang, 2012. Water Resources Flows Related to Urbanization in China: Challenges and Perspectives for Water Management and Urban Development. Water Resources Management 26(2), 531-552.

Barbier, López and Hochard, 2016. Debt, poverty and resource management in a rural smallholder economy. Environmental and Resource Economics 63(2), 411-427.

Becker, 2014. Chapter 9 - Developing Capacities for Resilience. Sustainability Science, Elsevier: 207-243.

Béné, Al-Hassan, Amarasinghe, Fong, Ocran, Onumah, Ratuniata, Tuyen, McGregor and Mills, 2016. Is resilience socially constructed? Empirical evidence from Fiji, Ghana, Sri Lanka, and Vietnam. Global Environmental Change 38, 153-170.

Bengtsson, 2016. How to plan and perform a qualitative study using content analysis. NursingPlus Open 2, 8-14.

Berkes, 2007. Understanding uncertainty and reducing vulnerability: lessons from resilience thinking. Natural Hazards 41(2), 283-295.

Bernsten and Rachim, 1982. Labor shortage as a constraint to increasing cropping intensity. Report of a Workshop on Cropping Systems Research in Asia. W. G. Rockwood and G. Argosino. Los Baños Laguna, Philippines, International Rice Research Institute: 591-616.

Best, 1988 . Change over time in a farming system based on shifting cultivation of hill rice in Sarawak, Malaysia. Agricultural Administration and Extension 29(1), 69-84.

Bie, 2004. Spatial-Temporal Mapping of Agro-Ecosystems and the need to build Thematic Legends XXth ISPRS Congress O. Altan. Istanbul, Turkey, ISPRS. XXXV 1148-1154

Bie, Nguyen, Ali, Scarrott and Skidmore, 2012. LaHMa: a landscape heterogeneity mapping method using hyper-temporal dataset. International Journal of Geographical Information Science 26(11), 21772192. 
Birkmann, 2006. Measuring vulnerability to natural hazards: towards disaster resilient societies. Tokyo, United Nations University Press.

Birkmann and Fernando, 2008. Measuring revealed and emergent vulnerabilities of coastal communities to tsunami in Sri Lanka. Disasters 32(1), 82-105.

Birkmann and Wisner, 2006. Measuring the Un-Measurable: The Challenge of Vulnerability. Bonn, Germany, UNU Institute for Environment and Human Security (UNU-EHS).

Birthal, Negi, Khan and Agarwal, 2015. Is Indian agriculture becoming resilient to droughts? Evidence from rice production systems. Food Policy 56, 112.

Boer and Subbiah, 2005. Agricultural Drought in Indonesia. Monitoring and predicting agricultural drought: A global study. V. K. Boken, A. P. Cracknell and R. L. Heathcote. New York, Oxford University Press: 330344.

Bolin and Stanford, 1998. The Northridge Earthquake: Community-based Approaches to Unmet Recovery Needs. Disasters 22(1), 21-38.

Bos and Tarnai, 1999. Content analysis in empirical social research. International Journal of Educational Research 31(8), 659-671.

Boschetti, Nutini, Manfron, Brivio and Nelson, 2014. Comparative Analysis of Normalised Difference Spectral Indices Derived from MODIS for Detecting Surface Water in Flooded Rice Cropping Systems. PLoS ONE $9(2)$.

Boschetti, Stroppiana, Brivio and Bocchi, 2009. Multi-year monitoring of rice crop phenology through time series analysis of MODIS images. International Journal of Remote Sensing 30(18), 4643-4662.

Bouman, Barker, Humphreys, Tuong, Atlin, Bennett, Dawe, Dittert, Dobermann, Facon, Fujimoto, Gupta, Haefele, Hosen, Ismail, Johnson, Johnson, Khan, Shan, Masih, Matsuno, Pandey, Shaobing Peng, Thiyagarajan and Wassman, 2007a. Rice: feeding the billions. Water for Food, Water for Life. D. Molden. United Kingdom, Earthscan: 515-549.

Bouman, R.M. Lampayan and Tuong, 2007b. Water management in irrigated rice: coping with water scarcity. Los Baños, Philippines, The International Rice Research Institute (IRRI).

BPS, 2017, Produksi Padi Menurut Provinsi (ton), 1993-2015. https://www.bps.go.id Retrieved 21-04, 2017.

Brown, Leung, Sudarmaji and Singleton, 2010. Movements of the Ricefield Rat, Rattus Argentiventer, Near a Trap-Barrier System in Rice Crops in West Java, Indonesia. International Journal of Pest Management 49(2), 123129.

Burnard, 1991. A method of analysing interview transcripts in qualitative research. Nurse Education Today 11(6), 461-466.

Campbell and Wynne, 2011. Introduction to Remote Sensing. United States of America, The Guilford Press. 
Cardona, 2004. The need for rethinking the concepts of vulnerability and risk from a holistic perspective: a necessary review and criticism for effective risk management. Mapping Vulnerability: Disasters, Development and People. G. Bankoff, G. Frerks and D. Hilhorst. London, Earthscan Publishers.

Cardona, 2005. Indicators of disaster risk and risk management-main technical report. Colombia, New York, National University of Colombia, Manizales Inter-American Development Bank.

Cardona, van Aalst, Birkmann, Fordham, McGregor, Perez, Pulwarty, Schipper and Sinh, 2012. Determinants of Risk: Exposure and Vulnerability. Managing the Risks of Extreme Events and Disasters to Advance Climate Change Adaptation. C. B. Field, V. R. Barros, T. F. Stocker, D. Qin, D. J. Dokken, K. L. Ebi, M. D. Mastrandrea, K. J. Mach, G.-K. Plattner, S. K. Allen, M. Tignor and P. M. Midgley. Cambridge, United Kingdom and New York, NY, USA, Cambridge University Press: 65-108.

Carpenter, Walker, Anderies and Abel, 2001. From metaphor to measurement: Resilience of What to What? Ecosystems 4(8), 765-781.

Carson, 2002. Silent Spring. New York, Houghton Mifflin Company.

Cervantes-Godoy and Dewbre, 2010. Economic importance of agriculture for sustainable development and poverty reduction: Findings from a case study of Indonesia. Global forum on agriculture.

Cesari de Maria, Bischetti, Chiaradia, Facchi, Miniotti, Rienzner, Romani, Tenni and Gandolfi, 2017. The role of water management and environmental factors on field irrigation requirements and water productivity of rice. Irrigation Science 35(1), 11-26.

Chakraborty and Joshi, 2016. Mapping disaster vulnerability in India using analytical hierarchy process. Geomatics, Natural Hazards and Risk 7(1), 308-325.

Chatenoux and Peduzzi, 2007. Impacts from the 2004 Indian Ocean Tsunami: analysing the potential protecting role of environmental features. Natural Hazards 40(2), 289-304.

Chau, Holland, Cassells and Tuohy, 2013. Using GIS to map impacts upon agriculture from extreme floods in Vietnam. Applied Geography 41,6574.

Chen, Jönsson, Tamura, Gu, Matsushita and Eklundh, 2004. A simple method for reconstructing a high-quality NDVI time-series data set based on the Savitzky-Golay filter. Remote Sensing of Environment 91(3-4), 332344.

Chuvieco and Huete, 2009. Fundamentals of Satellite Remote Sensing. Boca Raton, CRC Press

Cicourel, 1964. Method and Measurement in Sociology. New York, London, The Free Press, Collier Macmillan Publishers. 
Cimellaro, 2016. Resilience Indicators. Urban Resilience for Emergency Response and Recovery: Fundamental Concepts and Applications. Cham, Springer International Publishing: 49-69.

Cockshott, 2005. Probability Bow-Ties. Process Safety and Environmental Protection 83(4), 307-316.

Collier, Soentoro, Wiradi, Pasandaran, Santoso and Stepanek, 1982. Acceleration of Rural Development of Java. Bulletin of Indonesian Economic Studies 18(3), 84-101.

Congalton, 1991. A review of assessing the accuracy of classifications of remotely sensed data. Remote Sensing of Environment 37(1), 35-46.

Constas, Frankenberger, Hoddinott, Mock, Romano, Béné and Maxwell, 2014. A common analytical model for resilience measurement: Causal framework and methodological options. Resilience Measurement Technical Working Group. Rome, Food Security Information Network.

Coomes, Lapointe, Templeton and List, 2016. Amazon river flow regime and flood recessional agriculture: Flood stage reversals and risk of annual crop loss. Journal of Hydrology 539, 214-222.

Corfee-Morlot, Cochran, Hallegatte and Teasdale, 2011. Multilevel risk governance and urban adaptation policy. Climatic Change 104(1), 169197.

Cumming, Barnes, Perz, Schmink, Sieving, Southworth, Binford, Holt, Stickler and Van Holt, 2005. An Exploratory Framework for the Empirical Measurement of Resilience. Ecosystems 8(8), 975-987.

Cutter, 2016. Resilience to What? Resilience for Whom? The Geographical Journal 182(2), 110-113.

Cutter, Barnes, Berry, Burton, Evans, Tate and Webb, 2008. A place-based model for understanding community resilience to natural disasters. Global Environmental Change 18(4), 598-606.

Cutter and Finch, 2008. Temporal and spatial changes in social vulnerability to natural hazards. Proceedings of the National Academy of Sciences 105(7), 2301-2306.

Cutter and Gall, 2007. Hurricane Katrina: A failure of planning or a planned failure. Naturrisken und Sozialkatastrophen. Berlin, Heidelberg: Springer.

Dalal-Clayton and Dent, 1993. Surveys, Plans and People: A Review of Land Resource Information and its Use in Developing Countries. London, England, UK. , International Institute for Environment and Development: Environmental Planning Group.

Daléus, Palm, Sandell, Jayawardena and Siripala, 1988. Management and environmental constraints to rice yield within a village irrigation system - A case study from Sri Lanka. GeoJournal 17(3), 401-412.

Dalezios, Blanta, Spyropoulos and Tarquis, 2014. Risk identification of agricultural drought for sustainable Agroecosystems. Nat. Hazards Earth Syst. Sci. 14(9), 2435-2448. 
Dalgliesh, Charlesworth, Lonh and Poulton, 2016. Promoting resilience in Cambodian lowland rice ecosystems-Farming system research to support flexible climate response strategies for smallholder farmers. Field Crops Research 198, 148-159.

Darmawan, Takeuchi, Shofiyati, Sari and Wikantika, 2014. Seasonal analysis of precipitation, drought and Vegetation index in Indonesian paddy field based on remote sensing data. IOP Conference Series: Earth and Environmental Science 20(1), 012049.

Daruati, Rahmatulloh and Purwadhi, 2013. Agricultural Drought Pattern in West Java Using Thermal Vegetation Index from Modis-Terra Satellite.

Datta, 1981. Principles and Practices of Rice Production. Canada, John Wiley \& Sons.

de Desarrollo Asiático, 2006. Indonesia: Strategic Vision for Agriculture and Rural Development. Manila: Banco de Desarrollo Asiático.

Deng, Ling, Sun, Zhang, Fahad, Peng, Cui, Nie and Huang, 2015. Influence of temperature and solar radiation on grain yield and quality in irrigated rice system. European Journal of Agronomy 64, 37-46.

Déri, 2014. Maps, Knowledge and Resilience: Application of ArcGIS in Building Small Islands' Resilience to Climate Change. Geospatial Technologies and Climate Change. J. Sundaresan, K. M. Santosh, A. Déri, R. Roggema and R. Singh. Cham, Springer International Publishing: 137-174.

Dixon and Stringer, 2015. Towards a theoretical grounding of climate resilience assessments for smallholder farming systems in Sub-Saharan Africa. Resources 4(1), 128.

Dobermann and Fairhurst, 2000. Rice: nutrient disorders \& nutrient management, Int. Rice Res. Inst.

Dong, Xiao, Menarguez, Zhang, Qin, Thau, Biradar and Moore Iii, 2016. Mapping paddy rice planting area in northeastern Asia with Landsat 8 images, phenology-based algorithm and Google Earth Engine. Remote Sensing of Environment 185, 142-154.

Douxchamps, Debevec, Giordano and Barron, 2017. Monitoring and evaluation of climate resilience for agricultural development - A review of currently available tools. World Development Perspectives 5, 10-23.

Dovers and Handmer, 1992. Uncertainty, sustainability and change. Global Environmental Change 2(4), 262-276.

Dow, 1992. Exploring differences in our common future (s): The meaning of Vulnerability to global environmental change. Geoforum 23(3), 417-436.

Easterling, Meehl, Parmesan, Changnon, Karl and Mearns, 2000. Climate Extremes: Observations, Modeling, and Impacts. Science 289(5487), 2068-2074.

Ehrlich and Tenerelli, 2013. Optical satellite imagery for quantifying spatiotemporal dimension of physical exposure in disaster risk assessments. Natural Hazards 68(3), 1271-1289. 
Elo and Kyngäs, 2008. The qualitative content analysis process. Journal of Advanced Nursing 62(1), 107-115.

Evrendilek and Gulbeyaz, 2008. Deriving Vegetation Dynamics of Natural Terrestrial Ecosystems from MODIS NDVI/EVI Data over Turkey. Sensors $8(9), 5270$.

Fang, Zhao, Rasul and Wahid, 2016. Rural household vulnerability and strategies for improvement: An empirical analysis based on time series. Habitat International 53, 254-264.

FAO, 2015. The impact of disasters on agriculture and food security, Food and Agriculture Organization of the United Nations (FAO).

FAOSTAT, 2014. http://www.fao.org/faostat/en/ Retrieved 18-04-2017, 2017.

Fekete, Hufschmidt and Kruse, 2014. Benefits and Challenges of Resilience and Vulnerability for Disaster Risk Management. International Journal of Disaster Risk Science 5(1), 3-20.

Field, 2009. Discovering Statistics using SPSS, SAGE Publications Ltd.

Folke, Colding and Berkes, 2003. Synthesis: building resilience and adaptive capacity in social-ecological systems. Navigating social-ecological systems: Building resilience for complexity and change 9(1), 352-387.

Foody, 2002. Status of land cover classification accuracy assessment. Remote Sensing of Environment 80(1), 185-201.

Ganji, Shokoohi and Samani, 2012. Developing an agricultural flood loss estimation function (case study: rice). Natural Hazards 64(1), 405-419.

Gao, 1996. NDWI-A normalized difference water index for remote sensing of vegetation liquid water from space. Remote Sensing of Environment 58(3), 257-266.

Gao, Huete, $\mathrm{Ni}$ and Miura, 2000. Optical-Biophysical Relationships of Vegetation Spectra without Background Contamination. Remote Sensing of Environment 74(3), 609-620.

Gardoni, Murphy and Rowell, 2016. Risk analysis of natural hazards: Interdisciplinary challenges and integrated solutions. Risk Analysis of Natural Hazards: Interdisciplinary Challenges and Integrated Solutions. P. Gardoni, C. Murphy and A. Rowell. Cham, Springer International Publishing: $1-7$.

Gathorne-Hardy, Reddy, Venkatanarayana and Harriss-White, 2016. System of Rice Intensification provides environmental and economic gains but at the expense of social sustainability - A multidisciplinary analysis in India. Agricultural Systems 143, 159-168.

Gauch and Whittaker, 1981. Hierarchical Classification of Community Data. Journal of Ecology 69(2), 537-557.

Gerkensmeier and Ratter, 2016. Multi-risk, multi-scale and multi-stakeholder - the contribution of a bow-tie analysis for risk management in the trilateral Wadden Sea Region. Journal of Coastal Conservation, 1-12. 
Gill and Malamud, 2016. Hazard interactions and interaction networks (cascades) within multi-hazard methodologies. Earth Syst. Dynam. 7(3), 659-679.

Gómez-Baggethun, Reyes-García, Olsson and Montes, 2012. Traditional ecological knowledge and community resilience to environmental extremes: A case study in Doñana, SW Spain. Global Environmental Change 22(3), 640-650.

Goswami, Venugopal, Sengupta, Madhusoodanan and Xavier, 2006. Increasing Trend of Extreme Rain Events over India in a Warming Environment. Science 314(5804), 1442-1445.

GRiSP, 2013. Rice almanac. Los Baños (Philippines), International Rice Research Institute.

Guilpart, Grassini, Sadras, Timsina and Cassman, 2017. Estimating yield gaps at the cropping system level. Field Crops Research 206, 21-32.

Gumma, Gauchan, Nelson, Pandey and Rala, 2011. Temporal changes in ricegrowing area and their impact on livelihood over a decade: A case study of Nepal. Agriculture, Ecosystems \& Environment 142(3-4), 382-392.

Gumma, Mohanty, Nelson, Arnel, Mohammed and Das, 2015. Remote sensing based change analysis of rice environments in Odisha, India. Journal of Environmental Management 148, 31-41.

Guo, Jia, Huang, Kumar and Burger, 2015. Farmer field school and farmer knowledge acquisition in rice production: Experimental evaluation in China. Agriculture, Ecosystems \& Environment 209, 100-107.

Gustoni, 2013. Pemberdayaan KUMKM Jawa Barat dalam Menghadapi Masyarakat Ekonomi Asean 2015. Jakarta, Indonesia, Pemerintah Provinsi Jawa Barat: 45.

Haefele, Kato and Singh, 2016. Climate ready rice: Augmenting drought tolerance with best management practices. Field Crops Research 190, 60-69.

Hallegatte, 2014. What Is a Disaster? An Economic Point of View. Natural Disasters and Climate Change: An Economic Perspective. Cham, Springer International Publishing: 9-50.

Harger, 1995. Air-temperature variations and ENSO effects in Indonesia, the Philippines and El Salvador. ENSO patterns and changes from 18661993. Atmospheric Environment 29(16), 1919-1942.

Hoang, Castella and Novosad, 2006. Social networks and information access: Implications for agricultural extension in a rice farming community in northern Vietnam. Agriculture and Human Values 23(4), 513-527.

Holling, 1973. Resilience and stability of ecological systems. Annual Review of Ecology and Systematics 4, 1-23.

Holling, 1986. The resilience of terrestrial ecosystems: local surprise and global change. Sustainable development of the biosphere 14, $292 \AA ̀ 317$.

Holz and Sioe, 1965. The Parasites of Rat in West-Java. Zeitschrift für Parasitenkunde 25(5), 405-412. 
Hoque, Hobbs, Elahi, Miah, Hossain, Quddus, Akanda, Rahman, Khan and Siddiqui, 1982. Testing of Rice-based Cropping Patterns at Four Selected Sites in Bangladesh. Report of a Workshop on Cropping Systems Research in Asia. W. G. Rockwood and G. Argosino. Los Baños Laguna, Philippines, International Rice Research Institute: 211-224.

Huang, Shan, Cao and Zou, 2016. The solar radiation-related determinants of rice yield variation across a wide range of regions. NJAS - Wageningen Journal of Life Sciences 78, 123-128.

Huete, Didan, Miura, Rodriguez, Gao and Ferreira, 2002. Overview of the radiometric and biophysical performance of the MODIS vegetation indices. Remote Sensing of Environment 83(1-2), 195-213.

Huete, Liu, Batchily and Leeuwen, 1997. A Comparison of Vegetation Indices over a Global Set of TM Images for EOS-MODIS. Remote Sensing and Environment 59, 440-451.

Husin, Murdiyarso, Khalil, Rasmussen, Shearer, Sabiham, Sunar and Adijuwana, 1995. Methane flux from Indonesian wetland rice: the effects of water management and rice variety. Chemosphere 31(4), 3153-3180.

Hussain, Wijerathna, Arif, Murtiningrum, Mawarni and Suparmi, 2006. Irrigation, Productivity and Poverty Linkages in Irrigation Systems in Java, Indonesia. Water Resources Management 20(3), 313-336.

IFRC, 2014. IFRC Framework for Community Resilience. Geneva, Switzerland, The International Federation of Red Cross and Red Crescent Societies (IFRC).

IPCC, 2014. Summary for policymakers. Climate Change 2014: Impacts,Adaptation, and Vulnerability. Part A: Global and Sectoral Aspect. C. B. Field, V. R. Barros, D. J. Dokken, K. J. Mach, M. D. Mastrandrea, T. E. Bilir, M. Chatterjee, K. L. Ebi, Y.O. Estrada, R.C. Genova, B. Girma, E. S. Kissel, A. N. Levy, S. MacCracken, P. R. Mastrandrea and L.L.White. Cambridge, United Kingdom, NewYork, NY, USA, Cambridge University Press: 1-32.

Islam, 2011. Living on the margin: The poverty-vulnerability nexus in the small-scale fisheries of Bangladesh. Poverty Mosaics: Realities and Prospects in Small-Scale Fisheries. S. Jentoft and A. Eide. Dordrecht, Springer Netherlands: 71-95.

Islam, Bala and Haque, 2010. Flood inundation map of Bangladesh using MODIS time-series images. Journal of Flood Risk Management 3(3), 210222.

Islam and Molla, 2001. Economic weeding method for irrigated rice production in Bangladesh. Agricultural Water Management 46(3), 267-276.

Jain, Keshri, Goswami, Sarkar and Chaudhry, 2009. Identification of droughtvulnerable areas using NOAA AVHRR data. International Journal of Remote Sensing 30(10), 2653-2668. 
Ji, Zhang and Wylie, 2009. Analysis of Dynamic Thresholds for the Normalized Difference Water Index. Journal of the American Society for Photogrammetry and Remote Sensing 75(11), 1307-1317.

Jiang, Huete, Didan and Miura, 2008. Development of a two-band enhanced vegetation index without a blue band. Remote Sensing of Environment 112(10), 3833-3845.

John, 2014. Rodent outbreaks and rice pre-harvest losses in Southeast Asia. Food Security 6(2), 249-260.

Jones and Tanner, 2017. 'Subjective resilience': using perceptions to quantify household resilience to climate extremes and disasters. Regional Environmental Change 17(1), 229-243.

Jonsson and Eklundh, 2002. Seasonality extraction by function fitting to timeseries of satellite sensor data. Geoscience and Remote Sensing, IEEE Transactions on $40(8), 1824-1832$.

Jülich, 2015. Development of a Composite Index with Quantitative Indicators for Drought Disaster Risk Analysis at the Micro Level. Human and Ecological Risk Assessment: An International Journal 21(1), 37-66.

Jülich, 2017. Towards a Local-Level Resilience Composite Index: Introducing Different Degrees of Indicator Quantification. International Journal of Disaster Risk Science 8(1), 91-99.

Juwana, Muttil and Perera, 2016. Application of West Java Water Sustainability Index to Three Water Catchments in West Java, Indonesia. Ecological Indicators 70, 401-408.

Keil, Zeller, Wida, Sanim and Birner, 2007. What determines farmers' resilience towards ENSO-related drought? An empirical assessment in Central Sulawesi, Indonesia. Climatic Change 86(3), 291.

Kementan, 2015. Rencana Strategis Kementerian Pertanian RI tahun 20152019. Jakarta: Biro Perencanaan Kementerian Pertanian RI. hlm 21.

Kendall and Stuart, 1973. The Advanced Theory of Statistics. New York, Hafner Publishing.

Kerner and Thomas, 2014. Resilience Attributes of Social-Ecological Systems: Framing Metrics for Management. Resources 3(4), 672.

Khan, de Bie, van Keulen, Smaling and Real, 2010. Disaggregating and mapping crop statistics using hypertemporal remote sensing. International Journal of Applied Earth Observation and Geoinformation 12(1), 36-46.

Khan and Shah, 2010. Agricultural Development and Associated Environmental and Ethical Issues in South Asia. Journal of Agricultural and Environmental Ethics 24(6), 629-644.

Klein, Nicholls and Thomalla, 2003. Resilience to natural hazards: How useful is this concept? Global Environmental Change Part B: Environmental Hazards 5(1), 35-45.

Klijn, Kreibich, de Moel and Penning-Rowsell, 2015. Adaptive flood risk management planning based on a comprehensive flood risk 
conceptualisation. Mitigation and Adaptation Strategies for Global Change 20(6), 845-864.

Knapp and Kruk, 2010. Quantifying Interagency Differences in Tropical Cyclone Best-Track Wind Speed Estimates. Monthly Weather Review 138(4), 1459-1473.

Kogan, 1995a. Application of vegetation index and brightness temperature for drought detection. Advances in Space Research 15(11), 91-100.

Kogan, 1995b. Droughts of the late 1980s in the United States as derived from NOAA polar-orbiting satellite data. Bulletin - American Meteorological Society 76(5), 655-668.

Kogan, 1997. Global Drought Watch from Space. Bulletin of the American Meteorological Society 78(4), 621-636.

Kogan and Sullivan, 1993. Development of global drought-watch system using NOAA/AVHRR data. Advances in Space Research 13(5), 219-222.

Kotera, Nagano, Hanittinan and Koontanakulvong, 2016. Assessing the degree of flood damage to rice crops in the Chao Phraya delta, Thailand, using MODIS satellite imaging. Paddy and Water Environment 14(1), 271-280.

Kotera, Nguyen, Sakamoto, Iizumi and Yokozawa, 2014. A modeling approach for assessing rice cropping cycle affected by flooding, salinity intrusion, and monsoon rains in the Mekong Delta, Vietnam. Paddy and Water Environment 12(3), 343-354.

Kouadio, Ghazi and Aljunid, 2012. Human impact and financial loss of floods in Southeast Asia, from 2007 to 2011. BMC Public Health 12(2), A9.

Kuenzer, Dech and Wagner, 2015. Remote Sensing Time Series Revealing Land Surface Dynamics: Status Quo and the Pathway Ahead. Remote Sensing Time Series: Revealing Land Surface Dynamics. C. Kuenzer, S. Dech and W. Wagner. Cham, Springer International Publishing: 1-24.

Kusmayadi, Kuno and Sawada, 1990. The Spatial Distribution Pattern of the Brown Planthopper Nilaparvata Lugens Stål (Homoptera: Delphacidae) in West Java, Indonesia. Researches on Population Ecology 32(1), 6783.

Kwak, Arifuzzanman and Iwami, 2015. Prompt Proxy Mapping of Flood Damaged Rice Fields Using MODIS-Derived Indices. Remote Sensing 7(12), 15805.

Kwak, Park and Fukami, 2014. Estimating floodwater from MODIS time series and SRTM DEM data. Artificial Life and Robotics 19(1), 95-102.

Lansing, Cox, Downey, Janssen and Schoenfelder, 2009. A robust budding model of Balinese water temple networks. World Archaeology 41(1), 112-133.

Lassa, 2012. Emerging 'agricultural involution'in Indonesia: impact of natural hazards and climate extremes on agricultural crops and food system. Economic and Welfare Impacts of Disasters in East Asia and Policy Responses, 2011-2018. 
Lavell, Oppenheimer, Diop, Hess, Lempert, Li, Muir-Wood and Myeong, 2012. Climate Change: New Dimensions in Disaster Risk, Exposure, Vulnerability, and Resilience. Managing the Risks of Extreme Events and Disasters to Advance Climate Change Adaptation. A Special Report of Working Groups I and II of the Intergovernmental Panel on Climate Change (IPCC). C. B. Field, V. R. Barros, T. F. Stocker, D. Qin, D. J. Dokken, K. L. Ebi, M. D. Mastrandrea, K. J. Mach, G.-K. Plattner, S. K. Allen, M. Tignor and P. M. Midgley. Cambridge, United Kingdom and New York, NY, USA, Cambridge University Press: 25-64.

Li and Guo, 2014. A New Accuracy Assessment Method for One-Class Remote Sensing Classification. IEEE Transactions on Geoscience and Remote Sensing 52(8), 4621-4632.

$\mathrm{Li}$, Zhang, Zhao, Ma, Cao and Cao, 2016. Assessing spatial vulnerability from rapid urbanization to inform coastal urban regional planning. Ocean \& Coastal Management 123, 53-65.

Lieth, 1974. Phenology and seasonality modeling. New York, Springer-Verlag New York.

List and Coomes, 2017. Natural hazards and risk in rice cultivation along the upper Amazon River. Natural Hazards, 1-20.

Liu, Golding and Gong, 2008. Farmers' coping response to the low flows in the lower Yellow River: A case study of temporal dimensions of vulnerability. Global Environmental Change 18(4), 543-553.

Liverpool-Tasie, 2014. Farmer groups and input access: When membership is not enough. Food Policy 46, 37-49.

Loebis and Syariman, 1993. Reservoir Operation Conflict in Citarum River Basin Management. Extreme Hydrological Events: Precipitation, Floods and Droughts. Yokohama. 213: 455-459.

Lou, Wu, Chen, Ji and Sun, 2012. Assessment of rice yield loss due to torrential rain: a case study of Yuhang County, Zhejiang Province, China. Natural Hazards 60(2), 311-320.

Ludlow and Klein, 2004. Suppressor Variables: The Difference between 'Is' versus 'Acting As'. Journal of Statistics Education 22.

Luers, Lobell, Sklar, Addams and Matson, 2003. A method for quantifying vulnerability, applied to the agricultural system of the Yaqui Valley, Mexico. Global Environmental Change 13(4), 255-267.

Lukas, 2013. Political Transformation and Watershed Governance in Java: Actors and Interests. Governing the Provision of Ecosystem Services. R. Muradian and L. Rival. Dordrecht, Springer Netherlands: 111-132.

Malla, Manzano, Mallick, Pathic, Veen and Mathema, 1982. Cropping pattern testing in Nepal. Report of a Workshop on Cropping Systems Research in Asia. W. G. Rockwood and G. Argosino, International Rice Research Institute: 237-262. 
Mandal, 2014. Flood, cropping pattern choice and returns in agriculture: A study of Assam plains, India. Economic Analysis and Policy 44(3), 333344.

Manjunath, More, Jain, Panigrahy and Parihar, 2015. Mapping of rice-cropping pattern and cultural type using remote-sensing and ancillary data: a case study for South and Southeast Asian countries. International Journal of Remote Sensing 36(24), 6008-6030.

Manyena, 2011. Disaster resilience: a bounce back or bounce forward ability? Local Environment 16(5), 417-424.

Marre and Renaud, 2011. Differentials in Impacts and Recovery in the Aftermath of the 2004 Indian Ocean Tsunami: Local Examples at Different Scales in Sri Lanka. Coping with Global Environmental Change, Disasters and Security: Threats, Challenges, Vulnerabilities and Risks. H. G. Brauch, Ú. Oswald Spring, C. Mesjasz, J. Grin, P. Kameri-Mbote, B. Chourou, P. Dunay and J. Birkmann. Berlin, Heidelberg, Springer Berlin Heidelberg: 1129-1146.

Martinis, Twele, Strobl, Kersten and Stein, 2013. A Multi-Scale Flood Monitoring System Based on Fully Automatic MODIS and TerraSAR-X Processing Chains. Remote Sensing 5, 5598-5619.

Marulanda, Cardona and Barbat, 2011. Revealing the Impact of Small Disasters to the Economic and Social Development. Coping with Global Environmental Change, Disasters and Security: Threats, Challenges, Vulnerabilities and Risks. H. G. Brauch, Ú. Oswald Spring, C. Mesjasz, J. Grin, P. Kameri-Mbote, B. Chourou, P. Dunay and J. Birkmann. Berlin, Heidelberg, Springer Berlin Heidelberg: 575-584.

Massey, Walker, Anders, Smith and Avila, 2014. Farmer adaptation of intermittent flooding using multiple-inlet rice irrigation in Mississippi. Agricultural Water Management 146(0), 297-304.

Matsuno, Horino and Hatcho, 2013. On-farm irrigation development and management in lower Myanmar: factors for sustainable rice production and collective action. Paddy and Water Environment 11(1), 455-462.

Mavhura, Manyena, Collins and Manatsa, 2013. Indigenous knowledge, coping strategies and resilience to floods in Muzarabani, Zimbabwe. International Journal of Disaster Risk Reduction 5, 38-48.

Maxwell, Constas, Frankenberger, Klaus and Mock, 2015. Qualitative Data and Subjective Indicators for Resilience Measurement. Resilience Measurement Technical Working Group. Rome, Food Security Information Network.

McFeeters, 1996. The use of the Normalized Difference Water Index (NDWI) in the delineation of open water features. International Journal of Remote Sensing 17(7), 1425-1432.

Mendershausen, 1939. Clearing Variates in Confluence Analysis. Journal of the American Statistical Association 34, 93-105. 
Merz, Kreibich, Schwarze and Thieken, 2010. Review article "Assessment of economic flood damage". Natural Hazards Earth System Sciences 10, 1697-1724.

Mickelbart, Hasegawa and Bailey-Serres, 2015. Genetic mechanisms of abiotic stress tolerance that translate to crop yield stability. Nat Rev Genet 16(4), 237-251.

Miller, Osbahr, Boyd, Thomalla, Bharwani, Ziervogel, Walker, Birkmann, Van der Leeuw, Rockström, Hinkel, Downing, Folke and Nelson, 2010. Resilience and vulnerability: Complementary or conflicting concepts? Ecology and Society 15(3).

Miro and Ismail, 2013. Tolerance of anaerobic conditions caused by flooding during germination and early growth in rice (Oryza sativa L.). Frontiers in Plant Science 4, 269.

Miura, Huete, Yoshioka and Holben, 2001. An error and sensitivity analysis of atmospheric resistant vegetation indices derived from dark target-based atmospheric correction. Remote Sensing of Environment 78(3), 284298.

Montz and Tobin, 2011. Natural hazards: An evolving tradition in applied geography. Applied Geography 31(1), 1-4.

Morrow, 1999. Identifying and Mapping Community Vulnerability. Disasters 23(1), 1-18

Motohka, Nasahara, Miyata, Mano and Tsuchida, 2009. Evaluation of optical satellite remote sensing for rice paddy phenology in monsoon Asia using a continuous in situ dataset. International Journal of Remote Sensing 30(17), 4343-4357.

Mutert and Fairhurst, 2002. Developments in rice production in Southeast Asia. Better Crops International 15, 12-17.

Naylor, Falcon, Rochberg and Wada, 2001. Using El Niño/Southern Oscillation Climate Data to Predict Rice Production in Indonesia. Climatic Change $50(3), 255-265$.

Neuendorf, 2016. The content analysis guidebook, Sage publications.

Nguyen, De Bie, Ali, Smaling and Chu, 2011. Mapping the irrigated rice cropping patterns of the Mekong delta, Vietnam, through hypertemporal SPOT NDVI image analysis. International Journal of Remote Sensing 33(2), 415-434.

Nguyen and James, 2013. Measuring Household Resilience to Floods: a Case Study in the Vietnamese Mekong River Delta. Ecology and Society 18(3).

Nguyen, Seddaiu, Virdis, Tidore, Pasqui and Roggero, 2016. Perceiving to learn or learning to perceive? Understanding farmers' perceptions and adaptation to climate uncertainties. Agricultural Systems 143, 205-216.

Nicholls, 1995. Long-term climate monitoring and extreme events. Climatic Change 31(2), 231-245. 
Nuryanto, Pawitan, Hidayat and Aldrian, 2016. Heavy Rainfall Distributions Over Java Sea in Wet Season. Procedia Environmental Sciences 33, 178186.

O'Brien, Eriksen, Schjolden and Nygaard, 2004. What's in a word? Conflicting interpretations of vulnerability in climate change research. CICERO Working Paper.

OECD, 2009. Managing Risk in Agriculture: A Holistic Approach. France, OECD Publishing.

Okazumi, Tanaka, Kwak, Shrestha and Sugiura, 2014. Flood vulnerability assessment in the light of rice cultivation characteristics in Mekong River flood plain in Cambodia. Paddy and Water Environment 12(2), 275-286.

Pain and Levine, 2012. A conceptual analysis of livelihoods and resilience: addressing the'insecurity of agency', ODI.

Pan, Li, Gong, He, Shi and Pu, 2003. An integrative classification of vegetation in China based on NOAA AVHRR and vegetation-climate indices of the Holdridge life zone. International Journal of Remote Sensing 24(5), 1009-1027.

Pan, Yu, Holst and Doluschitz, 2014. Integrated assessment of cropping patterns under different policy scenarios in Quzhou County, North China Plain. Land Use Policy 40, 131-139.

Pandey, Bhandari and Hardy, 2007. Economic costs of drought and rice farmers' coping mechanisms: a cross-country comparative analysis, Int. Rice Res. Inst.

Panuju, Mizuno and Trisasongko, 2013. The dynamics of rice production in Indonesia 1961-2009. Journal of the Saudi Society of Agricultural Sciences 12(1), 27-37.

Parry, Canziani, Palutikof, van der Linden and Hanson, 2007. Climate change 2007: impacts, adaptation and vulnerability, Cambridge University Press Cambridge.

Pasaribu, 2010. Developing rice farm insurance in Indonesia. Agriculture and Agricultural Science Procedia 1(0), 33-41.

Patel, Parida, Venus, Saha and Dadhwal, 2012. Analysis of agricultural drought using vegetation temperature condition index (VTCI) from Terra/MODIS satellite data. Environmental Monitoring and Assessment 184(12), 71537163.

Paul and Rasid, 1993. Flood Damage to Rice Crop in Bangladesh. Geographical Review 83(2), 150-159.

Pedhazur, 1982. Multiple Regression in Behavioral Research: Explanation and Prediction. New York, Thomson Learning.

Peng, Huete, Huang, Wang and Sun, 2011. Detection and estimation of mixed paddy rice cropping patterns with MODIS data. International Journal of Applied Earth Observation and Geoinformation 13, 13-23.

Pine, 2009. Natural Hazards Analysis: Reducing the Impact of Disasters. United States of America, CRC Press. 
Piwowar, Peddle and LeDrew, 1998. Temporal Mixture Analysis of Arctic Sea Ice Imagery: A New Approach for Monitoring Environmental Change. Remote Sensing of Environment 63(3), 195-207.

Plate, 2002. Flood risk and flood management. Journal of Hydrology 267(1-2), 2-11.

Powell, Jakeman and Croke, 2014. Can NDVI response indicate the effective flood extent in macrophyte dominated floodplain wetlands? Ecological Indicators 45, 486-493.

Powers, 2011. Evaluation: from precision, recall and f-measure to roc, informedness, markedness \& correlation. . Journal of Machine Learning Technologies., 37-63.

Qian, Robertson and Moron, 2010. Interactions among ENSO, the Monsoon, and Diurnal Cycle in Rainfall Variability over Java, Indonesia. Journal of the Atmospheric Sciences 67(11), 3509-3524.

Qiao, Luo, Sheng, Shen, Zhu and Ming, 2012. An Adaptive Water Extraction Method from Remote Sensing Image Based on NDWI. Journal of the Indian Society of Remote Sensing 40(3), 421-433.

Qin, Xiao, Dong, Zhou, Zhu, Zhang, Du, Jin, Kou, Wang and Li, 2015. Mapping paddy rice planting area in cold temperate climate region through analysis of time series Landsat 8 (OLI), Landsat 7 (ETM+) and MODIS imagery. ISPRS Journal of Photogrammetry and Remote Sensing 105, 220-233.

Qiu, Zeng, Tang and Chen, 2013. Characterizing spatiotemporal nonstationarity in vegetation dynamics in China using MODIS EVI dataset. Environmental Monitoring and Assessment 185(11), 9019-9035.

Quiring and Ganesh, 2010. Evaluating the utility of the Vegetation Condition Index (VCI) for monitoring meteorological drought in Texas. Agricultural and Forest Meteorology 150(3), 330-339.

Ranjan, Pradhan, Reddy and Syme, 2015. Chapter 8 - Evaluating the Determinants of Perceived Drought Resilience: An Empirical Analysis of Farmers' Survival Capabilities in Drought-Prone Regions of South India. Integrated Assessment of Scale Impacts of Watershed Intervention. Boston, Elsevier: 253-285.

Ravesteijn, 2002. Dutch engineering overseas: The creation of a modern irrigation system in Colonial Java. Knowledge, Technology \& Policy 14(4), 126-144.

Redfern, Azzu and Binamira, 2012. Rice in Southeast Asia: facing risks and vulnerabilities to respond to climate change. Building resilience for adaptation to climate change in the agriculture sector. A. Meybeck, J. Lankoski, S. Redfern, N. Azzu and V. Gitz. Rome, FAO \& OECD.

Rembold, Atzberger, Savin and Rojas, 2013. Using Low Resolution Satellite Imagery for Yield Prediction and Yield Anomaly Detection. Remote Sensing 5(4), 1704. 
Rizatus, Wataru, Parwati, Soni, Awaluddin and Wahyu, 2014. Indonesian drought monitoring from space. A report of SAFE activity: Assessment of drought impact on rice production in Indonesia by satellite remote sensing and dissemination with web-GIS. IOP Conference Series: Earth and Environmental Science 20(1), 012048.

Rochon, Johannsen, Landgrebe, Engel, Harbor, Majumder and Biehl, 2003. Remote sensing as a tool for achieving and monitoring progress toward sustainability. Clean Technologies and Environmental Policy 5(3), 310316.

Rosanne D'Arrigo, Wilson, Jonathan Palmer, Krusic, Curtis, Sakulich, Bijaksana, Zulaikah and Ngkoimani, 2006. Monsoon drought over Java, Indonesia, during the past two centuries. Geophysical Research Letters $33,4$.

Rouse, Hass, Schell and Deering, 1974. Monitoring Vegetation Systems in the Great Plains with ERTS. The 3rd Earth Resources Technology Satellite1 Symposium, 309-317.

Sakamoto, Van Nguyen, Kotera, Ohno, Ishitsuka and Yokozawa, 2007. Detecting temporal changes in the extent of annual flooding within the Cambodia and the Vietnamese Mekong Delta from MODIS time-series imagery. Remote Sensing of Environment 109(3), 295-313.

Sakamoto, Yokozawa, Toritani, Shibayama, Ishitsuka and Ohno, 2005. A Crop Phenology Detection Method Using Time-series MODIS Data. Remote Sensing of Environment 96, 366-374.

Sanyal and Lu, 2004. Application of Remote Sensing in Flood Management with Special Reference to Monsoon Asia: A Review. Natural Hazards 33(2), 283-301.

Sarangi, Maji, Singh, Sharma, Burman, Mandal, Singh, Ismail and Haefele, 2016. Using improved variety and management enhances rice productivity in stagnant flood -affected tropical coastal zones. Field Crops Research 190, 70-81.

Sawano, Hasegawa, Goto, Konghakote, Polthanee, Ishigooka, Kuwagata and Toritani, 2008. Modeling the dependence of the crop calendar for rainfed rice on precipitation in Northeast Thailand. Paddy and Water Environment 6(1), 83-90.

Schollaen, Heinrich, Neuwirth, Krusic, D'Arrigo, Karyanto and Helle, 2013. Multiple tree-ring chronologies (ring width, $\delta 13 \mathrm{C}$ and $\delta 180$ ) reveal dry and rainy season signals of rainfall in Indonesia. Quaternary Science Reviews 73, 170-181.

Seck, Diagne, Mohanty and Wopereis, 2012. Crops that feed the world 7: Rice. Food Security 4(1), 7-24.

Seidman, 2006. Interviewing as Qualitative Research: A Guide for Researchers in Education and the Social Sciences. New York and London, Teachers College Press. 
Serra and Pons, 2008. Monitoring farmers' decisions on Mediterranean irrigated crops using satellite image time series. International Journal of Remote Sensing 29(8), 2293-2316.

Setiawan, Liyantono, Fatikhunnada, Permatasari and Aulia, 2016. Dynamics Pattern Analysis of Paddy Fields in Indonesia for Developing a Near Realtime Monitoring System Using MODIS Satellite Images. Procedia Environmental Sciences 33, 108-116.

Sianturi, Jetten and Sartohadi, 2018. Mapping cropping patterns in irrigated rice fields in West Java: Towards mapping vulnerability to flooding using time-series MODIS imageries. International Journal of Applied Earth Observation and Geoinformation 66, 1-13.

Silva, Reidsma, Laborte and van Ittersum, 2017. Explaining rice yields and yield gaps in Central Luzon, Philippines: An application of stochastic frontier analysis and crop modelling. European Journal of Agronomy 82, Part B, 223-241.

Singh, Kudrat, Jain and Pandey, 2011a. Cropping pattern of Uttar Pradesh using IRS-P6 (AWiFS) data. International Journal of Remote Sensing 32(16), 4511-4526.

Singh, Mackill and Ismail, 2009. Responses of SUB1 rice introgression lines to submergence in the field: Yield and grain quality. Field Crops Research $113(1), 12-23$.

Singh, Mackill and Ismail, 2011b. Tolerance of longer-term partial stagnant flooding is independent of the SUB1 locus in rice. Field Crops Research 121(3), 311-323.

Singh, Roy and Kogan, 2003. Vegetation and temperature condition indices from NOAA AVHRR data for drought monitoring over India. International Journal of Remote Sensing 24(22), 4393-4402.

Singh and Singh, 2015. The response of farmers to the flood hazard under rice-wheat ecosystem in Somb basin of Haryana, India: an empirical study. Natural Hazards 75(1), 795-811.

Singleton, Brown and Jacob, 2004. Ecologically-based rodent management: its effectiveness in cropping systems in South-East Asia. NJAS Wageningen Journal of Life Sciences 52(2), 163-171.

Singleton, Sudarmaji, Jacob and Krebs, 2005. Integrated management to reduce rodent damage to lowland rice crops in Indonesia. Agriculture, Ecosystems \& Environment 107(1), 75-82.

Siswanto, van Oldenborgh, van der Schrier, Jilderda and van den Hurk, 2016. Temperature, extreme precipitation, and diurnal rainfall changes in the urbanized Jakarta city during the past 130 years. International Journal of Climatology 36(9), 3207-3225.

Smith, 1997. Satellite remote sensing of river inundation area, stage, and discharge: a review. Hydrol. Process 11, 1427-1439. 
Son, Chen, Chen, Minh and Trung, 2014. A comparative analysis of multitemporal MODIS EVI and NDVI data for large-scale rice yield estimation. Agricultural and Forest Meteorology 197, 52-64.

Son, Chena, Chen and Chang, 2013. Satellite-based Investigation of Floodaffected Rice Cultivation Areas in Chao Phraya River Delta, Thailand. ISPRS Journal of Photogrammetry and Remote Sensing 86, 77-88.

Statistik, 2012. Jawa Barat dalam Angka, Badan Pusat Statistik Provinsi Jawa Barat dan Bappeda Provinsi Jawa Barat: 1-571.

Strauß, 2011. Water Conflicts among Different User Groups in South Bali, Indonesia. Human Ecology 39(1), 69-79.

Stuart, Pame, Silva, Dikitanan, Rutsaert, Malabayabas, Lampayan, Radanielson and Singleton, 2016. Yield gaps in rice-based farming systems: Insights from local studies and prospects for future analysis. Field Crops Research 194, 43-56.

Sudana, Saefuddin and Bernsten, 1982. Economic Evaluation of the Introduced Cropping Patterns in Indramayu, West Java, 1977-78. Report of a Workshop on Cropping Systems Research in Asia. W. G. Rockwood and G. Argosino. Los Baños Laguna, Philippines, International Rice Research Institute: 637-653.

Sudarmaji, Singleton, Brown, Jacob and Herawati, 2010. Rodent Impacts in Lowland Irrigated Intensive Rice Systems in West Java, Indonesia. Rodent Outbreaks: Ecology and Impacts. G. Singleton, Steve Belmain, P. Brown and B. Hardy, International Rice Research Institute: 115-127.

Sun, Huang, Huete, Peng and Zhang, 2009. Mapping paddy rice with multidate moderate-resolution imaging spectroradiometer (MODIS) data in China. Sun et al. / J Zhejiang Univ Sci A 10(10), 1509-1522.

Sun, Zhou, Wang and Yuan, 2012. Farmers' response to agricultural drought in paddy field of southern China: a case study of temporal dimensions of resilience. Natural Hazards 60(3), 865-877.

Surmaini, Hadi, Subagyono and Puspito, 2014. Early detection of drought impact on rice paddies in Indonesia by means of Niño 3.4 index. Theoretical and Applied Climatology 121(3), 669-684.

Swain, 1973. Pattern Recognition: A Basis for Remote Sensing Data Analysis.

Tao and Gonzalez, 1974. Pattern Recognition Principles. Reading, AddisonWesley.

Tao, Zhang and Zhang, 2013. Changes in rice disasters across China in recent decades and the meteorological and agronomic causes. Regional Environmental Change 13(4), 743-759.

Thieken, Ackermann, Elmer, Kreibich, Kuhlmann, Kunert, Maiwald, Merz, Müller, Piroth, Schwarz, Schwarze, Seifert and Seifert, 2008. Methods for Evaluation of Direct and Indirect Flood Losses. 4th International Symposium on Flood Defence: Managing Flood Risk, Reliability and Vulnerability. Toronto, Ontario, Canada. 
Thomas, Albert and Hepburn, 2014. Contributors to the frequency of intense climate disasters in Asia-Pacific countries. Climatic Change 126(3), 381398.

Timmerman, 1981. Vulnerability, Resilience and the collapse of society: A review of models and possible climatic applications. Environmental Monograph. Toronto: Institute for Environmental Studies.

Toan, Ribbes, Li-Fang, Floury, Kung-Hau, Jin Au, Fujita and Kurosu, 1997. Rice crop mapping and monitoring using ERS-1 data based on experiment and modeling results. IEEE Transactions on Geoscience and Remote Sensing 35(1), 41-56.

Tong, 2017. Rice Intensive Cropping and Balanced Cropping in the Mekong Delta, Vietnam - Economic and Ecological Considerations. Ecological Economics 132, 205-212.

Tristiani, Murakami and Watanabe, 2003. Ranging and Nesting Behavior of the Ricefield Rat Rattus argentiventer (Rodentia: Muridae) in West Java, Indonesia. Journal of Mammalogy 84(4), 1228-1236.

Turner, Kasperson, Matson, McCarthy, Corell, Christensen, Eckley, Kasperson, Luers, Martello, Polsky, Pulsipher and Schiller, 2003. A framework for vulnerability analysis in sustainability science. Proceedings of the National Academy of Sciences 100(14), 8074-8079.

Twigg, 2004. Disaster risk reduction. Good Practice Review(9).

Twigg, 2007. Characteristics of a Disaster-resilient Community: A Guidance Note.

Uchida, 2010. Monitoring of Planting Paddy Rice with Complex Cropping Pattern in the Tropical Humid Climate Region using Landsat and Modis Data - A Case of West Java, Indonesia. 8th Symposium on Networking the World with Remote Sensing of ISPRS-Technical-Commission. K. Kajiwara, K. Muramatsu, N. Soyama, T. Endo, A. Ono and S. Akatsuka. Kyoto, Japan. 38: 477-481.

Udmale, Ichikawa, Manandhar, Ishidaira, Kiem, Shaowei and Panda, 2015. How did the 2012 drought affect rural livelihoods in vulnerable areas? Empirical evidence from India. International Journal of Disaster Risk Reduction 13, 454-469.

UN, 2004. World Population to 2300. New York, United Nations Department of Economic and Social Affairs/Population Division: 240.

UN, 2009. Global assessment report on disaster risk reduction.

UN, 2015. Sendai Framework for Disaster Risk Reduction 2015-2030. Sendai, Japan.

UN, 2017, Transforming our world: The 2030 Agenda for Sustainable Development. http://www.un.org/sustainabledevelopment/sustainabledevelopment-goals/ Retrieved 23 October, 2017.

UNISDR, 2005 Hyogo Framework for Action 2005-2015: Building the Resilience of Nations and Communities to Disasters. 22 
UNISDR, 2008. Linking Disaster Risk Reduction and Poverty Reduction: Good Practices and Lessons Learned United Nations.

UNISDR, 2009a. Global Assessment Report on Disaster Risk Reduction, UN.

UNISDR, 2009b. UNISDR Terminology on Disaster Risk Reduction, United Nation International Strategy for Disaster Reduction.

Uphoff and Wijayaratna, 2000. Demonstrated Benefits from Social Capital: The Productivity of Farmer Organizations in Gal Oya, Sri Lanka. World Development 28(11), 1875-1890.

USDA, 2011. SE ASIA: Widespread Flooding Impacts Regional Rice Production in 2011, USDA-FAS, Office of Global Analysis.

van den Berg, 2010. Household income strategies and natural disasters: Dynamic livelihoods in rural Nicaragua. Ecological Economics 69(3), 592602.

Van den Berg and Jiggins, 2007. Investing in Farmers-The Impacts of Farmer Field Schools in Relation to Integrated Pest Management. World Development 35(4), 663-686.

van Valkenburg, 1936. Agricultural Regions of Asia. Part IX--Java. Economic Geography 12(1), 27-44.

van Westen and Woldai, 2012. The RiskCity training package on multi - hazard risk assessment. International Journal of Applied Geospatial Research (IJAGR) 3(1), 41-52.

Verbesselt, Hyndman, Newnham and Culvenor, 2010. Detecting trend and seasonal changes in satellite image time series. Remote Sensing of Environment 114(1), 106-115.

Vermote, Kotchenova and Ray, 2011. MODIS Surface Reflectance User's Guide: $1-40$.

Walker, Holling, Carpenter and Kinzig, 2004. Resilience, adaptability and transformability in social-ecological systems. Ecology and Society 9(2).

Wang, Laza, Cassman, Huang, Nie, Ling, Centeno, Cui, Wang, Li and Peng, 2016. Temperature explains the yield difference of double-season rice between tropical and subtropical environments. Field Crops Research 198, 303-311.

Warburton., Villareal and Subramanian, 1999. Farmers' Rice Tungro Management Practices in India and the Philippines. Rice Tungro Disease Management. T. C. B. Chancellor, O. Azzam and K. L. Heong. Los Baños, Philippines: 93-104.

Ward, 1963. Hierarchical Grouping to Optimize an Objective Function. Journal of the American Statistical Association 58(301), 236-244.

Ward, Ortega, Spielman and Singh, 2014. Heterogeneous Demand for Drought-Tolerant Rice: Evidence from Bihar, India. World Development 64, 125-139.

Warner, Hamza, Oliver-Smith, Renaud and Julca, 2010. Climate change, environmental degradation and migration. Natural Hazards 55(3), 689715. 
Wei, Heilman, Qi, Nearing, Gu and Zhang, 2012. Assessing phenological change in China from 1982 to 2006 using AVHRR imagery. Frontiers of Earth Science 6(3), 227-236.

Weichselgartner and Kelman, 2015. Geographies of resilience: Challenges and opportunities of a descriptive concept. Progress in Human Geography 39(3), 249-267.

Westen, Alkema, Damen, Kerle and Kingma, 2011. Multi-hazard Risk Assessment.

White, 1945. Human adjustment to floods: a geographical approach to the flood problem in the United States, University of Chicago Chicago.

Winarto, Stigter, Prahara, Anantasari and Kristiyanto, 2011. Collaborating on Establishing an Agro-meteorological Learning Situation among Farmers in Java. Anthropological Forum 21(2), 175-197.

Wisner, Blaikie, Cannon and Davis, 2003. At Risk: Natural Hazards, People's Vulnerability, and Disasters. New York, Routledge.

Wu, Chen and Feng, 2014. Formation, failure, and consequences of the Xiaolin landslide dam, triggered by extreme rainfall from Typhoon Morakot, Taiwan. Landslides 11(3), 357-367.

Xiao, Boles, Frolking, Li, Babu, Salas and Moore Iii, 2006. Mapping paddy rice agriculture in South and Southeast Asia using multi-temporal MODIS images. Remote Sensing of Environment 100(1), 95-113.

Xiao, Boles, Frolking, Salas, Moore, Li, He and Zhao, 2002. Observation of flooding and rice transplanting of paddy rice fields at the site to landscape scales in China using VEGETATION sensor data. International Journal of Remote Sensing 23(15), 3009-3022.

Xiao, Boles, Liu, Zhuang, Frolking, Li, Salas and III, 2005. Mapping paddy rice agriculture in southern China using multi-temporal MODIS images. Remote Sensing of Environment 95, 480-492.

Yan, Ouyang, Guo, Jin and Zhao, 2010. Detecting the spatiotemporal changes of tidal flood in the estuarine wetland by using MODIS time series data. Journal of Hydrology 384(1-2), 156-163.

Yanto, Rajagopalan and Zagona, 2016. Space-time variability of Indonesian rainfall at inter-annual and multi-decadal time scales. Climate Dynamics 47(9), 2975-2989.

Yulianto, Sofan, Zubaidah, Sukowati, Pasaribu and Khomarudin, 2015. Detecting areas affected by flood using multi-temporal ALOS PALSAR remotely sensed data in Karawang, West Java, Indonesia. Natural Hazards, 1-27.

Zhang, Gu, Singh, Kong and Chen, 2015a. Spatiotemporal behavior of floods and droughts and their impacts on agriculture in China. Global and Planetary Change 131, 63-72.

Zhang, Xiao, Dong, Kou, Jin, Qin, Zhou, Wang, Menarguez and Biradar, 2015b. Mapping paddy rice planting areas through time series analysis of MODIS 
land surface temperature and vegetation index data. ISPRS Journal of Photogrammetry and Remote Sensing 106, 157-171.

Zhang, Zhang, Guo, Leinenkugel, Zhou, Li and Shen, 2014. Drought impact on vegetation productivity in the Lower Mekong Basin. International Journal of Remote Sensing 35(8), 2835-2856.

Zhao, Xu, Huang, Zhang and Liang, 2015. Characterisation of spatial patterns of regional paddy rice with time series remotely sensed data. Paddy and Water Environment, 1-11.

Zhou, Wang, Wan and Jia, 2010. Resilience to natural hazards: a geographic perspective. Natural Hazards 53(1), 21-41. 


\section{Summary}

The increasing global population inevitably demands for stable food production. As an important food crop, rice plays a major role in maintaining food security. However, irrigated rice fields are increasingly suffered from natural hazard occurrences worldwide, disrupting livelihoods of millions of people and jeopardizing food security. Therefore, there is an urgent need to reduce devastating disaster impacts in irrigated rice fields. In this respect, the concept and practice of disaster risk reduction (DRR) offer insights for reducing damages and losses from natural hazards. As a concept, DRR analyzes and manages causal factors of disaster events, including environmental and socioeconomic processes. In practice, DRR focuses on proactive activities of managing disaster risk instead of solely reacting to disaster impacts. Despite the benefits, surprisingly, few studies incorporate the concept and practice of DRR for investigating or proposing insights to reduce potential disaster impacts in irrigated rice fields.

The central question underlying the thesis is "How can disaster impacts in irrigated rice fields be reduced?" This thesis analyzes hazard, vulnerability, and resilience in irrigated rice fields in West Java to answer the question. The area under investigation consists of 4 districts East of Jakarta, containing approximately $37 \%$ of the total area of rice fields in West Java. This study uses primary and secondary data, such as stakeholders' responses and time-series MODIS imageries (MOD09A1). Both quantitative (e.g., remote sensing and statistical analyses) and qualitative approaches (e.g., qualitative content analysis of the interviews) were done. Findings presented in each chapter of this thesis can be used as inputs for designing effective strategies to reduce potential disaster impacts in irrigated rice fields.

Information on vulnerability to flooding is essential for estimating potential damages from flood events. Chapter 2 demonstrates that cropping patterns can be used as one of the inputs for deriving physical vulnerability to flooding in irrigated rice fields. Cropping patterns were generated from the spatial distribution of the multiannual Enhanced Vegetation Index, where the timeseries were clustered in areas with similar patterns of crop growth supported by local knowledge on phenology metrics. There is a large spatial and temporal variability in cropping schedules in the area, and at the same moment fields can have freshly planted to fully grown rice. The clusters can be roughly separated in 5 regions from North to South, with cropping patterns related to the timing and availability of irrigation water from the large reservoirs in the South of the area, and landscape position. Combined with vulnerability (damage) curves, cropping patterns can be used to determine vulnerability to flooding. Vulnerability varies in space and time and may shift because of extreme weather variabilities or human decisions. To understand 
the uncertainty sue to the low resolution, accuracy assessments were performed for the estimated spatial distribution and phenology metrics. For the former, the comparison between MOD09A1 and ALOS PALSAR (2010) and between MOD09A1 and Agricultural Statistics showed coherent results with $R^{2}$ of 0.81 and 0.93 , respectively. For the latter, the estimated RMSEs for SOS, heading stage, and EOS are $9.21(n=61), 9.29(n=46)$, and $9.69(n=49)$ days, respectively.

Robust flood detection methods are needed for understanding irrigated rice field areas affected by flood events. Previous studies suggested that EVI $\leq 0.1$ can be used to detect flood events in irrigated rice fields. However, nonhazardous agronomic inundation needed for rice growth, and hazardous flooding may be present at the same time in irrigated rice fields. Therefore, EVI $\leq 0.1$ may not be adequate to detect rice fields with flooding, and the attempt for distinguishing between rice fields with flooding and rice fields with agronomic inundation (RFAI) is therefore necessary. It was found that EVI $\leq$ 0.1 alone cannot distinguish between flooding and agronomic inundation in irrigated rice fields in the study area. However, when the period of EVI $<0.1$ extends beyond 40 days in at the start of the growing season (EVI 40 ) hazardous flood events can be recognized. However, misclassified flood pixels exist partly due to environmental processes, human decisions, and mixed pixels. Using the Start of Season (SOS) for assessing the accuracy of the derived flood map, it is estimated that the scores of Accuracy and $\mathrm{F} 1$ for $\mathrm{EVI}_{40}$ are $75.96 \%$ and $81.74 \%$, respectively. In other moments of the growing season when the fields have a mature crop, an sudden drop of EVI below 0.1 may be a sign of hazardous flooding.

The vulnerability of farmers to natural hazards may partly be explained by unsafe conditions. According to the Pressure and Release (PAR) model, vulnerability may progress from root causes, dynamic pressures to unsafe conditions. Some of the challenges on identifying unsafe conditions are the difference in 'vocabularies' among rice agriculture stakeholders (e.g., farmers, water managers, extension officers) and various potential reasons for unsafe conditions. In this respect, disruptions in cropping schedules may be used as a 'common language' to understand mechanisms of how unsafe conditions may increase vulnerability. Reasons for disruptions in cropping schedules have been identified, including economic motives, weather variabilities, geographic locations, coping strategies, farmers' interactions, and agricultural infrastructures. Unsafe conditions in irrigated rice fields in West Java has also been successfully documented, including dangerous locations, unsustainable farming activities, unsuitable coping strategies, fragile infrastructures, and inadequate knowledge and perception of the problems. 
Efforts to reduce potential disaster impacts in irrigated rice farming can be focused on building the resilience of farmers to natural hazards. However, the multi-faceted and multi-level nature of resilience leads to difficulties in its assessments. In the present study, resilience is defined as the ability of farmers to recover from recurrent impacts of natural hazards. Several assessments are performed. Firstly, the Vegetation Condition Index (VCI) is used to provide an overview of irrigated rice field conditions during the dry planting season 2015 and wet planting season 2016. Farmers in certain areas could not perform rice cultivation in the dry planting season 2015 because of an extreme water-deficit event. Nevertheless, it appeared that some of these farmers could perform rice cultivation in the wet planting season 2016 despite having no income from the previous planting season. Additionally, farmers experienced severe damages occurred during booting and ripening periods because of strong wind with rainfall, rice blast attacks (Magnaporthe grisea) and rodent attacks. The impacts of such events on irrigated rice fields are not able to be captured by the time-series VCI, which is limited by the moderate spatial resolution.

Factors that significantly correlate with the resilience of farmers to natural hazards have been identified, including the ability of farmers to save money after selling harvests, reduction of harvest because of rat attacks, community recovery, and rice field tenure. Farmers that are affected look for sources of income by labour in neighbouring rice fields, or much further away from home. These factors indicate that irrigated rice fields in the study areas are interrelated where the outcomes of rice fields located near primary irrigation channels influence the outcomes of those located close to coastal areas and vice versa.

Addressing challenges related to the farming skills, reduction of harvest due to rat attacks, ability to save money after selling harvest, synchronous planting, and access to farming information may aid farmers to manifest their potential into actual resilience. Reducing potential disaster impacts can be performed by minimizing the risk of and building the resilience of farmers to natural hazards. These efforts should be supported by access to reliable farming and weather information. In addition to performing balanced farming practices (double rice cropping patterns with fallow), farmers incorporate measures that stretch beyond the on-the-farm or household level, such as farming insurance or cooperation. To ensure the long-term continuity, risk reduction activities should be embedded into national programs on rural or rice agricultural development.

Future research investigating dynamics in irrigated rice fields using higher spatial and temporal resolution imageries are suggested. Studies that focus on the ability of farmers' households and community to mobilize livelihood capitals for reducing risk and building resilience to natural hazards are also suggested. 
In practice, reducing disaster impacts in irrigated rice fields requires seamless communication and coordination among rice agricultural stakeholders, including the poor and the vulnerable. Such cooperation requires building trust. 


\section{Samenvatting}

Toename in de wereldbevolking vraagt om een stabiele en duurzame voedselproductie. Hierin spelt rijst een belangrijke rol, maar een toename in natuurrampen ("Natural Hazards") vormt een bedreiging voor de voedselzekerheid, en het levensonderhoud van bevolking die werkzaam is in de rijstbouw. Om de effecten van natuurrampen op rijstbouw en de schade te verminderen kan een raamwerk van "Disaster Risk Reduction" gebruikt worden, waarmee zowel de fysische als sociaaleconomische aspecten geanalyseerd kunnen worden. In het DRR-raamwerk kan de nadruk gelegd worden op het voorkomen van schade, in plaats van alleen op het reageren op een ramp. Ondanks dit voordelen wordt het verassend weinig toegepast in deze context van schade aan rijstbouw door natuurrampen.

De centrale vraag van dit onderzoek is: "hoe kunnen de effecten van natuurrampen op geïrrigeerde rijstbouw verkleind worden?". Dit onderzoek analyseert de bedreigingen ("hazards"), de kwetsbaarheid "(vulnerability") en de weerbaarheid "(resilience") gerelateerd aan de rijstbouw in Noordwest Java. Deze rijstbouw heeft normaal twee groeiseizoenen, gevoed oor een groot en complex irrigatie systeem vanuit 3 stuwdammen ten noorden van het gebied. Van noord naar zuid wordt de zekerheid van het krijgen van tijdige en voldoende irrigatie kleiner. De voornaamste bedreiging die hier bestudeerd wordt zijn overstromingen. Deze studie combineert primaire en secundaire data, zoals multi-temporele MODIS (MOD09A1) satellietbeelden en informatie van een groot aantal stakeholders in een kwantitatieve en kwalitatieve analyse. De resultaten kunnen gebruikt worden om effectieve strategieën te bedenken die de effecten van natuurrampen kan verminderen.

Informatie over de kwetsbaarheid van rijstvelden voor overstromingen is essentieel. Hoofdstuk 2 laat zien dat gewaspatronen kunnen worden gebruikt om de fysische kwetsbaarheid te definiëren. Het gebeid kent grote variabiliteit door landschappelijke verschillen en irrigatie waterbeheer. De kwetsbaarheid voor een overstroming hangt af van het groeistadium waarin het gewas zich bevindt. Gewas patronen in het gebied werden geanalyseerd door de gemiddelde twee wekelijkse veranderingen in de Enhanced Vegetation Index (EVI) van 2000-2016 te clusteren zodat ruimtelijke eenheden ontstonden, die een gelijke variatie in gewasbedekking laten zien. Deze ruimtelijke patronen van MODIS-beelden werden vergeleken met hoge resolutie ALOS PALSAR beelden (2010), en met statistische landbouw gegevens, om de juistheid te testen. Statistische testen laten respectievelijk een $R^{2}$ van 0.81 en 0.93 zien. Uit de vergelijking met landbouw gegevens blijkt dat de start van het groeiseizoen (SOS), moment van maximum ontwikkeling en einde van het seizoen (EOS) geschat kunnen worden met een RMSE van respectievelijk 9.21 $(n=61), 9.29(n=46)$, en $9.69(n=49)$ dagen. Met een combinatie van lokale 
informatie over de fenologische ontwikkeling van rijst en gewas rotatie kan zo achterhaald worden in welk stadium het gewas zich bevindt op ieder moment in het jaar. Dit geeft de mogelijkheid om, gegeven een specifieke locatie van een overstroming, te voorspellen wat de mogelijke schade zou kunnen zijn.

Robuuste detectie methodes voor overstromingen in geïrrigeerde rijstbouw zijn er niet, aangezien rijst voor een groot deel van het groeiseizoen onder water staat. Een veelgebruikte methode is de detectie in beelden van gebieden met een EVI waarde kleiner dan 0.1 (reflectie door water en geen vegetatie aanwezig). In dit onderzoek pogen we "agronomische inundatie" te scheiden van "gevaarlijke overstromingen". Door de stakeholder informatie te combineren met de lengte van de periode waarin EVI $<0.1$, blijkt dat gedurende de start van het groeiseizoen (SOS) de periode onder water groter is dan 40 dagen $\left(\mathrm{EVI}_{40}\right)$, er sprake is van een "gevaarlijke overstroming". Zodoende kunnen gebieden geselecteerd worden die werkelijk overstroomd zijn. Dit is getest aan de hand van een bekende overstroming door een dijkdoorbraak in een van de dorpen. De nauwkeurigheid en F1 waarde van deze detectie methoden is respectievelijk $76 \%$ en $82 \%$, o.a. door een onzekerheid veroorzaakt door misclassificatie en 'mixed pixels'. In andere momenten in het groeiseizoen wanneer het gewas gebied dekkend is kan een waarde van EVI $<0.1$ een directe aanduiding voor overstroming zijn, ongeacht de lengte van de periode.

De kwetsbaarheid van boeren werd voor allerlei "onveilige omstandigheden" is onderzocht met een "Pressure and Release" (PAR) model. Het PAR-model bekijkt in hoeverre intrinsieke kwetsbaarheid kan veranderen van een set van basis oorzaken, door middel van invloed van buitenaf (pressure), tot een onveilige situatie (release). Een van de problemen in een dergelijke analyse is het vinden van een gemeenschappelijk vocabulaire tussen de onderzoeker, water managers, boeren en landbouwdeskundigen. Boeren maken geen onderscheid tussen verschillende soorten bedreigingen (overstroming, droogte, ongedierte en gewas ziektes). Gewas rotatie en onderbrekingen daarvan blijkt de beste gemeenschappelijke basis te zijn voor het verkrijgen van informatie. In dit onderzoek blijken economische omstandigheden, de variabiliteit van het weer, de geografische locatie, beheer strategieën, interacties tussen boeren en de fragiele landbouw infrastructuur ( $\mathrm{vnl}$. het complexe irrigatiesysteem), de meeste invloed te hebben als 'pressures'.

Vergroten van de weerbaarheid (resilience) is een van de manieren om de effecten van natuurrampen te verminderen. Dit is niet eenvoudig omdat weerbaarheid veel aspecten en niveaus kent. Om een idee te krijgen waar in het onderzoeksgebied locaties zijn waar zich problemen voordeden tijdens in de onderzoeksperiode 2015/16, werd voor het tweede groeiseizoen van 2015 en het eerste groeiseizoen van 2016 een Vegetation Condition Index (VCI) 
analyse uitgevoerd. Dit gaf een indruk welke gebieden een slechte tot geen productie hadden in 2015 (ongeacht de oorzaak). In deze gebieden werden uitgebreide interviews gehouden om een beter idee te krijgen van mechanismes van weerbaarheid. Dit levert een complex beeld op. Veel boeren hadden geen inkomen door droogte in 2015, en dus geen geld voor rijstproductie in 2016. Verder waren er boeren die veel schade ondervonden door sterke wind en neerslag, en door gewas ziektes (Magnaporthe grisea) en aan vallen van ongedierte ("rodent attacks") in verschillende groeistadia. De factoren die het meeste de weerbaarheid beïnvloeden zijn de mogelijkheid om geld te sparen na de verkoop van de oogst, herstel van de gemeenschap als geheel, en type eigendom ("tenure") van de rijstvelden en schade door ongedierte. Boeren die getroffen zijn zoeken een inkomen op ander plekken. Dit kunnen bedrijven uit dezelfde gemeenschap zijn maar ook bedrijven veel verder weg. Zodoende beïnvloeden rijst gebieden die zich dicht bij de primaire irrigatie kanalen bevinden en grote water zekerheid hebben, de gebieden dicht bij de kust met een lage water zekerheid omdat ze zich aan het einde van het irrigatie systeem bevinden, en vice versa. Met andere woorden, sommige boeren hadden toch financiën om in 2016 rijst te verbouwen ondanks de schade op het eigen bedrijf in 2015.

De analyse karakteriseert potentiele en actuele niveaus van weerbaarheid, en laat zien dat potentiele weerbaarheid gerealiseerd kan worden door de technische kennis te verbeteren, mechanismes om een financiële reserve aan te leggen, synchroon te planeten met anderen vanwege verbeterde mogelijkheden voor irrigatie management en betere informatie over bedrijfsvoering en weersvoorspellingen. Betere informatie zorgt voor meer gestructureerde rijstbouw als een gemeenschap waardoor beter gebruik kan worden gemaakt van de infrastructuur. Additionele ondersteuning zou kunnen worden gegeven in activiteiten die verder reken dan een huishouden, zoals verzekering en ondersteuning voor samenwerking. Voor lange termijn ondersteuning zou dit kunnen worden opgenomen in nationale ontwikkelingsprogramma's.

Toekomstig onderzoek zou gebaad zijn bij hogere ruimtelijke resolutiebeelden, omdat er zich soms enkele tientallen rijstvelden in een pixel bevinden. Dit introduceert een ruimtelijke onzekerheid bij het gebruik van MODISproducten. Dit zou een betere analyse kunnen geven van gebieden met problemen. Het oplossen van de problemen op huishoudelijk niveau, veroorzaakt door natuurlijke bedreigingen moet vooral gezocht worden in het verhogen van de weerbaarheid, door middel van een verhoogde kapitaal opbouw en kennis, en door middel van betere communicatie en coördinatie tussen de stakeholders, inclusief de armen en kwetsbare boeren. Hiervoor is vertrouwen nodig. 


\section{Author's biography}

Riswan Septriayadi Sianturi was born on 19 September 1988 in Pangkalpinang, Indonesia. In 2010 he obtained the degree of Bachelor with Honors in Geography (S.Si.) from Universitas Gadjah Mada. In 2011 and 2012, he received the degree of Master in Management (M.M.) from Atma Java University Yogyakarta and Master of Science in Geography (M.Sc.) from Universitas Gadjah Mada, respectively. In 2013, he was awarded a scholarship from

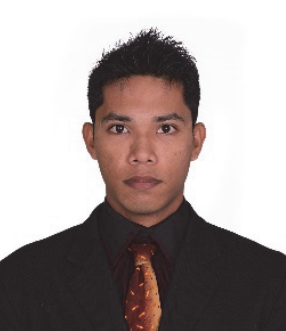
Beasiswa Pendidikan Indonesia Lembaga Pengelola Dana Pendidikan (BPI LPDP) Indonesia to pursue the degree of Ph.D. at Earth System Analysis (ESA) department, Faculty of ITC, University of Twente in the Netherlands.

\section{Author's publications}

\section{Conference proceedings (full paper)}

Riswan S. Sianturi ; Willem Nieuwenhuis and V. G. Jetten, " Seasonal parameter extraction of paddy rice fields in West Java using multitemporal MODIS imagery datasets ", Proc. SPIE 9637, Remote Sensing for Agriculture, Ecosystems, and Hydrology XVII, 963703 (October 14, 2015); doi: 10.1117/12.2194999;

http://dx.doi.org/10.1117/12.2194999

\section{Peer-reviewed journal articles}

Sianturi, Jetten and Sartohadi, 2018. Mapping cropping patterns in irrigated rice fields in West Java: Towards mapping vulnerability to flooding using time-series MODIS imageries. International Journal of Applied Earth Observation and Geoinformation 66, 1-13.

Sianturi and Jetten, 2018. Towards understanding vulnerability: investigating disruptions in cropping schedules in irrigated rice fields in West Java. International Journal of Disaster Risk Reduction 28 (in press).

Sianturi, R., Ettema, J., Jetten, V.G., Sartohadi, J. (2018) Distinguishing between Flooding and Agronomic Inundation in Irrigated Rice Fields: A case study from West Java (in review).

Sianturi, R., (2018) Factors influencing Resilience of Farmers to Natural Hazards in Irrigated Rice Fields in West Java (submitted) 


\section{Appendix}

Appendix Table E-1: Questionnaire for investigating resilience of farmer to natural hazard

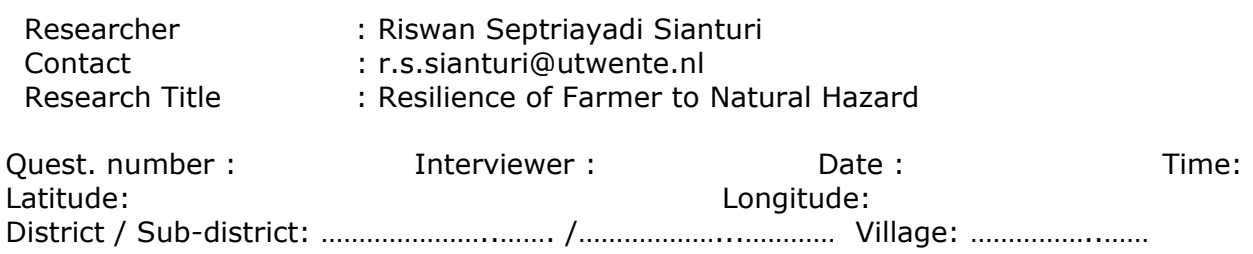

\section{HOUSEHOLD CHARACTERISTICS}

Name:

a.1. Age: Years of
experience:

a.3. Tenure of rice fields

$\square$ Farmer (owning rice field)

a.4... Ha

$\square$ Tenant (rent rice field)

a.4... Ha
a.5. Gender
Male
Female

b. The highest grade of formal educational level completed.

$\square$ Grade ..... $\square$ elementary school $\square$ junior high school

c. Income from the previous season (rendeng 2016)

d. Number of family members without an employment. Male:

Female:

e. Yield from previous season (rendeng 2016) harvests

f. Source of capital for pursuing the last planting season.

$\square$ Own capital $\square$ Loan with interest

\section{FARMING PRACTICES AND PROCESSES}

A. CROPPING CALENDAR

a. Rendeng planting dates generally does not conform to government cropping calendar in this village.
$\square$ very disagree
$\square$ disagree
$\square$ agree
very agree

b. Gadu planting dates generally does not conform to government cropping calendar in this village.
$\square$ very disagree
disagree
agree
very agree

c. Current rendeng planting dates is favorable for farmers in this village.
$\square$ very disagree
$\square$ disagree
$\square$ agree
$\square$ very agree

d. Current gadu planting dates is favorable for farmers in this village. $\square$ very disagree
$\square$ disagree
$\square$ agree
$\square$ very agree
don't

B. ECONOMIC ASPECT

a. Current selling price of rice supports farmers' welfare.
$\square$ very disagree
disagree
$\square$ agree
very agree

b. You have extra money for saving after harvest.
$\square$ very disagree
$\square$ disagree
$\square$ agree
very agree 
c. Income from of rendeng farming is sufficient for meeting your family daily needs until next season.

$\square$ very disagree $\square$ disagree $\quad \square$ agree $\quad \square$ very agree

d. Income from rendeng and gadu farming combined is sufficient for meeting your family daily needs.
$\square$ very disagree
disagree
agree
very agree

e. Your family has various sources of income to support rice farming.
$\square$ very disagree
disagree
$\square$ agree
$\square$ very agree

f. You can access funds for rice farming from closest family members or neighbours easily.
$\square$ very disagree
disagree
agree
very agree

g. In case of planting or harvest failures, you can do other jobs for fulfilling daily needs.

$\square$ very disagree $\square$ disagree $\quad \square$ agree $\quad \square$ very agree

C. SOCIAL ASPECT

a. Access to agricultural rice inputs information (other than weather) is easy. $\square$ very disagree $\square$ disagree $\square$ agree $\square$ very agree

b. Farmers are united to face agricultural challenges (e.g. natural hazards).
$\square$ very disagree
$\square$ disagree
$\square$ agree
$\square$ very agree

c. You get information from other farmers about farming.
$\square$ very disagree
$\square$ disagree
$\square$ agree
very agree

d. You are active to look for information to improve agricultural production.
$\square$ very disagree
$\square$ disagree
$\square$ agree
$\square$ very agree

e. Farmers in southern areas (previous rice classes) use excessive irrigation water during gadu.
$\square$ very disagree
disagree
$\square$ agree
very agree

f. Neighbouring farmers in the same village use excessive irrigation water during gadu.
$\square$ very disagree
$\square$ disagree
agree
very agree

g. Cell phone supports you to face challenges in rice farming.
$\square$ very disagree
$\square$ disagree
$\square$ agree
$\square$ very agree

D. INSTITUTIONAL ASPECT

a. Agricultural officers support you for succeeding rice farming.
$\square$ very disagree
$\square$ disagree
$\square$ agree
$\square$ very agree

b. Water officers support you for succeeding rice farming.
$\square$ very disagree
$\square$ disagree
agree
$\square$ very agree

c. Access of weather information for supporting rice practices is easy in this village.
$\square$ very disagree
$\square$ disagree
agree
$\square$ very agree

d. You join farming insurance.
$\square$ very disagree
$\square$ disagree
agree
very agree

e. Regardless of joining or not joining, farming insurance will provide benefit for you. 
$\square$ very disagree $\square$ disagree $\quad \square$ agree $\quad \square$ very agree

f. Government aid is adequate during and after flooding
$\square$ very high
$\square$ high
$\square$ low $\square$ very low
$\square$ no problem

g. Government aid is adequate during and after drought
$\square$ very high
$\square$ high
$\square$ low $\square$ very low
no problem

E. INDIVIDUAL ASPECT

a. Weather is difficult to predict in the last 5 years.
$\square$ very disagree
disagree
agree
very agree

b. Generally, you can manage rat attacks.
$\square$ very disagree
$\square$ disagree
$\square$ agree
very agree

c. Generally, you can manage brown plant hopper attacks.
$\square$ very disagree
$\square$ disagree
$\square$ agree
very agree

d. Are you a member of any group farming in the last 3 years?

Yes / No

e. Do you join any farming training in the last 3 years?

Yes / No

\section{NATURAL HAZARDS}

a. Water-deficit problem in your rice fields.
$\square$ very high
$\square$ high
low
very low
no problem

b. Flooding problem in your rice fields.
$\square$ very high
high
low $\square$ very low
no problem

c. Saline water intrusion problem in your rice field.
$\square$ very high
$\square$ high
$\square$ low $\square$ very low
no problem

d. Irrigation infrastructure problem in this village.
$\square$ very high
$\square$ high
$\square$ low $\square$ very low
no problem

e. River shallowing and narrowing problem in this village.
$\square$ very high
$\square$ high
$\square$ low $\square$ very low
no problem

f. Variation of weather in rainy season disrupt harvest time in this village.
$\square$ very disagree
$\square$ disagree
$\square$ agree
very agree

g. Variation of weather in dry season disrupt harvest time in this village.
$\square$ very disagree
$\square$ disagree
$\square$ agree
$\square$ very agree

h. Rat attacks reduce your harvest yield.
$\square$ very disagree
$\square$ disagree
agree
very agree

i. Brown plant hopper attacks reduce your harvest yield.
$\square$ very disagree
$\square$ disagree
$\square$ agree
very agree

j. Excessive irrigation water use cause flooding in lower-lying rice fields.
$\square$ very disagree
$\square$ disagree
$\square$ agree
very agree

\section{RESILIENCE OUTCOME}

a. Recovery from past event:

With respect to [EVENT], how well do you consider you managed to recover?

$\square$ Not at all, and I don't think I will be able to recover 
Not yet, fully recovered and it will be difficult/long

Not yet, but hope very soon

Have fully recovered, but it was long and painful

Have fully recovered, and it was not too difficult

Have fully recovered, and I am better off now

b. Relative recovery from past event:

With respect to [EVENT], how well do you consider you did, compared to the rest of the community?

Did worse than most of the others

As bad as some people but better than others

Like most of the others

Did better than most of the others

Did better than anyone else

c. With respect to the damages and losses from [EVENTS]. How many cropping seasons do you need to recover to your normal economic state?

d. Community recovery from past event:

With respect to [EVENT], how well do you consider the community recovered?

$\square$ Not at all, and I don't think we will be able to recover

$\square$ Not yet fully recovered and it will be difficult/long

$\square$ Not yet, but hopefully very soon

$\square$ Have fully recovered, but it was long and painful

Have fully recovered, and it was not too difficult

$\square$ Have fully recovered, and we are now better off

e. Capacity to handle future event:

With respect to [EVENT], if it is to happen again in the near future how do you consider you would be able to recover?

Would be worse than last time

As bad as last time

More or less the same than last time

As well as last time

Would do better than last time

\section{QUALITY OF LIFE DIMENSIONS}

How is your [QUALITY OF LIVE INDICATORS] on average in the last 3 years?

a. Income from farming.
$\square$ poor
$\square$ fair
average
$\square$ good
excellent

b. Ability to meet daily need.

$\square$ poor $\square$ fair

average $\quad \square$ good

excellent

c. Housing conditions.
$\square$ poor
$\square$ fair
average
$\square$ good
excellent

d. Environmental condition in this village (e.g. cleanliness) in general.
$\square$ poor
$\square$ fair
$\square$ average
$\square$ good
excellent

e. Health status of family members.
$\square$ poor
$\square$ fair
$\square$ average
good
excellent

f. Social connections among farmers in general.
$\square$ poor
$\square$ fair
$\square$ average
good
excellent 
g. Social connections among farmers in time of crisis.
$\square$ poor
$\square$ fair
$\square$ average
$\square$ good
excellent

h. Work motivation in general.
$\square$ poor
$\square$ fair
$\square$ average
$\square$ good
excellent

i. Work motivation in time of crisis.
$\square$ poor
$\square$ fair
$\square$ average
good
excellent
j. Current skills as a farmer.

$\square$ poor $\square$ fair
average
good
excellent

6. CROPPING SCHEDULE FACTORS

A. ECONOMIC ASPECT

a. Prices of chemical agricultural inputs, such as fertilizers and pesticides, influence planting time in this village.
$\square$ very disagree
$\square$ disagree
$\square$ agree
$\square$ very agree

b. Future selling price of rice influences planting time in this village.
$\square$ very disagree
$\square$ disagree
$\square$ agree
$\square$ very agree

c. Farmers who own rice fields influence planting time in this village
$\square$ very disagree
$\square$ disagree
$\square$ agree
$\square$ very agree

d. Delay in rendeng influences planting time in the whole Jatiluhur irrigated rice fields. $\square$ very disagree $\square$ disagree $\quad \square$ agree $\quad \square$ very agree

e. Delay in Gadu influences planting time in the whole Jatiluhur irrigated rice fields.
$\square$ very disagree
$\square$ disagree
$\square$ agree
$\square$ very agree

f. Cropping pattern
$\square$ single-cropping pattern
double-cropping pattern
triple-cropping pattern

g. Triple-cropping pattern influences planting time in the whole Jatiluhur irrigated rice fields.
$\square$ very disagree
disagree
agree
very agree

h. Rat attacks influence planting time in this village.
$\square$ very disagree
$\square$ disagree
$\square$ agree
very agree

B. FARMERS' INTERACTION ASPECT

a. Local belief "kemeian" influences planting time in this village.
$\square$ very disagree
$\square$ disagree
$\square$ agree
$\square$ very agree

b. Community events influence planting time in this village.
$\square$ very disagree
$\square$ disagree
$\square$ agree
$\square$ very agree

c. National religion events influence planting time in this village.
$\square$ very disagree
$\square$ disagree
$\square$ agree
$\square$ very agree

d. A two-weekly local government meeting (minggon) influences planting time in this village.
$\square$ very disagree
disagree
agree
very agree 
e. Difference between rice agricultural rules between current and Old Order era (before 2000) influence planting time in this village.

$\square$ very disagree $\square$ disagree $\square$ agree $\quad \square$ very agree

f. Current planting time is better that Old Order era (before 2000).
$\square$ very disagree
disagree
$\square$ agree
$\square$ very agree

g. For Jatiluhur irrigation system, current planting time is better that Old Order era (before 2000).

$\square$ very disagree $\square$ disagree $\quad \square$ agree $\quad \square$ very agree

h. Size of rice fields influence planting time
$\square$ very disagree
$\square$ disagree
agree
very agree

C. WEATHER CONDITIONS AND NATURAL HAZARDS ASPECT

a. Weather in rainy season influences planting time in this village.
$\square$ very disagree
$\square$ disagree
$\square$ agree
$\square$ very agree

b. Weather in dry season influences planting time in this village.
$\square$ very disagree
disagree
$\square$ agree
$\square$ very agree

c. Flooding events influence planting time in this village.
$\square$ very disagree
$\square$ disagree
$\square$ agree
very agree

d. Water deficit events influence planting time in this village.
$\square$ very disagree
$\square$ disagree

$\square$ agree

very agree

D. GEOGRAPHICAL LOCATIONS ASPECT

a. Rent prices of rice field is too expensive in this village.
$\square$ very disagree
$\square$ disagree
agree
very agree

b. Soil quality decrease in the last 5 years in this village.
$\square$ very disagree
$\square$ disagree
$\square$ agree
very agree

c. Seed quality decrease in the last 5 years in this village.
$\square$ very disagree
$\square$ disagree
agree
very agree

d. Access to irrigated water influence planting time in this village.
$\square$ very disagree
$\square$ disagree
$\square$ agree
$\square$ very agree

E. COPING MECHANISMS ASPECT

a. Farmers' coping mechanisms to flooding influence planting time in this village. $\square$ very high $\square$ high $\square$ low $\square$ very low $\square$ no problem

b. Farmers' coping mechanisms to water-deficit event influence planting time in this village.
$\square$ very high
high
$\square$ low
very low
no problem

F. AGRICULTURAL INFRASTRUCTURES ASPECT

a. Conditions of irrigation infrastructures influence planting time in this village. $\square$ very disagree $\square$ disagree $\square$ agree $\square$ very agree

b. Conditions of river channels influence planting time in this village.
$\square$ very disagree
disagree
$\square$ agree
$\square$ very agree

c. Rice varieties influence planting time in this village.
$\square$ very disagree
disagree
agree
very agree 
d. Availability of labours influences planting time in this village.

$\square$ very disagree $\quad \square$ disagree $\quad \square$ agree $\quad \square$ very agree

Thank you for your cooperation 
Appendix Table E-2: Results of Independent-samples t-test for resilience of farmers to natural hazard

\section{Household Characteristics \\ a.1 age \\ a.2 years of experience}

a.3 rice field tenure

a.4 areas of rice field

b education level

c income from the previous season (rendeng 2016) (rupiah)

d dependent family member

e capital source from the previous season (rendeng 2016)

\section{Farming Practices}

A. Cropping schedule

a Rendeng planting dates generally does not conform to government cropping calendar in this village

b Gadu planting dates generally does not conform to government cropping calendar in this village

c Current rendeng planting dates is

favorable for farmers in this village

d Current gadu planting dates is favorable for farmers in this village

B. Economic factors

a Current selling price of rice supports farmers' welfare

b You have extra money for saving after harvest
Resilience Score

(Mean \pm Standard Deviation) Low High

above $50 ; \mathrm{n}=60$; $9.21 \pm 5.64$

above 30 year;

$$
n=59 \text {; }
$$

$9.71 \pm 5.62$

rent; $\mathrm{n}=31$;

$8.45 \pm 4.57$

1 abouw or below; $\mathrm{n}=61$;

$8.6 \pm 4.25 *$

elementary school or lower; $\mathrm{n}=104$;

$9.29 \pm 5.12$

Rp. $7,000,000$ or below; $\mathrm{n}=72$;

$8.65 \pm 4.19 *$

1 member or below;

$$
n=84 \text {; }
$$

$9.3 \pm 5.46$

Ioan; $\mathrm{n}=81$;

$8.71 \pm 4.76 * *$
50 or below; $\mathrm{n}=$ 72 ;

$10.19 \pm 5.41$

30 years or

below;

$\mathrm{n}=73$;

$9.78 \pm 5.47$

owner; $\mathrm{n}=101$;

$10.14 \pm 5.74$

above 1 bouw; $\mathrm{n}=71$;

$10.7 \pm 6.28 *$

junior school or

above;

$\mathrm{n}=28$;

$11.42 \pm 6.64$ above

Rp.7,000,000;

$\mathrm{n}=60$;

$11.06 \pm 6.57 *$

above 1

member;

$n=48$;

$10.52 \pm 5.58$

self-owned:

$\mathrm{n}=51$;

$11.39 \pm 6.25^{* *}$

$$
\begin{array}{cc}
\text { agree; } \mathrm{n}=107 ; & \text { disagree; } \mathrm{n}= \\
9.5 \pm 5.2 & 25 ; \\
& 10.8 \pm 6.74 \\
\text { agree; } \mathrm{n}=102 ; & \text { disagree; } \mathrm{n}= \\
9.57 \pm 5.28 & 30 ; \\
& 10.36 \pm 6.31 \\
\text { disagree; } \mathrm{n}=5 ; & \text { agree; } \mathrm{n}=127 \\
9.2 \pm 3.89 & 9.77 \pm 5.58 \\
\text { disagree; } \mathrm{n}=62 ; & \text { agree; } \mathrm{n}=70 \\
9.54 \pm 6.29 & 9.92 \pm 4.76
\end{array}
$$

disagree; $\mathrm{n}=106$; $9.69 \pm 5.79$

disagree; $\mathrm{n}=100$; $8.63 \pm 4.45^{* *}$ agree; $\mathrm{n}=26$;

$9.96 \pm 4.29$

agree; $\mathrm{n}=32$;

$13.25 \pm 6.98^{* *}$ 
c Income from rendeng is sufficient for meeting your family daily needs until next season

d Income from rendeng and gadu combined is sufficient for meeting your family daily needs

e Your family has various sources of income to support rice farming

$f \quad$ You can access funds for rice farming from closest family members or neighbors easily

g In case of planting or harvest failures, you can do other jobs for fulfilling daily needs

C. Social Aspect

a Access to agricultural rice inputs information (other than weather) is easy

b Farmers are united to face agricultural challenges (e.g. natural hazards)

c You get information from other farmers about farming

d You are active to look for information to improve agricultural production

e Farmers in southern areas (previous rice classes) use excessive irrigation water during gadu

f Neighboring farmers in the same village use excessive irrigation water during gadu.

g Cell phone supports you to face challenges in rice farming

\section{Institutional Aspect}

\section{a Agricultural officers support} you for succeeding rice farming

b Water officers support you for succeeding rice farming

c Access of weather information for supporting rice practices is easy in this village

d You join farming insurance

e Regardless of joining or not joining, farming insurance will provide benefit for you

f Government aid is adequate during and after flooding

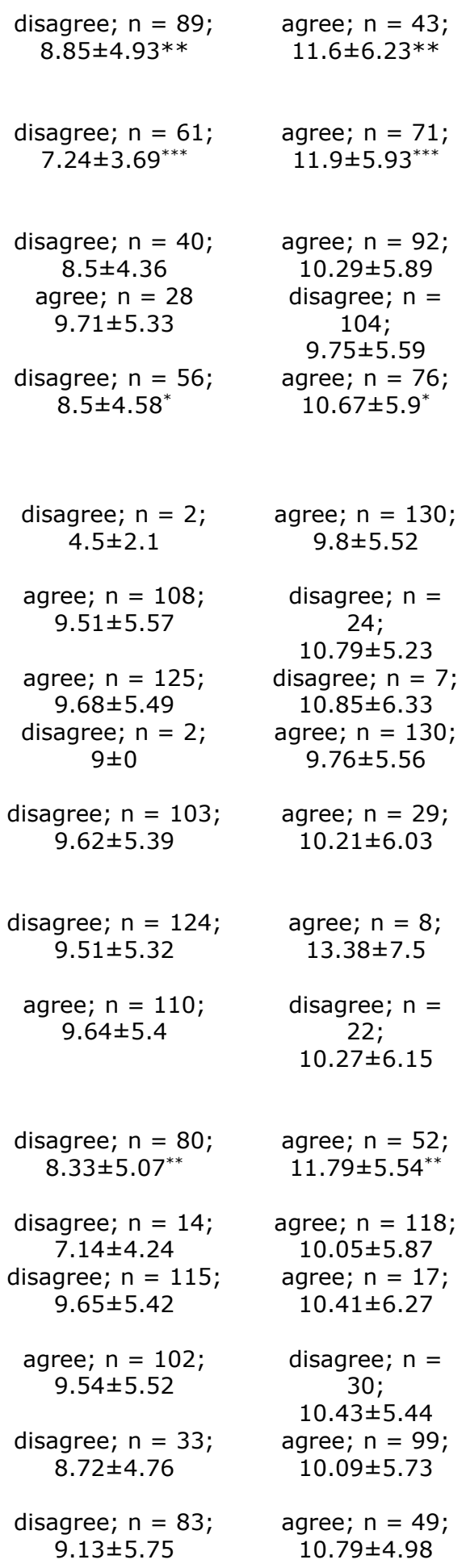




\section{E. Individual Aspect}

a Weather is difficult to predict in the last 5 years

b Generally, you can manage rat attacks

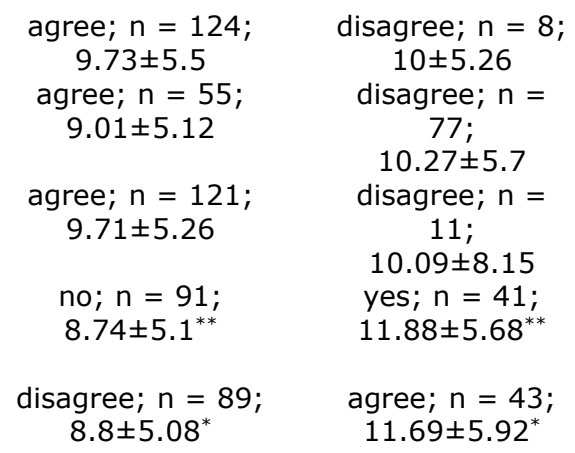

3. Natural Hazard

a Water deficit problem in your rice fields

severe; $\mathrm{n}=119$ $9.66 \pm 5.55$

not severe; $\mathrm{n}=$ 13 ;

$10.53 \pm 5.30$

b Flooding problem in your rice fields

severe; $\mathrm{n}=57$; $9.26 \pm 5.29$

not severe; $\mathrm{n}=$

c Saline water intrusion problem in your rice field

severe; $\mathrm{n}=23$;

$9.65 \pm 6.92$

$10.12 \pm 5.69$

not severe; $\mathrm{n}=$

$$
\text { 109; }
$$

$9.77 \pm 5.21$

severe; $\mathrm{n}=23$;

$7.26 \pm 5.85^{*}$

not severe;

$\mathrm{n}=109$;

$10.27 \pm 5.32^{*}$

not severe; $\mathrm{n}=88$;

$$
9.71 \pm 5.37
$$

problem in this village

$f \quad$ Variation of weather in rainy season disrupt harvest time in this village

g Variation of weather in dry season disrupt harvest time in this village

h Rat attacks reduce your harvest yield

agree; $\mathrm{n}=84$;

$9.39 \pm 5.15$

severe; $\mathrm{n}=44$

$9.81 \pm 5.87$

disagree; $\mathrm{n}=$

$$
\text { 48; }
$$

$10.37 \pm 6.11$

agree; $n=98$;

$9.63 \pm 5.16$

agree; $\mathrm{n}=120$;

$9.5 \pm 5.41$

disagree; $\mathrm{n}=8$;

$8.5 \pm 5.7$

agree; $\mathrm{n}=36$;

$8.77 \pm 6.3^{*}$

disagree; $\mathrm{n}=$

$$
34 ;
$$

$10.08 \pm 6.51$

disagree; $\mathrm{n}=$ 12 ;

$12.25 \pm 6.15$

agree; $\mathrm{n}=124$;

$9.83 \pm 5.52$

disagree; $\mathrm{n}=$ 96;

$10.11 \pm 5.18^{*}$

4. Resilience Outcome

a Recovery from past event

have not recovered;

have recovered;

$$
\mathrm{n}=107
$$$$
n=25 \text {; }
$$

$$
7.65 \pm 3.08^{* * *}
$$

$18.72 \pm 4.56^{* * *}$

b Relative recovery from past event (compared to other have not recovered; $\mathrm{n}=100$; have recovered $7.44 \pm 3^{* * *}$

$\mathrm{n}=32$; $16.96 \pm 5.37^{* * *}$ 


$$
\begin{gathered}
\text { slow } \\
(1-2 \text { seasons }) \\
n=44 \\
5.79 \pm 2.66^{* * *}
\end{gathered}
$$

d Community recovery from past event (farmers in the same village)

e Subjective resilience (Capacity to handle future event if the same hazardous events occur again)

have not recovered;

$$
\mathrm{n}=115
$$

$8.95 \pm 4.73^{* *}$

have not recovered;

$$
\mathrm{n}=117 \text {; }
$$

$9.19 \pm 4.97^{*}$

fast

(3 seasons or more);

$\mathrm{n}=88$;

$11.72 \pm 5.52^{* * *}$

have recovered;

$\mathrm{n}=17$;

$15.11 \pm 7.38^{* *}$

have recovered;

$\mathrm{n}=15$

$14.06 \pm 7.61^{*}$

\section{Quality of life}

a Income from farming

poor; $\mathrm{n}=89 ; \quad$ excellent;
$8.59 \pm 4.54^{* *}$

b Ability to meet daily need

poor; $\mathrm{n}=14$; $8.07 \pm 2.97$

c Housing conditions

poor; $\mathrm{n}=25$; $8.68 \pm 4.94$

d Environmental condition in this village (e.g. cleanliness) in general

e Health status of family members

f Social connections among farmers in general

g Social connections among farmers in times of crisis

poor; $\mathrm{n}=42$;

$9.12 \pm 4.79$

poor; $\mathrm{n}=17$;

$12.13 \pm 6.57^{* *}$

excellent; $\mathrm{n}=$

$$
118 \text {; }
$$

$9.94 \pm 5.72$

excellent; $\mathrm{n}=$

$$
\text { 107; }
$$

$10 \pm 5.63$

excellent; $\mathrm{n}=$

$$
90 \text {; }
$$

$10.04 \pm 5.83$

$8.64 \pm 3.85$ 115.

excellent; $\mathrm{n}=123$;

$9.83 \pm 5.63$

poor; $\mathrm{n}=84$;

$9.19 \pm 5.35$

poor; $\mathrm{n}=1$;
$6 \pm 0$

cellent; $\mathrm{n}=$

$9.91 \pm 5.72$

poor; $\mathrm{n}=9$.

$8.55 \pm 3.71$

excellent; $\mathrm{n}=$

$$
48 \text {; }
$$

$10.72 \pm 5.72$

excellent; $\mathrm{n}=$

131 ;

$9.77 \pm 5.53$

excellent; $\mathrm{n}=64 ; \quad$ poor; $\mathrm{n}=68$;

$9.62 \pm 5.83$

poor; $\mathrm{n}=73$;

$9.68 \pm 5.67$

$9.86 \pm 5.24$

excellent; $\mathrm{n}=$ 59 ;

$9.83 \pm 5.36$

\section{Cropping Schedule Factors}

A. Economic aspect

a Prices of chemical agricultural inputs, such as fertilizers and pesticides, influence planting time in this village

b Future selling price of rice influences planting time in this village

c Farmers who own rice fields influence planting time in this village 
Appendix E-3 - Excluded Variables in Multiple Linear Regression

\begin{tabular}{|c|c|c|c|c|}
\hline No & Variable & Beta & $\mathrm{t}$ & Sig. \\
\hline 1 & HOUSEHOLD CHARACTERISTICS & & & \\
\hline a.1 & Age & -.036 & -.491 & .624 \\
\hline a. 4 & Areas of rice field & .041 & .544 & .588 \\
\hline b & Education level & .062 & .826 & .411 \\
\hline c & $\begin{array}{l}\text { Income from the previous season (rendeng } \\
2016 \text { ) }\end{array}$ & .094 & 1.265 & .208 \\
\hline d & Dependent family member & -.095 & -1.287 & 201 \\
\hline$f$ & Capital source from the previous season & .144 & 1.814 & .072 \\
\hline 2 & FARMING PRACTICE & & & \\
\hline $\bar{A}$ & Cropping schedules & & & \\
\hline a & $\begin{array}{l}\text { Rendeng planting dates generally does not } \\
\text { conform to government cropping calendar } \\
\text { in this village }\end{array}$ & -.014 & -.185 & .853 \\
\hline c & $\begin{array}{l}\text { Current rendeng planting dates is favorable } \\
\text { for farmers in this village }\end{array}$ & -.110 & -1.517 & 132 \\
\hline d & $\begin{array}{l}\text { Current gadu planting dates is favorable for } \\
\text { farmers in this village }\end{array}$ & .094 & 1.217 & .226 \\
\hline$B$ & Economic factors & & & \\
\hline a & $\begin{array}{l}\text { Current selling price of rice supports } \\
\text { farmers' welfare }\end{array}$ & .079 & .989 & .325 \\
\hline e & $\begin{array}{l}\text { Your family has various sources of income } \\
\text { to support rice farming }\end{array}$ & -.090 & -1.222 & .224 \\
\hline$f$ & $\begin{array}{l}\text { You can access funds for rice farming from } \\
\text { closest family members or neighbors easily }\end{array}$ & -.032 & -.441 & .660 \\
\hline g & $\begin{array}{l}\text { In case of planting or harvest failures, you } \\
\text { can do other jobs for fulfilling daily needs. }\end{array}$ & .052 & .692 & .490 \\
\hline C & Social factors & & & \\
\hline a & $\begin{array}{l}\text { Access to agricultural rice inputs } \\
\text { information (other than weather) is easy }\end{array}$ & .017 & .220 & .826 \\
\hline b & $\begin{array}{l}\text { Farmers are united to face agricultural } \\
\text { challenges (e.g. natural hazards) }\end{array}$ & .030 & .400 & .690 \\
\hline c & $\begin{array}{l}\text { You get information from other farmers } \\
\text { about farming }\end{array}$ & -.126 & -1.672 & .097 \\
\hline d & $\begin{array}{l}\text { You are active to look for information to } \\
\text { improve agricultural production }\end{array}$ & -.089 & -1.222 & .224 \\
\hline e & $\begin{array}{l}\text { Farmers in southern areas (previous rice } \\
\text { classes) use excessive irrigation water } \\
\text { during gadu }\end{array}$ & -.040 & -.531 & .596 \\
\hline $\mathrm{g}$ & $\begin{array}{l}\text { Neighboring farmers in the same village } \\
\text { use excessive irrigation water during gadu }\end{array}$ & -.102 & -1.383 & .169 \\
\hline $\mathrm{h}$ & $\begin{array}{l}\text { Cell phone supports you to face challenges } \\
\text { in rice farming }\end{array}$ & .013 & .170 & .865 \\
\hline$D$ & Institutional aspect & & & \\
\hline a & $\begin{array}{l}\text { Agricultural officers support you for } \\
\text { succeeding rice farming }\end{array}$ & .046 & .567 & .572 \\
\hline$b$ & $\begin{array}{l}\text { Water officers support you for succeeding } \\
\text { rice farming }\end{array}$ & .123 & 1.648 & .102 \\
\hline C & $\begin{array}{l}\text { Access of weather information for } \\
\text { supporting rice practices is easy in this } \\
\text { village. }\end{array}$ & .114 & 1.530 & .128 \\
\hline
\end{tabular}


d You join farming insurance

$\begin{array}{lll}-.026 & -.343 & .732 \\ .088 & 1.187 & .238 \\ -.035 & -.477 & .634\end{array}$
after flooding

g Government aid is adequate during and after drought

E Individual aspect

a Weather is difficult to predict in the last 5 years.

$\begin{array}{lll}.054 & .715 \quad .476\end{array}$

b Generally, you can manage rat attacks

c Generally, you can manage brown plant

e Are you a member of any group farming in the last 3 years?

3 NATURAL HAZARDS

a Water deficit problem in your rice fields

b Flooding problem in your rice fields

d Irrigation infrastructure problem in this village

$.109 \quad 1.426 \quad .156$

e River shallowing and narrowing problem in this village

$f$ Variation of weather in rainy season disrupt harvest time in this village

$\begin{array}{lll}.031 & .406 \quad .685\end{array}$

$g$ Variation of weather in dry season disrupt harvest time in this village

i Brown plant hopper attacks reduce your harvest yield

$\begin{array}{ccc}-.064 & -.797 & .427 \\ .01 & .124 & .901\end{array}$

\section{QUALITY OF LIFE}

a Satisfaction to income farming

b Ability to meet daily need

.002

.002

$-.063$

$-.040$

$-.037$

Environmental condition in general

$-.037$

Health status of family members

$-.050$

.029

.320

$-.799$

$-.534$

$-.487$

$-1.382$

.977

Social connection among farmers in times of crisis

$-.050-\quad-.642$

$-.009$

$-.001$

-.009
-.820

$-.061 \quad-.820$

$-1.360$

Work motivation in times of crisis

$-.099$

1.360

\section{CROPPING SCHEDULE FACTORS}

A Economy aspect

c Farmers who own rice fields influence planting time in this village

$-.067-.903$

.368

d Size of rice fields influences planting time

.113

1.483

.141

f Cropping pattern

$-.023$

$-.305$

.761

h Triple-cropping pattern influences planting time in the whole Jatiluhur irrigated rice

.035

.453

.651

fields.

i Rat attacks influence planting time in this village

B Farmer interaction 
a Local belief "kemeian" influences planting time in this village

$\begin{array}{lll}-.048 & -.604 & .547 \\ .043 & .582 & .562 \\ -.040 & -.537 & .592 \\ -.049 & -.632 & .528 \\ .106 & 1.400 & .164 \\ .108 & 1.401 & .164 \\ & & .331 \\ .075 & .975 & .057 \\ .144 & 1.922 & .098 \\ .128 & 1.665 & \end{array}$

in this village

c National religion events influence planting time in this village.

d A two-weekly local government meeting (minggon) influences planting time in this village

e Difference between rice agricultural rules between current and Old Order era (before 2000 ) influence planting time in this village

$\mathrm{f}$ Current planting time is better that Old Order era (before 2000)

C Weather variabilities and natural hazards

a Weather in rainy season influences planting time in this village.

c Flooding events influence planting time in this village

d Water deficit events influence planting time in this village$$
1.665
$$

D Geographic locations

a Rent prices of rice field is too expensive in this village

$-.072 \quad-.911$

b Soil quality decrease in the last 5 years in this village

$\begin{array}{ll}-.072 & -.911 \\ -.103 & -1.416\end{array}$

C Soil quality decrease in the last 5 years in this village

$-.031-.418$

D Access to irrigated water influence planting time in this village

.035

E Coping mechanism

a Farmers' coping mechanisms to flooding influence planting time in this village

b Farmers' coping mechanisms to waterdeficit event influence planting time in this village

F Agricultural Infrastructures

a Conditions of irrigation infrastructures influence planting time in this village

c Rice varieties influence planting time in this village

d Availability of labours influences planting 
Appendix Table E-4: Responses (\%) from the questionnaire for investigating resilience of farmer to natural hazard $(N=132)$

\begin{tabular}{|c|c|c|c|c|c|c|c|}
\hline \multicolumn{6}{|c|}{ 1. Household characteristics } & & Mean \pm Stdev \\
\hline a.1 & age & & & & & & $49.38 \pm 10.27$ \\
\hline a. 2 & $\begin{array}{l}\text { years of } \\
\text { experience }\end{array}$ & & & & & & $29.56 \pm 11.58$ \\
\hline a.3 & rice field tenure & $\begin{array}{l}\text { (rent) } \\
23.5\end{array}$ & $\begin{array}{l}\text { (self- } \\
\text { owned) } \\
76.5\end{array}$ & & & & $0.76 \pm 0.42$ \\
\hline a.4 & areas of rice field & $\begin{array}{c}\text { (1 bouw } \\
\text { or less) } \\
46.2\end{array}$ & $\begin{array}{c}(1-2 \text { bouw }) \\
21.2\end{array}$ & $\begin{array}{c}(2-3 \\
\text { bouw }) \\
10.6\end{array}$ & $\begin{array}{c}(3-4 \\
\text { bouw) } \\
5.3\end{array}$ & $\begin{array}{c}(>4 \text { bouw }) \\
16.7\end{array}$ & $2.25 \pm 1.49$ \\
\hline b & education level & $\begin{array}{c}\text { (no } \\
\text { school) } \\
32.6\end{array}$ & $\begin{array}{c}\text { (elementar } \\
y \text { ) } \\
46.2\end{array}$ & $\begin{array}{l}\text { (junior } \\
\text { high) } \\
3\end{array}$ & $\begin{array}{c}\text { (senior } \\
\text { high) } \\
15.2\end{array}$ & $\begin{array}{c}\text { (undergrad. } \\
\text { or more) } \\
3\end{array}$ & $2.09 \pm 1.11$ \\
\hline C & $\begin{array}{l}\text { income from the } \\
\text { previous season } \\
\text { (rendeng 2016) } \\
\text { (rupiah) }\end{array}$ & & & & & Rp. $14,700,4$ & $=38,204,245.06$ \\
\hline d & $\begin{array}{l}\text { dependent family } \\
\text { member }\end{array}$ & $\begin{array}{c}\text { (no one) } \\
41.7\end{array}$ & $\begin{array}{c}\text { (1 person) } \\
22\end{array}$ & $\begin{array}{c}(2 \\
\text { members } \\
24.2\end{array}$ & $\begin{array}{c}(3 \\
\text { members } \\
9.1\end{array}$ & $\begin{array}{c}(>4 \\
\text { members }) \\
3\end{array}$ & $1.09 \pm 1.13$ \\
\hline$f$ & capital source & $\begin{array}{l}\text { (loan) } \\
61.4\end{array}$ & $\begin{array}{c}\text { (self- } \\
\text { owned) } \\
38.6\end{array}$ & & & & $1.38 \pm 0.48$ \\
\hline
\end{tabular}

2. Farming Practices and Processes

\begin{tabular}{|c|c|c|c|c|c|c|}
\hline A. & $\begin{array}{l}\text { Cropping } \\
\text { hedule }\end{array}$ & $\begin{array}{l}\text { Very } \\
\text { Disagree }\end{array}$ & Disagree & Agree & $\begin{array}{l}\text { Very } \\
\text { Agree }\end{array}$ & Mean \pm Stdev \\
\hline a & $\begin{array}{l}\text { Rendeng planting } \\
\text { dates generally } \\
\text { does not conform } \\
\text { to government } \\
\text { cropping calendar } \\
\text { in this village }\end{array}$ & 1.5 & 17.4 & 22.7 & 58.3 & $3.37 \pm 0.82$ \\
\hline b & $\begin{array}{l}\text { Gadu planting } \\
\text { dates generally } \\
\text { does not conform } \\
\text { to government } \\
\text { cropping calendar } \\
\text { in this village }\end{array}$ & 1.5 & 21.2 & 17.4 & 59.8 & $3.35 \pm 0.86$ \\
\hline C & $\begin{array}{l}\text { Current rendeng } \\
\text { planting dates is } \\
\text { favorable for } \\
\text { farmers in this } \\
\text { village }\end{array}$ & 0.00 & 3.8 & 94.7 & 1.5 & $2.98 \pm 0.23$ \\
\hline$d$ & $\begin{array}{l}\text { Current gadu } \\
\text { planting dates is } \\
\text { favorable for } \\
\text { farmers in this } \\
\text { village }\end{array}$ & 43.2 & 3.8 & 53 & 0.00 & $2.09 \pm 0.98$ \\
\hline B & Economic factors & $\begin{array}{c}\text { Very } \\
\text { Disagree }\end{array}$ & Disagree & Agree & $\begin{array}{l}\text { Very } \\
\text { Agree }\end{array}$ & Meant Stdev \\
\hline$a$ & $\begin{array}{l}\text { Current selling } \\
\text { price of rice } \\
\text { supports farmers' } \\
\text { welfare }\end{array}$ & 34.1 & 46.2 & 18.9 & 0.8 & $1.86 \pm 0.74$ \\
\hline b & $\begin{array}{l}\text { You have extra } \\
\text { money for saving } \\
\text { after harvest }\end{array}$ & 26.5 & 49.2 & 22 & 2.3 & $2 \pm 0.76$ \\
\hline
\end{tabular}




\begin{tabular}{|c|c|c|c|c|c|c|}
\hline C & $\begin{array}{l}\text { Income from of } \\
\text { rendeng farming } \\
\text { is sufficient for } \\
\text { meeting your } \\
\text { family daily needs } \\
\text { until next season }\end{array}$ & 28.8 & 38.6 & 31.1 & 1.5 & $2.05 \pm 0.81$ \\
\hline d & $\begin{array}{l}\text { Income from } \\
\text { rendeng and } \\
\text { gadu farming } \\
\text { combined is } \\
\text { sufficient for } \\
\text { meeting your } \\
\text { family daily needs }\end{array}$ & 20.5 & 25.8 & 40.9 & 12.9 & $2.46 \pm 0.96$ \\
\hline e & $\begin{array}{l}\text { Your family has } \\
\text { various sources } \\
\text { of income to } \\
\text { support rice } \\
\text { farming }\end{array}$ & 3.8 & 26.5 & 62.1 & 7.6 & $2.73 \pm 0.64$ \\
\hline$f$ & $\begin{array}{l}\text { You can access } \\
\text { funds for rice } \\
\text { farming from } \\
\text { closest family } \\
\text { members or } \\
\text { neighbors easily }\end{array}$ & 3 & 18.2 & 68.9 & 9.8 & $2.85 \pm 0.62$ \\
\hline g & $\begin{array}{l}\text { In case of } \\
\text { planting or } \\
\text { harvest failures, } \\
\text { you can do other } \\
\text { jobs for fulfilling } \\
\text { daily needs }\end{array}$ & 9.1 & 33.3 & 45.5 & 12.1 & $2.61 \pm 0.82$ \\
\hline & Social Aspect & $\begin{array}{c}\text { Very } \\
\text { Disagree }\end{array}$ & Disagree & Agree & $\begin{array}{c}\text { Very } \\
\text { Agree }\end{array}$ & \\
\hline a & $\begin{array}{l}\text { Access to } \\
\text { agricultural rice } \\
\text { inputs } \\
\text { information } \\
\text { (other than } \\
\text { weather) is easy }\end{array}$ & 0 & 1.5 & 45.5 & 53 & $3.51 \pm 0.53$ \\
\hline b & $\begin{array}{l}\text { Farmers are } \\
\text { united to face } \\
\text { agricultural } \\
\text { challenges (e.g. } \\
\text { natural hazards) }\end{array}$ & 6.1 & 12.1 & 48.5 & 33.3 & $3.09 \pm 0.83$ \\
\hline C & $\begin{array}{l}\text { You get } \\
\text { information from } \\
\text { other farmers } \\
\text { about farming }\end{array}$ & 3 & 2.3 & 15.9 & 78.8 & $3.7 \pm 0.66$ \\
\hline$d$ & $\begin{array}{l}\text { You are active to } \\
\text { look for } \\
\text { information to } \\
\text { improve } \\
\text { agricultural } \\
\text { production }\end{array}$ & 0.00 & 1.5 & 17.4 & 81.1 & $3.8 \pm 0.44$ \\
\hline e & $\begin{array}{l}\text { Farmers in } \\
\text { southern areas } \\
\text { (previous rice } \\
\text { classes) use } \\
\text { excessive } \\
\text { irrigation water } \\
\text { during gadu }\end{array}$ & 15.9 & 62.1 & 15.2 & 6.8 & $2.13 \pm 0.76$ \\
\hline
\end{tabular}




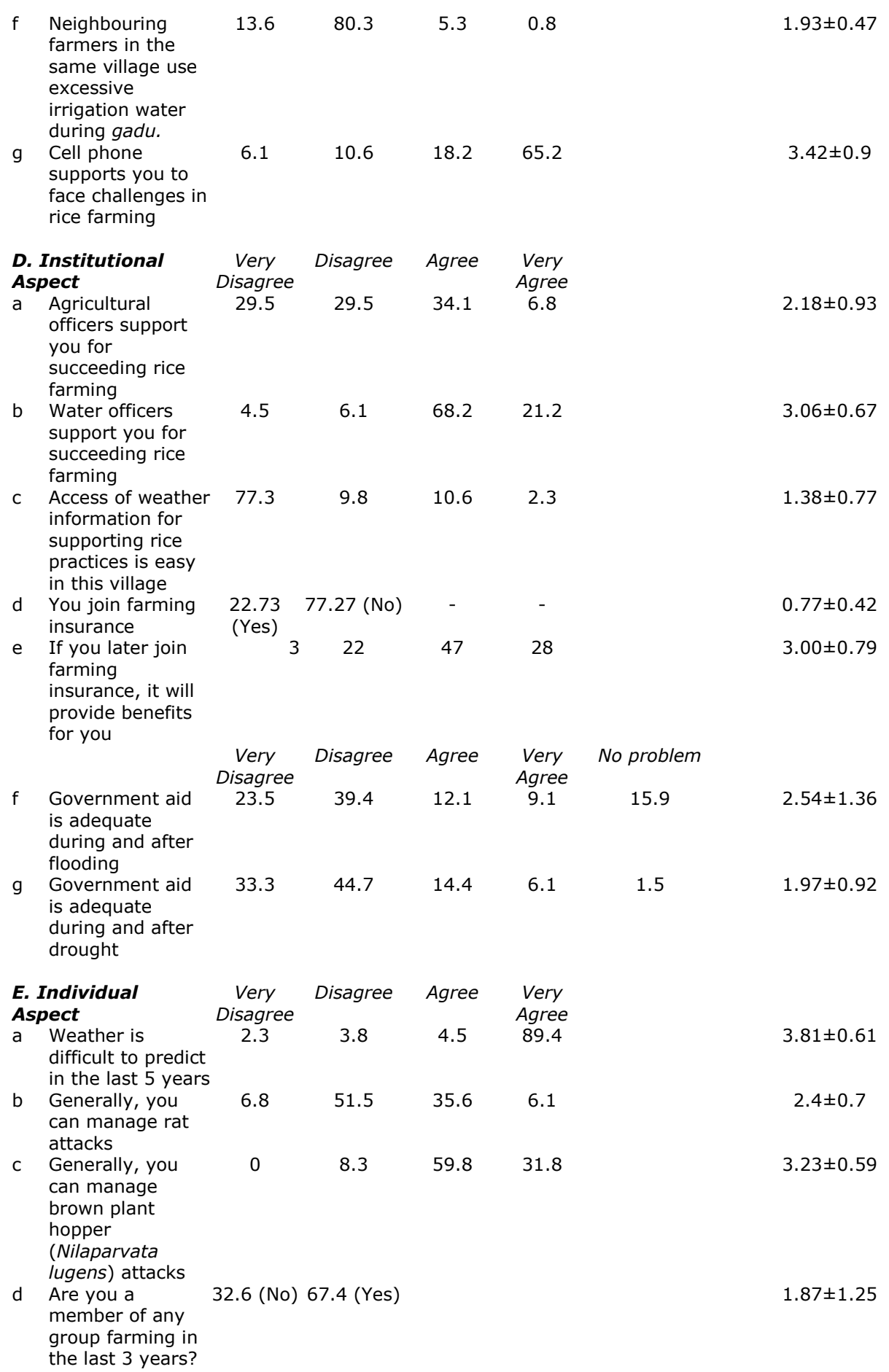


e Do you join any 32.6 (No) 67.4 (Yes)

farming training

in the last 3

years?

\begin{tabular}{|c|c|c|c|c|c|c|c|}
\hline 3. & $\begin{array}{l}\text { Natural } \\
\text { Hazard }\end{array}$ & Very high & High & Low & Very low & No problem & \\
\hline a & $\begin{array}{l}\text { Water deficit } \\
\text { problem in your } \\
\text { rice fields }\end{array}$ & 60.4 & 29.5 & 6.1 & 3.8 & 0.00 & $1.52 \pm 0.77$ \\
\hline b & $\begin{array}{l}\text { Flooding problem } \\
\text { in your rice fields }\end{array}$ & 25.8 & 17.4 & 12.9 & 15.9 & 28 & $3.01 \pm 1.58$ \\
\hline c & $\begin{array}{l}\text { Saline water } \\
\text { intrusion problem } \\
\text { in your rice field }\end{array}$ & 9.8 & 7.6 & 0.8 & 15.2 & 66.7 & $4.21 \pm 1.35$ \\
\hline d & $\begin{array}{l}\text { Irrigation } \\
\text { infrastructure } \\
\text { problem in this } \\
\text { village }\end{array}$ & 3 & 14.4 & 15.2 & 5.3 & 62.1 & $4.08 \pm 1.27$ \\
\hline \multirow[t]{2}{*}{ e } & River shallowing & 6.1 & 27.3 & 10.6 & 3.8 & 52.3 & $3.67 \pm 1.48$ \\
\hline & & $\begin{array}{c}\text { Very } \\
\text { Disagree }\end{array}$ & Disagree & Agree & $\begin{array}{l}\text { Very } \\
\text { Agree }\end{array}$ & & \\
\hline$f$ & $\begin{array}{l}\text { Variation of } \\
\text { weather in rainy } \\
\text { season disrupt } \\
\text { harvest time in } \\
\text { this village }\end{array}$ & 4.5 & 31.8 & 47.7 & 15.9 & & $2.80 \pm 0.76$ \\
\hline$g$ & $\begin{array}{l}\text { Variation of } \\
\text { weather in dry } \\
\text { season disrupt } \\
\text { harvest time in } \\
\text { this village }\end{array}$ & 2.3 & 23.5 & 59.1 & 15.2 & & $2.87 \pm 0.68$ \\
\hline $\mathrm{h}$ & $\begin{array}{l}\text { Rat attacks } \\
\text { reduce your } \\
\text { harvest yield }\end{array}$ & 0 & 8.3 & 59.8 & 31.8 & & $3.12 \pm 0.53$ \\
\hline $\mathrm{i}$ & $\begin{array}{l}\text { Brown plant } \\
\text { hopper attacks } \\
\text { reduce your } \\
\text { harvest yield }\end{array}$ & 0 & 6.1 & 72 & 22 & & $3.15 \pm 0.5$ \\
\hline j & $\begin{array}{l}\text { Excessive } \\
\text { irrigation water } \\
\text { use cause } \\
\text { flooding in lower- } \\
\text { lying rice fields }\end{array}$ & 19.7 & 53 & 14.4 & 12.9 & & $2.20 \pm 0.91$ \\
\hline
\end{tabular}

\begin{tabular}{|c|c|c|c|c|c|c|c|c|}
\hline 4. & Resilience & & & & & Mean \pm Stdev & & \\
\hline a & Recovery from & (HR1) & (HR2) & (HR3) & (R1) & (R2) & (R3 & $3.02 \pm 1.03$ \\
\hline & past event - A & 5.3 & 20.5 & 55.3 & 6.1 & 11.4 & $\underset{1.5}{)}$ & \\
\hline b & $\begin{array}{l}\text { Relative recovery } \\
\text { from past event } \\
\text { (compared to } \\
\text { other farmers in } \\
\text { the same village) } \\
\text { - B }\end{array}$ & $\begin{array}{c}\left(\mathrm{RR}^{\mathrm{f}} 1\right) \\
4.5\end{array}$ & $\begin{array}{c}(\mathrm{RR} 2) \\
15.2\end{array}$ & $\begin{array}{c}(\mathrm{RR} 3) \\
56.1\end{array}$ & $\begin{array}{c}(\text { RR4) } \\
15.9\end{array}$ & $\begin{array}{c}\text { (RR5) } \\
8.3\end{array}$ & & $3.08 \pm 0.9$ \\
\hline & $\begin{array}{l}\text { Resilience score } \\
(A * B)\end{array}$ & $\begin{array}{c}1-10 \\
\text { points } \\
72.7\end{array}$ & $\begin{array}{c}11-20 \\
\text { points } \\
25\end{array}$ & $\begin{array}{c}21-30 \\
\text { points } \\
2.3\end{array}$ & & & & \\
\hline C & Time to recover & $\begin{array}{c}(1 \\
\text { season) } \\
35.6\end{array}$ & $\begin{array}{c}\text { (2 seasons) } \\
31.1\end{array}$ & $\begin{array}{c}(3 \\
\text { seasons }) \\
12.9\end{array}$ & $\begin{array}{c}(4 \\
\text { season) } \\
18.9\end{array}$ & $\begin{array}{c}\text { (5 seasons) } \\
1.5\end{array}$ & & $2.19 \pm 1.17$ \\
\hline
\end{tabular}




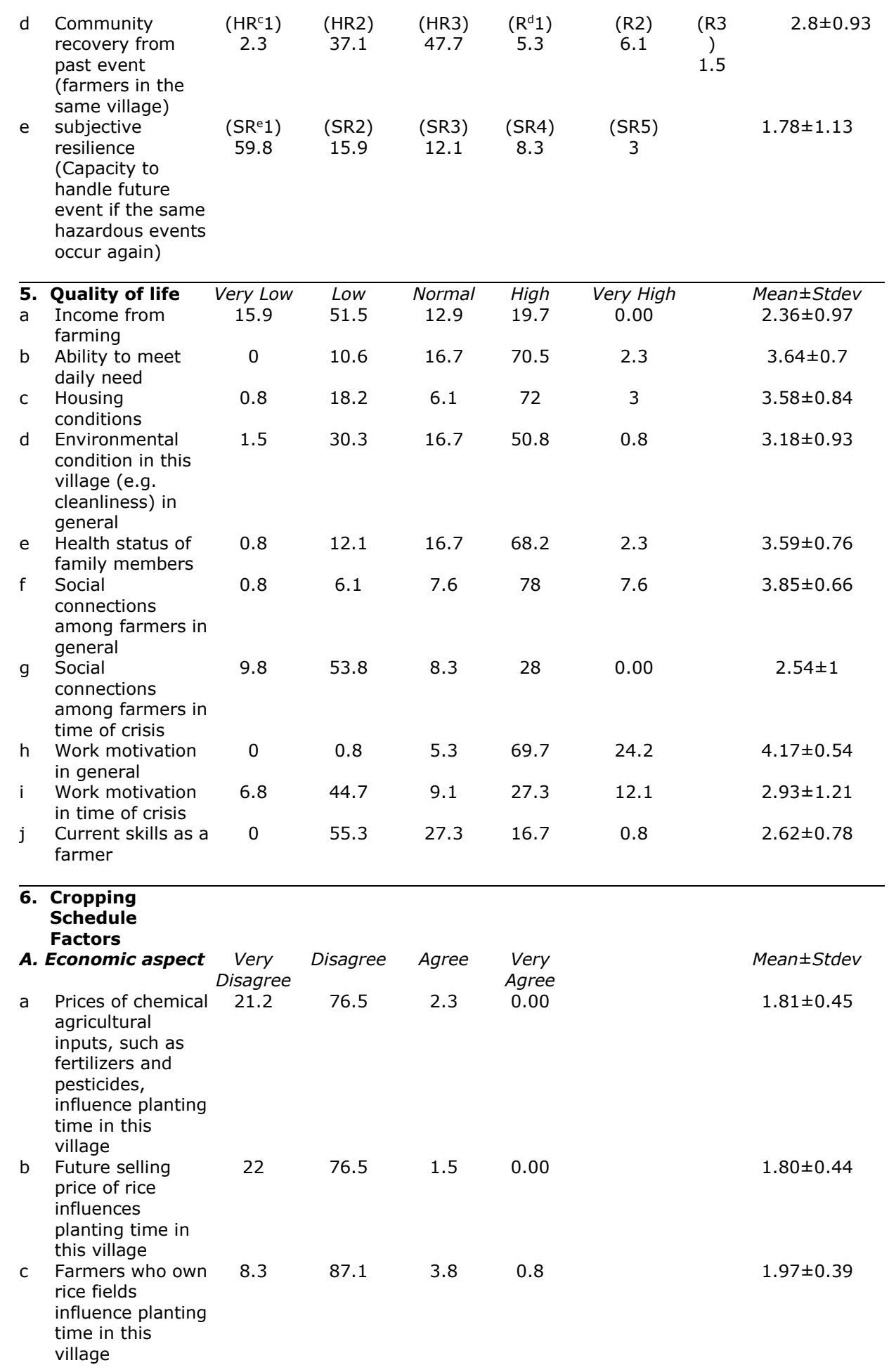




\begin{tabular}{|c|c|c|c|c|c|c|}
\hline$d$ & $\begin{array}{l}\text { Delay in rendeng } \\
\text { influences } \\
\text { planting time in } \\
\text { the whole } \\
\text { Jatiluhur irrigated } \\
\text { rice fields }\end{array}$ & 3.8 & 5.3 & 33.3 & 57.6 & $3.45 \pm 0.76$ \\
\hline e & $\begin{array}{l}\text { Delay in Gadu } \\
\text { influences } \\
\text { planting time in } \\
\text { the whole } \\
\text { Jatiluhur irrigated } \\
\text { rice fields }\end{array}$ & 0.00 & 3.8 & 35.6 & 60.6 & $3.57 \pm 0.57$ \\
\hline$f$ & Cropping pattern & $\begin{array}{l}\text { (single) } \\
37.9\end{array}$ & $\begin{array}{c}\text { (double) } \\
47.7\end{array}$ & $\begin{array}{c}\text { (triple) } \\
14.4\end{array}$ & & $1.76 \pm 0.68$ \\
\hline & & $\begin{array}{c}\text { Very } \\
\text { Disagree }\end{array}$ & Disagree & Agree & $\begin{array}{l}\text { Very } \\
\text { Agree }\end{array}$ & \\
\hline g & $\begin{array}{l}\text { Triple-cropping } \\
\text { pattern influences } \\
\text { planting time in } \\
\text { the whole } \\
\text { Jatiluhur irrigated } \\
\text { rice fields }\end{array}$ & 0.00 & 4.5 & 62.1 & 33.3 & $3.28 \pm 0.54$ \\
\hline $\mathrm{h}$ & $\begin{array}{l}\text { Rat attacks } \\
\text { influence planting } \\
\text { time in this } \\
\text { village }\end{array}$ & 8.3 & 43.9 & 34.1 & 13.6 & $2.53 \pm 0.83$ \\
\hline \multicolumn{2}{|c|}{$\begin{array}{l}\text { B. Farmers' } \\
\text { interaction }\end{array}$} & $\begin{array}{c}\text { Very } \\
\text { Disagree }\end{array}$ & Disagree & Agree & $\begin{array}{l}\text { Very } \\
\text { Agree }\end{array}$ & Mean \pm Stdev \\
\hline a & $\begin{array}{l}\text { Local belief } \\
\text { "kemeian" } \\
\text { influences } \\
\text { planting time in } \\
\text { this village }\end{array}$ & 60.6 & 28.8 & 6.8 & 3.8 & $1.53 \pm 0.78$ \\
\hline b & $\begin{array}{l}\text { Community } \\
\text { events influence } \\
\text { planting time in } \\
\text { this village }\end{array}$ & 17.4 & 47 & 29.5 & 6.1 & $2.24 \pm 0.81$ \\
\hline C & $\begin{array}{l}\text { National religion } \\
\text { events influence } \\
\text { planting time in } \\
\text { this village }\end{array}$ & 0 & 11.4 & 58.3 & 30.3 & $3.18 \pm 0.61$ \\
\hline$d$ & $\begin{array}{l}\text { A two-weekly } \\
\text { local government } \\
\text { meeting } \\
\text { (minggon) } \\
\text { influences } \\
\text { planting time in } \\
\text { this village }\end{array}$ & 13.6 & 39.4 & 36.4 & 10.6 & $2.43 \pm 0.85$ \\
\hline e & $\begin{array}{l}\text { Difference } \\
\text { between rice } \\
\text { agricultural rules } \\
\text { between current } \\
\text { and Old Order era } \\
\text { (before 2000) } \\
\text { influence planting } \\
\text { time in this } \\
\text { village }\end{array}$ & 0.8 & 15.2 & 9.8 & 74.2 & $3.57 \pm 0.77$ \\
\hline $\mathrm{f}$ & $\begin{array}{l}\text { Current planting } \\
\text { time is better } \\
\text { that Old Order } \\
\text { era (before } 2000 \text { ) }\end{array}$ & 37.1 & 29.5 & 26.5 & 6.8 & $2.03 \pm 0.95$ \\
\hline
\end{tabular}




\begin{tabular}{|c|c|c|c|c|c|c|c|}
\hline $\mathrm{g}$ & $\begin{array}{l}\text { For Jatiluhur } \\
\text { irrigation system, } \\
\text { current planting } \\
\text { time is better } \\
\text { that Old Order } \\
\text { era (before 2000) }\end{array}$ & 36.4 & 32.6 & 25.8 & 5.3 & & $2 \pm 0.91$ \\
\hline h & $\begin{array}{l}\text { Size of rice fields } \\
\text { influence } \\
\text { cropping } \\
\text { schedules }\end{array}$ & 10.6 & 32.6 & 42.4 & 14.4 & & $2.61 \pm 0.86$ \\
\hline \multicolumn{2}{|c|}{$\begin{array}{l}\text { C. Weather } \\
\text { conditions and } \\
\text { Natural Hazard }\end{array}$} & $\begin{array}{c}\text { Very } \\
\text { Disagree }\end{array}$ & Disagree & Agree & $\begin{array}{l}\text { Very } \\
\text { Agree }\end{array}$ & & Mean \pm Stdev \\
\hline a & $\begin{array}{l}\text { Weather in rainy } \\
\text { season influences } \\
\text { planting time in } \\
\text { this village }\end{array}$ & 1.5 & 17.4 & 31.8 & 49.2 & & $3.28 \pm 0.80$ \\
\hline b & $\begin{array}{l}\text { Weather in dry } \\
\text { season influences } \\
\text { planting time in } \\
\text { this village }\end{array}$ & 0.00 & 15.9 & 23.5 & 60.6 & & $3.44 \pm 0.75$ \\
\hline C & $\begin{array}{l}\text { Flooding events } \\
\text { influence planting } \\
\text { time in this } \\
\text { village }\end{array}$ & 12.1 & 25 & 25.8 & 37.1 & & $2.88 \pm 1.05$ \\
\hline d & $\begin{array}{l}\text { Water deficit } \\
\text { events influence } \\
\text { planting time in } \\
\text { this village }\end{array}$ & 0.00 & 3.8 & 30.3 & 65.9 & & $3.62 \pm 0.56$ \\
\hline \multicolumn{2}{|c|}{$\begin{array}{l}\text { D. Geographical } \\
\text { Locations }\end{array}$} & $\begin{array}{c}\text { Very } \\
\text { Disagree }\end{array}$ & Disagree & Agree & $\begin{array}{l}\text { Very } \\
\text { Agree }\end{array}$ & & Mean \pm Stdev \\
\hline a & $\begin{array}{l}\text { Rent prices of rice } \\
\text { field is too } \\
\text { expensive in this } \\
\text { village }\end{array}$ & 10.6 & 49.2 & 15.2 & 25 & & $2.55 \pm 0.98$ \\
\hline b & $\begin{array}{l}\text { Soil quality } \\
\text { decrease in the } \\
\text { last } 5 \text { years in } \\
\text { this village }\end{array}$ & 16.7 & 38.6 & 40.2 & 4.5 & & $2.32 \pm 0.8$ \\
\hline C & $\begin{array}{l}\text { Seed quality } \\
\text { decrease in the } \\
\text { last } 5 \text { years in } \\
\text { this village }\end{array}$ & 5.3 & 31.8 & 56.1 & 6.8 & & $2.64 \pm 0.69$ \\
\hline$d$ & $\begin{array}{l}\text { Access to } \\
\text { irrigated water } \\
\text { influence planting } \\
\text { time in this } \\
\text { village }\end{array}$ & 0 & 0.8 & 31.8 & 67.4 & & $3.67 \pm 0.49$ \\
\hline \multicolumn{2}{|c|}{$\begin{array}{l}\text { E. Coping } \\
\text { Mechanisms }\end{array}$} & $\begin{array}{c}\text { Very } \\
\text { Disagree }\end{array}$ & Disagree & Agree & $\begin{array}{l}\text { Very } \\
\text { Agree }\end{array}$ & No problem & Mean \pm Stdev \\
\hline a & $\begin{array}{l}\text { Farmers' coping } \\
\text { mechanisms to } \\
\text { flooding influence } \\
\text { planting time in } \\
\text { this village }\end{array}$ & 0.8 & 10.6 & 13.6 & 45.5 & 29.5 & $2.92 \pm 0.96$ \\
\hline b & $\begin{array}{l}\text { Farmers' coping } \\
\text { mechanisms to } \\
\text { water-deficit } \\
\text { event influence } \\
\text { planting time in } \\
\text { this village }\end{array}$ & 0.8 & 14.4 & 81.8 & 3 & 0 & $2.87 \pm 0.43$ \\
\hline
\end{tabular}




\begin{tabular}{|c|c|c|c|c|c|c|}
\hline \multicolumn{2}{|c|}{$\begin{array}{l}\text { F. Agriculture } \\
\text { infrastructure }\end{array}$} & $\begin{array}{c}\text { Very } \\
\text { Disagree }\end{array}$ & Disagree & Agree & $\begin{array}{l}\text { Very } \\
\text { Agree }\end{array}$ & Mean \pm Stdev \\
\hline$a$ & $\begin{array}{l}\text { Conditions of } \\
\text { irrigation } \\
\text { infrastructures } \\
\text { influence planting } \\
\text { time in this } \\
\text { village }\end{array}$ & 0.00 & 1.5 & 47 & 51.5 & $3.5 \pm 0.53$ \\
\hline b & $\begin{array}{l}\text { Conditions of } \\
\text { river channels } \\
\text { influence planting } \\
\text { time in this } \\
\text { village }\end{array}$ & 0.00 & 3.8 & 38.6 & 57.6 & $3.53 \pm 0.57$ \\
\hline C & $\begin{array}{l}\text { Rice varieties } \\
\text { influence planting } \\
\text { time in this } \\
\text { village }\end{array}$ & 4.5 & 25 & 49.2 & 21.2 & $2.87 \pm 0.79$ \\
\hline d & $\begin{array}{l}\text { Availability of } \\
\text { labors influences } \\
\text { planting time in } \\
\text { this village }\end{array}$ & 19.7 & 53 & 14.4 & 12.9 & $2.2 \pm 0.9$ \\
\hline
\end{tabular}




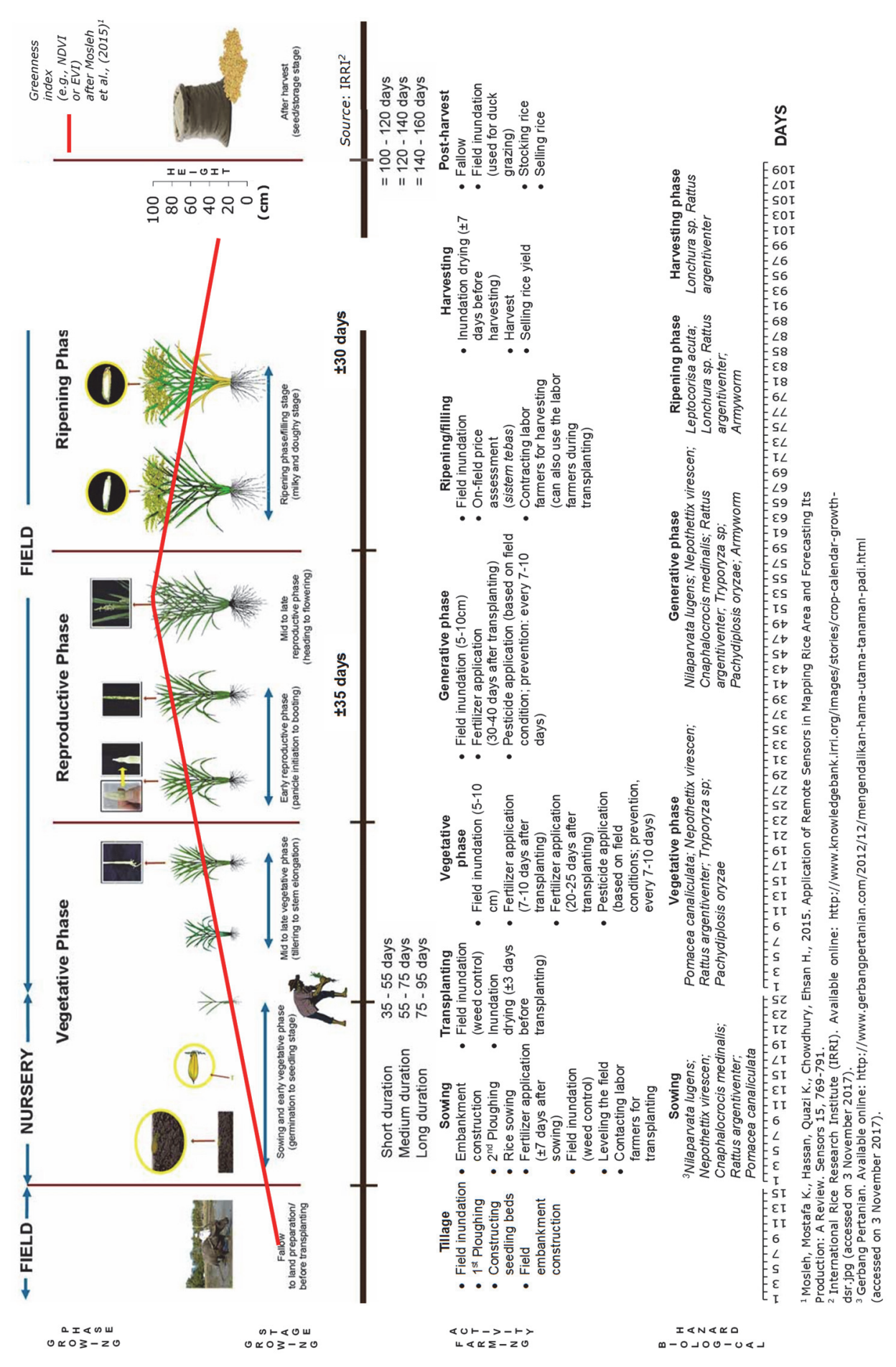

